\title{
QTLs for Oil Content and their Relationships to other Agronomic Traits in an European x Chinese Oilseed Rape Population
}

\author{
Doctoral Dissertation \\ Submitted for the degree of Doctor of Agricultural Sciences \\ of the Faculty of Agricultural Sciences \\ Georg-August University of Göttingen (Germany)
}

\author{
by \\ Jianyi Zhao \\ from Hangzhou, China
}

Göttingen, November 2002 
D7

$1^{\text {st }}$ examiner :

Prof. Dr. Heiko C. Becker

$2^{\text {nd }}$ examiner :

Prof. Dr. Elke. Pawelzik

Date of oral examination: 14. Nov. 2002 
To my memorable years in Göttingen

为纪念在 Göttingen 度过的这段难忘的岁月 


\section{Table of contents}

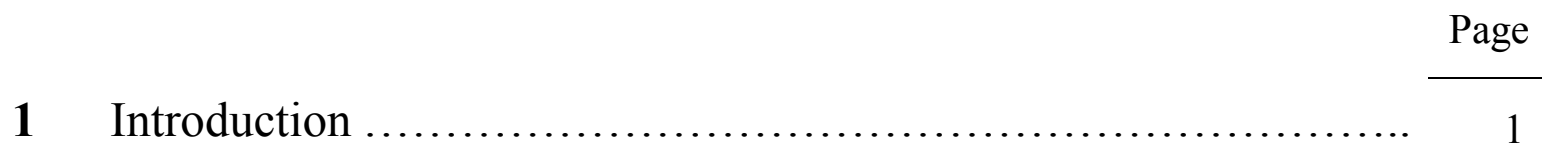

$2 \quad$ Literature Review ........................................ 5

2.1 Markers, populations and map construction ......................... 5

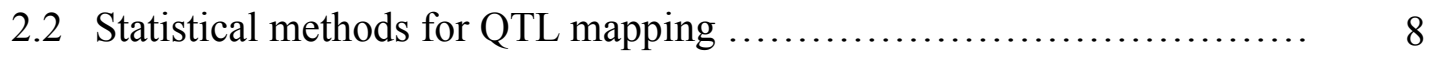

2.2.1 Single-marker analysis ................................... 8

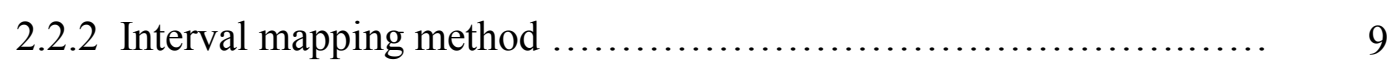

2.2.3 Composite interval mapping .................................. 9

2.3 QTL $x$ environment interaction ................................. 10

2.4 Epistatic QTLs .................................................. 10

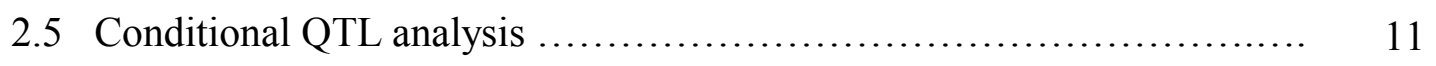

2.6 QTL Mapping in Brassica species ................................ 11

2.6.1 Linkage maps ............................................ 11

2.6.2 Applications of maps in breeding .............................. 13

2.7 Mapping QTL for oil and protein content in other oil crops ............ 15

2.8 References ........................................................ 16

$3 \quad$ Experimental Results ( six separate manuscripts ) 27

3.1 Construction of a linkage map and identification of QTLs for oil content 27

3.1 .1 Introduction................................................ 27

3.1.2 Material and methods...................................... 28

3.1 .3 Results ............................................... 31

3.1.4 Discussion.................................................. 38

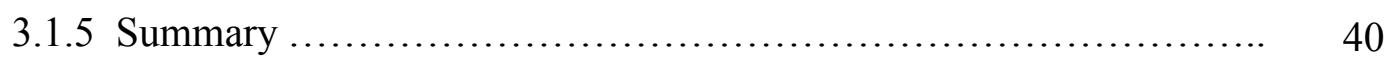

3.1.6 References............................................... 40

3.2 QTLs for protein content and their relationships with oil content 43

3.2 .1 Introduction.............................................. 43

3.2.2 Material and methods...................................... 44

3.2 .3 Results ................................................. 46

3.2 .4 Discussion.............................................. 54

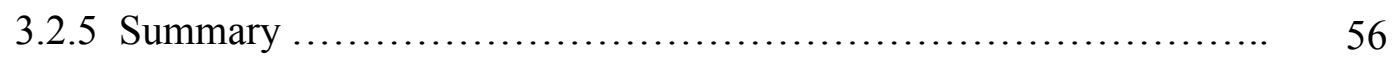

3.2 .6 References ............................................ 57 
3.3 Relationships between oil and protein content with developmental stages $\quad 60$

3.3.1 Introduction................................................. 60

3.3.2 Material and methods........................................ 61

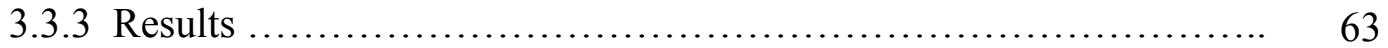

3.3.4 Discussion................................................ 70

3.3.5 Summary ................................................. 72

3.3 .6 References............................................... 73

3.4 Relationships between oil and protein content with plant height and yield 75 components

3.4.1 Introduction..................................................... 75

3.4.2 Material and methods...................................... 76

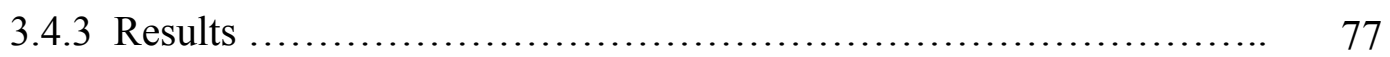

3.4.4 Discussion................................................ 82

3.4 .5 Summary.................................................... 84

3.4.6 References................................................... 84

3.5 QTLs for yield components and their relationships with developmental 86 stages

3.5.1 Introduction.................................................. 86

3.5.2 Material and methods....................................... 87

3.5.3 Results ................................................. 88

3.5.4 Discussion.................................................. 94

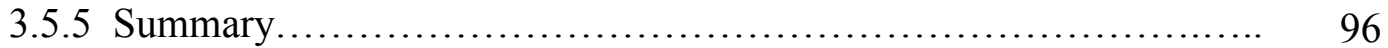

3.5.6 References................................................ 97

3.6 QTLs for plant height and branching number and for time of flowering 99 and maturity

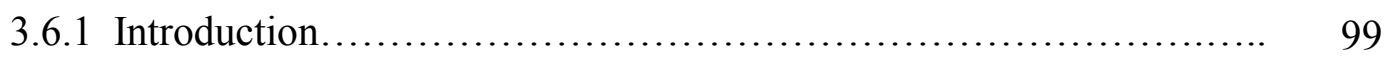

3.6.2 Material and methods........................................ 100

3.6.3 Results ..................................................... 101

3.6.4 Discussion..................................................... 108

3.6 .5 Summary.................................................... 110

3.6.6 References................................................... 111

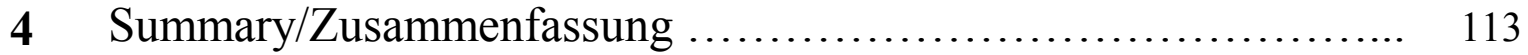

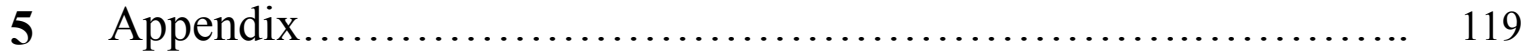

6 Acknowledgments...................................... 129 


\section{Introduction}

The successful development of 'canola' or 'double low' oilseed rape ( erucic acid free and low glucosinolate content in seed) have opened almost unlimited avenues into the food and feed markets worldwide and today rapeseed ranks the world's number two oilseed crop just behind soybeans. The growing area and total production were developed very fast both in China and Europe in the last two decades ( Fig 1 ). China is the largest producer with 8.0 million ha of harvested area followed by European countries with 4.7 million ha in 2001 ( FAO 2002 ), which occupied about 33 and $20 \%$ of total areas, 31 and $34 \%$ of total world production, respectively. Rapeseed production in Germany accounts for about $25 \%$ of the total area in Europe.
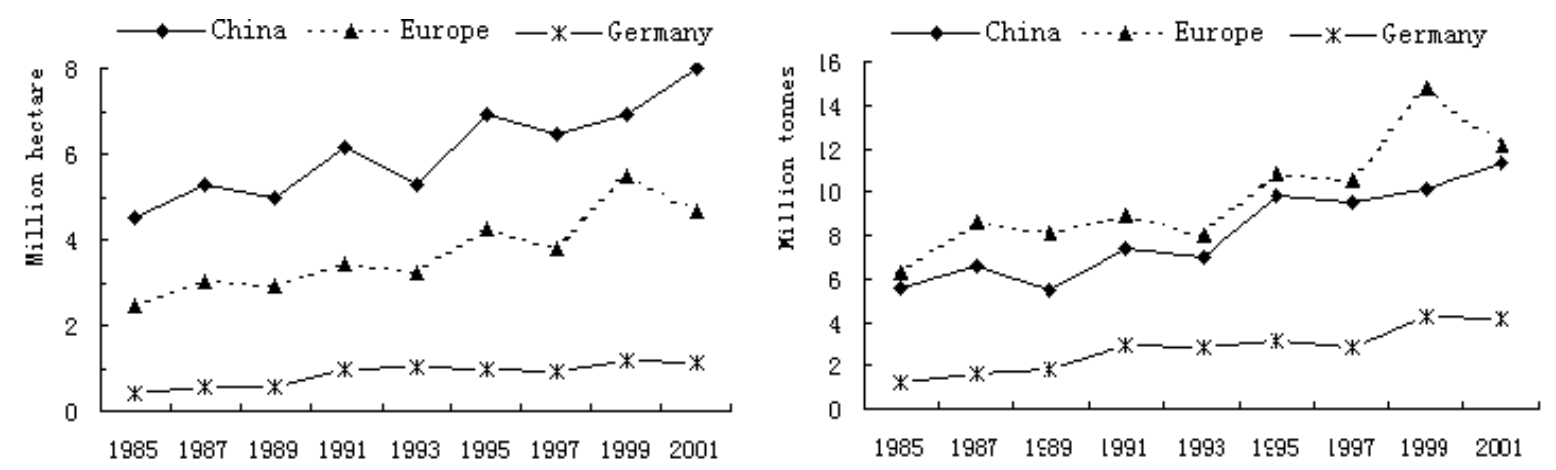

Fig 1. The development of oilseed rape area ( left ) and production ( right ) in China, whole Europe and Germany during 1985 - 2001 ( data from FAO 2002)

Chinese landraces and European cultivars of Brassica napus are two distinct gene pools ( Becker et al. 1995; Zhao and Becker 1998 ). Combination of both gene pools could be of mutual benefit for both regions. This has partly been confirmed by successful rapeseed breeding in China after integrating genes for low erucic acid and low glucosinolate content from European materials. On the other hand, Chinese cultivars might be important for European rapeseed breeding to broaden the genetic basis. We found in both pools materials with high oil content. It is quite interesting to study their genetic control system and allelic differentiation and distribution. Oil content, together with seed yield, is the most important breeding aim for oilseed rape, but also increasing the protein content in rapeseed meal is interesting since its well balanced amino acid composition ( Krzymanski 1998 ) and the worldwide shortage of protein supplement for feed today. 
Oil and protein content in rapeseed are typically quantitative traits under polygenetic control and influenced by environmental conditions. Furthermore, oil and protein share the basic sources of energy in their metabolic pathway and are, to some extent, related with developmental stages and yield traits. This makes their genetic inheritance complicated and difficult to be understood.

Recent advances in molecular marker techniques provide the possibilities to trace gene behavior at individual gene loci, which greatly helps to understand the complex genetics of quantitative traits as oil and protein content. Several mapping experiments for oil content have been reported in different Brassica species (see literature review), however mapping for protein content and their relationships with oil QTLs are limited. A number of QTL mapping for flowering time were published (see literature review), but the genetic influence to oil and protein content on individual QTL was not analysed so far. Also QTLs for plant type traits and yield components have been rarely investigated in oilseed rape.

The commonly used QTL mapping methods as interval mapping ( IM, Lander and Botstein 1989 ) or composite interval mapping ( CIM, Zeng 1994 ) can only detect the overall effect of single-locus QTLs in separate environments. Epistatic effects between QTLs are either neglected or separately analysed using different analytical tools as two-way ANOVA or multiple regression methods ( Xiao et al. 1995; Li et al. 1997; Holland et al. 1998 ). However, with such indirect calculation, it is difficult to evaluate the importance of additive and epistatic effects related to one QTL, because the genetic effect of QTL detected by IM or CIM include additive and epistasis (if any) in DH population. Another disadvantage is that the estimation of epistasis by indirect way measures actually the effects between marker loci and the exact QTL effect is biased ( Xing et al. 2002 ). QTL $\mathrm{x}$ environment ( $Q E$ ) interaction is another important component for quantitative traits. QTLs detected in one environment but not in another might indicate $Q E$ interaction ( Veldboom and Lee 1996a, b; Jansen et al. 1995 ), while consistency in detection of QTLs at different environments may not conclusively indicate the absence of $Q E$ interaction ( Yan et al. 1998 ). In the present study, we used a mixed model based QTL mapping program ( Wang et al. 1999 ) which detects QTLs with additive and epistatic effects as well as their $Q E$ interaction effects simultaneously.

Another important point is that the genetic relationships among oil and protein, and their relationships with developmental stages or with seed yield related traits are estimated by combining the statistical procedure for analyzing conditional genetic effects ( Zhu 1995 ) with a mapping approach, so called conditional mapping analysis. Using conditional mapping 
method, the effects of QTLs for trait 1 ( e.g. oil content ) are analysed under the condition of no variation for trait 2 ( e.g. protein content ). Comparisons between unconditional and conditional mapping results show the genetic interdependency between oil and protein content and their genetic relationships with developmental stages and with yield related traits on individual QTL level. This is a new attempt in QTL mapping analysis.

The objectives of this study focus on the following aspects:

1. to map QTLs for oil, seed and meal protein content and to study the complex genetic relationships among them and the influence of developmental stages

2. to trace the genetic behavior of individual QTL for oil and protein content under excluding the variations of yield related traits to evaluate the genetic relationships between two types of traits

3. to identify QTLs controlling other agronomic traits, and to analyze their genetic response to developmental stages and genetic relationships among them.

This thesis includes six separate manuscripts corresponding with these objectives. The first manuscript describes the details about the development of $\mathrm{DH}$ populations, marker analysis and map construction, explanation of the mapping program and mapping procedures. QTL mapping for oil content concerning additive, digenic epistasis and QTL $\mathbf{x}$ environment interaction effects is also presented in manuscript 1. Mapping QTLs for protein content in seed and meal, and their complex genetic relationships with oil content are analyzed in the second manuscript. The following two manuscripts mainly focus on analyzing QTLs for oil and protein content in their relationships to developmental stages and yield related traits, respectively. In the next manuscript, QTLs for seed size, seed number and silique length are mapped and their genomic positions are compared. The possible genetic relationship between seed size, seed number and separate developmental stages is also examined in this manuscript. The last manuscript deals with the mapping of QTLs for the two plant type traits: plant height and number of primary branches, and the two most important development traits: flowering time and maturity. Before these results are presented, the following chapter gives a short literature review on QTL mapping in rapeseed. 


\section{References}

Becker HC, Engqvist GM, Karlsson B (1995) Comparison of rapeseed cultivars and resynthesized lines based on allozyme and RFLP markers. Theor. Appl. Genet. 91: 62-67

FAO 2002. Production Year Book, FAO, Rome.

Holland JB (1998) EPISTACY: A SAS program for detection two-locus epistatic interactions using genetic marker information. The Journal of Heredity 89: 374-375

Jansen RC, Van Ooijen JW, Stam P, Lister C, Dean C (1995) Genotype by environment interaction in genetic mapping of multiple quantitative trait loci. Theor. Appl. Genet. 91: 33-37

Krzymanski J (1998) Agronomy of oilseed Brassicas. Acta Hort. 459: 55-60

Lander ES, Botstein D (1989) Mapping mendelian factors underlying quantitative traits using RFLP linkage maps. Genetics 121: 185-199

Li ZK, Pinson SRM, Park WD, Paterson AH, Stansel JW (1997) Epistasis for three grain yield components in rice ( Oryza sativa L.). Genetics 145: 453-465

Veldboom LR, Lee M (1996a ) Genetic mapping of quantitative trait loci in maize in stress and non-stress environments: I. grain yield and yield components. Crop Science 36: 1310-1319

Veldboom LR, Lee M (1996b) Genetic mapping of quantitative trait loci in maize in stress and non-stress environments: II. Plant height and flowering. Crop Science 36: 1320-1327

Wang DL, Zhu J, Li ZK, Paterson AH (1999) Mapping of QTL with epistatic effects and QTL x environment interactions by mixed model approaches. Theor. Appl. Genet. 99: 1255-1264

Xiao J, Li J, Yuan LP, Tanksley SD ( 1995 ) Dominance is the major genetic basis of heterosis in rice as revealed by QTL analysis using molecular markers. Genetics 140: 745-754

Xing YZ, Tan YF, Hua JP, Sun XL, Xu CG, Zhang Q (2002) Characterization of the main effects, epistatic effects and their environmental interactions of QTLs on the genetic basis of yield traits in rice. Theor. Appl. Genet. 105: $248-257$

Yan J, Zhu J, He C, Benmoussa M, Wu P (1998) Molecular dissection of developmental behavior of pant height in rice (Oryza sativa L.). Genetics 150: 1257-1265

Zeng ZB (1994 ) Precision mapping of quantitative trait loci. Genetics 136: 1457-1468

Zhao JY and Becker HC (1998) Genetic variation in Chinese and European oilseed rape (B.napus) and turnip rape (B.campestris) analysed with isozymes. Acta Agron. Sinica, China 24: 213-220

Zhu J (1995) Analysis of conditional genetic effects and variance components in developmental genetics. Genetics 141: 1633-1639 


\section{Literature Review}

Most of agronomic important traits in crops are quantitative in nature. They are controlled by polygenes, displaying interactions among genes and with environments. These make their genetic inheritance complicated and difficult to be understood. The procedures for finding and locating the quantitative trait loci (QTLs) and analyzing their magnitude of genetic effects and interactions with environment are called QTL mapping. This bridges the gap between continuous phenotypic variation and the inherited mechanisms by dissecting genetic variation into individual loci ( Phillipsa 1998 ). QTL mapping might open up new possibilities for marker based selection and map-based cloning and transformation in plant breeding. Basically, the procedures of QTL mapping involve construction of linkage map and searching for a relationship between traits and polymorphic markers. The efficiency and accuracy of QTL mapping depends on a large number of polymorphic markers, the mapping population, the quality of the linkage map, and an appropriate statistical approach.

\subsection{Markers, populations and map construction}

\section{Genetic markers}

It has long been realized that dissection of complex traits into individual QTLs needs the assistance of genetic markers ( Sax 1923; Rasmusson 1933; Thoday 1961; Tanksley et al. 1982 ). Prior to molecular markers, morphological markers (such as leaf shape and seed color) were used to study the inheritance of quantitative traits ( Sax 1923; Rasmusson 1933 ). Protein markers became useful in the 1950s ( Hunter and Markert 1957 ). Two types of protein markers ( biochemical marker ) were used: isozymes and storage proteins separated mainly by SDSPAGE ( Sodium Dodecylsulfate Polyacrylamide Gel Electrophoresis). However, these technologies proved inadequate for assembling high-density complete genetic maps.

In 1980, it was suggested that large numbers of genetic markers might be found by studying differences in the DNA molecule itself, revealed as restriction fragment length polymorphisms (RFLP) (Botstein et al. 1980). Since then many other molecular marker techniques have been developed and used for genetic map construction and gene tagging. Generally, DNA markers can be classified into two types: hybridization-based marker as RFLP, EST ( Qin et al. 2001 ), FISH ( Pinkel et al. 1986 ), and PCR-based marker as AFLP ( Vos et al. 1995 ), SSR ( Herne et al. 1992 ), RAPD ( Williams et al. 1990), STS ( Fukuoka et al. 1994 ) and others. 
Microsatellites, or simple sequence repeats (SSR) ( Herne et al. 1992 ), are randomly interspersed within eukaryotic genomes. They are highly variable with regard to repeat number, show co-dominant inheritance in most gene loci and are highly efficient in the fingerprinting and pedigree analysis of different crops ( Plaschke et al.1995; Rongwen et al. 1995; Struss and Plieske 1998 ). These advantages make them an ideal marker system for genetic mapping, genome analysis and the characterization of germplasm ( Akkaya et al. 1992; Röder et al. 1995; Struss and Plieske 1998 ).

The abundance, characterization and the usefulness of microsatellite markers in Brassica species is well documented by Lagercrantz et al. (1993), Kresovich et al.(1995), SzeweMeFadden et al.(1996), Uzunova and Ecke (1999). A large number of microsatellites from rapeseed (Brassica napus L.) have been identified and characterized by Plieske and Struss (2001), and their potentials as a useful marker in breeding programs of Brassica oleracea was shown by Saal et al. (2001).

\section{Mapping populations}

Genetic maps of plants are constructed based on several different kinds of populations, with each population structure having unique strengths and weaknesses. Four types of population are commonly used for map construction and mapping experiment, they are $F_{2}$ population, back cross population $(\mathrm{BC})$, doubled haploid $(\mathrm{DH})$ population, and recombinant inbred lines (RI). Most genetic mapping populations in plants have been derived from crosses between largely homozygous parents.

F2 population: This is a popular type in mapping experiment of plant. Such populations can be quickly developed and harbor all possible combinations of parental alleles ( Lander et al. 1987 ). However, each F2 individual has a different genotype and no experimental design can be employed to effectively control environmental influence. To solve this problem, evaluation of heterogeneous progenies derived from individual segregants by selfing (such as F3) can be used but gains in precision are partly sacrificed due to genetic heterogeneity ( Paterson et al.1990; Paterson, 1997 ).

BC population: This is another widely used mapping population. It is derived by crossing F1 individuals to one of the two parents, and has similar advantages and drawbacks as F2 populations. However, a $\mathrm{BC}$ population contains less genetic information than the $\mathrm{F} 2$ because additive effects cannot be distinguished from dominance effects, and some types of epistatic effects are also confounded. A major disadvantage of both F2 and BC populations is that the 
data of marker genotypes cannot be repeatedly used, which is the most expensive part of QTL mapping.

DH population: Doubled haploids are commonly used in many plant species in recent years, which are amenable to anther or microspore culture (usually from F1 plants), followed by chromosome doubling. Because the plant has two identical homologues, the amount of recombinational information is exactly equivalent to a backcross. However, DH individuals are completely homozygous, and can be self-pollinated to produce large numbers of progeny which are all genetically identical. This permits replicated testing of phenotypes, and also facilitates distribution of identical DH populations to many different researchers. Thus, a DH population can also be called a permanent population. A major drawback of $\mathrm{DH}$ population is firstly, it is not possible to estimate dominance effects and related types of epistasis; secondly, the rates of pollens or microspores successfully turned into DH plants may vary with genotypes, thus causing segregation distortion and false linkage between some marker loci.

RI population: Homozygous "permanent" populations can also be made by traditional means by selfing or sib-mating individuals for many generations starting from F2 by the single seed descent approach until almost all of the segregating loci be come homozygous. Theoretically, the genetic structure of a RI population is identical to that of a $\mathrm{DH}$ population from the same parents: each of the loci having allelic difference in parents has two genotypes with equal frequencies. However genetic distances based on RI population are enlarged compared to those obtained from F2, BC or DH populations, because many generations of selfing or sib-mating will increase the chance of recombination. A major shortcoming of RI population is similar as for DH population: the missing information on dominance and related epistasis. Furthermore, development of RI population takes long time and it is not possible for all individuals to be homozygous at all segregating loci through limited generations of selfing or sibmating, which decreases the efficiency for QTL mapping to some extent.

\section{Map construction}

Construction of linkage map includes two main steps, grouping markers and ordering the markers within each group. Linkage grouping is placing markers into linkage groups based on their linkage relationships. Usually, the parameter used to determine the linkage or non-linkage between two markers is a recombination value. There is no specific cutoff criterion used in marker group ( $\mathrm{Lu}$ et al. 1998 ), though this is important because it directly determines the number of linkage groups. The commonly accepted threshold for the LOD value $\geq 3.0$ for 
statistical acceptance of linkage and critical distance between two linked markers $\leq 40 \mathrm{cM}$ (Kosambi or Haldane function, Lu et al. 1998; Lincoln et al. 1993). The term LOD is an abbreviation for $\log$ of the odds ratio. The LOD score, denoted by Z, is defined as the base 10 logarithm of the likelihood ratio. The interpretation of a LOD score $Z$, is that the alternative hypothesis is $10^{Z}$ times more likely than null hypothesis ( Lander and Green 1987; Lincoln et al. 1993 ). After that, to arrange the markers in each group in correct order and to estimate map distances between loci are the major goals. Many methods for that have been suggested, including minimum sum of adjacent recombination fraction (SARF) ( Falk 1989 ), minimum product of adjacent recombination fractions (PARF) ( Wilson 1988 ), maximum sum of adjacent LOD scores (SALOD) ( Weeks and Lange 1987 ), and maximum likelihood (ML) were proposed ( Lander and Green 1987). The maximum likelihood method is most widely used to date.

\subsection{Statistical Methods for QTL Mapping}

Undoubtedly, the development of statistical methods have played an important role for the detection of the association between DNA markers and quantitative characters. QTL mapping programs can be roughly classified into different groups according to the number of markers, or genetic models and analytical approaches applied ( Liu 1998; Hoeschele et al. 1997 ). According to the number of markers, single-QTL models and multiple-locus models can be classified (Liu 1998). According to the analytical technology, the methods can be grouped into one-way ANOVA or simple t-test, simple linear regression, multiple linear regression, nonlinear regression, log-linear regression, likelihood functions, MCMC ( Markoff Chain Monte Carlo), mixed linear models, and Bayesian approach ( Weller 1986; Lander and Botstein 1989; Haley and Knott 1992; Jansen 1992, 1993a; Zeng 1993, 1994; Wang et al. 1999).

\subsubsection{Single-marker analysis}

Analysis of variance (ANOVA), or t- test was the first method for detection of associations between genetic markers and quantitative traits (Elston et al. 1973; Hill 1975; Mcmillan and Robertson 1974; Soller et al. 1976). Simple regression method was also suggested for association detection (Zeng 1994 ), which is virtually the same in statistical power. However, the marker-QTL association based on this type of methods does not give information about the precise locations of QTLs. It is also not possible to distinguish a tight linked QTL with small effect from a loosely linked QTL with large effects ( Lander and Botstein 1989 ). Nevertheless, this early approach is still considered as a very useful first step to roughly detect the associations between DNA markers and quantitative traits. 
The maximum likelihood function was introduced to improve the accuracy of estimating QTL effects. Several maximum likelihood procedures based on single markers were proposed ( Weller et al. 1988; Luo and Kearsey 1991; Darvasi and Weller 1992 ). Maximum likelihood methods have similar power as ANOVA or t-test for the detection and evaluation of the effects at QTL when the marker and the QTL are closely linked. However, the single-marker maximum likelihood method also cannot decide the position of the QTL relative to the marker (right or left ).

\subsubsection{Interval mapping method}

Interval mapping method was first proposed by Lander and Botstein (1989). Intervals between adjacent pairs of markers along a chromosome are scanned and the likelihood profile of a QTL position at any particular point in each interval is determined. The Log value of the odds ratio of likelihood ( LOD is an abbreviation for log of the odds ratio ) of there being one vs. no QTL at a particular point ( Lander and Botstein 1989 ) is calculated. This method has been most widely used with the very popular software package MapMaker/QTL ( Lincoln et al. 1992 ). An alternative approach using multiple regression was developed ( Hayley and Knott 1992; Martinez and Curnow 1992 ). It produces very similar results to LOD mapping both in term of accuracy and precision, and the advantage is the speed and simplicity of program. However, some unsolved problems with interval mapping still remain. One of the major problems is the influence of closely linked QTLs. Simulation results indicated that a "ghost QTL" might appear between two real linked QTLs in interval mapping while the two real QTLs are hidden by the "ghost QTL" ( Moreno-Gonzalez 1992 ). Another disadvantage is that this method deals with the effects of additional QTL as sampling variation, which may cause the biased estimation of QTL and the testing power will decrease.

\subsubsection{Composite interval mapping}

To overcome the problems of low testing power and "ghost QTL", composite interval mapping ( CIM ) approaches were proposed (Zeng 1993, 1994; Jansen 1993b). CIM will perform the analysis in the same way as IM but the variance from other QTL is accounted for by including partial regression coefficients from markers ("cofactors") in other regions of the genome. Simulation results showed that composite interval mapping has higher resolution and detection power than interval mapping ( Zeng 1994 ). Different algorithms such as multiple linear regression ( Jansen 1993a), maximum likelihood function ( Zeng 1993, 1994 ) and the Markov Chain Monte Carlo (MCMC) approach were applied to composite interval mapping. However, such methods can only detect single-locus QTLs and estimate the genetic effects in separate 
environments. Therefore digenic epistasis and GE interactions of QTLs were not able to be dissected, simultaneously. Recently, the mixed linear model approach was introduced to composite interval mapping ( Wang et al. 1999; Piepho 2000 ). Due to the flexibility of the mixed linear model approach, the genetic model can be easily extended to more complex genetic situations such as GE interaction and epistasis ( Wang et al. 1999 ).

\subsection{QTL x environment interaction}

Genotype by environment interaction is a common phenomenon for quantitative traits, demonstrated by classical genetics studies, and has been of great concern for plant breeding programs ( Falconer 1960; Lin et al.1986; Westcott 1986 ). QTL mapping offer the opportunity to trace genotype by environment interactions between individual QTLs and environments. Reports about inconsistency in detection of QTLs across different environments are numerous. In contrast, Stuber et al. (1992) and Schön et al. (1994) reported that QTL detection was relatively consistent across diverse environments. The difference in observations may be a function of the traits studied and may also be a function of the methods of identifying genotype by environment interaction.

In most previous mapping reports, possible QTL $\mathrm{x}$ environment interactions were analyzed by comparing the QTLs detected separately in each environment or using the mean value of all environments. It was suggested that a QTL detected in one environment but not in another might indicate QTL $x$ environment interaction. However, even in the absence of true QTL $x$ environment interaction, a QTL can be detected in one environment but not in another, because the chance of simultaneous detection in both environments is naturally small ( Jansen et al. 1995 ). On the other hand, consistency in detection of QTLs at different environments may not conclusively indicate the absence of QTL $x$ environment interaction. Recently, some methods have been proposed for dealing with QE interactions ( Jansen et al. 1995; Romagosa et al.1996; Wang et al. 1999; Piepho 2000 ) and several reports were published to detect QE interaction effects ( Jansen et al. 1995; Romagosa et al. 1996; Yan et al. 1998a,1999; Cao et al. 2001; Xing et al. 2002)

\subsection{Epistatic QTLs}

Epistasis is a term originally used by Bateson in 1909 to describe the situation that the gene action at one locus has an effect on the gene action at another locus. Later, this term was endowed a more general meaning that is synonymous with nonadditive interactions between alleles at different loci by Fisher (1918). Classical quantitative genetics has strongly suggested 
the importance of epistasis, or nonadditive gene action between loci in quantitative inheritance ( Fasoulas and Allard 1962; Spickett and Thoday 1966; Falconer 1981; Mather and Jinks 1982; Pooni et al. 1987; Allard 1988 ). QTL mapping experiments have also provided some results regarding the importance of epistasis affecting complex traits in many crops ( Tanskley and Hewitt 1988; Lark et al. 1995; Doebley et al. 1995; Cockerham and Zeng 1996; Luo et al. 2001; Li et al. 2001; Xing et al. 2002 ). Results strongly suggest that epistasis contributes to the genetic basis of quantitative traits.

\subsection{Conditional QTL analysis}

The conditional statistical method was proposed by Zhu (1995) for analyzing conditional genetic effects and conditional genetic variance components caused by gene action during the specific plant developmental periods. This method combined with mapping programs was used for mapping conditional QTLs in different time intervals for plant height ( Yan et al.1999; Gao et al. 2001 ) and tiller number ( Yan et al. 1998b) in rice. The conditional QTL mapping approach was extended to study closely related traits as yield and yield components to dissect the complex relationships and to reveal the contribution of each component to yield on QTL level ( Benmoussa 1998; Cao 2000 ).

\subsection{QTL mapping in Brassica species}

Most of the mapping work in Brassica was started from the beginning of 1990's. It is focused mostly on rapeseed, B. napus, and on all the three diploid cultivated species, B. nigra, B. oleracea and B. rapa. More recently, mapping has been expanded to B. juncea. Genetic maps in Brassicea so far mainly served as double purposes: a) understanding the relationship among the genomes of the cultivated diploid Brassica species, and b) utilization in applied genetics and breeding of the numerous Brassica crops.

\subsubsection{Linkage maps}

\section{Map development in different Brassica species}

Several linkage maps for Brassica species were developed in the last ten years, mainly using RFLP markers in F2 or backcross populations. The first map of Brassica oleracea was published in 1990 by Slocum et al. and many maps were constructed later ( Landry et al. 1992; Kianian and Quiros 1992; Quiros et al.1994; Kearsey et al.1996; Ramsay et al. 1996; Camargo et al. 1997 ). The two most extensive maps created for B. rapa were developed by Chyi et al.(1992 ) and Slocum (1989 ) with Song et al. (1991 ). Other maps were developed by several researchers ( McGrath and Quiros 1991; Teutonico and Osborn 1994). In Brassica nigra, Truco 
and Quiros (1994) developed a map based on single F2 population. Lagercrantz and Lydiate (1995) developed a RFLP map in a backcross population. This map was recently expanded by Lagercrantz ( 1998 ). Most of the mapping activities in Brassica has been focused on B. napus because its economic importance. Several independent maps have been reported by various laboratories. The first map was developed by Landry et al. (1991), comprising 120 markers in a cross between two closely related spring rapeseed varieties using RFLP markers. In the past few years, several other maps were developed based on F2 progenies or doubled haploid lines ( Ferreira et al. 1994; Uzunova et al.1995; Sharpe et al. 1995; Parkin et al. 1995; Foisset et al. 1996; Cheung et al.1997).

\section{Integrative and comparative maps}

With common sets of markers being included in genetic maps of different Brassica species or different populations, comparisons between the maps are possible, and can shed further insights into genome organization and evolution of the diploid genomes in the amphidiploids. Lydiate et al. (1993 ) compared the B. napus maps derived from two highly polymorphic crosses and found almost complete collinearity of both maps. More recently, Lombard et al. (2001) developed a consensus linkage map of Brassica napus, integrating three individual maps of DH populations. The consensus approach allowed to map a larger number of markers, to obtain a near-complete coverage of the rapeseed genome, to fill gaps, and to consolidate the linkage groups of the individual maps. Sebastian et al. (2000) reported the first integrated map of $B$. oleracea from the data of two very different $\mathrm{F}_{1}$ - derived $\mathrm{DH}$ mapping populations. Map integration resulted in increased locus density and effective population size, providing a stronger framework for subsequent physical mapping and for precision mapping of QTLs using substitution lines. Linkage maps among different Brassica species are also compared and reported and genome of a synthetic $B$. napus is essentially unrearranged with respect to the $B$. oleracea and B. rapa progenitors used to generate the synthetic amphidiploid (Lydiate 1993), while when comparing normal B. oleracea and B. napus (Cheung and Landry 1996), in most cases, the extent of the B. oleracea homoeology only covers part of the B. napus linkage groups. The observed homoeology is segmental, suggesting that $B$. napus evolution has been accompanied by more complicated rearrangements than were observed for the synthetic $B$. napus. Hoenecke and Chyi (1991) compared the maps among B. rapa, B. oleracea and B. napus. The results support the close evolutionary relationship between these diploid species but also indicate that deletions and insertions may have occurred after divergence of the species. Schmidt et al. ( 2001 ) reported the comparative structural genomics in the Brassicaceae family. 


\subsubsection{Applications of maps in breeding}

The Brassica linkage maps are extensively applied to tag genes of interest, including QTL of agronomic importance. Generally, mapping experiments in Brassica species mainly include four parts: 1) traits related with F1 hybrid production; 2) genes for disease resistance; 3) traits controlling seed and meal quality; 4) QTLs governing plant morphological and yield related traits.

\section{Marker utilization in hybrid breeding}

The successful identification of restorer gene for cytoplasmic male sterility (CMS) in ogu-CMS system ( Delourme et al. 1994; Delourme et al 1998; Wu et al. 2000 ), and in pol- and napCMS system ( Jean et al. 1998; Li et al.1998; Phogat et al. 2000) has already led to application of marker-assisted selection in hybrid breeding ( Hansen et al. 1997 ). An alternative $F_{1}$ production mechanism is the use of self-incompatibility through S-alleles from B. oleracea and B. rapa, which are responsible for pollen rejection at the stigma surface wherever the pollen and stigma bear identical S-alleles. DNA markers linked to some of the S-alleles have been identified (Kamisugi et al. 1998; Niikura and Matsuura 1998; Uyenoyama. 2000; Miege et al. 2001; Watanabe et al. 2001; Shiba et al. 2002 )

\section{QTLs for disease resistance}

Intensive research in mapping disease resistance genes have been carried out worldwide and some of them are being successfully used for screening in practical breeding programs. Fungal disease resistance genes like blackleg in B. napus and B. rapa (Ferreira et al. 1995a; Dion et al. 1995; Pilet et al. 1998; Dixelius and Wahlberg 1999; Pilet et al. 2001), white rust in B. napus ( Ferreira et al. 1995c) and B. rapa, ( Kole et al. 1996; Kole et al. 2002 ), clubroot in B. napus ( Figdore et al., 1993; Manzanares et al. 2000 ) in B. oleracea (Grandclement et al. 1996; Moriguchi-Katsumi 1999 ), and in B. rapa ( Kikuchi-Motoyuki 1999; Matsumoto et al. 1998) have been identified with various molecular markers. Virus disease resistance genes mainly from $B$. rapa also attracted great attentions and were mapped in diverse sources ( Walsh et al. 1999; Dreyer et al. 2001). Besides, markers linked to Phoma resistance genes in B. nigra and B. napus ( Plieske and Struss 2001) were also reported.

\section{QTLs related to the seed quality traits}

A large proportion of the cultivated Brassicas are used as oilseeds for human consumption, and their crushed meal is used as animal feed since the changes from high to low erucic acid content of oil and from high to low content of glucosinolates in the meal. Genes controlling the level of 
glucosinolates in seeds have been tagged by QTL mapping ( Uzunova et al. 1995; Toroser et al.1995; Hall et al. 2001). The gene loci regulate the individual hydrolysis product has been mapped ( Magrath et al. 1994; Parkin et al. 1994; Lambrix Vet al. 2001). Mapping of erucic acid has been reported in B. napus ( Ecke et al. 1995; Thormann et al. 1996; Jourdren et al. 1996b; Rajcan et al. 1999 ) and two genomic regions were identified to associate with erucic acid.

Increase of seed oil and meal protein content and further improvement of oil and meal quality are the most important breeding aims in Brassica oilseed rape. Mapping for oil content was reported in different Brassica species. Ecke et al. (1995) and Cheung et al.(1998) detected three and two QTLs for oil content in B. napus and B. juncea respectively by RFLPs, however these QTLs (two of three by Ecke et al. 1995 ) showed a complete linkage with two erucic acid genes, indicating a direct effect of the erucic acid genes on oil content on these loci. Sharma et al. 1999 ) also identified QTLs for oil content in Indian mustard. More recently, Gül (2002) identified six oil QTLs ( two of them were the same as detected by Ecke et al. 1995) and four of them showed a close negative linkage with protein QTLs, explaining the conflict between oil and protein content in seed, while two oil QTLs and one protein QTL might be inherited independently, demonstrating the potential for combining high seed oil and protein contents.

Many researches for individual fatty acid are regarded that they are controlled by few major genes. It has been reported that high oleic acid is inherited monogenically ( Tanhuanpää et al.1998; Scheffler et al.1997; Rücker and Röbbelen 1997; Schierholt et al. 2000). Markers for linolenic acid content have been identified by several laboratories ( Tanhuanpää et al. 1995a; Hu et al. 1995; Jourdren et al.1996a; Thormann et al. 1996; Hu et al. 1999 ). Tanhuanpää et al. 1995b also detected a RAPD marker associated to palmitic acid in the same linkage group associated to oleic acid content. Molecular markers for assistant to improve meal quality for amino acid, phytic acid, sinapine and tannins content are not yet reported to date.

\section{Mapping of morphological QTLs}

Flowering-time: Variation in flowering time is important for the adaptation of a plant species to different natural and agricultural environments. Mapping for vernalization requirement and flowering QTLs in Brassica species are widely reported. In B. oleracea, Camargo et al. 1996 detected two QTLs on different linkage groups associated with both flowering time and flowering-time index and one additional QTL was found associated only with flowering-time index. In B. rapa, two QTLs (VFR1 and VFR2) determining biennial habit have been identified ( Teutonico and Osborn 1995; Osborn et al. 1997), which were shown to be homologous to two 
regions in B. napus carrying QTLs (VFN1 and VFN2) controlling vernalization-responsive flowering time (Osborn et al. 1997; Butruille et al.1999). QTLs VFR2 and VFN2 were also homologous to a region at the top of chromosome 5 in Arabidopsis thaliana, where the flowering-time genes CONSTANS (CO), EMBRYONIC FLOWER 1 (EMF1), FY and FLOWERING LOCUS C (FLC) are located ( Lagercrantz et al. 1996; Osborn et al. 1997). More recently, evidence was presented for homology of flowering-time genes VFR2 from Brassica rapa and FLC from Arabidopsis thaliana ( Kole et al. 2001) and pointed out that multiple flowering time QTLs within several Brassica species could be the result of duplicated copies of one ancestral gene, possibly the ancestor of CO ( Axelsson et al. 2001 ).

Yellow seed coat: Yellow seeds have increased oil and protein contents and lower levels of fibers due to thinner seed coat. DNA markers flanking the locus controlling yellow seed $(Y l s)$ have been mapped in B. rapa ( Teutonico and Osborn 1994; Chen et al. 1997 ), in Brassica juncea ( Upadhyay et al. 1996; Negi et al. 2000) and in B. napus ( Van-Deynze et al. 1995). Somers et al.(2001) found that in B. napus, there is a dominant, epistatic interaction between the pigment one locus and the two additional genes.

Other agronomic traits: Genes or markers for 28 traits, some of which were associated to as many as five QTLs were determined in a B. rapa progeny of Chinese cabbage $\mathrm{x}$ Spring broccoli ( Song et al., 1995 ). The same type of study was done by Kennard et al. (1994) for 22 traits in an $\mathrm{F}_{2}$ population $B$. oleracea, resulting from crossing broccoli and cabbage. In B. napus, Butruille et al.1999 developed four populations of inbreed backcross lines (IBLs ) and mapped genomic regions from the donor parent (a winter-type cultivar) that affect agronomic traits in spring-type inbreds and hybrids. Results indicated that the number of QTL detected for each trait and the number of effective factors calculated by using biometrical methods were of similar magnitude. Populations of IBLs were shown to be valuable for both marker mapping and QTL analysis.

\subsection{Mapping QTL for oil and protein content in other oil crops}

As the most important vegetable oil crop in the world, soybean attracted great attentions in QTL analysis for economically important traits including protein and oil content. Most of the results indicated that protein and oil QTLs are genetic linked but did not exclude that some independent genes exist. Shoemaker et al. (1996) reported that QTL for seed protein and oil showed correspondence across homozygous regions; Lee et al.(1996) identified various common markers on five linkage groups which associated with both seed protein and oil. Brummer et al. (1997) reported that environmentally stable and environmentally sensitive quantitative trait loci 
(QTL) were identified for both protein and oil contents in eight different populations over two years. Sebolt et al. ( 2000 ) reported that in a backcross population, genetic marker alleles linked to the QTL allele were significantly associated with higher protein and lower oil concentration, reduced yield, smaller seeds, taller plants, and earlier maturity. Markers linked to the second QTL allele were not significantly associated with seed quality or agronomic traits. In the genetic background tests, a marker allele on LG I was found to be linked with an increase in protein concentration in two of the three crosses. In maize, Luebberstedt et al. (1997) identified four QTLs for protein yield and ten for protein concentration. Three QTLs for oil content and three for flowering date were detected in sunflower ( Mestries et al. 1998). Leon et al. (1995), using a RFLP map, located six regions representing $57 \%$ of the genetic variation of seed oil of sunflower. Two of these regions were associated with kernel oil, two with kernel percentage, and two with both components. Additive gene action was detected to be predominant for seed oil and its components.

\subsection{References}

Akkaya SM, Bhagwat AA, Cregan PB (1992) Length polymorphism of simple sequence repeat DNA in soybean. Genetics 132: 1131-1139

Allard RW (1988) Future directions in plant population genetics, evolution and breeding. In Plant Population Genetics and Germplasm Resources. ed. by A. H. D. Brown, M. T. Clegg, A. L. Kahler, B.S. Weir. Sinauer Associates Inc., Sunderland, MA. pp: 1-19

Axelsson T, Shavorskaya O, Lagercrantz U ( 2001 ) Multiple flowering time QTLs within several Brassica species could be the result of duplicated copies of one ancestral gene. Genome 44: 856-864

Bateson W (1909) Mendel's Principles of Heredity. Cambridge Univ. Press, Cambridge, UK

Benmoussa, M. (1998) Molecular dissection of yield and yield components in rice (Oryza sativa L.) by using genotype $\mathrm{x}$ environment interaction models. Ph.D Dissertation. Zhejiang Agricultural University, Hangzhou, China

Botstein D, White RL, Skolnick M, Davies RW (1980) Construction of a genetic map in man using restriction fragment length polymorphisms. Am. J. Hum. Genet. 32: 314-331

Brummer EC Graef GL Drf Wilcox JR Shoemaker RC (1997) Mapping QTL for seed protein and oil content in eight soybean populations. Crop Science 37: 370-378

Butruille DV, Guries RP and Osborn TC (1999) Linkage analysis of molecular markers and quantitative trait loci in populations of inbred backcross lines of Brassica napus L. Genetics 153: 949-964

Camargo LEA, Osborn TC (1996) Mapping loci controlling flowering time in Brassica oleracea. Theor. Appl. Genet. 92: 610-616 
Camargo LEA, Savides L, Jung G, Nienhuis J, Osborn TC (1997) Location of the self-incompatibility locus in an RFLP and RAPD map of Brassica oleracea. J. of Hered. 88: 57-59

Cao G, Zhu J, He C, GaoY, Yan J, Wu P ( 2001) Impact of epistasis and QTL x environment interaction on the developmental behavior of plant height in rice (Oryza sativa L.) Theor. Appl. Genet. 103: 153-160

Cao G (2000) QTL analysis of epistatic and conditional effects for some agronomic traits in rice ( Oryza sativa L.) Ph.D Dissertation. Zhejiang Agricultural University. Hangzhou, China

Chen BY, Jorgensen RB, Cheng BF, Heneen WK (1997) Identification and chromosomal assignment of RAPD markers linked with a gene for seed colour in a Brassica campestris-alboglabra addition line. Hereditas (Lund) 126: 133-138

Cheung WY, Landry BS (1996) Current status of genome mapping in the cruciferae. In: Andrew H. Paterson (eds) Genome Mapping in Plants. R.G. Landes Company. pp: 194-210

Cheung WY, Friesen L, Rakow GFW, Seguin-Swartz G, Landry BS (1997) A RFLP-based linkage map of mustard (Brassica juncea L. Czern and Coss) Theor. Appl. Genet. 94: 841-851

Cheung WY, Landry BS (1998) Molecular mapping of seed quality traits in Brassica juncea L. Czern. and Coss. Proc. Int. Symp on Brassica. Acta Hort. 459: 139-147

Chyi YS, Hoenecke ME, Sernyk JL (1992 ) A genetic linkage map of restriction fragment length polymorphism loci for Brassica rapa (syn. campestris). Genome 35: 746-757

Cockerham CC, Zeng ZB (1996) Design III with marker loci. Genetics 143: 1437-1456

Darvasi A, Weller JI (1992) On the use of the moments method of estimation to obtain approximate maximum likelihood estimation of linkage between a genetic marker and a quantitative locus. Heredity 68: 43-46

Delourme R, Bouchereau A, Hubert N, Renard M, Landry BS (1994 ) Identification of RAPD markers linked to a fertility restore gene for the Ogura radish cytoplasmic male sterility of rapeseed (Brassica napus L.) Theor. Appl. Genet. 88: 741-748

Delourme R, Foisset N, Horvais R, Barret P, Champagne G, Cheung WY, Landry BS, Renard M (1998) Characterisation of the radish introgression carrying the Rfo restorer gene for the Ogu-INRA cytoplasmic male sterility in rapeseed (Brassica napus L.) Theor. Appl. Genet. 97: 129-134

Dion Y, Gugel RK, Rakow GF, Seguin SG, Landry BS (1995 ) RFLP mapping of resistance to the blackleg disease [causal agent, Leptosphaeria maculans (Desm) Cas et de Not] in canola (Brassica napus L). Theor. Appl. Genet.91: 1190-1194

Dixelius C, Wahlberg S (1999) Resistance to Leptosphaeria maculans is conserved in a specific region of the Brassica B genome. Theor. Appl. Genet. 99: 368-372

Doebley J, Stec A, Gustus C (1995) teosinte branchedI and the origin of maize: evidence for epistasis and the evolution of dominance. Genetics 141: 333-346

Dreyer F, Graichen K, Jung C (2001) A major quantitative trait locus for resistance to Turnip Yellows Virus (TuYV, syn. beet western yellows virus, BWYV) in rapeseed. Plant Breeding 120: 457-462

Ecke W, Uzunova M, Weißleder K (1995) Mapping the genome of rapeseed (Brassica napus L.). II. Localization of genes controlling erucic acid systhesis and seed oil content. Theor. Appl. Genet. 91: 972-977

Elston RC, Stewand J (1973 ) The analysis of quantitative traits for simple genetic models from parental, F1 and backcross data. Genetics 73: 695-711 
Falconer DS (1960 ) Introduction to Quantitative Genetics. $1^{\text {st }}$ Ed. Oliver and Boyd, Edinburgh, UK

Falconer DS (1981) Introduction to Quantitative Genetics. $2^{\text {nd }}$ Ed. Longman Press, New York, USA

Falk CT (1989) A simple scheme for preliminary ordering of multiple loci: application to 45 CF families. In: Elston, Spence, Hodge and MacCluer (eds.), Multipoint Workshop 6. Liss, New York, pp: 17-22

Fasoulas AC, Allard RW (1962) Nonallelic gene interactions in the inheritance of quantitative characters in barley. Genetics 47: 899-907

Ferreira ME, Williams PH, Osborn TC (1994) RFLP mapping of Brassica using doubled haploid lines. Theor. Appl. Genet. 89: 615-621

Ferreira ME, Rimmer SR, Williams PH, Osborn TC (1995 a) Mapping loci controlling Brassica napus resistance to Leptosphaeria maculans under different screening conditions. Phytopathology 85: 213-217

Ferreira ME, Williams PH, Osborn TC et al. (1995b) Mapping of a locus controlling resistance to Albugo candida in Brassica napus using molecular markers. Phytopathology 85: 218-220

Figdore SS, Ferriera ME, Slocum MK, Williams PH (1993 ) Association of RFLP markers with trait loci affecting clubroot resistance and morphological characters in Brassica oleracea. Euphytica 69: 33-44

Fisher RA (1918) The correlations between relatives on the supposition of Mendelian inheritance. Trans. R. Soc. Edinb. 52: 399-433

Foisset N, Delourme R, Barret P, Hubert N, Landry BS, Renard M (1996) Molecular mapping analysis of Brassica napus using isozyme, RAPD and RFLP markers on doubled haploid progeny. Theor. Appl. Genet. 93: $1017-1025$

Fukuoka S, Inoue T, Miyao A, Monna L, Zhong HS, Sasaki T, Minobe Y (1994 ) Mapping of sequence-tagged sites in rice by single strand conformation polymorphism. DNA Res. 1: 271-277

Grandclement C, Laurent F, Thomas G (1996 ) Detection and analysis of QTLs based on RAPD markers for polygenic resistance to Plasmodiophora brassicae Woron in Brassica oleracea L. Theor.Appl.Genet. 93: $86-90$

Gül MK (2002) QTL-Kartierung und Analyse von QTL x Stickstoff Interaktionen beim Winterraps (Brassica napus L.) Ph.D thesis, Fachbereich Agtarwissenschaften der Georg-August-Universität, Göttingen

Haley CS, Knott SA (1992) A simple regression method for mapping quantitative trait loci in line crosses using flanking markers. Genetics 69: 315-324

Hall C, McCallum D Drescott_A Mithen R (2001) Biochemical genetics of glucosinolate modification in Arabidopsis and Brassica Theor.Appl.Genet.102: 69-374

Hansen M, Hallden C, Nilsson NO, Sall T (1997) Marker-assisted selection of restored male-fertile Brassica napus plants using a set of dominant RAPD markers. Molecular-Breeding 3: 449-456

Hayley CS, Knott SA (1992) A simple regression method for mapping quantitative trait loci in line crosses using flanking markers. Heredity 69: 315-324

Herne CM, Ghosh S, Todd JA (1992) Microsatellite for linkage analysis of genetic traits. Trends Genet. 8: 288-294

Hill AP (1975) Quantitative linkage: A statistical procedure for its detection and estimation. Ann. Hum. Genet. Land. 38: 439-559 
Hoenecke M, Chyi YS (1991) Comparison of Brassica napus and B. rapa genomes based on restruction fragment length polymorphism mapping. In: McGregor DI ed. Proc $8^{\text {th }}$ Int. Rapeseed Cong. GCIRC, Saskatoon, pp: $1102-1107$

Hoeschele I, Uimari P, Grignola FE, Zhang Q, Gage KM (1997) Advances in statistical methods to map quantitative trait loci in outbred populations. Genetics 147: 1455-1457

Hu J, Li G, Struss D, Quiros CF (1999) SCAR and RAPD markers associated with 18-carbon fatty acids in rapeseed, Brassica napus. Plant Breeding 118: 145-150

Hu J, Quiros CF, Arus P, Struss D, Röbbelen G (1995 ) Mapping of a gene determining linolenic acid concentration in rapeseed with DAN-based markers. Theor.Appl.Genet.90,258-262

Hunter RL, Markert CL (1957) Histochemical demonstration of enzymes separated by zone electrophoresis in starch gels. Science 125: 1294-1295

Jansen RC (1992 ). A general mixture model for mapping quantitative trait loci by using molecular markers. Theor. Appl. Genet. 85: 252-260

Jansen RC (1993a). Interval mapping of multiple quantitative trait loci. Genetics 135: 205-211

Jansen RC (1993b) Maximum likelihood in a generalized linear finite mixture model by using the EM algorithm. Biomatrics 49: 227-231

Jansen RC, Van Ooijen JW, Stam P, Lister C, Dean C (1995) Genotype by environment interaction in genetic mapping of multiple quantitative trait loci. Theor. Appl. Genet. 91: 33-37

Jean M, Brown GG, Landry BS (1998) Targeted mapping approaches to identify DNA markers linked to the Rfp1 restorer gene for the 'Polima' CMS of canola (Brassica napus L.) Theor. Appl. Genet. 97: 431-438

Jourdren C, Barret P, Horvais R, Foisset N, Delourme R, Renard M (1996a ) Identification of RAPD markers linked to the linolenic acid genes in rapeseed. Euphytica 90: 351-357

Jourdren C, Barret P, Horvais R, Foisset N, Delourme R, Renard M (1996b) Identification of RAPD markers linked to the loci controlling erucic acid level in rapeseed. Mol. Breed. 2: 61-71

Kamisugi Y, Nakayama S, O'-Neil CM, Mathias RJ, Trick M, Fukui K (1998) Visualization of the Brassica selfincompatibility S-locus on identified oilseed rape chromosomes. Plant Molecular Biology 38: 1081-1087

Kearsey MJ, Ramsay LD, Jennings DE, Lydiate DJ, Bohuon EJR, Marshall DF (1996 ) Higher recombination frequencies in female compared to male meiosis in Brassica oleracea. Theor. Appl. Genet. 92: 363-367

Kennard WC, Slocum MK, Figdore SS et al.(1994) Genetic analysis of morphological variation in Brassica oleracea using molecular markers. Theor.Appl.Genet. 87: 721-732

Kianian SF, Quiros CF (1992 ) Generation of a Brassica oleracea composite RFLP map: linkage arrangements among various populations and evolutionary implications. Theor. Appl. Genet. 84: 544-554

KikسchiM Ajisaka_ KuginukiY HiraiM (1999) Conversion of RAPD markers for a clubroot resistance gene of Brassica rapa into sequence - Tagged sites (STSs). Breeding Science 49: 83-88

Kole C, Teutonico R, Mengistu A, Williams PH, Osborn TC (1996 ) Molecular mapping of a locus controlling resistance to Albugo candida in Brassica rape. Phytopathology 86: 367-369

Kole C, Quijada P, Michaels SD, Amasino RM, Osborn TC ( 2001) Evidence for homology of flowering-time genes VFR2 from Brassica rapa and FLC from Arabidopsis thaliana. Theor. Appl. Genet. 102: 425-430 
Kole Williams PH Rimmer SR Bshorn TC (2002 ) Linkage mapping of genes controlling resistance to white rust (Albugo candida) in Brassica rapa (syn. campestris) and comparative mapping to Brassica napus and Arabidopsis thaliana. Genome 45: 22-27

Kresovich S, Szewc-McFadden AK, Bliek SM, McFerson JR (1995) Abundance and characterization of simple sequence repeats (SSR) loci isolated from a size-fractionated genomic library of Brassica napus L. (rapeseed). Theor. Appl. Genet. 91: 206-211

Lagercrantz U, Ellegren H, Andersson L (1993 ) The abundance of various polymorphic microsatellite motifs differs between plants and vertebrates. Nucleic Acids Res. 21: 1111-1115

Lagercrantz U, Lydiate DJ (1995) RFLP mapping in Brassica nigra indicates differing recombination rates in male and female meiosis. Genome 38: 255- 264

Lagercrantz U, Putterill J, Coupland G, Lydiate D (1996) Comparative mapping of Arabidopsis and Brassica, fine scale genome collinearity and congruence of genes controlling flowering time. The plant Jour. 9: 13-20

Lagercrantz U (1998) Comparative mapping of Arabidopsis thaliana and Brassica nigra indicates that Brassica genomes have evolved through extensive genome replication accompanied by chromosome fusions and frequent rearrangements. Genetics 150: 1217-1228

Lambrix V, Reichelt M, Mitchell OT, Kliebenstein_DJ Gershenzon J (2001) The Arabidopsis epithiospecifier protein promotes the hydrolysis of glucosinolates to nitriles and influences Trichoplusia ni herbivory. Plant Cell 13: 2793-2807

Lander ES, Green P, Abrahamson J, Barlow A., Daly MJ, Lincoln SE, Newburg L (1987 ). MAPMAKER: an interactive computer package for constructing primary genetic linkage maps of experimental and natural populations. Genomics 1: 174-181

Lander ES, Green P (1987) Construction of multilocus genetic linkage maps in humans. Proc. Natl. Acad. Sci. 84: 2363-2367

Lander ES, Botsein D (1989) Mapping mendelian factors underlying quantitative traits using RFLP linkage maps. Genetics 121: 185-199

Landry BS, Hubert N, Etoh T, Harada JJ, Lincoln SE (1991) A genetic map for Brassica napus based on restriction fragment length polymorphisms detected with expressed DNA sequences. Genome 34: 543-552

Landry BS, Hubert N, Crete R, Chang MS, Lincoln SE, Etho T (1992) A genetic map of Brassica oleracea based on RFLP markers detected with expressed DNA sequences and mapping of resistance genes to race 2 of Plasmodiophora brassicae ( Woronin ). Genome 35: 409-420

Lark KG, Chase K, Adler F, Mansur LM, Orf JH (1995) Interaction between quantitative trait loci in soybean in which trait variation at one locus is conditional upon a specific allele at another. Proc. Natl. Acad. Sci. USA 92: 4656-4660

Lee SH, Bailey MA, Mian MAR, Carter TEJr, Shipe ER, Ashley DA et al.(1996) RFLP loci associated with soybean seed protein and oil content across populations and locations. Theor.Appl.Genet.93: 649-657

Leon_AJ Lee M Rufener GK Berry ST Mowers RP(1995) Use of RFLP markers for genetic linkage analysis of oil percentage in sunflower seed. Crop Science 35: 558-564

Li ZK, Luo LJ, Mei HW, Wang DL, Shu QY, Tabien R (2001) Overdominant Epistatic Loci Are the Primary Genetic Basis of Inbreeding Depression and Heterosis in Rice. I. Biomass and Grain Yield. Genetics 158: $1737-1753$ 
Li XQ, Jean M, Landry BS; Brown GG (1998) Restorer genes for different forms of Brassica cytoplasmic male sterility map to a single nuclear locus that modifies transcripts of several mitochondrial genes. Proceedings of the National Academy of Sciences of the United States of America. 95: 10032-10037

Lin CS, Binns MR, Lefkovitch LP (1986) Stability analysis: where do we stand? Crop Sci. 26: 894-900

Lincoln S, Daly M, Lander E (1992) Mapping genes controlling quantitative traits with MAPMAKER/QTL 1.1. Whitehead Institute Technical Report. $2^{\text {nd }}$ Ed.

Lincoln SE Daly MJ and Lander ES (1993) Constructing genetic linkage maps with MAPMARKER/EXP 3.0. A tutorial and reference manual. Whitehead Institute for Biomedical Research. USA

Liu, BH (1998) Computational tools for study of complex traits. In: Molecular Dissection of Complex Traits. ed. by Paterson AH, CRC press, Boca Raton New York. pp: 43-80

Lombard V, Delourme R (2001) A consensus linkage map for rapeseed (Brassica napus L.): Construction and integration of three individual maps from DH populations. Theor. Appl. Genet. 103: 491-507

Lu ZX, Sosinski B, Reighard GL, Baird WV, Abbott AG (1998) Construction of a genetic linkage map and identification of AFLP markers for resistance to root-knot nematodes in peach rootstocks. Genome 41: 199-207

Luebberstedt T, Melchinger AE Klein D Degenhardt H PaulC (1997) QTL mapping in testcrosses of European flint lines of maize: II. Comparison of different testers for forage quality traits. Crop Science 37: 19131922

Luo LJ, Li ZK, Mei HW, Shu QY, Tabien R, Zhong DB (2001) Overdominant Epistatic Loci Are the Primary Genetic Basis of Inbreeding Depression and Heterosis in Rice. II. Grain Yield Components. Genetics 158: $1755-1771$

Luo ZW, Kearsey MJ (1991) Maximum likelihood estimation of linkage between a marker gene and a quantitative locus. II. Application to backcross and doubled haploid populations. Heredity 66: 117-124

Lydiate D, Sharpe A, Lagercrantz U, Parkin I (1993) Mapping the Brassica genome. Outlook in Agriculture 22: 8592

Magrath R, Bano F, Morgner M et al. (1994) Genetics of aliphatic glucosinolates. I. Side chain elongation in Brassica napus and Arabidopsis thaliana. Heredity 72: 290-299

Manzanares DMI, Delourme R Baron E Thomas G (2000) Mapping of one major gene and of QTLs involved in resistance to clubroot in Brassica napus. Theor. Appl. Genet. 101: 885-891

Martinez O, Curnow RN (1992) Estimating the locations and the sizes of the effects of quantitative trait loci using flanking markers. Theor. Appl. Genet. 85: 480-488

Mather K, Jinks JL (1982 ) Biometrical genetics. $3^{\text {nd }}$ Ed. Chapman and Hall, London

Matsumato E Easuid Dhi_M Tsukada_M (1998) Linkage analysis of RFLP markers for clubroot resistance and pigmentation in Chinese cabbage (Brassica rapa ssp. pekinensis). Euphytica 104 : 79-86

McGrath JM, Jancso MM, Pichersky E (1991) Inheritance of isozyme and RFLP markers in Brassica campestris and comparison with B. oleracea. Theor. Appl. Genet. 82: 668-673

Mcmillan I, Robertson A (1974) The power of methods for the detection of major genes affecting quantitative traits. Heredity 32: 349-356 
Mestries E, Gentzhittel Le-Labrowhe DT Wicolas P Dear F (1998) Analyses of quantitative trait loci associated with resistance to Sclerotinia sclerotiorum in sunflowers (Helianthus annuus L.) using molecular markers. Molecular Breeding 4: 215-226

Miege C, Ruffio CV Schierup MH Cabrillac D Dumas C Gaude T Cock IM (2001) Intrahaplotype polymorphism at the Brassica S locus. Genetics 159: 811-822

Moriguchi_K Kimizuka TC Lshii K K N K morphological markers and QTL analysis for clubroot resistance in Brassica oleracea. Breeding Science 49: $257-265$

Moreno GJ (1992) genetic models to estimate additive and non-additive effects of marker-associated QTL using multiple regression techniques. Theor. Appl. Genet. 85: 435-444

Negi MS, Devic M, Delseny M, Lakshmikumaran M (2000) Identification of AFLP fragments linked to seed coat colour in Brassica juncea and conversion to a SCAR marker for rapid selection. Theor.Appl.Genet. 101: 146-152

Niikura S, Matsuura S (1998) Identification of self-incompatibility alleles (S) by PCR-RFLP in radish (Raphanus sativus L.) Euphytica 102: 379-384

Osborn TC, Kole C, Parkin IAP, Sharpe AG, Kuiper M, Lydiate DJ, Trick M (1997) Comparison of flowering time genes in Brassica rapa, B. napus and Arabidopsis thaliana. Genetics 146: 1123-1129

Parkin IAP, Sharpe AG, Keith DJ, Lydiate DJ (1995) Identification of the A and C genomes of amphidiploid Brassica napus (oilseed rape). Genome 38: 1122-1131

Parkin I, Magrath R, Keith D et al. (1994) Genetics of aliphatic glucosinolates. II. Hydroxylation of alkenyl glucosinolates in Brassica napus. Heredity 72: 594-598

Paterson AH, Deverna JW, Lanini B, Tanksley SD (1990) Fine mapping of quantitative trait loci using selected overlapping recombinant chromosomes in an interspecies cross of tomato. Genetics 124: 735-742

Paterson AH (1997) Comparative mapping of plant phenotypes. Plant Breed Rev. 14: 13-37

Phillipsa PC (1998) The language of gene interaction. Genetics 149: 1167-1171

Bhogat_SK Burma_PK Penta_D (2000) High frequency regeneration of Brassica napus varieties and genetic transformation of stocks containing fertility restorer genes for two cytoplasmic male sterility systems. Journal of Plant Biochemistry and Biotechnology 9: 73-79

Piepho HP ( 2000) A Mixed-Model Approach to Mapping Quantitative Trait Loci in Barley on the Basis of Multiple Environment Data. Genetics 156: 2043-2050

Pilet ML, Delourme R, Foisset N, Renard M (1998) Identification of loci contributing to quantitative field resistance to blackleg disease, causal agent Leptosphaeria maculans (Desm.) Ces. et de Not., in winter rapeseed (Brassica napus L.) Theor.Appl.Genet.96: 23-30

Bilet ML Duplan G Archipiano M Barret P Baron C, Horvais R et al. (2001) Stability of QTL for field resistance to blackleg across two genetic backgrounds in oilseed rape. Crop Science 41: 197-205

Pinkel D, Strume T, Gray GW (1986) Cytogenetic analysis using quantitative, high-sensitively fluorescence hybridization. Proc. Natl. Acad. Sci. USA 83: 2934

Plaschke J, Ganal MW, Röder MS (1995) Detection of genetic diversity in closely related bread wheat using microsatellite markers. Theor. Appl. Genet. 91: 1001-1007 
Plieske J, Struss D (2001) STS markers linked to Phoma resistance genes of the Brassica B-genome revealed sequence homology between Brassica nigra and Brassica napus. Theor.Appl.Genet. 102: 483-488

Plieske J, Struss D (2001) Microsatellite markers for genome analysis in Brassica. I. development in Brassica napus and abundance in Brassicaceae species. Theor. Appl. Genet. 102: 689-694

Pooni HS, Coombs DJ, Jinks PS (1987) Detection of epistatsis and linkage of interacting genes in the presence of reciprocal differences. Heredity 58: 257-266

Qin L, Prins P, Jones JT, Popeijus H et al. (2001) Genest, a powerful bi-directional link between cDNA sequence data and gene expression profiles generated by cDNA-AFLP. P62 The international Conference on Plant Animal Genome IX January. San Diego, CA.

Quiros CF, Hu J, Truco MJ (1994 ) DNA-based marker Brassica maps. In Phillips RL and Vasil IK (eds.) Advances in Cellular and Molecular Biology of Plants. Vol. I: DNA based Markers in Plants. Kluwer Academic Publ., Dordrecht, pp: 199-222

Bajcan I Kasha KJ KottLS, Beversdorf WD (1999) Detection of molecular markers associated with linolenic and erucic acid levels in spring rapeseed (Brassica napus L.). Euphytica 105: 173-181

Ramsay LD, Jennings DE, Bohuon EJR, Arthur AE, Lydiate DJ, Kearsey MJ, Marshall DF (1996) The construction of a substitution library of recombination backcross lines in Brassica oleracea for the precision mapping of quantitative loci. Genome 39: 558- 567

Rasmusson JM (1933) A contribution to the theory of quantitative character inheritance. Hereditas 18: 245-261

Romagosa IS, Ullrich E, Han F, Hayes PM (1996) Use of the genetic main effects and multiplicative interaction model in QTL mapping for adaptation in barley. Theor. Appl. Genet. 93: 30-37

Rongwen J, Akkaya MS, Bhagwat AA, Lavi U, Gregan PB (1995) The use of microsatellite DNA markers for soybean genotype identification. Theor. Appl. Genet. 90: 43-48

Röder MS, Plaschke J, König SU, Börner A, Sorrells E, Tanksley SD, Ganal M (1995) Abundance, variability and chromosomal location of microsatellites in wheat. Mol. Gen. Genet. 246: 327-333

Rücker B, Röbbelen G (1997) Mutants of Brassica napus with altered seed lipid fatty acid composition. In: J.P. Williams, M.V. Kalm and N.W. Lem (eds.) Proc 12th Int Symp Plant Lipids: physiology, biochemistry and molecular biology of plant lipids. Kluwer Academic Publ, Dordrecht, the Netherlands, pp: 316-318

Saal B, Plieske J, Hu J, Quiros CF, Struss D (2001) Microsatellite markers for genome analysis in Brassica. II. Assignment of rapeseed microsatellite to the A and C genomes and genetic mapping in Brassica oleracea L. Theor. Appl. Genet. 102: 695-699

Sax K (1923) The association of size differences with seed coat pattern and pigmentation in Phaseolus vulgaris. Genetics 8: $552-560$

Scheffler JA, Sharpe AG, Schmidt H, Sperling P, Parkin IAP, Lühs W, Lydiate D, Heinz E (1997) Desaturase ultigene families of Brassica napus arose through genome dublication. Theor. Appl. Genet. 94: 583-591

Schmidt R, Acarkan A, Boivin K (2001) Comparative structural genomics in the Brassicaceae family. Plant Physiology and Biochemistry Paris 39: 253-262

Schierholt A, Becker HC, Ecke W (2000 ) Mapping a high oleic acid mutation in winter oilseed rape (Brassica napus L.). Theor. Appl. Genet.101: 897-901 
Schön CC, Melchinger AE, Boppenmaier J, Brunklaus-Jung E, Herrmann RG, Seitzer JF (1994) RFLP mapping in maize: Quantitative trait loci affecting testcross performance of elite European flint lines. Crop Sci. 34: 378-389

Sebastian R.L, Howell EC, King GJ, Marshall DF, Kearsey M.J (2000) An integrated AFLP and RFLP Brassica oleracea linkage map from two morphologically distinct doubled-haploid mapping populations. Theor. Appl. Genet. 100: 75-81

Sebolt AM Shoemaker RC Diers BW (2000) Analysis of a quantitative trait locus allele from wild soybean that increases seed protein concentration in soybean. Crop Science 40: 1438-1444

Sharma R, Mohapatra T, Mukherjee AK, Krishanpal, Sharma RP (1999) Molecular markers for seed oil content in Indian mustard. Journal of plant biochemistry and biotechnology 8: 99-102

Sharpe AG, Parkin IAP, Keith DJ, Lydiate DJ (1995) Frequent nonreciprocal translocations in the amphidiploid genome of oilseed rape (Brassica napus ). Genome 38: 1112-1121

Shiba $H$, Ewano M Entani T, Lshimoto K, Shimosato H, Che FS et al. (2002) The dominance of alleles controlling self-incompatibility in Brassica pollen is regulated at the RNA level. Elant Cell. 4: 491- 504

Shoemaker RC, Polzin K, Lahate I Specht I Brummer EC Dlson T et al. (1996) Genome duplication in soybean (Glycine subgenus soja). Genetics 144:329-338

Slocum MK (1989) Analyzing the genomic structure of Brassica species using RFLP analysis. In: Helentjaris T, Burr B (eds.). Development and application of molecular markers to problems in plant genetics. Cold Spring Harbor Lab. Press, NY., pp: 73-80

Slocum MK, Figdore SS, Kennard WC, Suzuki JY, Osborn TC (1990) Linkage arrangement of restriction fragment length polymorphism loci in Brassica oleracea Theor. Appl. Genet. 80: 57-64

Soller M, Brody T, Genizi A ( 1976 ) In the power of experimental designs for detection of linkage between marker loci and quantitative loci in crosses between inbred lines. Theor. Appl. Genet. 47: 35-39

Somers DJ, Rakow G, Prabhu VK, Friesen KRD (2001) Identification of a major gene and RAPD markers for yellow seed coat colour in Brassica napus. Genome 44: 1077-1082

Song KM, Slocum MK, Osborn TC (1995) Molecular markers analysis of genes controlling morphological variation in Brassica rapa (syn. campestris) Theor. Appl. Genet. 90: 1-10

Song KM, Suzuki JY, Slocum MK, Williams PH, Osborn TC (1991 ) A linkage map of Brassica rapa (syn. campestris) based on restriction fragment length polymorphism loci. Theor. Appl. Genet. 82: 296-304

Spickett SG, Thoday JM (1966 ) Regular response to selection. 3. Interaction between located polygenes. Genet. Res. 7: $96-121$

Struss D, Plieske J (1998) The use of microsatellite markers for detection of genetic diversity in barley populations. Theor. Appl. Genet. 97: 308-315

Stuber CW, Lincoln SE, Wolff DW, Helentjaris T, Lander ES (1992) Identification of genetic factors contributing to heterosis in a hybrid from two elite maize inbred lines using molecular markers. Genetics 132: 823-839

Szewc-McFadden AK, Kresovich S, Bliek SM, Mitchell SE, McFerson JR (1996) Identification of polymorphic, conserved simple sequence repeats (SSRs) in cultivated Brassica species. Theor. Appl. Genet. 93: 534538

Tanhuanpää P, Vilkki J, Vihinen M (1998) Mapping and cloning of FAD2 gene to develop allele-specific PCR for oleic acid in spring turnip rape (Brassica rapa ssp. oleifera). Mol. Breed. 4: 543-550 
Tanhuanpää PK, Vilkki JP, Vilkki HJ (1995a), Association of a RAPD marker with linolenic acid concentration in the seed oil of spring turnip rape (Brassica napus L.) Genome 38: 414-416

Tanhuanpää PK, Vilkki JP, Vilkki HJ (1995b) Identification of a RAPD marker for palmitic acid concentration in the seed oil of spring turnip rape ( Brassica rapa ssp oleifera ) Theor.Appl.Genet.91: 477-480

Tanksley SD, Medina-Filho H, Rick CM (1982) Use of naturally-occurring enzyme variation to detect and map genes controlling quantitative traits in an interspecific backcross of tomato. Heredity 49: 11-25

Tanksley SD, Hewitt JD (1988) Use of molecular markers in breeding for soluble solids in tomato - a reexamination. Theor. Appl. Genet. 75: 811-823

Teutonico RA, Osborn TC (1994) Mapping of RFLPs and quantitative traits loci in Brassica and comparison to the linkage maps of B. napus, B. oleracea and Arabidopsis thaliana. Theor. Appl. Genet. 89: 885-894

Teutonico RA, Osborn TC (1995) Mapping loci controlling vernalization requirement in Brassica rapa. Theor. Appl. Genet. 91: 1279-1283

Thoday J. M (1961) Location of polygenes. Nature. 191: 368-370

Thormann CE, Romero J, Mantet J, Osborn TC (1996 ) Mapping loci controlling the concentrations of erucic and linolenic acids in seed oil of Brassica napus L. Theor. Appl. Genet.93: 282-286

Toroser D, Thormann CE, Osborn TC, Mithen R (1995) RFLP mapping of quantitative trait loci controlling seed aliphatic-glucosinolate content in oilseed rape (Brassica napus L.) Theor. Appl. Genet. 91: 802-808

Truco MJ, Quiros CF (1994) Structure and organization of the B. genome based on a linkage map in Brassica nigra. Theor. Appl. Genet. 89: 590-598

Upadhyay A, Mohapatra T, Pai RA, Sharma RP (1996) Molecular mapping and character tagging in mustard (Brassica juncea). II: Association of RFLP markers with seed coat colour and quantitative traits. Journal of Plant Biochemistry and Biotechnology 5: 17-22

Uyenoyama MK (2000) Evolutionary dynamics of self-incompatibility alleles in Brassica. Genetics 156: 351-359

Uzunova MI, Ecke W, Weissleder K, Röbbelen G (1995) Mapping the genome of rapeseed (Brassica napus L.) I. Construction of an RFLP linkage map and localization of QTLs for seed glucosinolate content. Theor. Appl. Genet. 90: 194-204

Uzunova MI, Ecke W (1999) Abundance, polymorphism and genetic mapping of microsatellites in oilseed rape (Brassica napus L.). Plant Breed 118: 323-326

Van DAE, Landry BS, Pauls KP (1995 ) The identification of restriction fragment length polymorphisms linked to seed colour genes in Brassica napus. Genome 38: 534-542

Vos P, Hogers R, Bleeker M, Reijians M, Lee V, Hornes M et al. (1995) AFLP: a new technique for DNA fingerprinting. Nucl. Acids Res. 23: 4407-4414

Walsh JA, Sharpe AG, Jenner CE, Lydiate DJ ( 1999 ) Characterisation of resistance to turnip mosaic virus in oilseed rape (Brassica napus) and genetic mapping of TuRB01. Theor. Appl. Genet. 99: 1149-1154

Wang DL, Zhu J, Li ZK, Paterson AH (1999) Mapping of QTL with epistatic effects and QTL x environment interactions by mixed model approaches. Theor. Appl. Genet. 99: 1255-1264

Watanahe M Matakeyama K Takada Y Hinata K (2001) Molecular aspects of self-incompatibility in Brassica species. Plant and Cell physiology 42: 560-565

Weeks DE, Lange K (1987) Preliminary ranking procedures for multilocus ordering. Genomics 1: 236-242 
Weller JI (1986) Maximum likelihood techniques for mapping and analysis of quantitative trait loci with the aid of genetic markers. Biometrics 42: 627-640

Weller JI, Soller M, Brody T (1988) Linkage analysis of quantitative traits in an interspecific cross of tomato ( Lycopersicon eseulentum $\times$ Lycopersicon pimpinellifolium ) by means of genetic markers. Genetics 118 : 329-339

Westcott B (1986 ) Some methods of analysing genotype-environment interaction. Heredity 56: 243-253

Williams J, Kubelik A, Livak K, Rafalski J, Tingey S (1990) DNA polymorphism amplified by arbitrary primers are useful as genetic markers. Nucleic Acids Res. 18: 6531-6535

Wilson SR (1988) A major simplification in the preliminary ordering of linked loci. Genet. Epidemiol. 5: 75-80

Wu Y, Tulsieram L, Tao Q, Zhang HB, Rothstein SJ (2000) A binary vector-based large insert library for Brassica napus and identification of clones linked to a fertility restorer locus for Ogura cytoplasmic male sterility (CMS) Genome 43: 102-109

Xing YZ, Tan YF, Hua JP, Sun XL, Xu CG, Zhang Q (2002) Characterization of the main effects, epistatic effects and their environmental interactions of QTLs on the genetic basis of yield traits in rice. Theor. Appl. Genet. 105: 248-257

Yan J, Zhu J, He C, Benmoussa M, Wu P (1998a ) Molecular dissection of developmental behavior of pant height in rice (Oryza sativa L.). Genetics 150: 1257-1265

Yan JQ, Zhu J, He CX, Benmoussa M, Wu. P (1998b). Quantitative trait loci analysis for the developmental behavior of tiller number in rice (Oryza sativa L.) Theor. Appl. Genet. 97: 267-274

Yan J, Zhu J, He C, Benmoussa M, Wu P (1999) Molecular marker-assisted dissection of genotype x environment interaction for plant type traits in rice (Oryza sativa L.) Crop Sci. 39: 538-544

Zeng ZB (1993) Theoretical basis for separation of multiple linked gene effects in mapping quantitative trait loci. Proc. Natl. Acad. Sci. USA 90: 10972-10976

Zeng ZB (1994). Precision mapping of quantitative trait loci. Genetics 136: 1457-1468

Zhu J (1995) Analysis of conditional genetic effects and variance components in developmental genetics. Genetics 141: $1633-1639$ 


\section{Experimental results (six separate manuscripts)}

\subsection{Construction of a linkage map and identification of QTLs for oil content}

\subsubsection{Introduction}

The successful development of canola oilseed rape ( erucic acid free and low glucosinolate content in seed ) have opened almost unlimited avenues into the food and feed markets worldwide. Increasing seed oil content and further improvement of oil quality become one of the most important breeding criteria. However, oil content in Brassica species is a complex quantitative trait, composed of individual fatty acids, synthesized concurrently with a number of other storage and structural compounds in seed, and influenced by environmental conditions. All these factors make its genetic control mechanism complicated and difficult to be evaluated accurately by classical quantitative genetics and conventional statistical methods. Previous researches reported that additive gene action was observed as main genetic factor, dominance being not significant and epistasis absent (Grami and Stefansson 1977a; Engqvist and Becker 1991). The number of genes involved is obviously smaller than that for seed yield (Olsson, 1960). Ecke et al. (1995) and Cheung et al.(1998) detected, by RFLPs, three and two QTLs (quantitative trait loci ) for oil content in B. napus and B. juncea, respectively, however these QTLs (two of three by Ecke et al.) showed a close linkage with two erucic acid genes, indicating a direct effect of the erucic acid genes on oil content.

Chinese landraces and old European cultivars of B. napus are two distinct gene pools (Becker et al. 1995; Zhao and Becker 1998). However we found in both pools materials with high oil content. It is highly interesting to study their genetic control system and allelic differentiation and distribution.

The abundance, characterization and the usefulness of microsatellite markers (SSR) were widely reported in Brassica species ( Lagercrantz et al.1993; Kresovich et al.1995; SzeweMeFadden et al.1996; Uzunova and Ecke 1999; Leroy et al. 2000; Varghese et al. 2000; Plieske and Struss 2001; Saal et al. 2001; Rudolph 2001). In this contribution, we present an SSR linkage map in B. napus for a doubled haploid (DH) population derived from European and Chinese old cultivars with high oil content. The objective of this study was to perform a comprehensive genetic analysis for QTLs controlling seed oil content using this SSR map and 
phenotypic data from 4 environments, 2 in Europe and 2 in China. Our QTL mapping results may provide useful information for improving oil content in rapeseed by combining favorable alleles from European and Chinese sources.

\subsubsection{Material and Methods}

Plant materials: The segregating DH population used for map construction and QTL mapping was developed from a cross between two highly genetic diverse winter rapeseed 'Sollux' and 'Gaoyou' (inbreeding line). 'Sollux' is an old cultivar from Germany and 'Gaoyou' is an old landrace from China. Both have high erucic acid and glucosinolate content, and exhibited high seed oil content. Four individual $\mathrm{F}_{1}$ plants were used to produce a $\mathrm{DH}$ population by microspore culture. Since no differences in marker alleles have been observed among DH lines derived from different donors, they were merged into one population including 380 lines in total. Microspore culture was done according to a modified procedure of Lichter (1982). $F_{1}$ seedlings after vernalization were transferred to an environmentally controlled growth chamber maintained at a $16 \mathrm{~h}$ photoperiod, a day/night temperature of $12^{\circ} \mathrm{C} / 8^{\circ} \mathrm{C}$, and a relative humidity of $80 \%$. Flower buds of 3 to $4 \mathrm{~mm}$ length were collected from the terminal raceme and the two or three uppermost primary branches. Induction mediums were prepared according to Lichter (1982). Ploidy level was determined with young leaves from plantlets by flow cytometry. Chromosome doubling were achieved by treatment with colchicines. Roots of plantlets were washed and immerged into a $0.05 \%$ solution of colchicine overnight.

Phenotyping experiments: The DH population of 282 lines (randomly selected from $380 \mathrm{DH}$ lines) together with parents 'Sollux ', 'Gaoyou', $F_{1}$ and four check cultivars (different check cultivars for the experiments in China and Germany) were evaluated in 2000/2001 at four locations, two near Göttingen of Germany (Reinshof and Weende), and two in China: Xian ( West China) and Hangzhou (East China). The field experiments were in a randomized complete block design with two replications. The seeds were sown in two rows for each plot, 2.5 $\mathrm{m}$ in length with $0.33 \mathrm{~m}$ between rows and $0.12 \mathrm{~m}$ between plants within rows in Göttingen and $2.5 \mathrm{~m}, 0.33 \mathrm{~m}$ and $0.15 \mathrm{~m}$, respectively, in China. Seed samples of at least $10 \mathrm{~g}$ were bulk harvested from terminal raceme and the two uppermost primary branches of five healthy plants in each plot. Seed oil content from all locations was determined by near-infrared reflectance spectrophotometry (NIRS, Reinhardt 1992) based on 9\% moisture of seeds.

SSR primer pairs and PCR analysis: Total genomic DNA of 282 (same as for field test) DH lines, parental lines and $\mathrm{F}_{1}$ plants were extracted from young leaves of greenhouse grown plants 
using the procedure described by Uzunova and Ecke (1995). In total, around 500 specific primer pairs flanking microsatellite sequences were tested with parents and $F_{1}$ plants. Of them, 112 primers with the designation MR or MD were developed at the Institute of Agronomy and Plant Breeding, University of Göttingen. The isolation of microsatellites and designation of primer pairs were described previously by Uzunova et al. (1999) and Rudolph (2001). The remaining primer pairs, designated HMR were analyzed by Saaten-Union Resistenzlabor GmbH, Hovedissen, Germany. The designations of the markers are derived from primer name combined with number of loci expressed with letters. For example, HMR295b is the second loci that could be mapped with primer pair HMR295. PCR reactions were carried out in a volume of $10 \mu 1$ with $25 \mathrm{ng}$ of template DNA, $0.5 \mu \mathrm{M}$ of each primer, $1.5 \mathrm{mM} \mathrm{MgCl}_{2}, 0.2 \mathrm{mM}$ dNTPs, $2 \% \mathrm{DMSO}, 1 \mathrm{x}$ reaction buffer (10mM Tris-HCl, $\left.1.5 \mathrm{mM} \mathrm{MgCl}_{2}, 50 \mathrm{mM} \mathrm{KCl}, \mathrm{PH} 9.0\right)$. and 1unit of Tag DNA polymerase (PeqLeb). After a denaturing step of 2-min at $94{ }^{\circ} \mathrm{C}$ a 'touch down' amplification profile was used ( Kresovich et al. 1995). This profile included a denaturing step of $60 \mathrm{~s}$ at $94{ }^{\circ} \mathrm{C}$ and an extension step of $45 \mathrm{~s}$ at $72{ }^{\circ} \mathrm{C}$. The initial annealing step was $30 \mathrm{~s}$ at $65^{\circ} \mathrm{C}$ for two cycles and was subsequently dropped by $1{ }^{\circ} \mathrm{C}$ every two cycles until a final temperature of $55^{\circ} \mathrm{C}$ or 50 ${ }^{\circ} \mathrm{C}$ was reached ( according to the different primers ). The annealing temperature of $55^{\circ} \mathrm{C}$ or 50 ${ }^{\circ} \mathrm{C}$ was employed for the last 20 cycles of the amplification. PCR products were detected either using Applied Biosystems 3100 capillary sequencer by automatic laser fluorescence labelled at the 5'end of forward primers or by separation on 4\% MethaPhor agarose gels ( FMC BioProducts, Rockland, ME, USA) in 1 x TBE buffer ( $8.9 \mathrm{mM}$ Tris-borate, $0.2 \mathrm{mM}$ EDTA, PH 8.4 ) followed by ethidium bromide staining.

Segregation analysis and map construction: From marker screening, 102 primer pairs showed clear polymorphisms in 139 marker loci between parents. The segregation of allele distribution for each SSR marker locus was tested by the $\chi^{2}$ test $(\alpha=0.05)$. Linkage analysis and map construction were performed using Mapmaker/EXP version 3.0 ( Lincoln et al.1993 ). Map construction was carried out by three steps: first, loci which segregation fit 1:1 were selected to construct the core map. Markers were assigned to linkage groups with minimum LOD score 3.00 and maximum likelihood distance $40 \mathrm{cM}$ ( Kosambi function ) using 'group' command. The most probable locus order within each group were determined using commands 'three point' , 'order' and 'ripple' functions; then, the commands of 'near' and 'try' were used to assign deviated markers into existing linkage groups one by one combined checking the position of inserted markers and distance between markers using 'delete' command. The last step was done only with all unsigned markers after the first two steps. 
Data analysis and QTL mapping: Phenotypic data of oil content of $282 \mathrm{DH}$ lines over four environments were analysed with MINQUE method ( Zhu, 1992 ) to test the difference among DH lines and estimate variance components. A map including 125 SSR marker loci ( 125 markers of 139 polymorphic loci, in total, could be assigned into linkage groups) and a data set consisting of marker information and mean values of oil content ( average of two replications ) of 282 individual DH lines in each location were prepared and used for mapping analysis. QTLMapper version 1.0 ( Wang et al. 1999 ) was used for mapping QTLs with additive and additive $\mathrm{x}$ additive epistatic effects, as well as their interaction effects with environment ( $Q E)$ for oil content in the DH population under four environments. The genetic model can be expressed as:

$$
\begin{aligned}
y_{h k}= & \mu+a_{i} x_{A_{i k}}+a_{j} x_{A_{j k}}+a a_{i j} x_{A A_{i j k}}+u_{E_{h k}} e_{E_{h}}+u_{A_{i} E_{h k}} e_{A_{i} E_{h}}+u_{A_{j} E_{h k}} e_{A_{j} E_{h}}+u_{A A_{i j} E_{h k}} e_{A A_{i j} E_{h}}+ \\
& \sum_{f(h)} u_{M_{f k(h)}} e_{M_{f(h)}}+\sum_{l(h)} u_{M M_{l k(h)}} e_{M M_{l(h)}}+\varepsilon_{h k}
\end{aligned}
$$

where $y_{h k}$ is the phenotypic value of a quantitative trait measured on the $k$-th $\mathrm{DH}$ line in environment $h ; \mu$ is the population mean; $a_{i}$ and $a_{j}$ are the additive main effects ( fixed effects ) of the two putative $Q_{i}$ and $Q_{j}$ ( QTL ), respectively; $a a_{i j}$ is the additive x additive epistatic effect (fixed effect) between $Q_{i}$ and $Q_{j} ; x_{A_{i k}}, x_{A_{j k}}$ and $x_{A A_{i j k}}$ are coefficients of QTL effects derived according to the observed genotypes of the markers $\left(\mathrm{M}_{\mathrm{i}^{-}}, \mathrm{M}_{\mathrm{i}^{+}}\right.$and $\left.\mathrm{M}_{\mathrm{j}^{-}}, \mathrm{M}_{\mathrm{j}^{+}}\right) ; e_{E_{h}}$ is the random effect of environment $h$ with a coefficient $u_{E_{h k}} ; e_{A_{i} E_{h}}\left(\right.$ or $\left.e_{A_{j} E_{h}}\right)$ is the random additive $\mathrm{x}$ environment interaction effect with a coefficient $u_{A_{i} E}{ }_{h k}\left(\right.$ or $u_{A_{j} E}{ }_{h k}$ ) for $Q_{i}$ (or $Q_{j}$ ); $e_{A A_{i j} E_{h}}$ is the random epistasis $\mathrm{x}$ environment interaction effect with a coefficient $u_{A A_{i j} E_{h k}}$; $e_{M_{f(h)}}$ is the effect of marker $f$ nested within the $h$-th environment with coefficient $u_{M_{f k(h)}}$; $e_{M M_{l(h)}}$ is the effect of marker $\mathrm{x}$ marker interaction nested within the $h$-th environment with coefficient $u_{M M_{l k(h)}}$; and $\varepsilon_{h k}$ is the residual effect. The marker factors $e_{M_{f(h)}}$ and $e_{M M_{l(h)}}$ in the model are used to absorb additive and epistatic effects of background QTLs ( additionally segregating QTL other than the loci analysed ) for controlling the noise.

QTL mapping was carried out in three steps using the QTLMapper v 1.0. First, significant markers were identified across the genome using stepwise regression analysis based on single 
marker genotypes for putative main-effect QTL and based on all possible pairwise marker pairs for epistatic QTL in individual environment separately with a threshold of $P \leq 0.01$. Secondly, all putative main-effect and epistatic QTL were identified in putative QTL regions detected in the first step, using marker main and interaction effects to control the background genetic variation. The QTL effects and test statistics associated with significant effects of QTL $(P \leq 0.01)$ were simultaneously estimated at the positions of respective LOD peaks in individual putative QTL regions using the restricted maximum likelihood estimation method (Wang et al. 1999). Additive and epistatic main QTLs were filtrated under the threshold 0.005. Finally, their genetic effects were further tested by a t-test with the jackknifing resampling procedure. QTLs were presented when genetic main effects ( $a$ and $a a$ ) or $Q E$ interaction effect ( $a e$ and aae) were significantly different from zero $(P \leq 0.005)$.

\subsubsection{Results}

SSR markers and linkage groups: Linkage analysis was performed based on 139 marker loci, of which 125 markers initially were constituted into 21 groups. They were further assigned into19 linkage groups (LG) according to Parkin et al. (1995). This SSR map of B. napus (Fig1) spanned $1196.2 \mathrm{cM}$ length in total ( Kosambi function ) with an average interval of $9.6 \mathrm{cM}$ between markers. Forty four ( $35.2 \%$ ) of total 125 mapped markers showed significant segregation distortion $(P<0.05)$, of them 32 and 12 were significantly skewed towards 'Sollux' and 'Gaoyou', respectively. The distorted markers are largely clustered in linkage groups 2, 5, 9, 10 and 11-1. About 30\% ( 39 of 125 ) mapped markers showed a dominant and the others a codominant inheritance.

Phenotypic variation among DH lines: Table 1 shows the phenotypic variation of seed oil content at four locations and estimated variance components. The seed oil content of the parents differed among locations. Oil content of Sollux in Reinshof and Weende was about 3\% higher than that of Gaoyou, while the opposite situation was found in Hangzhou and almost the same value was observed in Xian in China. Large transgressive segregation within the DH lines was observed in each test environment. Variation between highest and lowest lines could be up to 17 and 10 percentage in Germany and in China, respectively. Estimated variance components indicated that the genetic variation was clearly larger than genetic by environment interaction effects. The frequency distributions of the 282 DHLs for oil content under four test locations ( Fig 2 ) were continuous but with conside rable difference between Chinese and German 
LGl

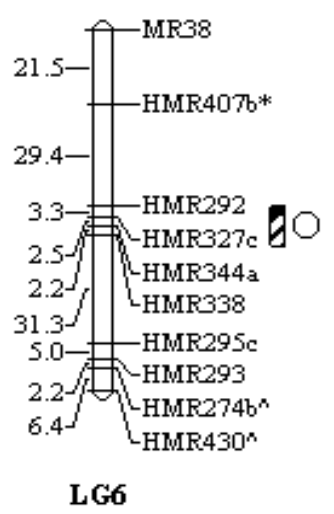

$26.2-\coprod_{-H M R S 576}^{-H M R 389}$

LG9

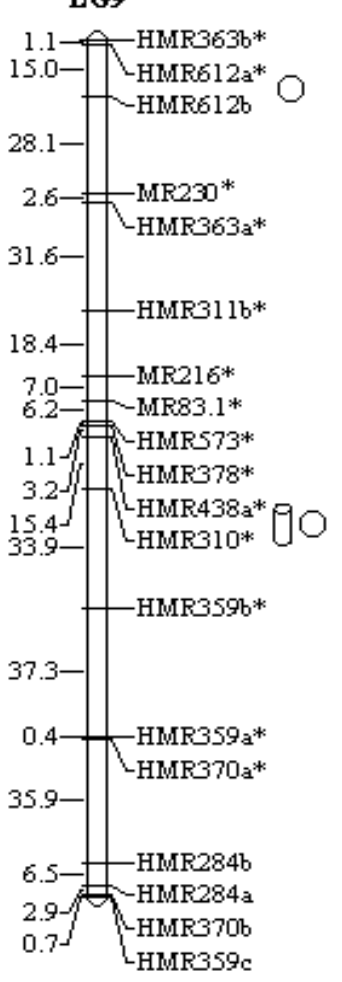

LG2

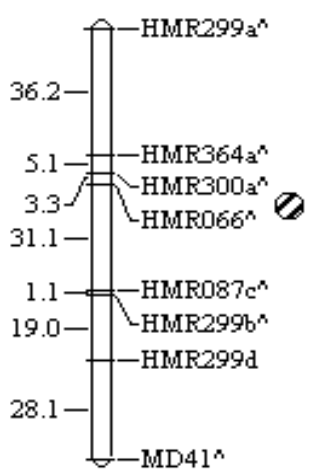

LG7

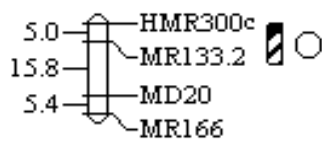

LG10

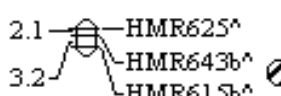

LG1 1-1

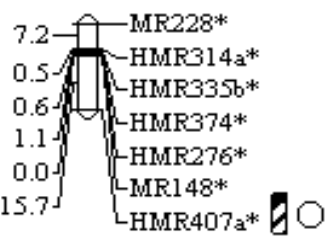

LG1 1-2

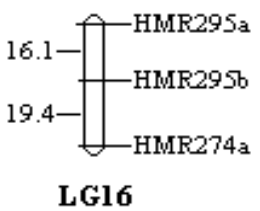

LGl6

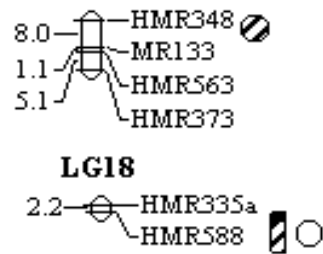

LG:3

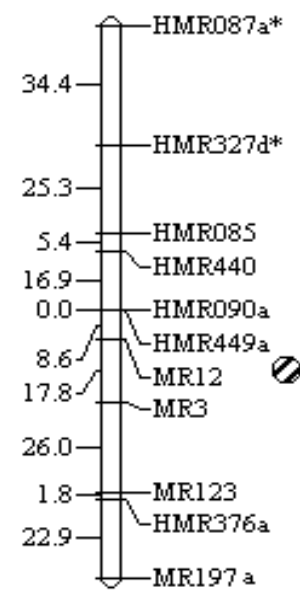

LG12

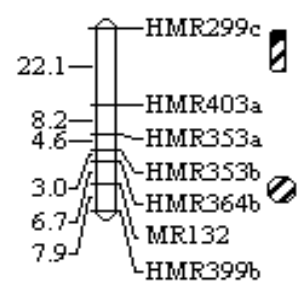

LG14-1

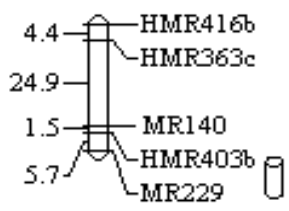

LGl4-2
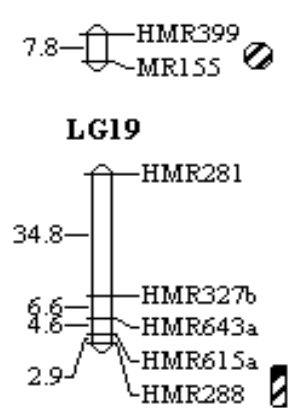

LG4

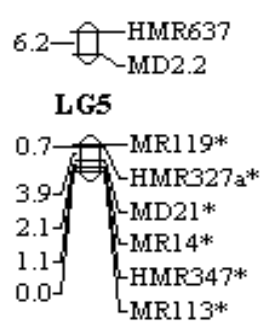

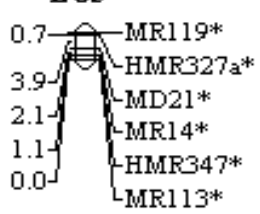

LGS

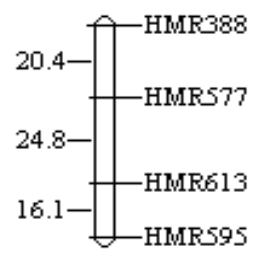

LG13

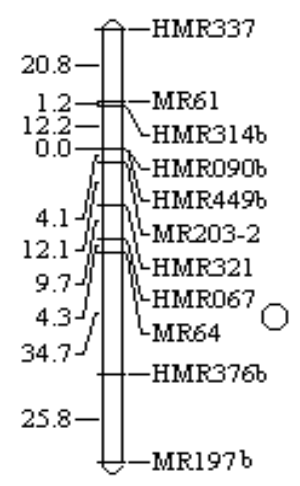

LG15

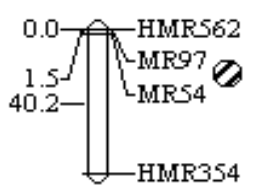

LG17

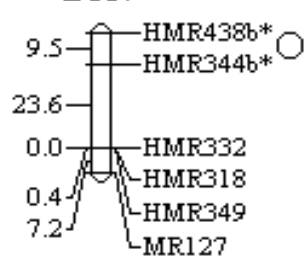

0: QTLs with $a$ and $a a$ effects, $\theta$ : QTLs with $\alpha$ and $a a$ effects

[]: OTLs with $a$ effect, $\mathrm{O}$ : OTLs with ae effect

Fig 1. SSR linkage map based on Sollux /Gaoyou (F1) DH population. Distances between markers are given in $\mathrm{cM}$, calculated from recombination frequencies according to the Kosambi mapping function. Map positions of putative QTLs controlling oil content were presented by signs above. $a$ : Additive main effect, $a a$ :

Additive $\mathrm{X}$ additive epistatic main effect of two loci, $a e$ : Additive by environment interaction effect. '*' and ' $\wedge$ ' indicate markers showing significant deviations $(\mathrm{P} \leqslant 0.05)$ from the expected $1: 1$ segregation ratio in favor of Sollux or Gaoyou alleles, respectively. 
locations. On average about $90 \%$ of the DH lines contained an oil content from $44 \%$ to $48 \%$ in locations in China and between $50 \%$ to $54 \%$ in locations in Germany, indicating a large environmental influence on this trait.

Table1. Phenotypic data of oil content (\%) in the Sollux /Gaoyou (F1) DH population evaluated over four locations and variance components

\begin{tabular}{|c|c|c|c|c|c|c|c|c|c|}
\hline \multirow{3}{*}{$\begin{array}{l}\text { Locations } \\
\text { Xian }\end{array}$} & \multicolumn{2}{|c|}{ Parents } & \multirow{3}{*}{$\begin{array}{l}\mathrm{F}_{1} \\
45.6\end{array}$} & \multicolumn{4}{|c|}{ DH Population $(n=282)$} & \multirow{2}{*}{\multicolumn{2}{|c|}{$\begin{array}{l}\text { Variances } \\
\text { components }\end{array}$}} \\
\hline & \multirow{2}{*}{$\begin{array}{l}\text { Sollux } \\
45.3\end{array}$} & \multirow{2}{*}{$\frac{\text { Gaoyou }}{45.4}$} & & \multirow{2}{*}{$\frac{\operatorname{Max}}{49.2}$} & \multirow{2}{*}{$\frac{\text { Min }}{40.4}$} & \multirow{2}{*}{$\begin{array}{l}\text { Mean } \\
44.7\end{array}$} & \multirow{2}{*}{$\frac{\mathrm{SD}}{1.60}$} & & \\
\hline & & & & & & & & $\mathrm{V}_{\mathrm{G}}$ & $8.89^{* *}$ \\
\hline Hangzhou & 41.6 & 44.7 & 42.5 & 49.5 & 38.3 & 44.2 & 1.80 & $\mathrm{~V}_{\mathrm{GE}}$ & $5.53 *$ \\
\hline Reinshof & 53.5 & 50.6 & 55.2 & 57.0 & 37.8 & 51.9 & 2.33 & $\mathrm{Ve}$ & $7.23 *$ \\
\hline Weende & 51.6 & 48.2 & 53.1 & 56.0 & 40.7 & 51.1 & 1.95 & & \\
\hline Mean & 48.0 & 47.2 & 49.1 & 52.9 & 39.3 & 48.0 & 1.92 & & \\
\hline
\end{tabular}

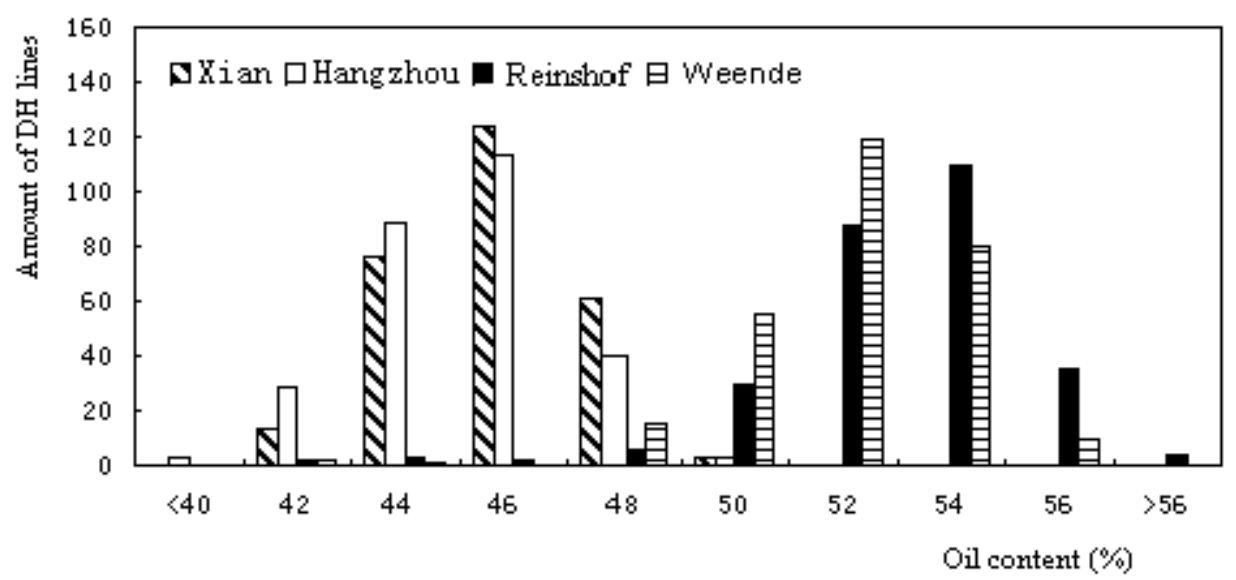

Fig2. Frequency distribution of oil content of Sollux/Gaoyou $\left(\mathrm{F}_{1}\right) \mathrm{DH}$ lines at four locations

QTLs and $Q E$ interactions for oil content: In total, 18 putative QTLs were detected with additive main effects $(a)$ and/or additive by environment interaction effects $(a e)$ ( Table 2 and Fig1 ). Of these, 3 QTLs showed only $a$ effects and 10 showed only significant ae effects while the remaining 5 exhibited both $a$ and $a e$ effects in one or more locations. Results indicted that favorable alleles for oil content were dispersed between the two parents. Of 8 additive main effect QTLs, Gaoyou alleles increased oil content in three genomic loci on LG7, LG11-1 and LG18 while Sollux alleles increased oil content on another five loci. Together, the 8 QTLs with 
additive main effects sum up to $5.4 \%$ of oil content for homozygous genotypes and explained about $40 \%$ of the mean phenotypic variation observed in the $\mathrm{DH}$ population ( difference between lines with highest and lowest mean values, Table1). Significant ae interactions of QTLs were detected in 15 genomic regions, and more were found in Hangzhou, China and Reinshof, Germany. Furthermore, it was shown that Chinese and European alleles were often more favorable for locations in China and Germany, respectively ( LG1, 2, 3, 9, 11-1,12,16 ). But we found five additional ae loci showing opposite allelic effects on linkage groups 10,14-2, 15,17 and 18 .

Table 2. Estimated additive ( $a$ ) and additive $\mathrm{x}$ environment interaction ( ae ) effects of QTLs for oil content $(\%)$

\begin{tabular}{|c|c|c|c|c|c|c|c|}
\hline $\begin{array}{l}\text { Linkage } \\
\text { group }\end{array}$ & Marker interval & $\begin{array}{l}\text { Position }{ }^{\mathrm{a}} \\
\text { (cM) }\end{array}$ & $a$ effect $^{\mathrm{b}}$ & $\begin{array}{l}a e \text { in } \\
\text { Xian }\end{array}$ & $\begin{array}{l}\text { ae in } \\
\text { Hangzhou }\end{array}$ & $\begin{array}{l}a e \text { in } \\
\text { Reinshof }\end{array}$ & $\begin{array}{l}a e \text { in } \\
\text { Weende }\end{array}$ \\
\hline 1 & HMR292/HMR327 & 0.0 & $0.373^{* *}$ & $-0.288 * *$ & & $0.239^{*}$ & \\
\hline 2 & HMR300a/ HMR066 & 0.0 & & & $-0.285^{* *}$ & $0.317 * *$ & \\
\hline 3 & HMR449a/MR12 & 8.0 & & & $-0.340 * *$ & $0.370^{* *}$ & \\
\hline 7 & HMR300c/MR133.2 & 2.0 & $-0.551 * *$ & & $-0.269^{*}$ & & \\
\hline 9 & HMR612a/ HMR612b & 0.0 & & $-0.413 * *$ & $-0.563 * *$ & $0.585^{* *}$ & $0.313 * *$ \\
\hline 9 & HMR438a/HMR310 & 14.0 & $0.338^{* *}$ & & $-0.476^{* *}$ & & \\
\hline 10 & HMR643b/HMR615b & 2.0 & & $0.305^{* *}$ & & $-0.353 * *$ & \\
\hline $11-1$ & MR148/HMR407a & 4.0 & $-0.257^{*}$ & & $-0.647 * *$ & $0.396^{* *}$ & \\
\hline 12 & HMR299c/HMR403a & 2.0 & $0.271^{*}$ & & & & \\
\hline 12 & HMR353b/HMR364b & 2.0 & & $-0.753 * *$ & $-0.343 * *$ & $0.661^{* *}$ & $0.410^{* *}$ \\
\hline 13 & HMR067/ MR64 & 0.0 & & $0.227 * *$ & $-0.293^{* *}$ & & \\
\hline $14-1$ & HMR403b/MR229 & 0.0 & $0.221^{* *}$ & & & & \\
\hline $14-2$ & HMR399a/MR155 & 6.0 & & $0.243^{* *}$ & $0.407 * *$ & $-0.492 * *$ & $-0.185^{*}$ \\
\hline 15 & MR97/ MR54 & 0.0 & & & $0.267^{* *}$ & $-0.307 * *$ & \\
\hline 16 & HMR348/ MR133 & 0.0 & & & $-0.329 * *$ & $0.342 * *$ & \\
\hline 17 & HMR438b/ HMR344b & 0.0 & & & $0.299 * *$ & $-0.270^{* *}$ & \\
\hline 18 & HMR335a/ HMR588 & 0.0 & $-0.517 * *$ & & $0.417^{* *}$ & $-0.226^{*}$ & $-0.213 * *$ \\
\hline 19 & HMR615a/ HMR288 & 0.0 & $0.224 * *$ & & & & \\
\hline
\end{tabular}

Epistasis and $Q E$ interactions for oil content: In addition to the QTLs with $a$ and ae effects, 11 pairs of epistatic QTLs were mapped, of which 7 showed only epistatic main effects ( $a a$ ) and two showed only significant epistasis by environmental effects (aae), while two displayed both $a a$ and $a a e$ effects in one or two locations (Table3). In total, nine pairs of aa QTLs sum up to $5.0 \%$ of oil content for homozygous genotypes, which is almost the same value as the total 
additive effects of homozygous genotypes. Of nine pairs of epistatic main QTLs, epistatic effect were negative on four pairs of loci, showing that the combination of two alleles from different parents at the interacting loci resulted in increased oil content, while on another five pairs of loci, the parental digenic combination were favorable for oil content. More important is that most identified QTLs simultaneously exhibited additive and epistatic effects for oil content. Six of eight additive main QTLs and seven of ten ae QTLs were involved in the pairs of $a a$ QTLs (Fig1). That made the genetic system more complicated. For example, for a good combination of additive effects, the alleles on LG11-1 and LG12 should be from Gaoyou and Sollux respectively, while for the epistatic combinations of these loci, both alleles should be from the same parent. Interactions aae were found in less loci compared to ae effect, but the directions of positive allele combinations were just opposite between the locations in China and Germany.

Table 3. Estimated epistatic ( $a a$ ) and epistasis $\mathrm{x}$ environment interaction (aae) effects of QTLs for oil content (\%)

\begin{tabular}{|c|c|c|c|c|c|c|c|c|}
\hline LG & Marker Interval & LG & Marker Interval & $\begin{array}{l}a a^{+} \\
\text {effect }\end{array}$ & $\begin{array}{l}\text { aae in } \\
\text { Xian }\end{array}$ & $\begin{array}{l}\text { aae in } \\
\text { Hangzhou }\end{array}$ & $\begin{array}{l}\text { aae in } \\
\text { Reinshof }\end{array}$ & $\begin{array}{l}\text { aae in } \\
\text { Weende }\end{array}$ \\
\hline 1 & HMR407b/HMR292 & 2 & HMR300a/HMR066 & $-0.294^{* *}$ & & & & \\
\hline 1 & HMR407b/HMR292 & 17 & HMR318/HMR439 & & $-0.277 * *$ & & $0.198^{*}$ & \\
\hline 1 & HMR295c/HMR293 & 12 & HMR353a/HMR353b & $0.384 * *$ & & & & \\
\hline 2 & HMR300a/HMR066 & 10 & HMR625/HMR643b & $0.323 * *$ & & & & \\
\hline 3 & HMR449a/MR12 & 7 & HMR300c/MR133.2 & $-0.195^{* *}$ & $-0.256^{* *}$ & & $0.219^{*}$ & \\
\hline 3 & HMR449a/MR12 & 18 & HMR335a/HMR588 & $-0.199^{* *}$ & & & & \\
\hline 4 & HMR637/MD2.2 & 12 & HMR353b/HMR364b & $-0.291^{* *}$ & & & & \\
\hline $11-1$ & MR148/HMR407a & 12 & HMR299c/HMR403a & $0.323^{* *}$ & & & & $-0.246^{*}$ \\
\hline $11-1$ & MR148/HMR407a & 16 & HMR348/MR133 & $0.205^{*}$ & & & & \\
\hline 13 & HMR314b/HMR090b & 15 & MR97/MR54 & $0.263 * *$ & & & & \\
\hline $14-2$ & HMR399a/MR155 & 19 & HMR615a/HMR288 & & & $-0.340 * *$ & $0.184 *$ & \\
\hline
\end{tabular}

${ }^{+}$Sing of epistatic effect: negative indicates that recombinant alleles from two parents and positive means that parental digenic genotypes increase phenotypic value, respectively.

QTL genotypes of lines with extreme phenotypes: To confirm the potential utilization of mapped QTLs, marker genotypes of the 20 lines with highest oil content and 20 lines with lowest oil content over four locations were compared at 13 marker loci (Table 4, 5). The first five loci displayed $a$ effect followed by a pair of loci with $a$ and $a a$ effects, and three pairs of loci with only $a a$ effects. The two favorable alleles from Gaoyou with relatively large effects on LG7 and LG18 were observed in 18 and 19 of 20 high oil lines, but only in 6 of 20 low oil lines 
respectively. The frequency of favorable alleles for these two loci reached 90 and $95 \%$ for high oil and 30\% for low oil lines, respectively. For the pair of loci on LG11-1 and LG12, $80 \%$ and $40 \%$ reasonable allele combinations (considering both $a$ and $a a$ effects) were received both for high and low oil types. Clearly the rate of favorable alleles were decreased on other marker loci

Table4. Twenty DH lines with highest oil content over four locations and their marker genotypes

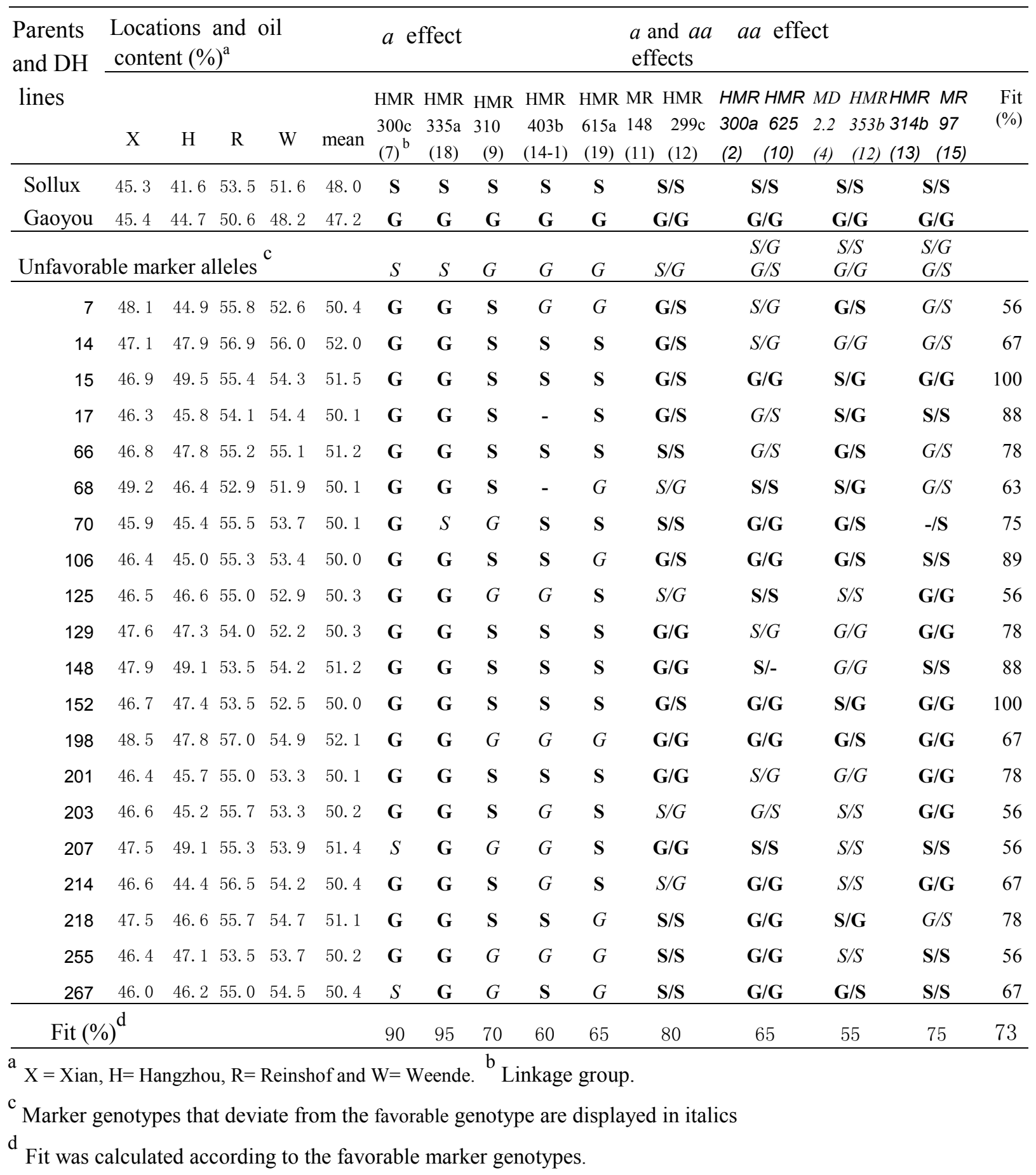


with relatively small $a$ effect $(60 \sim 70 \%)$ or with only $a a$ effects (55 75\%) for high oil genotypes and slightly increased (average 33\%) and (45\%) for low oil ones. When all 13 SSR loci were considered, the fit of favorable alleles ranged from $56 \%$ to $100 \%$ for high oil and from $11 \%$ to $67 \%$ for low oil lines. The average fit was $73 \%$ for high oil and $38 \%$ for low oil genotypes, respectively.

Table 5. Twenty DH lines with lowest oil content over four locations and their marker genotypes

\begin{tabular}{|c|c|c|c|c|c|c|c|c|c|c|c|c|c|c|c|}
\hline \multirow{2}{*}{$\begin{array}{l}\text { Parents } \\
\text { and DH } \\
\text { lines }\end{array}$} & \multicolumn{5}{|c|}{$\begin{array}{l}\text { Locations and oil } \\
\text { content }(\%)^{\mathrm{a}}\end{array}$} & \multicolumn{5}{|c|}{$a$ effect } & $\begin{array}{c}a \text { and } a a \\
\text { effects }\end{array}$ & \multicolumn{2}{|c|}{$a a$ effect } & \multirow[b]{2}{*}{$\begin{array}{ll}H M R & M R \\
314 b & 97 \\
(13) & (15) \\
\end{array}$} & \multirow[b]{2}{*}{$\begin{array}{l}\text { Fit } \\
(\%)\end{array}$} \\
\hline & $X$ & $\mathrm{H}$ & $\mathrm{R}$ & W & mean & $\begin{array}{l}\text { HMR } \\
300 \mathrm{c} \\
(7)^{b} \\
\end{array}$ & $\begin{array}{r}\text { HMR } \\
335 \mathrm{a} \\
(18) \\
\end{array}$ & $\begin{array}{l}\text { HMR } \\
310 \\
(9) \\
\end{array}$ & $\begin{array}{c}\text { HMR } \\
403 b \\
(14-1) \\
\end{array}$ & $\begin{array}{r}\text { HMR } \\
615 \mathrm{a} \\
(19) \\
\end{array}$ & $\begin{array}{ll}\text { MR } & \text { HMR } \\
148 & 299 \mathrm{c} \\
(11) & (12) \\
\end{array}$ & $\begin{array}{c}\text { HMR HMR } \\
300 a 625 \\
(2) \quad(10) \\
\end{array}$ & $\begin{array}{ll}M D & H M R \\
2.2 & 353 b \\
\text { (4) } & \text { (12) } \\
\end{array}$ & & \\
\hline Sollux & 45.3 & 41.6 & 53.5 & 51.6 & 48.0 & $\mathbf{S}$ & $\mathbf{S}$ & $\mathbf{S}$ & $\mathbf{S}$ & $\mathbf{S}$ & $\mathbf{S} / \mathbf{S}$ & $\mathbf{S} / \mathbf{S}$ & $\mathbf{S} / \mathbf{S}$ & $\mathbf{S} / \mathbf{S}$ & \\
\hline Gaoyou & 45.4 & 44.7 & 50.6 & 48.2 & 47.2 & G & $\mathbf{G}$ & $\mathbf{G}$ & $\mathbf{G}$ & $\mathbf{G}$ & G/G & G/G & G/G & G/G & \\
\hline Unfavora & ble ma & ker al & leles & & & $S$ & $S$ & $G$ & $G$ & $G$ & $S / G$ & $\begin{array}{l}S / G \\
G / S \\
\end{array}$ & $\begin{array}{c}S / S \\
G / G \\
\end{array}$ & $\begin{array}{l}S / G \\
G / S \\
\end{array}$ & \\
\hline 16 & 45.4 & 42.4 & 46.3 & 47.0 & 45.3 & $S$ & $S$ & $G$ & $G$ & $\mathbf{S}$ & $S / G$ & $\mathbf{G} / \mathbf{G}$ & $\mathbf{S} / \mathbf{G}$ & $\mathbf{S} / \mathbf{S}$ & 44 \\
\hline 22 & 43.3 & 39.2 & 48.5 & 48.3 & 44.8 & $S$ & $S$ & $\mathbf{S}$ & $\mathbf{S}$ & $\mathbf{S}$ & $S / G$ & $\mathbf{G} / \mathbf{G}$ & $\mathbf{S} / \mathbf{G}$ & $\mathbf{S} / \mathbf{S}$ & 67 \\
\hline 40 & 41.2 & 45.3 & 48.7 & 48.3 & 45.9 & $\mathbf{G}$ & $S$ & $\mathbf{S}$ & $G$ & $G$ & $S / G$ & $G / S$ & $G / G$ & $G / S$ & 22 \\
\hline 41 & 41.5 & 42.7 & 48.0 & 49.6 & 45.4 & $S$ & $S$ & $G$ & - & $\mathbf{S}$ & $\mathbf{S} / \mathbf{S}$ & $\mathbf{G} / \mathbf{G}$ & $S / S$ & $G / S$ & 33 \\
\hline 44 & 42.4 & 40.7 & 49.9 & 49.9 & 45.7 & $S$ & $S$ & $G$ & $G$ & $\mathbf{S}$ & $\mathbf{G} / \mathbf{S}$ & $G / S$ & $\mathbf{G} / \mathbf{S}$ & $\mathbf{S} / \mathbf{S}$ & 44 \\
\hline 51 & 42.6 & 42.8 & 49.8 & 47.7 & 45.7 & $S$ & $S$ & $G$ & $G$ & $G$ & $S / G$ & $\mathbf{S} / \mathbf{S}$ & $S / S$ & $G / S$ & 11 \\
\hline 78 & 43.1 & 38.7 & 50.1 & 47.5 & 44.9 & $S$ & $S$ & $\mathbf{S}$ & $G$ & $G$ & $\mathbf{S} / \mathbf{S}$ & $G / S$ & $S / S$ & $\mathbf{S} / \mathbf{S}$ & 33 \\
\hline 79 & 41.2 & 38.3 & 49. 0 & 47.2 & 43.9 & $S$ & $S$ & $\mathbf{S}$ & $G$ & $G$ & $S / G$ & $G / S$ & $\mathbf{G} / \mathbf{S}$ & G/G & 33 \\
\hline 90 & 43.2 & 40.5 & 48.9 & 48.7 & 45.3 & $S$ & $S$ & $\mathbf{S}$ & $G$ & $G$ & $\mathbf{S} / \mathbf{S}$ & G/G & $S / S$ & G/G & 44 \\
\hline 120 & 40.5 & 44.7 & 41.8 & 42.3 & 42.3 & $\mathbf{G}$ & $\mathbf{G}$ & $G$ & $G$ & $G$ & $\mathbf{G} / \mathbf{G}$ & G/G & $\mathbf{G} / \mathbf{S}$ & $G / S$ & 56 \\
\hline 153 & 42.8 & 40.2 & 47.5 & 47.8 & 44.6 & $\mathbf{G}$ & $S$ & $G$ & $G$ & $G$ & $S / G$ & $S / G$ & $S / S$ & $G / S$ & 11 \\
\hline 155 & 44.0 & 42.2 & 48.7 & 48.3 & 45.8 & $S$ & G & $\mathbf{S}$ & $G$ & $G$ & $\mathbf{G} / \mathbf{S}$ & $\mathbf{S} / \mathbf{S}$ & $S / S$ & $S / G$ & 44 \\
\hline 178 & 43.6 & 44.7 & 37.8 & 40.7 & 41.7 & $S$ & $\mathbf{G}$ & $G$ & $G$ & $G$ & $\mathbf{S} / \mathbf{S}$ & $G / S$ & $S / S$ & $\mathbf{S} / \mathbf{S}$ & 33 \\
\hline 182 & 40.4 & 43.4 & 44.7 & 42.0 & 42.6 & $\mathbf{G}$ & $S$ & $\mathbf{S}$ & $G$ & $G$ & $S / G$ & $G / S$ & $G / G$ & $G / S$ & 22 \\
\hline 246 & 44.7 & 42.9 & 42.7 & 47.3 & 44.4 & $S$ & $\mathbf{G}$ & $\mathbf{S}$ & $G$ & $\mathbf{S}$ & $S / G$ & G/G & $S / S$ & $G / S$ & 44 \\
\hline 250 & 42.2 & 40.2 & 49.6 & 49.7 & 45.4 & $\mathbf{G}$ & $\mathbf{G}$ & $G$ & $\mathbf{S}$ & $\mathbf{S}$ & G/G & $S / G$ & $S / S$ & $\mathbf{S} / \mathbf{S}$ & 67 \\
\hline 252 & 44.8 & 42.9 & 47.7 & 47.9 & 45.8 & $S$ & $S$ & $G$ & $\mathbf{S}$ & $G$ & $S / G$ & $\mathbf{S} / \mathbf{S}$ & $\mathbf{S} / \mathbf{G}$ & $G / S$ & 33 \\
\hline 261 & 40.6 & 41.7 & 42.9 & 47.1 & 43.1 & $S$ & $S$ & $\mathbf{S}$ & $G$ & $G$ & $S / G$ & $G / S$ & $\mathbf{S} / \mathbf{G}$ & $\mathbf{S} / \mathbf{S}$ & 33 \\
\hline 263 & 41.6 & 40.6 & 50.6 & 47.7 & 45.1 & $S$ & $\mathbf{G}$ & $\mathbf{S}$ & $G$ & $G$ & $S / G$ & $S / G$ & G/S & $G / S$ & 33 \\
\hline 277 & 43.5 & 41.4 & 49.6 & 48.6 & 45.8 & $\mathbf{G}$ & $S$ & $\mathbf{S}$ & $\mathbf{S}$ & $\mathbf{S}$ & $S / G$ & $S / G$ & $\mathbf{G} / \mathbf{S}$ & $G / S$ & 56 \\
\hline Fit (\%) ${ }^{\mathrm{d}}$ & & & & & & 30 & 30 & 55 & 20 & 35 & 40 & 45 & 45 & 45 & 38 \\
\hline
\end{tabular}

${ }^{\mathrm{a}} \mathrm{X}=$ Xian, $\mathrm{H}=$ Hangzhou, $\mathrm{R}=$ Reinshof and $\mathrm{W}=$ Weende. ${ }^{\mathrm{b}}$ Linkage group.

${ }^{\mathrm{c}}$ Marker genotypes that deviate from the favorable genotype are displayed in italics

${ }^{\mathrm{d}}$ Fit was calculated according to the favorable marker genotypes. 


\subsubsection{Discussion}

SSR linkage map: The present study reported a genetic map of B. napus integrating European and Chinese genetic background. The number of linkage groups were more than 19 as expected, which imply the interruption within chromosomes caused by large gaps between several small groups or pairs, suggesting more markers should be added to get a better genome coverage later.

We used two methods for identifying polymorphism of PCR products. With separation of PCR products on 4\% MethaPhor agarose gels, 32 SSR loci from 30 polymorphic primer pairs were produced (on average 1.07 loci per primer pair), while by the means of Applied Biosystems 3100 capillary sequencer, 109 polymorphic loci were detected from 72 primer pairs (max. three loci identified per one primer pair, on average 1.51 loci per primer pair). Clearly, with Capillary Sequencer, more polymorphism as small as two base pair difference between alleles could be identified. Both methods revealed about one third marker loci with dominant and the rest of co-dominant nature, as also observed earlier ( Uzunova and Ecke, 1999 ).

Genetic basis of oil content: Because of the complicated genetic control, the inheritance of oil content in Brassica species is still poorly understood. Our mapping results confirmed the previous reports that additive effects are the most important genetic factor and additive by environment interaction is significant (Grami and Stefansson 1977a; Röbbelen and Thies 1980; Engqvist and Becker 1991). The results suggest that the markers flanking the QTLs with larger genetic main effects could be selected as the candidates firstly, while QTLs with QE interaction might also be involved to select the markers for breeding purpose in specific environments. The occurrence of large transgression for oil content in the mapping population can be explained by the dispersion of alleles with positive and negative effects between parents. Integration of positive alleles from Chinese and German material into European and Chinese elite breeding lines is most interesting. Another point is that ae effects sometimes can be expected in a specific direction, most ae loci showed that Chinese and European alleles displayed positive effects in the respective locations in China and Germany. That might be due to artificial selection for alleles favorable to ecological conditions during the breeding process.

The importance of epistasis between alleles of different loci is widely reported and highly paid attentions in the study of complex economically important quantitative traits and practical plant breeding programs ( Lark et al. 1995; Eshed and Zamir 1996; Li et al. 2001; Luo et al. 2001 ). The present study strongly supports this point. We found that besides the additive effects for oil content, additive $\mathrm{x}$ additive epistatic effects were also quite substantial and often combined with additive/or additive by environment effects. This has not been recognized in the 
previous researches by classical genetic analysis ( Grami et al. 1977a; Grami et al.1977b; Engqvist and Becker 1991 ).

Exploitation of mapped QTLs: Results from this study revealed several very high oil content lines, which are around $15 \%$ and $10 \%$ higher in oil content than local check varieties both in China and in Germany. However the close relation between oil content and high erucic acid alleles reported previously ( Ecke et al. 1995; Cheung et al.1998) might partly explain the relative low oil content of double low check varieties. Although mapping of QTLs for erucic acid is impossible in this study because of no significant segregation for this trait in the DH population, it does not exclude the existence of possible linkage between QTLs for oil and erucic acid. However, the number of loci detected for oil content from this study was clearly more than that for erucic acid ( Jönsson 1977 ) and the genetic control system was much more complicated, so the potential for increasing oil content combined with erucic acid free rapeseed exist by selectively integrating favorable alleles for oil content. Further research for genetic relationship between mapped oil QTL and genes for erucic acid is necessary and great effort must be taken when QTL with positive linkage of oil with erucic acid were transferred into elite varieties or breeding materials. The present results exposed several SSR markers closely linked with high oil alleles. Two important alleles on LG7 and LG18 with Gaoyou genotypes are suggested to be merged into the elite cultivars or breeding materials. The combination of parental alleles on LG11-1 and on LG12 are recommended. Two Sollux alleles on LG14-1 and on LG19 might be also interesting. Selection only based on epistatic loci seems less reliable. Some additive by environment QTLs as on LG 9, 12, 14-2 are proposed for oil improvement in specific environments.

To sum up, the developed SSR linkage map provide the possibility for mapping other economically important quantitative traits and for further researches in other aspects. The identified high oil lines and mapped QTLs show highly potentials to improve oil content in the breeding programs both for Europe and China. 


\subsubsection{Summary}

A linkage map of rapeseed comprising 125 SSR markers and covering $1196.2 \mathrm{cM}$ length of genome was constructed using an $\mathrm{F}_{1}$ derived doubled haploid ( $\mathrm{DH}$ ) population between two high oil cultivars Sollux ( European ) and Gaoyou ( Chinese ). To better understand the genetic basis of oil content in B. napus, QTLs with additive and epistasis as well as their interactions with environments were estimated using a mixed model approach. In total, $282 \mathrm{DH}$ lines were phenotypically evaluated in 4 environments, 2 in Europe and 2 in China. Mapping results revealed 8 QTLs with additive main effects and 9 pairs of digenic loci with epistatic main effects for oil content, collectively accounted for $40 \%$ of the phenotypic variation observed in the population, respectively. The distribution of alleles increasing oil content were dispersed between the parents, which explains the transgressive segregation within $\mathrm{DH}$ lines. The present experiment identified two important alleles in Chinese parents, two alleles in European parents and one pair of digenic loci for oil content. These QTLs were confirmed by the comparison of the 20 highest and 20 lowest DH lines for oil content. A number of QTLs with interactions between environment and additive effects for oil content were observed. The results indicated the complex inheritance of seed oil content in oilseed rape and suggested a joint utilization of QTLs with additive, epistatic and $Q E$ interaction effects by marker assisted selection.

Key words Brassica napus L. Microsatellites · Oil content · Quantitative trait loci ( QTL) · Epistasis · QTL by environment interaction

\subsubsection{References}

Becker HC, Engqvist GM, Karlsson B (1995) Comparison of rapeseed cultivars and resynthesized lines based on allozyme and RFLP markers. Theor. Appl. Genet. 91:62-67

Cheung WY, Landry BS (1998) Molecular mapping of seed quality traits in Brassica juncea L. Czern. and Coss. Proc. Int. Symp on Brassica. Acta Hort. 459: 139-147

Ecke W, Uzunova M, Weißleder K (1995) Mapping the genome of rapeseed (Brassica napus L.). II. Localization of genes controlling erucic acid systhesis and seed oil content. Theor. Appl. Genet. 91: 972-977

Engqvist GM, Becker HC (1991) Relative importance of genetic parameters for selecting between oilseed rape crosses. Hereditas 115: 25-30

Eshed Y, Zamir D (1996) Less-than additive epistatic interactions of quantitative trait loci in tomato. Genetics 143: 1807-1817 
Grami B, Stefansson BR (1977a) Gene action for protein and oil content in summer rape. Can. J. Plant Sci. 57: $625-631$

Grami B, Baker RJ, Stefansson BR (1977b) Genetics of protein and oil content in summer rape: Heritability, number of effective factors, and correlations. Can. J. Plant. Sci. 57: 937-943

Jönsson R (1977) Erucic acid heredity in rapeseed ( Brassica napus L. and Brassica campestris L.) Hereditas 86: $159-170$

Kresovich S, Szewc-McFadden AK, Bliek SM, McFerson JR (1995) Abundance and characterization of simple sequence repeats (SSR) loci isolated from a size -fractionated genomic library of Brassica napus L. (rapeseed) . Theor. Appl. Genet. 91: 206-211

Lagercrantz U, Ellegren H, Andersson L (1993) The abundance of various polymorphic microsatellite motifs differs between plants and vertebrates. Nucleic Acids Res. 21: 1111-1115

Lark KG, Chase K, Adler FR, Mansur LM, Orf JJ (1995) Interactions between quantitative traits loci in soybean in which trait variation at one locus is conditional upon a specific allele at another. Proc Natl Acad Sci USA 92: $4656-4660$

Leroy XJ, Leon K, Branchard M (2000) Characterisation of Brassica oleracea L. by microsatellite primers. Plant Systematics and Evolution. 225: 235-240

Li ZK, Luo LJ, Mei HW, Wang DL, Shu QY, Tabien R et al. (2001) Overdominant epistatic loci are the primary genetic basis of inbreeding depression and heterosis in rice. I. Biomass and Grain Yield. Genetics 158: $1737-1753$

Lichter R (1982 ) Induction of haploid plant from isolated pollen of Brassica napus. Z. Pflanzenphysiol. 105: 427434

Lincoln SE, Daly MJ, Lander ES (1993) Constructing genetic linkage maps with MAPMARKER/EXP 3.0. A tutorial and reference manual. Whitehead Institute for Biomedical Research. USA

Luo LJ, Li ZK, Mei HW, Shu QY, Tabien R, Zhong DB et al. (2001) Overdominant epistatic loci are the primary genetic basis of inbreeding depression and heterosis in rice. II. Grain Yield Components. Genetics 158: $1755-1771$

Olsson G (1960) Some relationships between number of seeds per pod, seed size and oil content and the effects of selection for these characters in Brassica and Sinapis. Hereditas 46: 29-70

Parkin IAP, Sharpe AG, Keith DJ, Lydiate DJ (1995) Identification of the A and C genomes of amphidiploid Brassica napus (oilseed rape). Genome 38: 1122-1131

Plieske J, Struss D (2001) Microsatellite markers for genome analysis in Brassica. I. development in Brassica napus and abundance in Brassicaceae species. Theor. Appl. Genet. 102: 689-694

Reinhardt TC (1992) Entwicklung und Anwendung von Nah-In-frarot-spektroskopischen Methoden für die Bestimmung von Öl-Protein-, Glucosinolate-, Feuchte- und Fettsäure-Gehalten in intaker Rapssaat. Dissertation, Universität Göttingen, Cuvillier Verlag Göttingen

Röbbelen G, Thies W (1980) Biosynthesis of seed oil and breeding for improved oil quality of rapeseed. In Tsunoda S, Hinta K and Gomez-Campo C (eds) Brassica crops and wild allies: Biology and breeding. Japan Scientific Societies Press, Tokyo, pp: 253-283 
Rudolph B (2001) Entwicklung, Charakterisierung und genetische Kartierung von Mikrosatelliten-Markern beim Raps (Brassica napus L.) Ph.D thesis, Mathematisch-Naturwissenschaftliche Fakultät der Georg-AugustUniversität zu Göttingen

Saal B, Plieske J, Hu J, Quiros CF, Struss D (2001) Microsatellite markers for genome analysis in Brassica. II. Assignment of rapeseed microsatellite to the $\mathrm{A}$ and $\mathrm{C}$ genomes and genetic mapping in Brassica oleracea L. Theor. Appl. Genet. 102: 695-699

Szewe-MeFadden AK, Kresovich S, Bliek SM, Mitchell SE, McFerson JR (1996) Identification of polymorphic, conserved simple sequence repeats (SSRs) in cultivated Brassica species. Theor. Appl. Genet. 93: 534-538

Uzunova MI, Ecke W, Weissleder K, Röbbelen G (1995) Mapping the genome of rapeseed (Brassica napus L.) I. Construction of an RFLP linkage map and localization of QTLs for seed glucosinolate content. Theor. Appl. Genet. 90: 194-204

Uzunova MI, Ecke W (1999) Abundance, polymorphism, and genetic mapping of microsatellites in oilseed rape (Brassica napus L.). Plant Breed. 118: 323-326

Varghese JP, Rudolph B, Uzunova MI, Ecke W (2000) Use of 5'-anchored primers for the enhanced recovery of specific microsatellite markers in Brassica napus L. Theor. Appl. Genet. 91: 206-211

Wang DL, Zhu J, Li ZK, Paterson AH (1999) Mapping of QTL with epistatic effects and QTL x environment interactions by mixed model approaches. Theor. Appl. Genet. 99: 1255-1264

Zhao JY, Becker HC (1998) Genetic variation in Chinese and European oilseed rape (B.napus) and turnip rape (B.campestris) analysed with isozymes. Acta Agron. Sinica, China 24: 213-220

Zhu J (1992) Mixed model approaches for estimating genetic variances and covariance. J. Biomath.7: 1-11 


\subsection{QTLs for protein content and their relationships with oil content}

\subsubsection{Introduction}

Rapeseed is now the world's number two oilseed crop, ranking behind soybeans and ahead of cottonseed, peanuts and sunflower seeds. One reason for this position is that oil from “double low" ( zero erucic acid in oil and low glucosinolate in meal ) or "canola” rapeseed has one of the best fatty acid composition of vegetable oils for human nutrition, while the meal, after extraction of the oil, has a protein content of 38 to $46 \%$ with well balanced amino acid components ( Newkirk et al. 1997; Krzymanski, 1998 ) and is a valuable protein in animal feed mixtures. Therefore, breeding for both high oil and protein content is desirable. However, oil and protein share the basic sources of energy in the metabolic pathway, which causes the significant negative correlation between oil and protein content in seeds ( Grami and Stefansson, 1977b; Stefansson and Kondra,1975; Röbbelen and Thies 1980 ). For feeding purpose, protein content in meal is practically more important than protein content in the whole seed. Meal protein content largely depends on seed protein, but is also influenced by oil and other components in the seed. Oil and protein content in Brassica species are complex quantitative traits, controlled by polygenes, and influenced by environments. This makes their genetic control system complicated and difficult to be understood. Additive gene action is regarded as main genetic factor, dominance being not significant and epistasis absent (Grami and Stefansson, 1977a). Engqvist and Becker (1991) found that for oil content, only additive gene action was detected, but in some cases, significant epistatic gene action was identified for protein content. Alemayehu ( 2001) reported besides additive and non additive genetic effects, also significant cytoplasmic effects for the inheritance of protein content in B. carinata.

Recent advances in the construction of molecular linkage maps have led to the detection and mapping of important quantitative trait loci (QTL) in B. napus including fatty acids, glucosinolates, disease resistance, yield related traits and many other agronomic traits ( Rajcan et al. 1999; Scheffler et al.1997; Schierholt et al. 2000; Hu et al. 1999; Hall et al. 2001; Lambrix et al. 2001; Pilet et al. 2001; Axelsson et al. 2001; Kole et al. 2002 ; Plieske and Struss 2001; Osborn et al. 1997; Somers et al. 2001; Butruille et al. 1999 ). Mapping for oil content were also reported in different Brassica species. ( Ecke et al. 1995; Cheung et al. 1998; Sharma et al. 1999 ). More recently, Gül (2002) identified six oil QTLs ( two of them were the 
same as detected by Ecke et al. 1995 ) and four of them showed a close negative linkage with protein QTLs, explaining the conflict between oil and protein in seed, while two oil QTLs and one protein QTL might be inherited independently, demonstrating the potential for combining high seed oil and protein contents.

In this study, the genetic basis of protein content in seed and meal were analyzed using the developed SSR linkage map (see thesis 3.1 ) from a cross between European and Chinese high oil genetic background. Furthermore, by combining the statistical procedures for analyzing conditional genetic effects ( Zhu 1995 ) and the QTL mapping method based on mixed model approach ( Wang et al. 1999 ), conditional mapping analysis among oil, seed protein and meal protein were performed. The QTLs detected by the conditional mapping method reflect the net effects of oil content under excluding variation in protein content, and vice versa. The objectives of the present study were to identify the QTLs for seed and meal protein content; to study the genetic relationships between oil and protein in seed and meal on individual gene loci and to investigate the potentials of combining high oil and seed protein or high oil and meal protein simultaneously in practical rapeseed breeding.

\subsubsection{Material and methods}

\section{Plant materials and SSR map}

A mapping population of $282 \mathrm{DH}$ lines were derived from a cross $\left(\mathrm{F}_{1}\right)$ between two winter rapeseed cultivars 'Sollux' and 'Gaoyou' through microspore culture (see thesis 3.1 ). 'Sollux' is an old variety from Germany and 'Gaoyou' is an old landrace from China. Both contain high erucic acid and glucosinolate content, and are selected for high oil content in the seeds.

The SSR linkage map consisting of 125 genetic markers initially was constituted into 21 groups with a total length of $1196 \mathrm{cM}$ ( Kosambi function ) and were further assigned into 19 linkage groups according to the previous research ( Parkin et al. 1995 ). The details of map construction, SSR primer pairs and PCR analysis were described previously (see thesis 3.1 ).

\section{Field experiments}

$\mathrm{DH}$ population of 282 lines together with the parents Sollux and Gaoyou, the $\mathrm{F}_{1}$ and four check cultivars were evaluated in four locations, two in Göttingen (Reinshof and Weende), Germany and two in China: Xian ( West China) and Hangzhou (East China) in 2000/2001. The field experiments were in a randomized complete block design with two replications. The seeds were sown in two rows for each plot, $2.5 \mathrm{~m}$ in length with $0.33 \mathrm{~m}$ between rows and $0.12 \mathrm{~m}$ between plants within rows in Göttingen, and $2.5 \mathrm{~m}, 0.33 \mathrm{~m}$ and $0.15 \mathrm{~m}$, respectively in China. Seed 
samples of at least $10 \mathrm{~g}$ were bulk harvested from terminal raceme and the two uppermost primary branches of five healthy plants in each plot. Seed oil and protein content from all locations were measured by near-infrared reflectance spectrophotometry ( NIRS, Reinhardt 1992 ), based on 9\% moisture of seeds. Meal protein was calculated from seed protein and oil content:

Protein content in meal $(\%)=\frac{\text { protein }(\text { in seed }) \%}{100-\text { oil } \%} \times 100$

\section{Statistical analysis}

Phenotypic data of seed and meal protein were analysed with MINQUE method (Zhu 1992) to test the difference among DH lines and estimate variance components and covariance components between two traits. Genetic and phenotypic correlation coefficients were then estimated. A map including 125 SSR marker loci and a data set consisting of marker information and replication mean values of seed and meal protein content at 282 individual DH lines for four locations were prepared. QTLMapper 1.0 ( Wang et al. 1999 ) was used for mapping QTLs of seed and meal protein content. The phenotypic value of the $k$-th DH line in environment $h$ can be partitioned by the following mixed linear model.

$$
\begin{aligned}
y_{h k}= & \mu+a_{i} x_{A_{i k}}+a_{j} x_{A_{j k}}+a a_{i j} x_{A A_{i j k}}+u_{E_{h k}} e_{E_{h}}+u_{A_{i} E_{h k}} e_{A_{i} E_{h}}+u_{A_{j} E_{h k}} e_{A_{j} E_{h}}+u_{A A_{i j} E_{h k}} e_{A A_{i j} E_{h}}+ \\
& \sum_{f(h)} u_{M_{f k(h)}} e_{M_{f(h)}}+\sum_{l(h)} u_{M M_{l k(h)}} e_{M M_{l(h)}}+\varepsilon_{h k}
\end{aligned}
$$

where $\mu$ is the population mean; $a_{i}$ and $a_{j}$ are the additive main effects (fixed effects) of the two putative $Q_{i}$ ( QTL ) and $Q_{j}$, respectively; $a a_{i j}$ is the additive $\mathrm{x}$ additive epistatic effect (fixed effect) between $Q_{i}$ and $Q_{j} ; x_{A_{i k}}, x_{A_{j k}}$ and $x_{A A_{i j k}}$ are coefficients of these genetic main effects; $e_{E_{h}}$ is the random effect of environment $h$ with a coefficient $u_{E_{h k}} ; e_{A_{i} E_{h}}\left(\right.$ or $e_{A_{j} E_{h}}$ ) is the random additive $\mathbf{X}$ environment interaction effect with a coefficient $u_{A_{i} E_{h k}}\left(\right.$ or $u_{A_{j} E}{ }_{h k}$ ) for $Q_{i}$ (or $\left.Q_{j}\right) ; e_{A A_{i j} E_{h}}$ is the random epistasis $\mathrm{x}$ environment interaction effect with a coefficient $u_{A A_{i j} E_{h k}} ; e_{M_{f(h)}}$ is the random effect of marker $f$ nested within the $h$-th environment with a coefficient $u_{m_{f k(h)}} ; e_{M M_{l(h)}}$ is the random effect of the $l$-th marker $\mathrm{x}$ marker interaction nested within the $h$-th environment with a coefficient $u_{M M_{l k(h)}} ; \varepsilon_{h k}$ is the random residual effect. The marker factors $e_{M_{f(h)}}$ and $e_{M M_{l(h)}}$ in the model are used to absorb additive and epistatic effects of background QTLs for controlling the noise. 
The conditional phenotypic value $\left(y_{h k(T \mid T 2)}\right)$ was obtained by the mixed model approaches for the conditional analysis of quantitative traits ( Zhu 1995 ), where T1|T2 denotes trait 1 conditioned on trait 2 ( oil|SP $=$ oil conditioned on seed protein, $\mathrm{SP} \mid$ oil $=$ seed protein conditioned on oil content, and so on). Conditional QTL mapping was then performed using QTLMapper version 1.0 (Wang et al. 1999). Results from conditional mapping present the effects of QTLs for oil content under the condition of no variation for protein content or vice verse. Comparison between unconditional and conditional mapping results, it is possible to identify the genetic relationship between oil and protein content on individual gene loci. Mapping procedure was described in detail previously ( Wang et al. 1999; thesis 3.1 ). The likelihood -ratio threshold was chosen at $\alpha=0.005$ for claiming putative QTLs. Their genetic effects were further tested by a t-test with jackknifing re-sampling procedure. QTLs were presented when genetic main effects ( $a$ and $a a$ ) or $Q E$ interaction effect ( $a e$ and aae) were significantly different from zero $(P \leq 0.005)$.

\subsubsection{Results}

\section{Phenotypic variation of protein content in seed and meal}

The phenotypic distribution of seed and meal protein over four locations, as well as the two parents are presented in Table1. Transgressive segregation in the DH population was observed in all experiments for both traits. Protein content was relatively lower in Germany than in

Table1 Protein content in seed and meal under four environments ( measured by NIRs, based on $9 \%$ moisture of seeds )

\begin{tabular}{|c|c|c|c|c|c|c|c|c|}
\hline \multirow{2}{*}{ Traits } & \multirow{2}{*}{ Locations } & \multicolumn{2}{|c|}{ Parents } & \multirow[b]{2}{*}{$\mathrm{F} 1$} & \multicolumn{4}{|c|}{ DH Population $(n=282)$} \\
\hline & & Sollux & Gaoyou & & Max & Min & Mean & SD \\
\hline \multirow{5}{*}{$\begin{array}{c}\text { Protein } \\
(\text { seed } \%)\end{array}$} & Xian & 21.7 & 22.0 & 21.3 & 25.0 & 19.9 & 22.1 & 0.99 \\
\hline & Hangzhou & 24.4 & 21.8 & 23.0 & 26.2 & 18.5 & 22.1 & 1.37 \\
\hline & Reinshof & 16.4 & 19.4 & 15.3 & 24.2 & 14.1 & 17.1 & 1.66 \\
\hline & Weende & 17.8 & 20.1 & 16.8 & 23.5 & 14.8 & 17.9 & 1.46 \\
\hline & Mean & 20.1 & 20.8 & 19.1 & 24.7 & 16.8 & 19.8 & 1.37 \\
\hline \multirow{5}{*}{$\begin{array}{l}\text { Protein } \\
(\text { meal \%) }\end{array}$} & Xian & 39.9 & 40.3 & 39.2 & 43.8 & 35.5 & 40.0 & 1.49 \\
\hline & Hangzhou & 41.8 & 39.5 & 39.9 & 43.3 & 34.8 & 39.6 & 1.63 \\
\hline & Reinshof & 35.1 & 39.2 & 34.0 & 41.6 & 30.9 & 35.5 & 1.91 \\
\hline & Weende & 36.9 & 38.8 & 35.9 & 40.7 & 32.3 & 36.5 & 1.80 \\
\hline & Mean & 38.4 & 39.5 & 37.3 & 42.4 & 33.4 & 37.9 & 1.71 \\
\hline
\end{tabular}

China. Sollux showed lower protein content than Gaoyou at both locations in Germany, while the opposite situation was observed in Hangzhou, China. In Xian, both parents showed similar 
content of seed and meal protein.

Significant phenotypic correlation between seed and meal protein ranged from 0.73 to 0.89 respectively in different locations ( Fig1). The genetic correlation ( Table2) was 0.69 between seed and meal protein, -0.81 between seed oil and seed protein and insignificant between seed oil and meal protein. Estimated variance components (Table2) indicated that the variation of seed protein observed in the DH population was caused with $33 \%$ by genetic and with $30 \%$ by genetic $x$ environment interactions, and with $40 \%$ and $20 \%$ for meal protein, respectively.

Fig 1. Phenotypic distribution of seed and meal protein in four environments, mean values of two parents indicated as arrows.

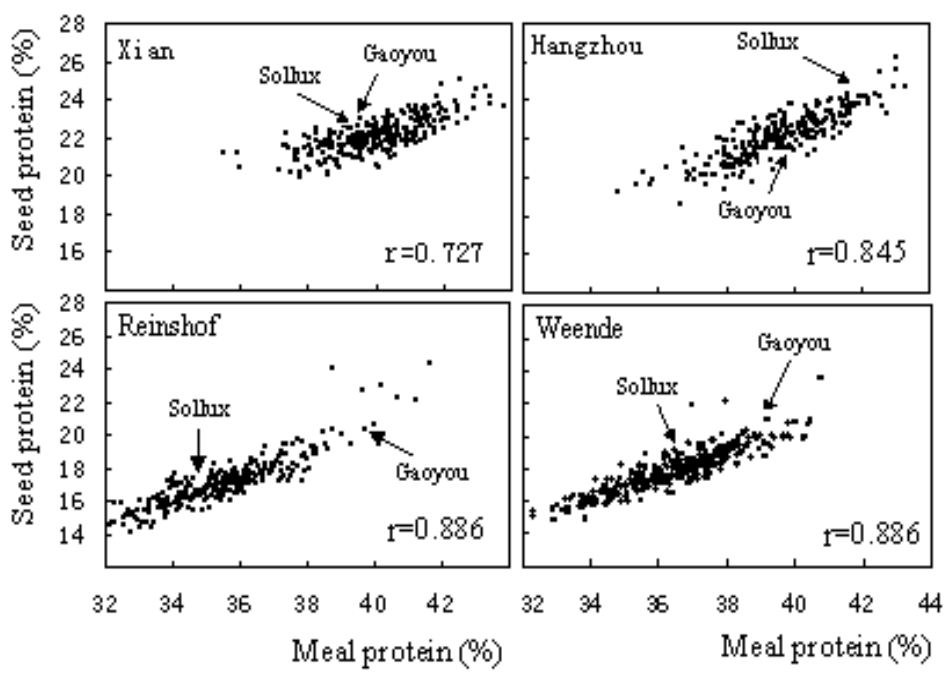

Table2. Estimated correlations and variances over four environments

\begin{tabular}{|c|c|c|c|c|c|c|}
\hline \multicolumn{4}{|c|}{ Correlation among oil and protein content } & \multicolumn{3}{|c|}{ Estimated variances } \\
\hline Traits & Genotype & GXE & Phenotype & Component $^{\mathrm{a}}$ & $\begin{array}{l}\text { Seed } \\
\text { protein }\end{array}$ & $\begin{array}{l}\text { Meal } \\
\text { protein }\end{array}$ \\
\hline Seed protein \& meal protein & $0.694 * *$ & $0.884 * *$ & $0.952 * *$ & $\mathrm{~V}_{\mathrm{G}}$ & $3.084 * *$ & $6.450^{* *}$ \\
\hline Seed protein \& oil & $-0.812^{* *}$ & $-0.943 * *$ & $-0.982 * *$ & $\mathrm{~V}_{\mathrm{GE}}$ & $2.847 * *$ & $3.05 * *$ \\
\hline Meal protein \& oil & -0.137 & $-0.691 * *$ & $-0.370 *$ & $\mathrm{~V}_{\mathrm{e}}$ & $3.510^{* *}$ & $6.15 * *$ \\
\hline & & & & $\mathrm{Vp}$ & $9.440^{* *}$ & $15.65^{* *}$ \\
\hline
\end{tabular}

*** Significant at the 0.05 and 0.01 probability levels, respectively

${ }^{\mathrm{a}} \mathrm{V}_{\mathrm{G}}, \mathrm{V}_{\mathrm{GE}}$, Ve and $\mathrm{Vp}$ are genetic main effect, genotype $\mathrm{X}$ environment interaction effect, residual and phenotypic variances respectively.

\section{QTLs for protein content in seed and meal}

QTLs with additive $(a)$ and additive by environment interaction effects $(a e)$ for seed and meal protein are shown in Table 3. In total, 8 and 11 QTLs with $a$, and/or ae effects were 
Table 3. Estimated additive main $(a)$ and additive $\times$ environment interaction ( $a e$ ) effects of QTLs for seed protein (SP) and conditioned on seed oil (SP|Oil) (\%), meal protein (MP) and conditioned on seed oil (MP|Oil)

\begin{tabular}{|c|c|c|c|c|c|c|c|}
\hline Traits & $\begin{array}{l}\text { Linkage } \\
\text { group }\end{array}$ & Marker interval & $a$ effect $^{++}$ & $\begin{array}{l}\text { ae in } \\
\text { Xian }\end{array}$ & $\begin{array}{l}\text { ae in } \\
\text { Hangzhou }\end{array}$ & $\begin{array}{l}a e \text { in } \\
\text { Reinshof }\end{array}$ & $\begin{array}{l}\text { ae in } \\
\text { Weende }\end{array}$ \\
\hline \multirow{24}{*}{$\begin{array}{l}\text { SP } \\
\text { SFIOil }\end{array}$} & 1 & HMR $292 / H M R ~ 327 \mathrm{c}$ & $-0.209 *$ & 0.313 & & $-0.239 \div$ & \\
\hline & & & $-0.122^{4+k}$ & $-^{+}$ & & - & \\
\hline & 1 & HMR2746/HMR 430 & - & & - & & \\
\hline & & & $-0.100^{5 * k}$ & & -0.118 dek & & \\
\hline & 3 & HMR376a/MR197.1 & & & $\begin{array}{c}-0.356^{-4} \\
-\end{array}$ & $\begin{array}{l}0.188 * \\
-\end{array}$ & $\begin{array}{l}0.256^{*} \\
-\end{array}$ \\
\hline & 7 & HMR $300 \mathrm{c} / \mathrm{MR} 1332$ & 0.303 & & & & \\
\hline & & & - & - & & & \\
\hline & 7 & HD20MR166 & $\overline{0.110 *}$ & $-\overline{0.137+*}$ & $\overline{0.130+* k}$ & & \\
\hline & 8 & HMR 388 HMR 577 & -0.2394 & & & & \\
\hline & & & $-0.22 S^{* * *}$ & & & & \\
\hline & 9 & HMR 310HMR 359a & - & & & & \\
\hline & & & $0.165^{* *}$ & & & & \\
\hline & 9 & HMR $284 b / H M R 284 a$ & - & & & - & \\
\hline & & & $-0.123^{* *}$ & & & $0.104+26$ & \\
\hline & 12 & HMR353/HMR364b & & 0.213 & 0.153 & $-0.386^{\#+}$ & \\
\hline & & & & - & $0.113^{\text {t*k }}$ & $-0.107^{\text {tok }}$ & \\
\hline & 13 & HMR 337MR61 & $0.232 *$ & & & & \\
\hline & & & $0.190^{+2 *}$ & & & & \\
\hline & $14-2$ & HMR399a/MR155 & & & $-0.166^{+t}$ & $0.166^{\star t}$ & \\
\hline & & & & & - & - & \\
\hline & 15 & MRG7/MRS4 & - & & & & \\
\hline & & & $-0.110^{\text {tak }}$ & & & & \\
\hline & 18 & HMR335a/ HMRS88 & $0.247^{\star \star}$ & $-0.173^{*}$ & & $0.226^{* 1}$ & \\
\hline & & & - & - & & - & \\
\hline \multirow{28}{*}{$\begin{array}{l}\text { MP } \\
\text { MF|Oil }\end{array}$} & 1 & HMR $292 / \mathrm{HMR} 327 \mathrm{c}$ & - & $0.246 *$ & 0.244 & $-0.312 *$ & \\
\hline & & & $-0.184 * k$ & - & $0.251^{* * *}$ & $-0.340^{\mathrm{k} * k}$ & \\
\hline & 1 & HMR2746/HMR430 & - & & -0.353 & $0.154^{\star}$ & \\
\hline & & & $-0.189+2 k$ & & $\bar{n}$ & - & \\
\hline & 2 & HMR 364a/HMR 300a & & & $\begin{array}{l}0.260^{*} \\
0.199+*\end{array}$ & $-0.240^{+6 *}$ & \\
\hline & 3 & HMR376a/MR197.1 & & & - & - & \\
\hline & & & & & $-0.240^{\text {t*k }}$ & $0.303^{+* k}$ & \\
\hline & 7 & HD20MR166 & $0.283^{\prime \prime}$ & $-0.263^{* \prime}$ & & & \\
\hline & & & $0.219^{+* k}$ & - & & & \\
\hline & 8 & HMR 388 HMR 577 & 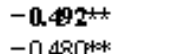 & & & & \\
\hline & 9 & HMR284b/MMR $284 a$ & & - & & & - \\
\hline & & & & $-0.211^{* * *}$ & & & $0.151 *$ \\
\hline & 10 & HMR6436/HMR61sb & $-0.230^{*}$ & $0.236^{* t}$ & 0.184 & - & $-0.172 *$ \\
\hline & & & $-0.213^{\text {t*k }}$ & - & - & $-0.198^{\circ+k}$ & $-0.25 g^{\text {tek }}$ \\
\hline & 12 & HMR 299/ HMR 403a & $\overline{0.256^{* k}}$ & & & & \\
\hline & 12 & HMR $3536 / \mathrm{MMR} 364 \mathrm{~b}$ & & & 0.363 & -0.454 & \\
\hline & & & & & $0.218^{2 * *}$ & $-0.326^{\text {tok }}$ & \\
\hline & 13 & HMR 337MMR61 & $0.243^{\prime \prime}$ & & & & \\
\hline & & & $0.307^{* k *}$ & & & & \\
\hline & 13 & HMR067MR64 & & & - & - & \\
\hline & & & & & $0.250^{\text {tok }}$ & $-0.205^{* *}$ & \\
\hline & $14-2$ & HMR399a/MR155 & -0.174 & & & & \\
\hline & & & - & & & & \\
\hline & 15 & MRG/MRS4 & - & & & & - \\
\hline & & & $-0.242^{* * *}$ & & & & $-0.224^{* * *}$ \\
\hline & 16 & HMRS63HMR 373 & $-0.182 \ldots$ & & & - & - \\
\hline & & & $-0.273^{+k+k}$ & & & $-0.247^{* * k}$ & $0.187^{+* *}$ \\
\hline & 18 & HMR335a/ HMRS88 & $0.159 \div$ & & & & \\
\hline
\end{tabular}

*, ** indicate the significance level at 0.005 and 0.001 , respectively to declare the QTL positions and genetic effects. ${ }^{+}$: indicate not significant $a$ or $a e$ effects detected. ${ }^{++}$The QTL effect, is the phenotypic effect due to substitution of an 'Gaoyou' allele by an allele of 'Sollux'. 

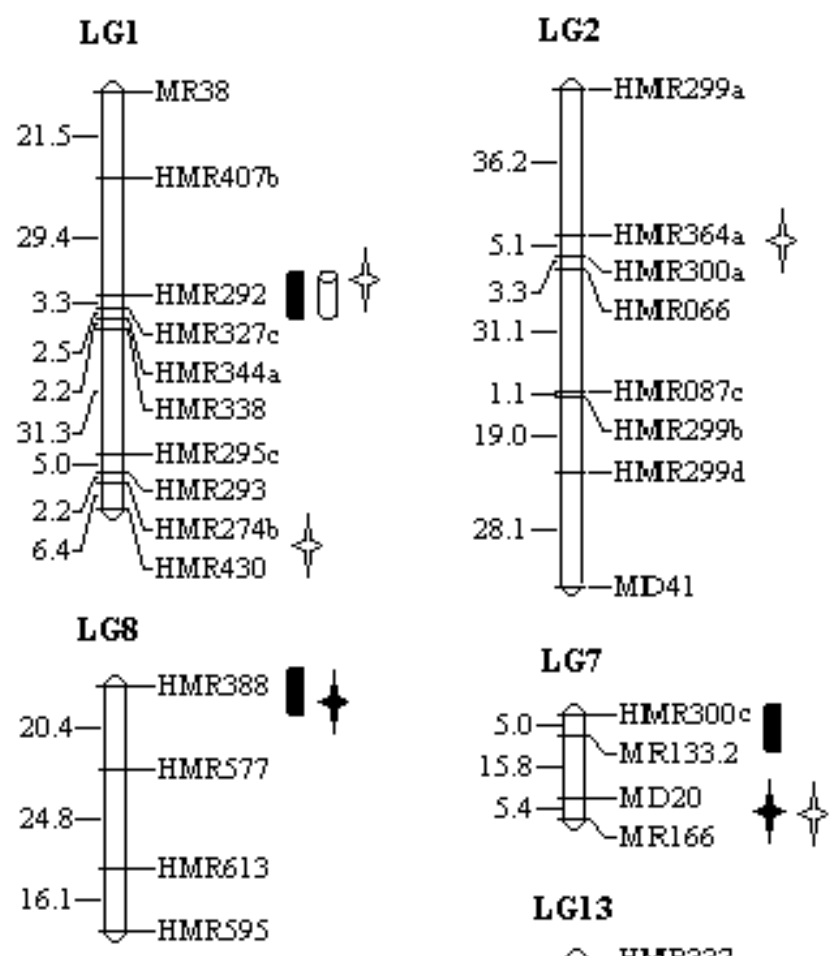

\section{LG3}
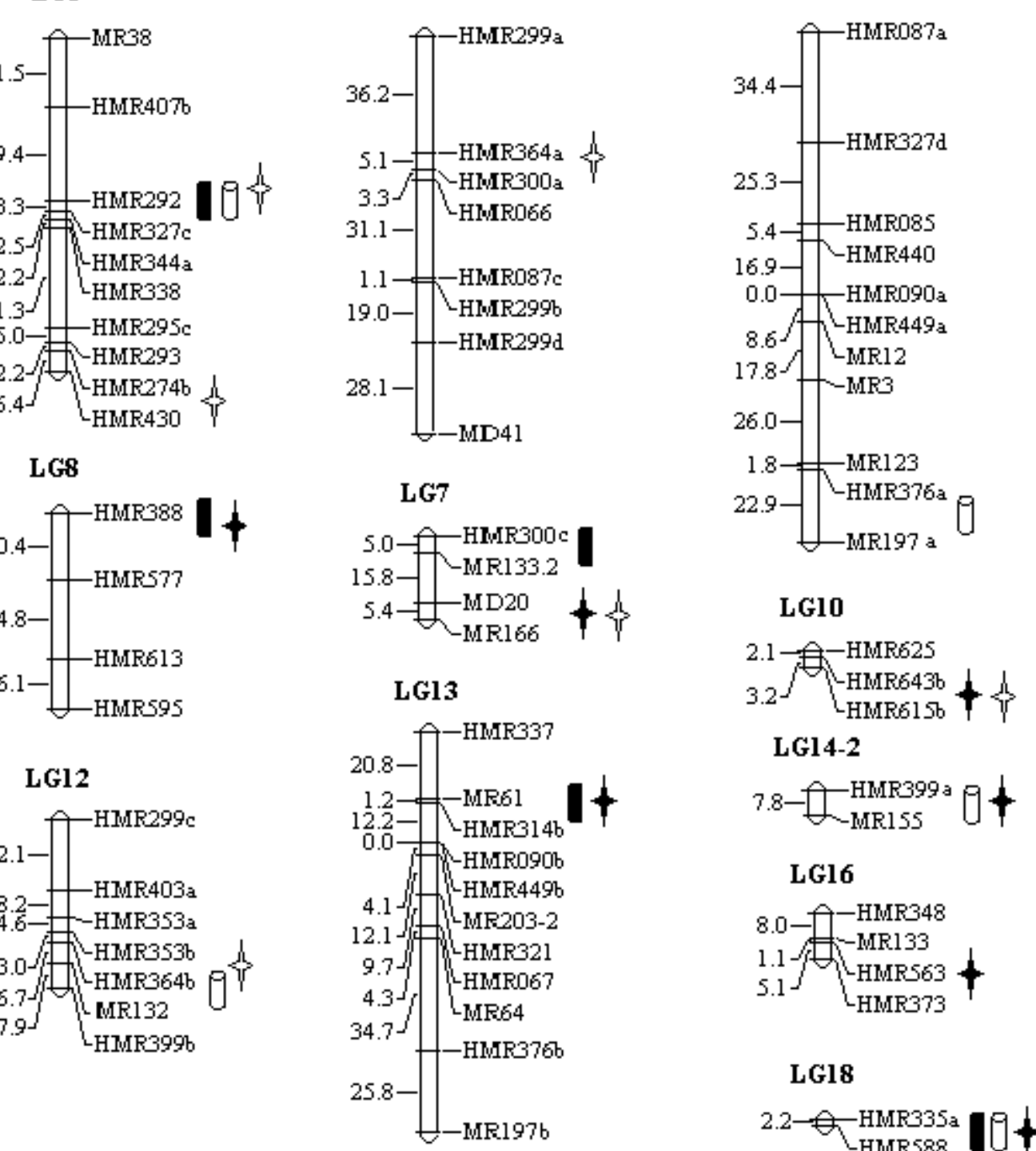

\section{LGl6}

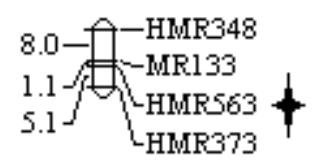

\section{LG18}

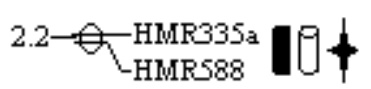

QTLs with $a$ effect of seed protein, + QTL s with $a$ effect of meal prote in
QTLs with $a$ effect of meal prote in

Fig 2. Map positions for QTLs influencing seed and meal protein with additive main ( $a$ ) and/or additive by environment interaction effect $(a e)$

identified for seed and meal protein respectively. Of them, four QTLs with additive effects on identical or adjacent positions of linkage groups (LG) 7,8,13 and 18, and two ae or $a$ \& ae loci on LG1and LG12 showed same direction and similar effects both for seed and meal protein content ( Table 3, Fig 2 ). Another two additive main loci and three additive $\mathrm{x}$ environment loci were detected specifically for meal protein and only one ae loci was found specifically for seed 
protein (Fig 2). Together five and seven main additive QTLs sum up to $2.44 \%$ and $3.53 \%$ of seed and meal protein content respectively for the difference between homozygous genotypes and explained about $30 \%$ and $40 \%$ of the difference between highest and lowest lines observed in the DH population. Mapping results showed that alleles with increasing or decreasing effects on the trait were dispersed between the two parents, which explained the occurrence of the transgressive segregation in the DH population. A number of ae QTLs were detected both for seed and meal protein content. However, ae QTLs for meal or seed protein were different in most cases. Strong environmental interactions for both traits were consistent with the significant genotype by environment interaction variance components.

Table 4. Epistatic ( $a a$ ) and epistasis $\mathrm{x}$ environment interaction (aae) effects of QTLs for seed and meal protein content (\%), and conditioned on seed oil (SP|Oil, MP|Oil)

\begin{tabular}{|c|c|c|c|c|c|c|c|c|c|}
\hline \multicolumn{4}{|c|}{ Seed protein } & \multicolumn{5}{|c|}{ Unconditional $a a$ and $a a e$ effects } & \multirow{2}{*}{$\begin{array}{l}\text { SP|Oil } \\
a a\end{array}$} \\
\hline LG & $\begin{array}{l}\text { Nearest } \\
\text { marker }\end{array}$ & LG & $\begin{array}{l}\text { Nearest } \\
\text { marker }\end{array}$ & $\begin{array}{l}a a^{\dagger} \\
\text { effect }\end{array}$ & $\begin{array}{l}\text { aae in } \\
\text { Xian }\end{array}$ & $\begin{array}{l}\text { aae in } \\
\text { Hangzhou }\end{array}$ & $\begin{array}{l}\text { aae in } \\
\text { Reinshof }\end{array}$ & $\begin{array}{l}\text { aae in } \\
\text { Weende }\end{array}$ & \\
\hline 1 & HMR292 & 3 & HMR440 & & & & & & $0.151 * *$ \\
\hline 1 & HMR274b & 9 & HMR573 & & & & & & $-0.120 * *$ \\
\hline 1 & HMR292 & $14-1$ & HMR416b & $0.164 * *$ & & & & & \\
\hline 2 & HMR087c & 7 & MR133.2 & & $0.113 * *$ & $0.183 * *$ & $-0.368 * *$ & & \\
\hline 2 & HMR087c & 10 & HMR643b & $0.204 *$ & & & & & \\
\hline 3 & MR3 & 19 & HMR327b & $-0.125^{*}$ & & & & & \\
\hline 4 & MD2.2 & 7 & MR133.2 & & & & & & $-0.099 * *$ \\
\hline 4 & MD2.2 & 12 & HMR353b & $0.160^{*}$ & & & & & \\
\hline 7 & MR133.2 & 9 & HMR363b & & $0.158 * *$ & & & $-0.167 * *$ & \\
\hline 7 & MD20 & $14-2$ & HMR399a & $0.150 * *$ & & & & & \\
\hline $11-1$ & HMR148 & 13 & MR61 & & $-0.126^{*}$ & & & $0.209 * *$ & \\
\hline $11-1$ & MR288 & 19 & HMR615 & & & & & & $0.107^{* *}$ \\
\hline 12 & HMR299c & 15 & MR97 & $-0.220 *$ & & & & & \\
\hline \multicolumn{4}{|c|}{ Meal protein } & & & & & & MP|Oil \\
\hline 1 & HMR292 & 3 & HMR440 & & & & & & $0.277 * *$ \\
\hline 1 & HMR292 & $11-1$ & MR314a & & & & & & $0.171^{*}$ \\
\hline 1 & HMR292 & 13 & MR61 & $0.152 *$ & & & & & \\
\hline 1 & HMR292 & 17 & HMR332 & $-0.229 * *$ & & & & & \\
\hline 1 & HMR274b & 9 & HMR573 & $-0.271 * *$ & & & & & $-0.258 * *$ \\
\hline 2 & HMR364a & 9 & HMR573 & & $0.184 *$ & & & $-0.200^{*}$ & \\
\hline 2 & HMR087c & 10 & HMR643b & $0.210^{* *}$ & & & & & \\
\hline 2 & HMR364a & $11-2$ & HMR295b & & & & & & $0.187^{* *}$ \\
\hline 3 & MR3 & 19 & HMR327b & $-0.243 * *$ & $-0.185^{*}$ & $0.205^{*}$ & & & \\
\hline 4 & MD2.2 & 7 & MR133.2 & & & & & & $-0.265^{* *}$ \\
\hline 7 & MD20 & 8 & HMR613 & & & & & & $-0.180 * *$ \\
\hline 7 & MR133.2 & 17 & HMR332 & & & & & & $0.160 * *$ \\
\hline 8 & HMR338 & 12 & HMR364b & & & $-0.214 * *$ & & & \\
\hline $11-1$ & MR314a & 19 & HMR615a & $0.212 * *$ & & & & $0.339 * *$ & $0.250 * *$ \\
\hline $14-1$ & HMR363c & 19 & HMR327b & & & & & & $-0.173 * *$ \\
\hline
\end{tabular}

${ }^{\dagger}$ Sing of epistatic effect: negative indicates that recombinant alleles from two parents and positive means that parental digenic genotypes increase phenotypic value, respectively 
Of nine pairs of digenic epistatic QTLs affecting seed protein, six showed epistatic main effects ( $a a)$ and three exhibited epistatic $\mathrm{x}$ environment effects (aae) (Table 4). For meal protein, eight pairs of loci were mapped, four with $a a$, two with aae and two with both $a a$ and aae effects (Table 4). In total, six pairs of aa loci sum up to $2.0 \%$ and $2.6 \%$ for homozygous genotypes and explained about $26 \%$ and $30 \%$ of the mean phenotypic variation observed in the DH population ( difference between lines with highest and lowest mean values, Table1) for seed and meal protein respectively. Simultaneous expression of additive and epistatic effects of QTLs commonly occurred for both traits as observed earlier for oil content (Thesis 3.1). Of eight seed protein QTLs with $a$ and/or $a$ effects, five were involved in the pairs of $a a$ or aae loci. For meal protein, four of seven loci with $a$ effects and all the ae loci except one also shared $a a$ or aae effects.

Unlike the situation of QTLs with additive effects, only two pairs of epistatic loci on LG2/LG10 and LG3/LG19 were identical for seed and meal protein.

\section{Relationship among QTLs for oil, seed and meal protein}

\section{Oil content conditioned on seed protein}

QTLs for oil content were largely changed after conditional mapping when seed protein content was conditioned (Table 5). Four additive QTLs failed to show significant effects. Two QTLs showed reduced effects. However there were two QTLs showing similar effects as in unconditional mapping analysis. Six conditional QTLs were observed on additional genomic regions. All the ae loci did no longer exhibit significant effects with two exceptions. Four new ae loci were observed in one to three environments.

Additive $x$ additive epistatic effects were also markedly changed (Table 6). Eight of nine a loci lost significant effects and one reduced effect, while three conditional pairs of loci were detected on new genomic regions.

\section{Seed protein conditioned on seed oil}

To further confirm the interdependency of oil and protein content at individual QTL, conditional mapping for seed protein given oil content was also performed. Results in Table 3 shown that three of five QTLs with additive effects on LG1, 7 and 18 had no or reduced conditional effects, which was consistent with the results of oil|SP (Table 5). Two loci remained with similar effects. Five new conditional loci with small effects occurred. As observed in oil|SP, four of five ae loci did not show the significant effects, one had a reduced effect and three loci presented conditional ae effects in additional genomic regions. 
Conditional epistatic effects of SP|oil showed also similar situation as inspected in oil|SP (Table 4). All six a a loci lost significant effects and four new pairs of loci were observed.

Table 5. Estimated additive main ( $a$ ) and additive $X$ environment interaction ( $a e$ ) effects of QTLs for oil content (\%), and conditioned on seed protein ( Oil|SP)

\begin{tabular}{|c|c|c|c|c|c|c|c|}
\hline Traits & $\begin{array}{l}\text { Linkage } \\
\text { group }\end{array}$ & Marker interval & $a$ effect & $\begin{array}{l}a e \text { in } \\
\text { Xian }\end{array}$ & $\begin{array}{l}a e \text { in } \\
\text { Hangzhou }\end{array}$ & $\begin{array}{l}a e \text { in } \\
\text { Reinshof }\end{array}$ & $\begin{array}{l}a e \text { in } \\
\text { Weende }\end{array}$ \\
\hline \multirow{43}{*}{$\begin{array}{l}\text { Oil } \\
\text { Oil|SP }\end{array}$} & 1 & HMR407b/HMR292 & $0.373 * *$ & $-0.288 * *$ & & $0.239 *$ & \\
\hline & & & $0.200^{* *}$ & $-^{\dagger}$ & & - & \\
\hline & 1 & HMR274b/HMR430 & - & & - & & \\
\hline & & & $-0.166^{*}$ & & $-0.181 * *$ & & \\
\hline & 2 & HMR066/HMR087c & - & & $-0.285 * *$ & $0.317 * *$ & \\
\hline & & & $0.243 * *$ & & - & - & \\
\hline & 3 & HMR085/HMR440 & - & & $-0.340 * *$ & $0.370 * *$ & \\
\hline & & & $-0.143 * *$ & & - & - & \\
\hline & 7 & HMR300c/MR133.2 & $-0.551 * *$ & & $-0.269 * *$ & - & - \\
\hline & & & $-0.173^{*}$ & & $-0.190^{* *}$ & $0.189 * *$ & $0.138^{* *}$ \\
\hline & 7 & MD20/MR166 & - & - & - & & \\
\hline & & & - & $-0.247 * *$ & $0.231 * *$ & & \\
\hline & 8 & HMR388/HMR577 & - & & & & \\
\hline & & & $-0.180^{* *}$ & & & & \\
\hline & 9 & HMR612a/HMR612b & & $-0.413 * *$ & $-0.563 * *$ & $0.585 * *$ & $0.313 * *$ \\
\hline & & & & - & - & - & - \\
\hline & 9 & HMR438a/HMR310 & $0.338 * *$ & & $-0.476 * *$ & & \\
\hline & & & - & & - & & \\
\hline & 9 & HMR284a/HMR359c & - & - & - & & \\
\hline & & & $-0.213 * *$ & $-0.206^{* *}$ & $0.244^{*}$ & & \\
\hline & 10 & HMR643b/HMR615b & & $0.305 * *$ & & $-0.353 * *$ & \\
\hline & & & & - & & - & \\
\hline & $11-1$ & MR148/HMR407a & $-0.257 *$ & & $-0.647 * *$ & $0.396 * *$ & \\
\hline & & & - & & - & - & \\
\hline & 12 & HMR299c/HMR403a & $0.271 *$ & & & & \\
\hline & & & $0.229 * *$ & & & & \\
\hline & 12 & HMR353b/HMR364b & & $-0.753 * *$ & $-0.343 * *$ & $0.661 * *$ & $0.410 * *$ \\
\hline & & & & - & - & - & - \\
\hline & 13 & HMR067/ MR64 & & $0.227 * *$ & $-0.293 * *$ & & \\
\hline & & & & - & - & & \\
\hline & $14-1$ & HMR403b/MR229 & $0.221 * *$ & - & & - & - \\
\hline & & & $0.222 * *$ & $-0.148^{*}$ & & $0.160 * *$ & $0.163 * *$ \\
\hline & $14-2$ & HMR399a/MR155 & & $0.243 * *$ & $0.407 * *$ & $-0.492 * *$ & $-0.185^{*}$ \\
\hline & & & & - & - & - & - \\
\hline & 15 & MR97/MR54 & - & & $0.267 * *$ & $-0.307 * *$ & \\
\hline & & & $-0.205^{* *}$ & & - & - & \\
\hline & 16 & HMR348/MR133 & & & $-0.329 * *$ & $0.342 * *$ & \\
\hline & & & & & - & - & \\
\hline & 17 & HMR438b/HMR344b & & & $0.299 * *$ & $-0.270 * *$ & \\
\hline & & & & & - & - & \\
\hline & 18 & HMR335a/HMR588 & $-0.517 * *$ & $0.193 *$ & $0.417 * *$ & $-0.226^{*}$ & $-0.213 * *$ \\
\hline & & & - & - & - & $-0.156^{* *}$ & $-0.214^{* *}$ \\
\hline & 19 & HMR615a/HMR288 & $\begin{array}{l}0.224 * * \\
-\end{array}$ & & & & \\
\hline
\end{tabular}

${ }^{\dagger}$ - : indicate not significant $a$ or ae effects detected. 


\section{Meal protein conditioned on seed oil}

The situation of meal protein conditioned on oil content differed as observed for SP|oil (Table 3). Four of seven loci kept similar additive effects and all these QTLs were not identified for oil content. Two loci lost significant effects, one locus had an increased effect and four new conditional loci occurred. Of six loci with ae effects, three remained similar, two lost significant effects and one showed opposite directions between Chinese and German environments. Another five new ae loci were observed.

For the QTLs with epistatic effects, the number of pairs increased from six to nine after conditional mapping (Table 4). Of them, two pairs remained almost unchanged, four pairs did no longer show significant effects, while seven new pairs of loci occurred.
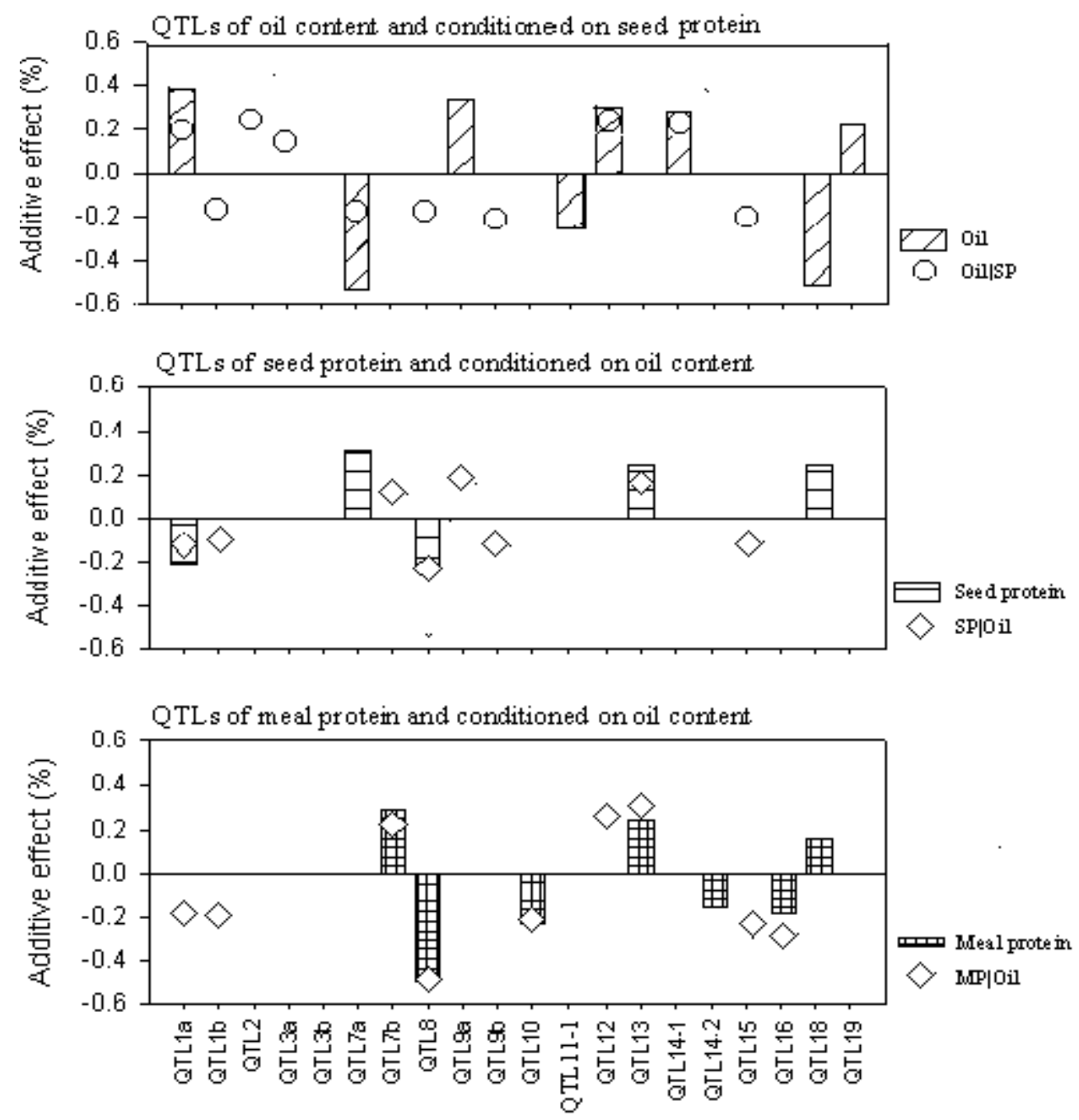

Fig3. Comparison of QTL behavior under conditional and unconditional mapping analysis between oil and protein content in common 20 loci, named as QTL with relevant linkage group. If there was more than one locus in a group, the letters was added after that. 
Table 6. Estimated epistatic main ( $a a$ ) effect of QTLs for oil content (\%), oil conditioned on seed protein (Oil|SP) (\%)

\begin{tabular}{|c|c|c|c|c|c|}
\hline \multirow{2}{*}{$\begin{array}{l}\text { Linkage } \\
\text { group }\end{array}$} & \multirow[t]{2}{*}{ Marker interval } & \multirow{2}{*}{$\begin{array}{l}\text { Linkage } \\
\text { group }\end{array}$} & \multirow[t]{2}{*}{ Marker interval } & \multirow{2}{*}{$\begin{array}{l}a a \text { effect } \\
\text { Oil }\end{array}$} & $\begin{array}{l}\text { Conditional } \\
a a\end{array}$ \\
\hline & & & & & Oil|SP \\
\hline 1 & HMR407b/HMR292 & 2 & HMR300a/HMR066 & $-0.294 * *$ & \\
\hline 1 & HMR274b/HMR430 & 10 & HMR643b/HMR615b & & $0.252^{* *}$ \\
\hline 1 & HMR295c/ HMR293 & 12 & HMR353b/HMR364b & $0.384 * *$ & $0.141 *$ \\
\hline 2 & HMR300a/HMR066 & 10 & HMR625/HMR643b & $0.323^{* *}$ & \\
\hline 3 & HMR449a/ MR12 & 7 & HMR300c/ HMR133.2 & $-0.195^{* *}$ & \\
\hline 3 & HMR085/ HMR440 & $11-1$ & MR148/ HMR407a & & $-0.246^{* *}$ \\
\hline 3 & HMR449a/MR12 & 18 & HMR335a/ HMR588 & $-0.199^{* *}$ & \\
\hline 4 & HMR637/ MD2.2 & 12 & HMR353b/HMR364b & $-0.291^{* *}$ & \\
\hline 7 & MR133.2/MD20 & 17 & HMR318/HMR349 & & $0.128^{* *}$ \\
\hline $11-1$ & MR148/HMR407a & 12 & HMR299c/HMR403a & $0.323 * *$ & \\
\hline $11-1$ & MR148/HMR407a & 16 & HMR348/MR133 & $0.205^{*}$ & \\
\hline 13 & HMR314b/HMR090b & 15 & MR97/MR54 & $0.263^{* *}$ & \\
\hline
\end{tabular}

\subsubsection{Discussion}

In practical breeding programs, breeders normally measure the protein and oil content by percentages of dried matter of seeds. However, the protein content in the meal is practically more important for animal feeding. According to the genetic correlation in the current study, only around $50 \%\left(\mathrm{R}^{2}\right)$ common genetic basis between seed and meal protein were estimated (Table2). Therefore mapping QTLs for seed and meal protein is important to understand and compare their genetic overlapping and independence on individual QTL. Our results revealed that most QTLs for seed and meal protein showed both additive and epistatic effects. This might be one explanation for their complex genetic inheritance. The results also provide several evidences for explaining their unshared part of genetic basis. First, although almost all the QTLs with additive effects for seed protein were confirmed also for meal protein content, two additional QTLs specifically for meal protein content were identified. They probably are related to oil and fibre content or other substances in seed or meal. Second, significant epistatic effects were detected both for seed and meal protein, which are reported previously in B. napus (Engqvist and Becker 1991) and other oilseed crops as soybean (Chauhan and Singh 1983) and peanut (Upadhyaya and Nigam 1999). All detected pairs of loci for seed and meal protein were different except two, which indicates that these two traits are controlled by different genetic system in most of the epistatic loci. Third, it is common situation that protein content is affected by environment since its quantitative trait in nature. However our results showed most loci with additive by environment interactions for seed and meal protein presented in different genomic 
regions. This might also be one of the causes for unshared part of genetic basis between seed and meal protein.

QTLs for oil and protein in seed are often reported as linked loci or with pleiotropic effects although some independent loci are suggested. Gül (2002) identified six oil QTLs in B. napus and found that four of them showed a close negative linkage with protein QTLs, however another two oil QTLs and one additional protein QTL were detected in separate linkage groups. In soybean, Shoemaker et al. (1996) reported QTL for seed protein and oil showed correspondence across homozygous regions, Lee et al.(1996) identified various common markers on five linkage groups which associated with both seed protein and oil. Our results, based on conditional mapping analysis between oil and seed protein, might provide further information of their genetic relationships. This conclusion was supported by the comparison of results between unconditional and conditional mapping analysis for oil and protein content, which are presented in Fig3 (summarizing two mapping results based on 20 common loci with additive effects among oil and protein content) and Table 4 and 6: 1) It may help to distinguish the pleiotropic effect or gene linkage for QTLs which contribute to both traits in the same genomic intervals. The QTLs on LG7 and LG18 might be regarded as pleiotropy effects and QTL on LG1 more like gene linkage. 2) For the QTLs with significant effects for one trait but not for another, conditional mapping might further confirm their independence or related to another. For example, two QTLs for oil content on LG12 and LG14-1, and two QTLs for seed protein content on LG8 and LG13 kept almost unchanged effects after conditional mapping one another, showing the potential to increase, simultaneously, both traits. In another case, gene loci showed significant effects only for oil content but still significantly influenced by protein content as QTLs on LG9, 11-1 and LG19. These may be explained by the existence of insignificant effects for seed protein in the same genomic regions (data not shown). Such influence normally is ignored without mapping for conditional QTLs. 3) The appearance of number of conditional new QTLs may express the genetic relationship between oil and protein of seed on another hand. 4) Large changes of allele combinations and number of pairs for QTLs with epistatic effects between unconditional and conditional mapping results (Table 4 and 6) indicate that interaction between loci very much depends on the genetic background and are largely influenced each other. This may be also one of explanations for the complex relationship and complicated inheritances of oil and seed protein content.

To sum up, results indicate that oil and protein in seed might share large part of genetic basis, which is in coincidence with the significant genetic correlation between this two traits $\left(\mathrm{r}_{\mathrm{G}}=-0.812^{* *}\right)$ but did not exclude the existence of some independent gene loci for both traits 
and also indicated that in some gene loci, oil content might relate more with other components in seed.

Increase of oil content in seed with stable or even increased protein content in meal are the objectives in oilseed breeding. The potential for raising oil and protein in seed simultaneously is limited, however our results confirmed that the possibilities for combining high content of seed oil and meal protein exist. The fact that four of seven additive QTL and two of six pairs of epistatic loci for meal protein showed similar effects under exclusion of oil content (Fig 3 ), indicating that these gene loci were not affected by oil content. Another three loci (with minor effects) and four new occurred conditional QTLs showed their possible relationships with oil content or other components in seed. The significant changes and increased pairs of conditional epistatic loci also demonstrate the genetic contributions to meal protein from oil or other components. We notice that when oil content was conditioned, four of five pairs of conditional seed protein loci consist with conditional meal loci, which might hint that oil content display the same way to influence both seed and meal protein by epistatic effects of loci.

After all, the results suggest that seed oil and meal protein share much less genetic overlapping than seed oil and seed protein. This might be the explanation for a low and insignificant genetic correction $(r=-0.14)$ in between and demonstrates the possibility to combine these two traits.

\subsubsection{Summary}

Oil content is one of the most important breeding aims for oilseed rape, but there is also interest in increasing the protein content in rapeseed meal. To learn more about the molecular genetic basis for seed and meal protein content and their relationships with seed oil on individual QTL, unconditional and conditional mapping studies were performed using a SSR linkage map of 125 marker loci integrated European and Chinese genetic background and the mixed linear model approach. The mapping population included 282 doubled haploid lines and the phenotypic evaluation was investigated in 4 environments, 2 in Europe and 2 in China. The results revealed that most QTLs for seed and meal protein showed both additive and epistatic effects. Almost all the QTLs with additive effects for seed protein were confirmed also for meal protein, but two additional QTLs were identified specifically for meal protein. The QTLs with epistatic and $Q E$ interaction effects for seed and meal protein were mostly inconsistent, explaining the unshared part of genetic basis between two traits. Conditional mapping analysis between oil and seed protein provide the possibilities to distinguish between pleiotropic effect and gene linkage of 
QTLs for both traits, or to confirm the independence for the QTLs detected for one trait but not for another. The results indicated that the genetic relationship between these two traits were also through digenic epistatic loci. The conclusion might be that oil and protein content in the seed share large part of their genetic basis. However, it is possible to combine high content of seed oil with high meal protein content, which supported by the detection of four out of seven additive QTL and two of six pairs of epistatic loci for meal protein were not affected by oil content and thus seed oil and meal protein show much less genetic overlapping than seed oil and seed protein.

Key words Brassica napus L. Protein content · Oil content · Conditional QTL mapping · Epistasis · QTL by environment interaction

\subsubsection{References}

Alemayehu N (2001) Germplasm diversity and genetics of quality and agronomic traits in Ethiopian mustard (Brassica carinata A.Braun) Doctoral Dissertation, Fachbereich Agtarwissenschaften der Georg-AugustUniversität, Göttingen pp: 81-96

Axelsson T, Shavorskaya O, Lagercrantz U (2001) Multiple flowering time QTLs within several Brassica species could be the result of duplicated copies of one ancestral gene. Genome 44 (5): 856-864

Butruille DV, Guries RP and Osborn TC (1999) Linkage analysis of molecular markers and quantitative trait loci in populations of inbred backcross lines of Brassica napus L. Genetics 153: 949-964

Chauhan VS, Singh BB (1983) Genetic analysis of protein and oil content in soybean. India J. agric. Sci. 53: 634637

Cheung WY, Landry BS (1998) Molecular mapping of seed quality traits in Brassica juncea L. Czern. and Coss. Proc. Int. Symp on Brassica. Acta Hort. 459: 139-147

Ecke W, Uzunova M, Weißleder K (1995) Mapping the genome of rapeseed (Brassica napus L.). II. Localization of genes controlling erucic acid systhesis and seed oil content. Theor. Appl. Genet. 91: 972-977

Engqvist GM, Becker HC (1991) Relative importance of genetic parameters for selecting between oilseed rape crosses. Hereditas 115: 25-30

Grami B, Stefansson BR (1977a) Gene action for protein and oil content in summer rape. Can.J. Plant Sci. 57: $625-631$

Grami B, Stefansson BR (1977b) Genetics of protein and oil content in summer rape. Heritability, numbers of effective factors, and correlations. Can.J.Plant Sci. 57: 937-943

Gül MK (2002) QTL-Kartierung und Analyse von QTL x Stickstoff Interaktionen beim Winterraps (Brassica napus L.) Ph.D thesis, Fachbereich Agtarwissenschaften der Georg-August-Universität, Göttingen

Hall C, McCallum D Drescott_A Mithen R (2001) Biochemical genetics of glucosinolate modification in Arabidopsis and Brassica Theor.Appl.Genet.102: 69-374 
Hu J, Li G, Struss D, Quiros CF (1999) SCAR and RAPD markers associated with 18-carbon fatty acids in rapeseed, Brassica napus. Plant Breeding. 118: 145-150

Kole C, Williams PH, Rimmer SR, Osborn TC (2002) Linkage mapping of genes controlling resistance to white rust (Albugo candida) in Brassica rapa (syn. campestris) and comparative mapping to Brassica napus and Arabidopsis thaliana. Genome 45 (1): 22-27

Krzymanski J (1998) Agronomy of oilseed Brassicas. Acta Hort. 459: 55-60

Lambrix V, Reichelt M, Mitchell OT, Eliehenstein_ Gershenzon J (2001) The Arabidopsis epithiospecifier protein promotes the hydrolysis of glucosinolates to nitriles and influences Trichoplusia ni herbivory. Plant Cell 13: $2793-2807$

Lee SH, Bailey MA, Mian MAR, Carter TEJr, Shipe ER, Ashley DA et al.(1996) RFLP loci associated with soybean seed protein and oil content across populations and locations. Theor.Appl.Genet.93: 649-657

Newkirk RW, Classen HL, Tyler RT (1997) Nutritional evaluation of low glucosinolate mustard meals (Brassica juncea) in broiler diets. Poultry Sci. 76: 1272-1277

Osborn TC, Kole C, Parkin IAP, Sharpe AG, Kuiper M, Lydiate DJ, Trick M (1997) Comparison of flowering time genes in Brassica rapa, B. napus and Arabidopsis thaliana. Genetics 146: 1123 - 1129

Parkin IAP, Sharpe AG, Keith DJ, Lydiate DJ (1995) Identification of the A and C genomes of amphidiploid Brassica napus (oilseed rape). Genome 38: 1122-1131

Pilet ML, Duplan G, Archipiano M, Barret P, Baron C, Horvais R et al. (2001) Stability of QTL for field resistance to blackleg across two genetic backgrounds in oilseed rape. Crop Science 41 (1): 197-205

Plieske J, Struss D (2001) Markers linked to Phoma resistance genes of the Brassica B-genome revealed sequence homology between Brassica nigra and Brassica napus. Theor. Appl.Genet.102: 483-488

Bajcan Lasha_KL Katt BS, Beversdorf WD (1999) Detection of molecular markers associated with linolenic and erucic acid levels in spring rapeseed (Brassica napus L.). Euphytica 105: 173-181

Reinhardt TC (1992) Entwicklung und Anwendung von Nah-In-frarot-spektroskopischen Methoden für die Bestimmung von Öl-Protein-, Glucosinolate-, Feuchte- und Fettsäure-Gehalten in intaker Rapssaat. Dissertation, Universität Göttingen, Cuvillier Verlag Göttingen

Röbbelen G, Thies W (1980) Biosynthesis of seed oil and breeding for improved meal quality. In Tsumoda S, Hinta K and Gomez-Campo C (eds) Brassica crops and wild allies: Biology and breeding. Japan Scientific Societies Press, Tokyo, pp: 285-299

Scheffler JA, Sharpe AG, Schmidt H, Sperling P, Parkin IAP, Lühs W et al. (1997) Desaturase multigene families of Brassica napus arose through genome dublication. Theor. Appl. Genet. 94: 583-591

Schierholt A, Becker HC, Ecke W (2000) Mapping a high oleic acid mutation in winter oilseed rape (Brassica napus L.). Theor. Appl. Genet.101: 897-901

Sharma R, Mohapatra T, Mukherjee AK, Krishanpal, Sharma RP (1999) Molecular markers for seed oil content in Indian mustard. Journal of plant biochemistry and biotechnology 8: 99-102

Shoemaker RC, Polzin K, Labate I Specht I Brummer FC, Dlson Tet al. (1996) Genome duplication in soybean (Glycine subgenus soja). Genetics 144: 329-338 
Somers DJ, Rakow G, Prabhu VK, Friesen KRD (2001) Identification of a major gene and RAPD markers for yellow seed coat colour in Brassica napus. Genome 44: 1077-1082

Stefansson BR, Kondra ZP (1975) Tower summer rape. Can.J. Plant Sci. 55:343-344

Thesis 3.1 Construction of a linkage map and identification of QTLs for oil content ( Manuscript 1 )

Upadhyaya HD and Nigam SN (1999) Detection of epistasis for protein and oil content and oil quality parameters in peanut. Crop Sci. 39: 115-118

Wang DL, Zhu J, Li ZK, Paterson AH (1999) Mapping of QTL with epistatic effects and QTL x environment interactions by mixed model approaches. Theor. Appl. Genet. 99: 1255-1264

Zhu J (1992) Mixed model approaches for estimating genetic variances and covariance. J. Biomath.7: 1-11

Zhu J (1995) Analysis of conditional genetic effects and variance components in developmental genetics. Genetics 141:1633-1639 


\subsection{Relationships between oil and protein content with developmental stages}

\subsubsection{Introduction}

Oil content in B. napus is generally regarded as a character with high heritability ( Loof and Appelqvist 1972; Röbbelen and Thies 1980 and Becker et al. 1999 ), but environmental factors including nutrients, photoperiod, water supply and temperature are also of influence. Among them, temperature has been found to be one of the most important. Low temperature in the period of seed development resulted in increased oil content which decreased with increasing temperature ( Canvin 1965 ). Growing European rapeseed varieties in the areas along the Yangtse River in China ( dominant regions of rapeseed production in China ) showed a markedly decrease of oil content ( see thesis 3.1 ), for which higher temperature during the reproductive stage is one of the main reasons. Oil synthesis and accumulation in the rapeseed follows a sigmoid curve during seed development. This shows a sharp rise in the middle third of the grain filling stage ( Fowler and Downey 1970; Rakow and McGregor 1975 ). Much less change in oil content was observed in the later stages to maturity ( Röbbelen and Thies 1980 ), some authors have even observed some decrease in oil content with further increase in seed weight ( Matile 1975 ). Plant developmental stages largely varied with environmental conditions, mainly temperature ( Mendham and Salisbury 1995 ), and consequently indirectly affecting oil and protein content in seed.

Oil and protein content of rapeseed are typical quantitative traits, partly controlled by the same genes (Grami and Stefansson 1977; Gül 2002; thesis 3.2). Developmental stages as flowering time and maturity are also quantitative in nature ( Thurling and Das 1977; Ferreira et al. 1995; Butruille 1999; Axelsson et al. 2001 ). Therefore the genetic relationships between these two types of trait are complicated and difficult to be dissected. The development of molecular marker techniques provide the possibilities to trace gene behavior at individual QTL, which greatly helps to understand the complex genetics of quantitative traits as oil and protein content in oilseed rape. By combining the statistical procedures for analyzing conditional genetic effects ( Zhu 1995 ) and the QTL mapping program ( Wang et al. 1999 ), conditional mapping analysis between oil, protein content and separated plant developmental stages were performed. Results from conditional mapping present the effects of QTLs for oil or protein content under the condition of no variation for individual developmental stage. Comparison 
between unconditional and conditional mapping results, it is possible to find the genetic relationship between oil or protein content and different developmental stages on individual loci. The results provide a valuable information of marker based selection of QTLs for improving oil and protein content without unexpected changes of developmental features in the practical breeding both in China and in Europe.

\subsubsection{Material and Methods}

\section{Plant materials}

A doubled haploid population of $282 \mathrm{DH}$ lines derived from a cross $\left(\mathrm{F}_{1}\right)$ between 'Sollux' and 'Gaoyou' (see thesis 3.1) was used in this study .'Sollux' is an old variety from Germany with typical winter type, exhibiting later flowering and longer growth period. Gaoyou is an old landrace from China, which is normally sown in autumn in China but also flowers under greenhouse conditions without vernalization. Both lines contained high erucic acid and glucosinolate content, and exhibited high oil content in the seeds.

\section{Phenotyping experiments}

The DH lines were evaluated in three experiments with two locations in China, Xian and Hangzhou, and one location in Reinshof of Germany in 2000/2001. Xian is situated in West China and Hangzhou is located in East China. Reinshof is located near Göttingen in West Germany. Four check cultivars from China and Europe were included. The field experimental design was a randomized complete block with two replications. The seeds were sown in two rows for each plot, $2.5 \mathrm{~m}$ in length with $0.33 \mathrm{~m}$ between rows and $0.12 \mathrm{~m}$ between plants within rows in Göttingen, and $2.5 \mathrm{~m}, 0.33 \mathrm{~m}$ and $0.15 \mathrm{~m}$ respectively in China.

Data have been collected both on morphological and seed attributes. Developmental stages were observed, including beginning of flowering ( $50 \%$ plants showed first flowers ), end of flowering ( $50 \%$ plants had no flowers and rest left one flower in maximum ) and maturity ( siliques changed to be yellow ). The traits analyzed were days from sowing to beginning of flower ( DTF ), days from sowing to maturity ( DTM ), flowering duration ( days from flowering to the end of flowering, DFE ), grain filling period ( days from end of flowering to maturity, DEM ) and days from flowering to maturity ( DFM ) were then calculated. Seed samples of at least $10 \mathrm{~g}$ were bulk harvested from terminal raceme and the two uppermost primary branches of five healthy plants in each plot. Seed oil and protein content from all locations were measured by near-infrared reflectance spectrophotometry ( NIRs, Reinhardt 
1992 ), based on 9\% moisture of seeds. Meal protein was calculated from seed protein and oil content: Protein content in meal $(\%)=\frac{\text { protein }(\text { in seed }) \%}{100-\text { oil } \%} \times 100$

\section{Linkage map}

The SSR linkage map consists of 125 genetic markers distributed across 21 groups with a total length of $1196 \mathrm{cM}$ (Kosambi function). They were further assigned into 19 linkage groups according to the previous researches ( Parkin et al. 1995 ). The details of map construction, SSR primer pairs and PCR analysis were described in previous paper (see thesis 3.1).

\section{Data analysis and mapping of conditional QTLs}

Data of $282 \mathrm{DH}$ lines, the parental lines and the $\mathrm{F}_{1}$ 's with two replications were analysed separately at four environments to test the difference among DH lines and further to estimate variance components and covariance components between seed quality and plant development stages with MINQUE method ( Zhu, 1992 ). Genetic and phenotypic correlation coefficients were then estimated.

The conditional phenotypic value $\left(y_{h k(T \mid T 2)}\right)$ was obtained by the mixed model approaches for the conditional analysis of quantitative traits ( Zhu 1995 ). Conditional QTL mapping were then performed using QTLMapper version 1.0 ( Wang et al. 1999 ). The conditional value $y_{h k(T 1 \mid T 2)}$ can be partitioned as:

$$
\begin{aligned}
y_{h k(T 1 \mid T 2)} & =\mu_{(T 1 \mid T 2)}+a_{i(T 1 \mid T 2)} x_{A_{i} k}+a_{j(T 1 \mid T 2)} x_{A_{j k}}+a a_{i j(T 1 T 2)} x_{A A}{ }_{i j k} \\
& +u_{E_{h k}} e_{E_{h(T 1 \mid T 2)}}+u_{A_{i} E_{h k}} e_{A_{i} E_{h(T 1 \mid T 2)}}+u_{A_{j} E_{h k}} e_{A_{j} E_{h(T 1 \mid T 2)}}+u_{A A_{i j} E_{h k}} e_{A A_{i j} E_{h(T 1 \mid T 2)}} \\
& +\sum_{f(h)} u_{M_{f k(h)}} e_{M f(h)(T 1 \mid T 2)}+\sum_{l(h)} u_{M M l k(h)} e_{M M l(h)(T 1 \mid T 2)}+\varepsilon_{h k(T 1 \mid T 2)}
\end{aligned}
$$

where T1|T2 denotes trait 1 conditioned on trait 2 (oil|DTF $=$ oil conditioned on days to flowering, $\mathrm{SP} \mid \mathrm{DTF}=$ seed protein conditioned on days to flowering, and so on).

For unconditional mapping of the developmental stages, the same mapping program QTLMapper v1.0 (Wang et al.1999) was used. The models, explanation of all the conditional and unconditional parameters and detailed mapping procedure were described previously ( Wang et al. 1999; thesis 3.1 and 3.2 ). The likelihood -ratio threshold was chosen at $\alpha=0.005$ for claiming putative QTL and genetic effects. 


\subsubsection{Results}

\section{Environments and developmental stages}

Monthly mean temperatures of the three experimental locations were described in Fig1. The mean daily temperature from sowing to flowering was about $1{ }^{\circ} \mathrm{C}$ and $4^{\circ} \mathrm{C}$ lower in Reinshof than in Xian and Hangzhou, and from flowering to maturity was on average $3{ }^{\circ} \mathrm{C}$ and $4^{\circ} \mathrm{C}$ higher in Xian and Hangzhou than in Reinshof, respectively. The difference mainly in temperature caused large variation of plant development stages between locations of China and Germany and to some extent also between locations within China ( Table1 ). Sollux was 17 days later to start flowering than Gaoyou in Xian and 29 days later in Hangzhou and Reinshof. The opposite situation was observed for flowering duration, where Gaoyou had longer flowering duration

Fig1. Monthly mean temperature of $2000 / 2001$ at three locations

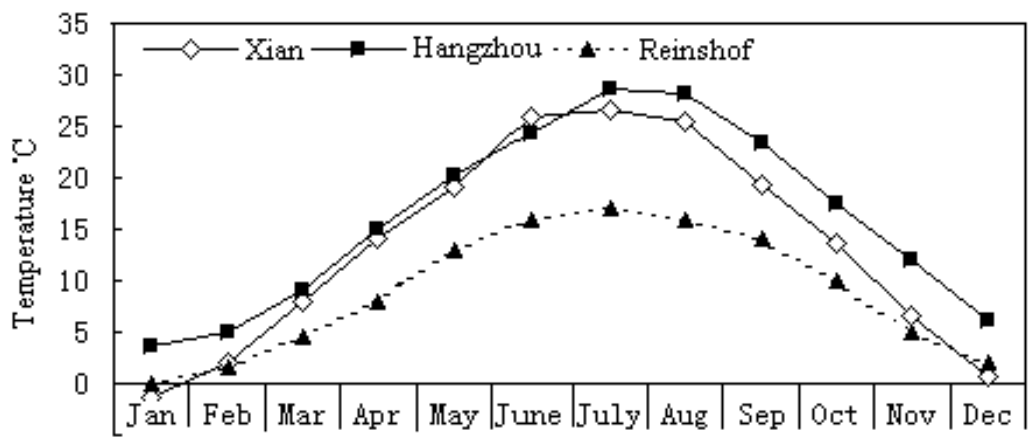

Table1. Phenotypic data of physiological developmental stages under four environments (calculated based on days)

\begin{tabular}{|c|c|c|c|c|c|c|c|c|}
\hline \multirow{2}{*}{ Traits $^{\mathrm{a}}$} & \multirow{2}{*}{ Locations } & \multicolumn{2}{|c|}{ Parents } & \multirow{2}{*}{$\mathrm{F} 1$} & \multicolumn{4}{|c|}{ DH Population $(\mathrm{n}=282)$} \\
\hline & & Sollux & Gaoyou & & Max & Min & Mean & SD \\
\hline \multirow{3}{*}{ DTF } & Xian & 193 & 176 & 184 & 190 & 175 & 183 & 3.28 \\
\hline & Hangzhou & 189 & 160 & 179 & 190 & 159 & 177 & 6.60 \\
\hline & Reinshof & 251 & 222 & 245 & 253 & 225 & 245 & 6.05 \\
\hline \multirow{3}{*}{ DFE } & Xian & 29 & 32 & 34 & 40 & 27 & 34 & 2.02 \\
\hline & Hangzhou & 27 & 31 & 31 & 38 & 22 & 29 & 2.80 \\
\hline & Reinshof & 27 & 44 & 27 & 48 & 23 & 29 & 4.52 \\
\hline \multirow{3}{*}{ DEM } & Xian & 25 & 25 & 26 & 31 & 19 & 25 & 2.31 \\
\hline & Hangzhou & 24 & 34 & 27 & 36 & 18 & 26 & 3.00 \\
\hline & Reinshof & 45 & 43 & 45 & 51 & 36 & 43 & 2.44 \\
\hline \multirow{3}{*}{ DFM } & Xian & 54 & 57 & 60 & 72 & 51 & 58 & 2.80 \\
\hline & Hangzhou & 51 & 65 & 58 & 65 & 46 & 55 & 3.23 \\
\hline & Reinshof & 72 & 87 & 72 & 92 & 64 & 72 & 4.93 \\
\hline \multirow{3}{*}{ DTM } & Xian & 247 & 233 & 243 & 249 & 232 & 242 & 3.58 \\
\hline & Hangzhou & 240 & 225 & 236 & 243 & 220 & 232 & 4.00 \\
\hline & Reinshof & 323 & 309 & 317 & 326 & 305 & 316 & 3.86 \\
\hline
\end{tabular}

${ }^{\mathrm{a}}$ DTF, DFE, DEM, FFM and DTM: days from sowing to flower, flowering duration, grain filling period, days from flowering to maturity, and days from sowing to maturity, respectively 
than Sollux. The grain filling period was similar in Xian and Reinshof, and was in Hangzhou 10 days longer for Gaoyou than for Sollux. Finally, the total growing period was about half month different between parents at all locations. No clear transgressive segregation in DH lines were found for flowering time, while, to some extent, for maturity and high transgression for flowering duration and grain filling period were observed at all locations. Genetic and phenotypic correlations ( Table2 ) showed that oil content had a lower positive genetic correlation with days to flowering, a small negative correlation with flowering duration and days from flowering to maturity, while protein content displayed positive correlations with flowering duration and days from flowering to maturity.

Table2: Genetic (upper figure), and phenotypic (low figure) correlation between oil, protein and developmental stages

\begin{tabular}{llllll}
\hline Traits & FSD & FDD & FED & FSM & TWD \\
\hline Oil & $0.172^{*}$ & $-0.354^{* *}$ & 0.049 & $-0.308^{* *}$ & -0.029 \\
& $0.233^{*}$ & $-0.347^{* *}$ & 0.018 & $-0.296^{* *}$ & 0.004 \\
& & & & & \\
Seed & -0.173 & $0.467^{* *}$ & 0.039 & $0.474^{* *}$ & 0.179 \\
protein & -0.121 & $0.497^{* *}$ & $0.105^{*}$ & $0.507^{* *}$ & $0.362^{* *}$ \\
& & & & & \\
Meal & -0.099 & $0.385^{* *}$ & $0.149^{* *}$ & $0.458^{* *}$ & 0.276 \\
protein & -0.034 & $0.424^{* *}$ & $0.217^{* *}$ & $0.516^{* *}$ & $0.487^{* *}$ \\
\hline
\end{tabular}

$*$,** Significant at the 0.05 , and 0.01 probability levels, respectively

${ }^{\mathrm{a}}$ Abbreviations of physiological developmental stages are same as in Table 1

\section{Genetic contributions of developmental stages to QTLs for oil content}

The results of conditional mapping for oil content when developmental stages were conditioned, separately were compared with the unconditional oil QTLs previously reported (Table 3, thesis 3.1 ). Of eight additive main oil QTLs, three retained similar or small changed effects after conditional mapping, showing almost independently of all developmental stages. Four QTLs on LG1, 11-1, 14-1 and 19 exhibited close relationships with all developmental stages except total growth period for QTL on LG14-1 and flowering duration for QTL on LG19. The QTL on LG12 was both influenced by DTF and DFM. One new conditional QTL was detected on LG16 when DTF, DFE and DEM was conditioned, respectively. We found three QTLs in the same genomic regions controlling oil content and flowering time simultaneously on LG12, 14-1 and LG19 with same directions ( Table 3 and 4 ). These oil QTLs failed to show significant effects after conditioned on days to flowering, indicating their direct genetic overlapping. This also partly explained the observation of genetic correlation between these two traits. Under excluding the effects of DFE and DEM, three and four oil 
Table3. Additive main ( $a$ ) effects of QTLs for oil content ( \% ) and conditioned on developmental stages

\begin{tabular}{|c|c|c|c|c|c|c|c|}
\hline LG & Marker interval & Oil $^{\mathrm{a}}$ & Oil |DTF ${ }^{b}$ & Oil |DFE & Oil |DEM & Oil |DFM & Oil |DTM \\
\hline 1 & HMR292/ HMR327 & $0.373 * *$ & & & & & \\
\hline 7 & HMR300c/MR133.2 & $-0.551^{* *}$ & $-0.547 * *$ & $-0.437 * *$ & $-0.464 * *$ & $-0.523 * *$ & $-0.554 * *$ \\
\hline 9 & HMR438a/HMR310 & $0.338^{* *}$ & $0.325^{*}$ & $0.526^{* *}$ & $0.415^{*}$ & $0.341^{*}$ & $0.572^{* *}$ \\
\hline $11-1$ & MR148/HMR407a & $-0.257^{*}$ & & & & & \\
\hline 12 & HMR299c/HMR403a & $0.271^{*}$ & & $0.308^{*}$ & $0.290 *$ & & $0.234 *$ \\
\hline $14-1$ & HMR403b/MR229 & $0.221^{* *}$ & & & & & $0.225 * *$ \\
\hline 16 & HMR348/ MR133 & & $-0.306^{*}$ & $-0.387 * *$ & $-0.308 * *$ & & \\
\hline 18 & HMR335a/HMR588 & $-0.517 * *$ & $-0.408 * *$ & $-0.377^{*}$ & $-0.431 * *$ & $-0.403 * *$ & $-0.423^{* *}$ \\
\hline 19 & HMR615a/HMR288 & $0.224 * *$ & & $0.210^{* *}$ & & & \\
\hline
\end{tabular}

Table 4. QTL positions and additive main $(a)$ effects of plant developmental stages

(a Abbreviations are same as in Table 1)

\begin{tabular}{clcclc}
\hline DTF & & \multicolumn{5}{c}{ DTM } \\
\hline LG & Marker interval & $a$ & LG & Marker interval & $a$ \\
\hline 1 & HMR295c/ HMR293 & $-1.22^{* *}$ & 1 & HMR295c/ HMR293 & $-0.57^{*}$ \\
2 & HMR066/ HMR087c & $1.54^{* *}$ & 3 & HMR376a/MR197 a & $0.77^{* *}$ \\
$11-2$ & HMR295a/HMR295b & $1.15^{* *}$ & 3 & MR12/MR3 & $0.74^{*}$ \\
12 & HMR299c/ HMR403a & $1.13^{* *}$ & 7 & HD20/MR166 & $0.85^{* *}$ \\
12 & HMR353b/HMR364b & $1.32^{* *}$ & 12 & HMR299c/ HMR403a & $1.54^{* *}$ \\
$14-1$ & HMR403b/MR229 & $0.71^{* *}$ & 12 & HMR353b/HMR364b & $1.10^{* *}$ \\
16 & HMR348/MR133 & $1.18^{* *}$ & 15 & MR97/MR54 & $-0.56^{* *}$ \\
19 & HMR643a/HMR615a & $1.07^{*}$ & 16 & HMR348/MR133 & $0.70^{* *}$ \\
& & & 19 & HMR281/HMR327b & $-0.67^{* *}$ \\
\hline DFE & & \multicolumn{5}{c}{ DFM } & & \\
\hline 9 & MR230.1/ HMR363a & $0.37^{*}$ & 16 & HMR348/MR133 & $-0.74^{* *}$ \\
16 & HMR348/MR133 & $-0.71^{* *}$ & $14-1$ & HMR403b/MR229 & $-0.61^{*}$ \\
\hline
\end{tabular}

QTLs lost significant effects. However, for the QTL of DFE and DFM ( Table 4 ), no corresponding QTLs for oil and protein were identified. When conditional mapping was conducted under excluding the variation from flowering to maturity ( DFM ), five of eight oil QTLs could not be detected significantly, which might show that variation of period from flowering to maturity more influenced the oil QTLs. Whole growth period showed relatively small effect on oil content, three (with relative small effects) of eight main QTLs failed to express genetic effects.

Epistasis caused by additive $x$ additive effects was significant in nine pairs of loci for oil content. When individual developmental stage was conditioned, all the epistatic loci and effects 
Table 5. Epistatic ( $a a$ ) effects of QTLs for oil content (\%) and conditioned on developmental stages

\begin{tabular}{|c|c|c|c|c|c|c|c|c|c|}
\hline LG & $\begin{array}{l}\text { Nearest } \\
\text { marker }\end{array}$ & LG & $\begin{array}{l}\text { Nearest } \\
\text { marker }\end{array}$ & Oil $^{a}$ & Oil |DTF & Oil |DFE & Oil |DEM & Oil |DFM & Oil |DTM \\
\hline 1 & HMR292 & 2 & HMR300a & $-0.294^{* *}$ & $-0.273 *$ & & & & \\
\hline 1 & HMR295c & 9 & HMR310 & & & $0.274 *$ & & & \\
\hline 1 & HMR295c & 12 & HMR353a & $0.384 * *$ & & & & & \\
\hline 2 & HMR300a & 10 & HMR625 & $0.323^{* *}$ & & $0.386^{* *}$ & $0.350^{* *}$ & $0.382 * *$ & $0.415^{* *}$ \\
\hline 3 & HMR449a & 7 & HMR300c & $-0.195 * *$ & & & & & \\
\hline 3 & HMR449a & 18 & HMR335a & $-0.199 * *$ & & & & & \\
\hline 4 & MD2.2 & 12 & HMR353b & $-0.291^{* *}$ & & & $-0.286^{*}$ & $-0.326^{*}$ & $-0.374 * *$ \\
\hline 9 & HMR612a & $11-2$ & HMR295a & & & $-0.228^{* *}$ & & & $-0.261^{*}$ \\
\hline 9 & HMR378 & $14-1$ & HMR403b & & & $0.252^{*}$ & & & \\
\hline 9 & HMR310 & 16 & HMR348 & & & & $0.225^{*}$ & & $0.258^{* *}$ \\
\hline $11-1$ & MR148 & 12 & HMR299c & $0.323^{* *}$ & & & & & \\
\hline $11-1$ & MR148 & 16 & HMR348 & $0.205^{*}$ & & & & & \\
\hline 12 & HMR403a & 19 & HMR327b & & $-0.325^{* *}$ & $-0.276^{*}$ & & & $-0.245^{*}$ \\
\hline 13 & HMR314b & 15 & MR97 & $0.263^{* *}$ & & & & & \\
\hline
\end{tabular}

${ }^{a}$ Sing of epistatic effect: negative indicates that recombinant alleles from two parents and positive means that parental digenic genotypes increase phenotypic value respectively, ${ }^{b}$ Abbreviations are same as in Table 3.

were markedly changed ( Table 5 ) except two pairs on LG2/LG10 and LG4/LG12. The number of epistatic loci sharply decreased to two pairs for oil|DTF and oil|DFM, three pairs for oil|DEM and five pairs for oil|DFE and oil|DTM, indicating that epistatic effects for oil content were largely influenced by variation of developmental stages.

\section{Genetic contributions of developmental stages to QTLs for protein content}

Conditional mapping results of protein given developmental stages showed that all the stages after flowering had larger contributions to protein content. For seed protein, three QTLs on LG1, 7 and 18 presented similar situation as observed for oil content conditioned on developmental stages ( Table 6 ), all the conditional effects on LG1 failed to show and on another two loci, all the effects kept almost unchangeable values in most cases except QTL on LG18 for PS|DFE. Seed protein QTL on LG8 was independently of the three developmental stages DTF, DFE, DEM and affected by the days from flowering to maturity (DFM) and days from sowing to maturity (DTM), while QTL on LG13 was more influenced by flowering duration (DFE) and grain filling period (DEM). A few new conditional QTLs were detected when specific developmental stages were conditioned.

For meal protein ( Table 7 ), The QTL on LG8 was independent of all developmental stages, three QTLs showed close relationships with all stages except the QTL of LG14-2 under 
Table 6. Additive main ( $a$ ) effects of QTLs for seed protein content (SP \%) and conditioned on developmental stages

\begin{tabular}{lllrrrrr}
\hline LG & Marker interval & SP & SP|DTF $^{\text {a }}$ & SP|DFE & SP|DEM & SP|DFM & SP|DTM \\
\hline 1 & HMR407b/HMR292 & $-0.209^{*}$ & & & & & \\
1 & HMR274b/HMR430 & & $-0.173^{* *}$ & & & & \\
2 & HMR299b/HMR299d & & & & $-0.236^{*}$ & & \\
7 & HMR300c/MR133.2 & $0.303^{* *}$ & $0.303^{* *}$ & $0.247^{* *}$ & $0.281^{* *}$ & $0.188^{* *}$ & $0.326^{* *}$ \\
8 & HMR388 & $-0.239^{* *}$ & $-0.188^{* *}$ & $-0.276^{* *}$ & $-0.219^{* *}$ & & \\
9 & HMR284b & & $-0.142^{* *}$ & $-0.125^{* *}$ & & & \\
$11-1$ & MR148 & & & & $0.432^{* *}$ & \\
13 & HMR 337/MR61 & $0.232^{* *}$ & $0.169^{* *}$ & & & $0.155^{* *}$ & \\
18 & HMR335a/ HMR588 & $0.247^{* *}$ & $0.234^{* *}$ & & $0.290^{* *}$ & $0.206^{* *}$ & $0.268^{* *}$ \\
\hline a SP|DTF, SP |DFE, SP |DEM, SP | DFM and SP |DTM indicate the seed protein content conditioned on \\
DTF, DFE, DEM, DFM and DTM respectively. Abbreviations of developmental stages are same as in table 1.
\end{tabular}

Table 7. Additive main ( $a$ ) effects of QTLs for meal protein content (MP \%) and conditioned on developmental stages

\begin{tabular}{|c|c|c|c|c|c|c|c|}
\hline LG & Marker interval & MP & $\operatorname{MP} \mid \mathrm{DTF}^{\mathrm{a}}$ & $\mathrm{MP} \mid \mathrm{DFE}$ & MP|DEM & MP|DFM & MP|DTM \\
\hline 1 & HMR274b/ HMR430 & & $-0.194 *$ & $-0.279^{* *}$ & & $-0.276^{* *}$ & $-0.263^{* *}$ \\
\hline 5 & MR14/ HMR347 & & & $-0.205^{*}$ & $-0.306^{* *}$ & & \\
\hline 7 & MD20/ MR 166 & $0.283 * *$ & $0.212^{* *}$ & $0.273^{*}$ & & $0.149^{*}$ & \\
\hline 8 & HMR388/HMR577 & $-0.492 * *$ & $-0.542 * *$ & $-0.506^{* *}$ & $-0.497 * *$ & $-0.618 * *$ & $-0.447 * *$ \\
\hline 9 & HMR284b/HMR284a & & $-0.275^{* *}$ & & & $-0.224 * *$ & \\
\hline 10 & HMR643b/HMR615b & $-0.230 *$ & & & & & \\
\hline 13 & MR61/HMR314 & $0.243^{* *}$ & $0.270 * *$ & $0.231 *$ & & & $0.319 * *$ \\
\hline $14-2$ & HMR399a/MR155 & $-0.174 * *$ & $-0.200^{*}$ & & & & \\
\hline 16 & MR133/HMR563 & $-0.182 * *$ & $-0.326^{* *}$ & & $-0.366^{* *}$ & & $-0.368 * *$ \\
\hline 18 & HMR335a/HMR588 & $0.159 * *$ & & & & & \\
\hline
\end{tabular}

MP|DTF. Another two QTLs mainly related to grain filling period. The QTL on LG16 was linked with the QTLs which associated with all the development stages except DFM ( Table 4 ) and conditional mapping results presented either undetectable (MP|DFE, MP|DFM ) or changed effects ( PM|DTF, PM|DEM and PM|DTM ).

Additive $\mathrm{X}$ additive interaction effects between loci displayed similar situation as observed for oil QTLs. With few exceptions, almost all the unconditional epistatic pairs did not show significant effects and several new conditional allele combinations were detected. The number of epistatic pairs were also largely decreased for seed and meal protein content when conditioned on all developmental stages, respectively ( Table 8 and 9 ).

Fig 2 summarized two mapping results for oil and protein content based on a set of comparable loci with main additive effects. The comparison of QTLs for unconditional and 
conditional analysis between oil and seed protein content ( Fig 2A and B), it was clear that some loci like QTL1a showed sensitive to all the developmental stages, QTL7a and QTL18 independently of all stages for both traits only with one exception, which further confirmed either pleiotropy or close linkage of QTLs for seed oil and seed protein in these three genomic regions ( thesis 3.2). Two independent QTL for oil, QTL12a and QTL14-1, and two for seed protein, QTL8 and QTL13, were influenced by some of the developmental stages, respectively.

Table 8. Epistatic ( $a a)$ effects of QTLs for seed protein content (SP \%) and conditioned on developmental stages

\begin{tabular}{|c|c|c|c|c|c|c|c|c|c|}
\hline $\mathrm{LG}$ & $\begin{array}{l}\text { Nearest } \\
\text { marker }\end{array}$ & LG & $\begin{array}{l}\text { Nearest } \\
\text { marker }\end{array}$ & SP & $\mathrm{SP} \mid \mathrm{DTF}^{\mathrm{a}}$ & $\mathrm{SP} \mid \mathrm{DFE}$ & SP|DEM & $\mathrm{SP} \mid \mathrm{DFM}$ & SP|DTM \\
\hline 1 & HMR292 & $14-1$ & HMR416b & $0.164 * *$ & & $0.192 * *$ & & & \\
\hline 1 & HMR338 & 12 & HMR353b & & $-0.179 * *$ & & & & \\
\hline 2 & HMR087c & 9 & HMR 284b & & & $-0.128 *$ & & & \\
\hline 2 & HMR299d & 10 & HMR643b & $0.204^{*}$ & & & & & \\
\hline 4 & MD2.2 & 15 & HMR354 & & $0.168 *$ & & & & \\
\hline 4 & MD2.2 & 12 & HMR353b & $0.160 *$ & & & & & \\
\hline 5 & MR14 & 17 & MR127 & & & & $-0.148^{* *}$ & & \\
\hline 7 & MR133.2 & $14-2$ & HMR399a & $0.150 * *$ & & & & & \\
\hline 7 & MR133.2 & 16 & HMR348 & & & & & $-0.117^{*}$ & $-0.160 * *$ \\
\hline 9 & HMR284a & 15 & HMR354 & & & $0.167 * *$ & & & \\
\hline 9 & HMR612a & 15 & HMR354 & & & & & $0.130 *$ & \\
\hline 9 & HMR612a & $11-2$ & HMR295a & & & & $0.200 * *$ & & \\
\hline $11-2$ & HMR295b & $14-2$ & HMR363c & & & & & $-0.287 * *$ & \\
\hline 12 & HMR353b & 13 & MR61 & $-0.200 * *$ & & & $-0.154 *$ & $-0.190 * *$ & \\
\hline 12 & HMR299c & 15 & MR97 & $-0.220^{*}$ & & & & & \\
\hline
\end{tabular}

${ }^{\mathrm{a}}$ Abbreviations are same as in Table 6.

Table 9. Epistatic ( $a a$ ) effects of QTLs for meal protein (MP \%) and conditioned on developmental stages

\begin{tabular}{|c|c|c|c|c|c|c|c|c|c|}
\hline LG & $\begin{array}{l}\text { Nearest } \\
\text { marker }\end{array}$ & LG & $\begin{array}{l}\text { Nearest } \\
\text { marker }\end{array}$ & MP & $\mathrm{MP} \mid \mathrm{DTF}^{\mathrm{a}}$ & $\mathrm{MP} \mid \mathrm{DFE}$ & MP|DEM & MP|DSM & MP|DTM \\
\hline 1 & HMR292 & 13 & MR61 & $0.152 *$ & & & & & \\
\hline 1 & HMR292 & 16 & MR133 & & $-0.234^{*}$ & $-0.231^{* *}$ & & & \\
\hline 1 & HMR292 & 17 & HMR332 & $-0.229^{* *}$ & & & & & \\
\hline 1 & HMR274b & 9 & HMR573 & $-0.271 * *$ & $-0.180^{*}$ & & $-0.212^{*}$ & & \\
\hline 2 & HMR087c & 10 & HMR643b & $0.210^{* *}$ & $0.251 *$ & $0.397 * *$ & $0.381^{* *}$ & & \\
\hline 2 & HMR066 & $11-2$ & HMR295a & & & & & $0.224 * *$ & \\
\hline 3 & HMR085 & $11-1$ & HMR374 & & $-0.235^{* *}$ & & & & $-0.286^{* *}$ \\
\hline 3 & MR3 & 19 & HMR327b & $-0.243^{* *}$ & & & & & \\
\hline 7 & MR166 & 8 & HMR595 & & & & & & $-0.209 * *$ \\
\hline 8 & HMR388 & 12 & HMR364b & & & & & $0.212^{* *}$ & \\
\hline 9 & MR230.1 & 13 & MR197.2 & $0.277 * *$ & & & & & \\
\hline $11-1$ & MR228 & 19 & HMR615a & $0.212 * *$ & & & & & \\
\hline $11-2$ & HMR374 & $14-1$ & HMR363c & & & $-0.231^{* *}$ & & & \\
\hline 13 & HMR067 & $14-1$ & HMR363c & & & & $0.191^{* *}$ & & \\
\hline
\end{tabular}

\footnotetext{
${ }^{\mathrm{a}}$ Abbreviations are same as in Table 7
} 

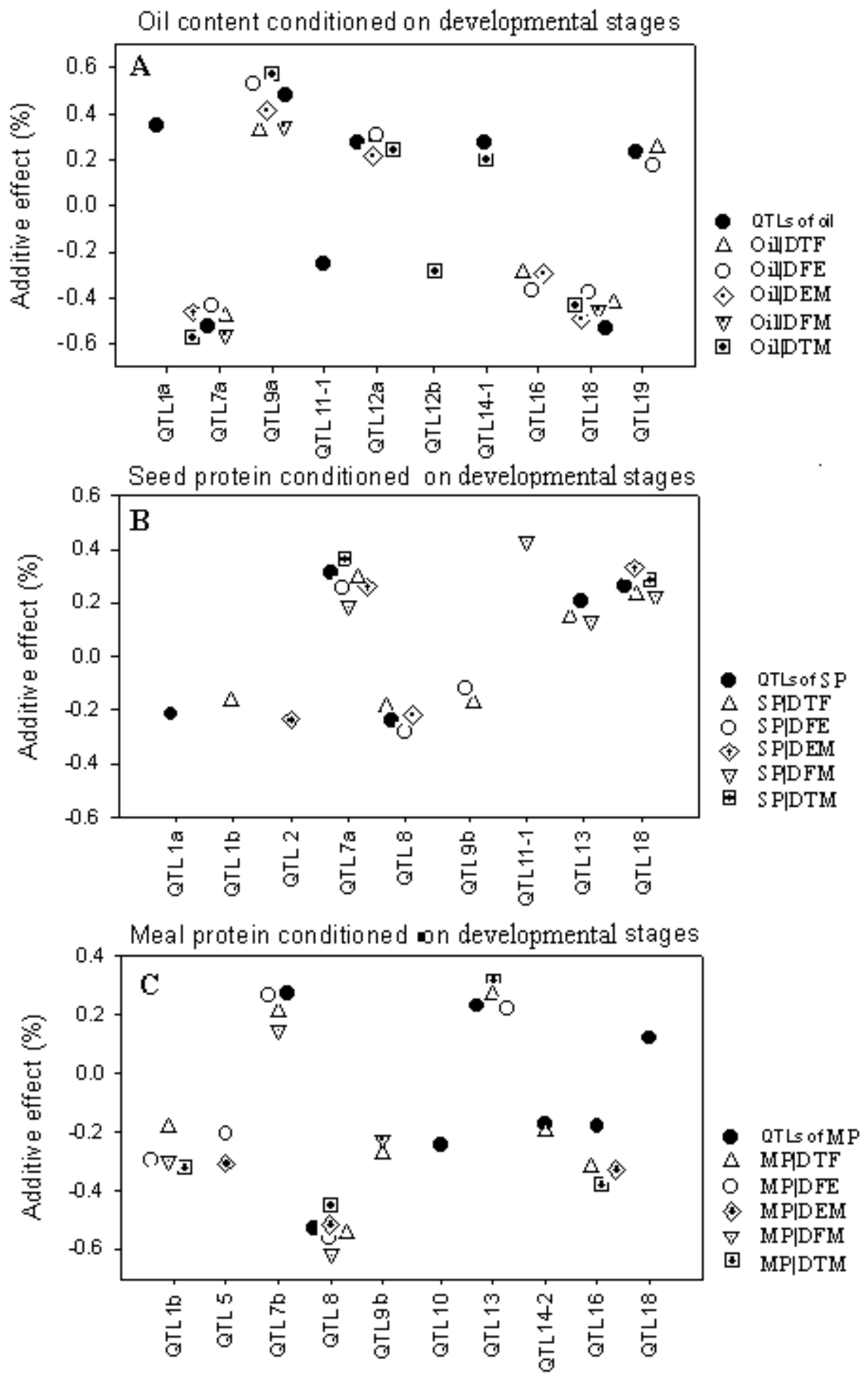

Fig 2. Comparison of QTL behavior for conditional and unconditional mapping analysis of oil (A), seed protein (B), meal protein (C) content conditioned on five plant developmental stages. Comparative loci among oil, seed and meal protein were named as QTL with linkage group. If there was more than one locus in a group, the letters were added after that. 
and QTL13 exhibited all independently of flowering time while QTL13 was more influenced by grain filling period and for seed protein, flowering duration was also of influence. It should be noted that QTL18 for seed protein was not influenced by all the developmental stages except DTM, while significantly related with all the stages for meal protein. Conditional QTL1b and QTL9b were detected in the new genomic regions both for seed and meal protein when one to four developmental stages were conditioned.

\subsubsection{Discussion}

\section{Genetic relationships between QTLs for seed oil, protein and developmental stages}

Despite the large variation of developmental stages, the oil and protein content between parents was about 3\% in difference with opposite directions between Reinshof, Germany and Hangzhou, China. Xian in China showed almost similar contents between parents. QTL mapping for oil content revealed the dispersion of favorable alleles between parents, which led to several transgressive high oil lines produced ( see thesis 3.1) and are of interest for rapeseed breeding. However, breeders may also be interested to know the genetic relationship between QTLs for oil and protein content and developmental stages. The current study provide some information, which might be interesting for breeding purposes in both countries. 1) All the developmental stages significantly affected oil content in certain gene loci. Relatively, flowering time and days from flowering to maturity exhibited more contributions, which might be mainly caused by positive pleiotropy on three QTLs for oil content and flowering time, and the negative pleiotropy on two loci for flowering time and days from flowering to maturity. These were consistent with the genetic correlations (Table2). Negative correlation between oil and flowering duration ( DFE ) could be the indirect affection of oil with flowering time. Positive genetic correlation between protein either with flowering duration ( DFE ) or with days from flowering to maturity ( DFM ) corresponded well with conditional mapping analysis, showing larger changes of genetic basis for seed and meal protein under these two stages were conditioned, respectively ( Table 6 and 7 ). Genetic correlation between either oil or seed protein and DEM are not significant, which did not agree well with conditional mapping results. The explanations might be firstly, significantly environmental affect occurred in this stage mainly due to temperature and disease resistance. Secondly, relatively larger experimental error could happen because the calculation for DEM is based on two observations, which may enlarge the error. This was supported by the estimation of variance components that DEM has the relatively largest environmental effect and experimental error from all developmental stages (data not 
shown). 2 ) Different QTLs for oil or protein content showed relationships with developmental stages in different ways. The two oil QTLs with the largest effects ( on LG7 and LG18, Table 3 ) were identified independently of all developmental stages. The favorable alleles come from the Chinese parent Gaoyou, and these two QTLs are good candidates for marker assistant to be transferred into European rapeseed breeding materials; The QTL on LG9 did not relate to any developmental stages. The QTL on LG12 showed positive pleiotropy or close linkage to QTL for flowering time and maturity, indicating that marker based selection for improved oil content will lead to later flowering and later maturity. The QTL on LG14-1 also showed positive pleiotropy for flowering time but negative pleiotropy effect for period from flowering to maturity, demonstrating association of increased oil content with later flowering and shorter duration from flowering to maturity.

\section{Combined improvement of oil and protein content without linkage with unexpected developmental features}

The potentials for combining oil and protein content in seed are limited (Gül 2002; Thesis 3. 2 ), however the strategy for simultaneously increasing oil content in seed and protein content in meal seems practical possible ( see thesis 3.2 ). Environmental conditions can largely alter the protein content as observed previously (Alemayehu 2001) and was also confirmed by molecular markers ( see thesis 3.2 ). Results from this study indicated that oil or protein content influenced by environmental conditions partly were due to the changes of developmental stages. Results provide some information for improving oil, protein content with possible linkage or independent of development features, which might be valuable in breeding program.

First, seed protein QTLs on LG8 and LG13 with favorable alleles from Gaoyou and Sollux respectively were found to be independently to oil content ( see thesis 3.2 ) and did not show significant linkage with all developmental stages ( Table 4 ). Conditional mapping results ( Fig 2B ) showed Chinese allele on LG8 independently of three separate stages of whole growth period. The Sollux allele on LG13 was not influenced by flowering time and the period from flowering to maturity. Integration of these alleles into elite lines might result in increased protein content without changing oil content and developmental stages.

Second, using flanking markers of QTLs on LG7, 8 and 13 will result in increased meal protein with unchanged oil content ( see thesis 3.2 ), similar flowering time and flowering period, while selection based on the QTL on LG16 for meal protein will have no negative effect on oil content but may lead to early flower, longer flowering duration and longer period from flowering to maturity and finally led to about one and half days early for maturity when Sollux allele was homozygous substituted by Gaoyou allele ( $a=0.70$, Table 4 and 7 ). QTLs on LG10, 
14-2 and 18 for meal protein showed an influence by almost all the developmental stages so attention might be paid when using flanking markers for these QTLs.

\section{QTLs with epistatic effects and their possible regulative functions}

Results from this study exhibited dramatic shift of additive $x$ additive epistasis for all three quality traits when genetic effects of developmental stages were conditioned. The number of epistatic loci largely decreased and most of unconditional epistatic QTLs failed to show significant effects and new conditional QTLs occurred with additional allele combinations. All of these indicated that additive $x$ additive epistatic effects could be one part of the most important genetic basis for oil and protein content and play an regulative function during the formation of both components in seed. Since epistatic effects are interactions between alleles of different loci, any influence for one of pair of loci will markedly change the QTLs and effects as reported previously ( Doebley et al. 1995; Li et al.1997; Cao et al. 2001 ), so it is not difficult to understand that the variation of developmental stages can easily alter the interactive pairs between loci and thus lead to more complex inheritance for these traits.

Our study provided genetic basis of relationships between oil, protein content and individual developmental stages on additive main loci, demonstrated the complex genetic influence by developmental stages on digenic epistatic loci both for oil and protein content. The results indicated that some QTLs for oil and protein content may be independent of developmental stages, while some are related to earlier or later flowering, or with some other developmental stages. These information are interesting for rapeseed breeding both in Europe and China.

\subsubsection{Summary}

Plant developmental stages of rapeseed largely varied with environmental conditions, and consequently indirectly affecting oil and protein content in seed. Since their quantitative traits in nature, the relationships between seed quality and developmental stages are complicated. The objective of this study was to dissect the genetic relationships between this two types of trait on individual gene loci and provide a useful information for breeding purpose. A linkage map of 125 SSR marker loci and a population of in total 282 doubled haploid lines derived from the F1 between the old German cultivar Sollux and the Chinese landrace Gaoyou were used for mapping experiments under 4 environments, two in Germany and two in China. A new mapping program QTLMapper version 1.0 was used for mapping unconditional and conditional QTLs with additive $(a)$ and additive $\mathrm{x}$ additive epistatic $(a a)$ effects. The results showed that flowering time exhibited more contribution to oil content, while days from flowering to maturity 
were more related with seed and meal protein. The two oil QTLs having largest effects were identified independently of all developmental stages. The favorable alleles come from the Chinese parent. Two QTLs with favorable alleles from the European parent for oil content also did not relate to any developmental stages or linked with early flowering gene. These QTLs are interesting for practical breeding in both regions.

Key words Brassica napus L. Oil and protein content · Development stages · Conditional QTL mapping · Epistasis

\subsubsection{References}

Alemayehu N (2001) Germplasm diversity and genetics of quality and agronomic traits in Ethiopian mustard (Brassica carinata A.Braun) Doctoral Dissertation pp: 81-96

Axelsson T, Shavorskaya O, Lagercrantz U (2001) Multiple flowering time QTLs within several Brassica species could be the result of duplicated copies of one ancestral gene. Genome 44 (5): 856-864

Becker HC, Löptien H and Röbbelen G (1999) Breeding of Brassica: An overview. In Gomez-Campo C (ed) Biology of Brassica coenospecies. Elsevier, Science BV, Amsterdam, pp: 413-460

Butruille DV, Guries R, Osborn TC (1999 ) Linkage Analysis of Molecular Markers and Quantitative Trait Loci in Populations of Inbred Backcross Lines of Brassica napus L. Genetics 153: 949-964

Canvin DT (1965) The effect of temperature on the oil content and fatty acid composition of the oils from several oilseed crops. Canadian Journal of Botany 43: 63-69

Cao G, Zhu J, He C, Gao Y, Yan J, Wu P ( 2001 ) Impact of epistasis and QTL x environment interaction on the developmental behavior of plant height in rice ( Oryza sativaL.). Theor. Appl. Genet. 103:153-160

Doebley J, Stec A, Gustus C (1995) Teosinte branched $l$ and the origin of maize: evidence for epistasis and the evolution of dominance. Genetics 141: 333-346

Ferreira ME, Satagopan J, Yandell BS, Williams PH and Osborn TC (1995) Mapping loci controlling vernalization requirement and flowering time in Brassica napus. Theor. Appl. Genet. 90: 727-732

Fowler DB and Downey RK (1970) Lipid and morphological changes in developing rapeseed, Brassica napus. Canadian Journal of Plant Science 50: 233-247

Grami B and Stefansson BR (1977) Genetics of protein and oil content in summer rape: Heritability, numbers of effective factors, and correlations. Canadian Journal of Plant Science 57: 937-943

Gül MK (2002) QTL-Kartierung und Analyse von QTL x Stickstoff Interaktionen beim Winterraps (Brassica napus L.) Ph.D thesis, Fachbereich Agtarwissenschaften der Georg-August-Universität, Göttingen

Li ZK, Pinson SRM, Park WD, Paterson AH, Stansel JW (1997) Epistasis for three grain yield components in rice Oryza sativa L. Genetics 145: 453-465

Loof B and Appelqvist LA (1972) Plant breeding for improved yield and quality. In Appelqvist LA and Ohlson R (eds) Rapeseed: Cultivation, composition, processing and utilization. Elsevier Publishing Company, Amsterdam, the Neatherlands, pp: 101-122 
Matile P (1975) The lytic compartment of plant cells. Cell Biology Monographs, Vol.1, Springer, Wien and New York

Mendham NJ and Salisbury PA (1995) Crop development, Growth and Yield. In Kimber D and McGregor DI (eds) Brassica Oilseeds: Production and Utilization. University Press, Cambridge, pp: 11-64

Parkin IAP, Sharpe AG, Keith DJ, Lydiate DJ (1995) Identification of the A and C genomes of amphidiploid Brassica napus (oilseed rape). Genome 38: 1122-1131

Rakow G and McGregor DI (1975) Oil, fatty acid and chlorophyll accumulation in developing seeds of two 'linolenic acid lines' of low erucic acid rapeseed. Canadian Journal of Plant Science 55: 197-203

Reinhardt TC (1992) Entwicklung und Anwendung von Nah-In-frarot-spektroskopischen Methoden für die Bestimmung von Öl-Protein-, Glucosinolate-, Feuchte- und Fettsäure-Gehalten in intaker Rapssaat. Dissertation, Universität Göttingen, Cuvillier Verlag Göttingen

Röbbelen G, Thies W (1980) Biosynthesis of seed oil and breeding for improved meal quality. In Tsumoda S, Hinta K and Gomez-Campo C (eds) Brassica crops and wild allies: Biology and breeding. Japan Scientific Societies Press,Tokyo, pp: 285-299

Thesis 3.1 Construction of a linkage map and identification of QTLs for oil content (manuscript 1)

Thesis 3.2 QTLs for protein content and their relationships with oil content (manuscript 2)

Thurling N and Vijendra Das LD (1977) Variation in the pre-anthesis development of spring rape (Brassica napus L.). Australian Journal of Agricultural Research 28: 597-607

Wang DL, Zhu J, Li ZK, Paterson AH (1999) Mapping of QTL with epistatic effects and QTL x environment interactions by mixed model approaches. Theor. Appl. Genet. 99: 1255-1264

Zhu J (1992) Mixed model approaches for estimating genetic variances and covariance. J. Biomath.7: 1-11

Zhu J (1995) Analysis of conditional genetic effects and variance components in developmental genetics.

Genetics 141:1633-1639 


\subsection{Relationships between oil and protein content with plant height and yield components}

\subsubsection{Introduction}

The interaction and synchronous operation among physiological development stages, plant organs growth and the accumulation of oil, protein and other components in seed has been well documented by Mendham and Salisbury (1995) in oilseed rape. Each stage and process is to a greater or lesser extent under genetic control, and is affected in varying degree by environmental factors, mainly temperature and photoperiod ( reviewed by Leon and Becker 1995 ). Detailed relationship between temperature and flowering time, between temperature and period from flowering to maturity were observed ( Thurling and Vijendra 1977; Mendham et al. $1981 b$ ). Differences in plant developmental stages resulted in marked variations of yield potential and its components as siliques per plant, seeds per silique and seed size ( Tayo and Morgan 1975; Mendham et al.1981a ). Genetic relationships between oil ( or protein ) content and development stages were analyzed by molecular markers ( Thesis 3.3 ), which exposed that some quantitative trait loci ( QTLs ) for oil and protein content were independent of all plant developmental stages, while some QTLs were closely linked to or significantly influenced by developmental stages. Simultaneous increase of seed oil and seed yield normally are difficult in practical breeding although many elite varieties today show high levels for both traits as results of great breeding efforts. Olsson (1960) indicated, from several field experiments, that the correlation between oil content and seed number was usually positive ( 13 of 15 experiments showed positive correlation ) while all the 15 experiments showed negative correlations between oil and seed weight, which was reported also by Riemann (1964). Therefore it might be difficult to combine high oil content with lager seed size. Plant height, the number of primary branches and silique length are not direct components of seed yield, however, they may influence the yield components and were analyzed as yield related traits together with seed size and seed number in this study.

Oil and protein content in oilseed rape are quantitative traits. Recent QTL mapping studies gained insight into their genetic basis using different molecular markers ( Ecke et al. 1995; Cheung et al.1998; Sharma et al. 1999; Gül et al. 2002; Thesis 3.1, 3.2 and 3.3 ). However, the genetic relationship between oil, protein and yield related traits on molecular level is still poorly understood. 
Our objectives were to evaluate the genetic relationships between oil, protein content and yield related traits on individual gene loci based on an established DH population ( Thesis 3.1 ) and by combining the statistical procedures for analyzing conditional genetic effects ( $\mathrm{Zhu}$ 1995 ) and the QTL mapping method based on mixed model approach ( Wang et al. 1999) to map conditional QTLs. Conditional mapping reflect the effects of QTLs for oil content (or protein content ) under the situation when individual yield related trait was conditioned, therefore the results might be valuable for combining oil (or protein) content and yield related traits or improving oil (or protein) content without negative effects for seed yield by marker aided selection.

\subsubsection{Material and Methods}

\section{Population and SSR map}

A doubled haploid (DH) population consisting of 282 lines was established by microspore culture from a cross between 'Sollux' and 'Gaoyou' ( Thesis 3.1 ). 'Sollux' is an old variety from Germany with typical winter type, exhibiting later flowering and longer growth period. Gaoyou is an old landrace from China, showing earlier to flower and maturity. Parental lines contained high erucic acid and glucosinolate content, and exhibited higher oil content in seeds. A linkage map comprising 125 microsatellite markers ( SSRs ) and covering a total length of $1196 \mathrm{cM}$ was used for mapping ( Thesis 3.1 ).

\section{Data collection}

As described previously ( Thesis 3.1), four separate experiments were conducted at two locations in China: Xian and Hangzhou, two locations in Göttingen of Germany: Reinshof and Weende in 2000/2001. The field experiments were in a randomized complete block design with two replications. The seeds were sown in two rows for each plot, $2.5 \mathrm{~m}$ in length with $0.33 \mathrm{~m}$ between rows and $0.12 \mathrm{~m}$ between plants within rows in Göttingen, and $2.5 \mathrm{~m}, 0.33 \mathrm{~m}$ and 0.15 $m$ respectively in China.

At the maturity stage, five representative plants from the middle of each plot were sampled for evaluating yield related traits and analysis of seed qualities. Data collection included thousand seed weight (SW), number of seeds per silique (NS), silique length (SL), plant height $(\mathrm{PH})$ and number of primary branches per plant (NB). NS and SL were measured based on 10 siliques, 2 from each plant, taken from the low part of main inflorescence. Around $10 \mathrm{~g}$ seeds were bulk harvested from terminal raceme and the two uppermost primary branches in each plot. Seed oil and protein content from all locations were determined by near-infrared 
reflectance spectrophotometry ( NIRS, Reinhardt 1992 ), based on 9\% moisture of seeds. Meal protein (MP) was calculated from seed protein (SP) and oil content: Protein content in meal (\%) $=\frac{\text { protein }(\text { in seed }) \%}{100-\text { oil } \%} \times 100$

\section{Data analysis and mapping of conditional QTLs}

Seed quality and yield related traits of $282 \mathrm{DH}$ lines were analysed firstly with MINQUE method (Zhu, 1992) to estimate variance components and covariance components. Genetic, phenotypic correction coefficients were then estimated between seed quality and five yield related traits evaluated.

The conditional phenotypic value $\left(y_{h k(T \mid T 2)}\right)$ was obtained by the mixed model approaches for the conditional analysis of quantitative traits ( Zhu 1995 ). Conditional QTL mapping were then performed using QTLMapper version 1.0 ( Wang et al. 1999 ). The conditional value $y_{h k(T 1 \mid T 2)}$ can be partitioned as:

$$
\begin{aligned}
y_{h k(T 1 \mid T 2)} & \mu_{(T 1 \mid T 2)}+a_{i(T 1 \mid T 2)} x_{A i k}+a_{j(T 1 \mid T 2)} x_{A_{j k}}+a a_{i j(T 1 \mid T 2)} x_{A A}{ }_{i j k} \\
& +u_{E_{h k}} e_{E_{h(T 1 \mid T 2)}}+u_{A_{i} E_{h k}} e_{A_{i} E_{h(T 1 \mid T 2)}}+u_{A_{j} E_{h k}} e_{A_{j} E_{h(T 1 \mid T 2)}}+u_{A A_{i j} E_{h k}} e_{A A_{i j} E_{h(T 1 \mid T 2)}} \\
& +\sum_{f(h)} u_{M_{f k(h)}} e_{M_{f(h)(T 1 \mid T 2)}}+\sum_{l(h)} u_{M M_{l k(h)}(h)} e_{M M_{l(h)(T 1 \mid T 2)}}+\varepsilon_{h k(T 1 \mid T 2)}
\end{aligned}
$$

where T1|T2 denotes trait 1 conditioned on trait 2 (oil $\mid \mathrm{SW}=$ oil conditioned on 1000-seeds weight, SP|SW = seed protein conditioned on 1000-seeds weight, and so on).

Unconditional mapping of three yield related traits used same mapping program QTLMapper V1.0 (Wang et al.1999). The models, explanation of all the conditional and unconditional parameters and detailed mapping procedure were described previously (Wang et al. 1999; Thesis 3.1 and 3.2 ). The likelihood -ratio threshold was chosen at $\alpha=0.005$ for claiming putative QTL and genetic effects.

\subsubsection{Results}

\section{Correlation between oil, protein and yield related traits}

Genetic and phenotypic correlation between oil, protein and five seed yield related traits shown on Table1. The correlation coefficients between two types of traits showed either small to medium or insignificant correlations. The magnitude of genetic correlation of all the trait pairs were similar as or larger than phenotypic correlation, implied the existence of true genetic associations between oil (or protein) and some yield related traits. It was found that silique 
length and the number of primary branches displayed insignificant or very small genetic correlation with oil and protein content. However seed size might be more related to meal protein, seed number and plant height be more connected with oil or seed protein. Therefore, the latter three yield related traits were further analyzed by conditional mapping approach to dissect their genetic relationships with seed oil or protein content on individual gene loci.

Table1. Correlation between quality traits and five yield related traits

\begin{tabular}{lllllllllll}
\hline \multirow{2}{*}{ Traits } & + & $\mathrm{SW}$ & \multicolumn{2}{c}{$\mathrm{NS}$} & \multicolumn{2}{c}{$\mathrm{SL}$} & \multicolumn{2}{c}{$\mathrm{PH}$} & \multicolumn{2}{c}{$\mathrm{NB}$} \\
\cline { 2 - 10 } & $\mathrm{r}_{\mathrm{G}}$ & $\mathrm{r}_{\mathrm{P}}$ & $\mathrm{r}_{\mathrm{G}}$ & $\mathrm{r}_{\mathrm{P}}$ & $\mathrm{r}_{\mathrm{G}}$ & $\mathrm{r}_{\mathrm{P}}$ & $\mathrm{r}_{\mathrm{G}}$ & $\mathrm{r}_{\mathrm{P}}$ & $\mathrm{r}_{\mathrm{G}}$ & $\mathrm{r}_{\mathrm{P}}$ \\
\hline Oil & -0.211 & $0.172^{*}$ & $0.468^{*}$ & $0.421^{* *}$ & 0.162 & $0.143^{*}$ & $0.366^{* *}$ & $0.403^{* *}$ & -0.050 & 0.123 \\
Seed & -0.125 & -0.098 & $-0.497^{* *}$ & $-0.329^{* *}$ & -0.167 & $-0.167^{*}$ & $-0.338^{* *}$ & $-0.332^{* *}$ & -0.078 & -0.112 \\
Meal & $-0.336^{* *}$ & 0.020 & -0.054 & -0.071 & -0.033 & $-0.125^{*}$ & -0.004 & $-0.104^{*}$ & $-0.181^{*}$ & $-0.211^{*}$ \\
\hline
\end{tabular}

*, ** Significant at the 0.05 , and 0.01 probability levels, respectively. $\mathrm{r}_{\mathrm{G}}$, and $\mathrm{r}_{\mathrm{P}}$ indicate genetic and phenotypic correlations, respectively. ${ }^{+} \mathrm{SW}, \mathrm{NS}, \mathrm{SL}, \mathrm{PH}$ and NB: thousand seed weight $(\mathrm{g})$, number of seeds per silique, silique length (cm), plant height $(\mathrm{cm})$ and number of primary branches per plant, respectively.

\section{The relationships between QTLs for oil content and three yield related traits}

QTLs of oil content showed different responses to yield related traits evaluated under conditional mapping analysis ( Table 2 ). Three of eight oil QTLs showed similar or small changed effects. Three QTLs on LG ( linkage group )1, 14-1 and 19 lost significant or largely changed effects when seeds per silique and plant height was conditioned, respectively. Another two QTLs were either significantly influenced by thousand seed weight and plant height ( LG11-1 ) or more related with seeds per silique (LG9 ). It was clear that more genetic basis for oil content was changed under oil| NS and oil| PH than oil|SW. These were principally in agreement with the genetic correlations ( Table 1 ).

Table2. Additive effects $(a)$ of QTLs for oil content (\%) and conditioned on three yield related traits

\begin{tabular}{|c|c|c|c|c|c|}
\hline \multirow{2}{*}{ LG } & \multirow{2}{*}{$\begin{array}{l}\text { Marker } \\
\text { interval }\end{array}$} & \multicolumn{3}{|c|}{ Additive main effect $(\%)^{\dagger}$} & \multirow[b]{2}{*}{ Oil $\mid \mathrm{PH}$} \\
\hline & & Oil & Oil |SW ${ }^{+}$ & Oil |NS & \\
\hline 1 & HMR292/HMR327c & $0.373 * *$ & $0.390 * *$ & & \\
\hline 7 & HMR300c/MR133.2 & $-0.551 * *$ & $-0.480 * *$ & $-0.421 * *$ & $-0.530 * *$ \\
\hline 9 & HMR438a/HMR310 & $0.338 * *$ & $0.387 * *$ & & $0.362 * *$ \\
\hline $11-1$ & MR148/HMR407a & $-0.257 *$ & & $-0.175^{*}$ & \\
\hline 12 & HMR299c/HMR403a & $0.271^{*}$ & $0.358 * *$ & $0.330 * *$ & $0.228 * *$ \\
\hline $14-1$ & HMR403b/MR229 & $0.221 * *$ & $0.324 * *$ & & \\
\hline 18 & HMR335a/ HMR588 & $-0.517 * *$ & $-0.455 * *$ & $-0.290 * *$ & $-0.385 * *$ \\
\hline 19 & HMR615a/ HMR288 & $0.224^{* *}$ & $0.206^{* *}$ & $0.418^{*}$ & \\
\hline
\end{tabular}

*,** indicate the significance level at 0.005 and 0.001 respectively to declare the QTL positions and genetic effects.

$\dagger$ The QTL effect, is the phenotypic effect due to substitution of an 'Gaoyou' allele by an allele of 'Sollux'. 'Oil |SW, Oil |NS, and Oil |PH: Oil conditioned on thousand seed weight, seeds per siliquae and plant height, respectively. 
The number of loci with epistatic effects decreased from nine pairs to three under oil|SW, seven after oil|NS and five pairs for oil|PH (Table 3). Under the condition of oil| NS and oil| PH, four common epistatic pairs were identified with similar effects and three of them were presented with the new pairs of loci, while 7 and 8 out of 9 unconditional pairs become undetectable. After oil|SW, two pairs remained similar effects, one new pair occurred and rest of seven pairs lost significant effects.

Table 3. Epistatic effects ( $a a)$ of QTLs for oil content (\%) and conditioned on three yield related traits $(\%)$

\begin{tabular}{|c|c|c|c|c|c|c|c|}
\hline \multirow{2}{*}{ LG } & \multirow{2}{*}{$\begin{array}{l}\text { Nearest } \\
\text { marker }\end{array}$} & \multirow[t]{2}{*}{ LG } & \multirow{2}{*}{$\begin{array}{l}\text { Nearest } \\
\text { marker }\end{array}$} & \multicolumn{4}{|c|}{ Epistatic main effects $(\%)^{\dagger}$} \\
\hline & & & & Oil & Oil $\mid \mathrm{SW}^{\dagger}$ & Oil |NS & Oil $\mid \mathrm{PH}$ \\
\hline 1 & HMR292 & 2 & HMR300a & $-0.294^{* *}$ & $-0.308 * *$ & $-0.242 *$ & \\
\hline 1 & HMR295c & 12 & HMR353a & $0.384 * *$ & & $0.381 * *$ & $0.296^{* *}$ \\
\hline 1 & HMR292 & $14-2$ & GMR140 & & & $-0.337^{* *}$ & \\
\hline 1 & HMR292 & 17 & HMR332 & & & $0.256^{* *}$ & $0.246^{* *}$ \\
\hline 2 & HMR299b & 9 & HMR311b & & & & $-0.596^{* *}$ \\
\hline 2 & HMR300a & 10 & HMR625 & $0.323^{* *}$ & $0.353^{* *}$ & & \\
\hline 3 & HMR449a & 7 & HMR300c & $-0.195 * *$ & & & \\
\hline 3 & MR12 & 18 & HMR335a & $-0.199 * *$ & & & \\
\hline 4 & $\mathrm{MD} 2.2$ & 9 & HMR $311 b$ & & & $-0.266^{*}$ & \\
\hline 4 & MD2.2 & 12 & HMR353b & $-0.291 * *$ & & & \\
\hline 5 & MD21 & 17 & HMR344b & & & $0.215^{*}$ & $0.240^{*}$ \\
\hline 9 & HMR612a & $11-2$ & HMR295a & & $-0.301 * *$ & & \\
\hline 9 & HMR612a & $14-1$ & HMR416b & & & $0.290^{* *}$ & $0.315^{* *}$ \\
\hline $11-1$ & MR148 & 12 & HMR299c & $0.323^{* *}$ & & & \\
\hline $11-1$ & MR148 & 16 & HMR348 & $0.205^{*}$ & & & \\
\hline 13 & HMR314b & 15 & MR97 & $0.263^{* *}$ & & & \\
\hline
\end{tabular}

Sing of epistatic effect: negative indicates that recombinant alleles from two parents and positive means that parental digenic genotypes increase phenotypic value, respectively. ${ }^{\ddagger}$ Abbreviations are the same as in table 2.

\section{The relationships between QTLs for protein content and three yield related traits}

Conditional mapping for seed protein when three yield related traits were conditioned, respectively, ( Table 4 ) showed that three QTLs exhibited similar or slightly changed additive effects ( LG7, 8 and 18 ). Another two QTLs on LG1 and LG13 were either influenced by all three traits or related to plant height. Two additional new QTLs occurred when thousand seed weight and seeds per silique, or plant height were conditioned, respectively. Comparison among three conditional mapping results ( $\mathrm{SP}|\mathrm{SW}, \mathrm{SP}| \mathrm{NS}$ and $\mathrm{SP} \mid \mathrm{PH}$ ), it was found that the genetic relationship between seed protein and plant height was larger than that with seeds per silique and less related with thousand seed weight. 
Table 4. Additive effects ( $a$ ) of QTLs for seed protein content ( $\%$ ) and conditioned on three yield related traits

\begin{tabular}{llcccc}
\hline \multirow{2}{*}{ LG } & Marker & \multicolumn{4}{c}{ Additive main effect (\%) } \\
\cline { 2 - 5 } & interval & \multicolumn{1}{c}{$\mathrm{SP}^{\dagger}$} & $\mathrm{SP} \mid \mathrm{SW}{ }^{*}$ & $\mathrm{SP} \mid \mathrm{NS}$ & $\mathrm{SP} \mid \mathrm{PH}$ \\
\hline 1 & HMR292/HMR327c & $-0.209^{*}$ & & & \\
7 & HMR300c/MR133.2 & $0.303^{* *}$ & $0.317^{* *}$ & $0.190^{* *}$ & $0.215^{* *}$ \\
7 & MD20/MR66 & & & & $0.268^{* *}$ \\
8 & HMR388/HMR577 & $-0.239^{* *}$ & $-0.242^{* *}$ & $-0.255^{* *}$ & $-0.294^{* *}$ \\
13 & HMR337/MR61 & $0.232^{*}$ & $0.205^{* *}$ & $0.199^{* *}$ & \\
18 & HMR335a/HMR588 & $0.247^{* *}$ & $0.216^{* *}$ & $0.184^{* *}$ & $0.191^{* *}$ \\
19 & HMR643a/HMR615a & & $-0.129^{* *}$ & $-0.146^{* *}$ & \\
\hline
\end{tabular}

${ }^{\dagger}$ SP: protein content in seed (\%). ${ }^{\ddagger}$ SP|SW, SP|NS and SP|PH: Seed protein conditioned on thousand seed weight, seeds per siliquae and plant height, respectively.

Table 5. Additive effects ( $a$ ) of QTLs for meal protein content (\%) and conditioned on three yield related traits

\begin{tabular}{|c|c|c|c|c|c|}
\hline \multirow{2}{*}{ LG } & \multirow{2}{*}{$\begin{array}{l}\text { Marker } \\
\text { interval }\end{array}$} & \multicolumn{4}{|c|}{ Additive main effect $(\%)$} \\
\hline & & $\mathrm{MP}^{\dagger}$ & $\mathrm{MP} \mid \mathrm{SW}^{+}$ & MP $\mid \mathrm{NS}$ & $\mathrm{MP} \mid \mathrm{PH}$ \\
\hline 1 & HMR292/MR327c & & $0.409^{* *}$ & & \\
\hline 1 & HMR293/HMR274b & & & & $-0.219 * *$ \\
\hline 7 & MD20/MR166 & $0.283^{* *}$ & $0.310^{* *}$ & $0.240^{* *}$ & $0.261 * *$ \\
\hline 8 & HMR388/HMR577 & $-0.492 * *$ & $-0.500^{* *}$ & $-0.515^{* *}$ & $-0.521 * *$ \\
\hline 9 & HMR612a/HMR612b & & $-0.215^{* *}$ & & \\
\hline 9 & HMR284b/HMR284a & & & & $-0.242^{* *}$ \\
\hline 10 & HMR643b/HMR615b & $-0.230^{*}$ & $-0.237^{*}$ & $0.219 *$ & \\
\hline 13 & HMR61/HMR314b & $0.243 * *$ & $0.312 * *$ & $0.241 * *$ & $0.218^{* *}$ \\
\hline $14-2$ & HMR399a/MR155 & $-0.174^{* *}$ & & & \\
\hline 15 & MR97/MR54 & & $-0.208^{* *}$ & & \\
\hline 16 & HMR563/HMR373 & $-0.182^{* *}$ & & & $-0.171^{*}$ \\
\hline 18 & HMR335a/HMR588 & $0.159^{* *}$ & & & \\
\hline
\end{tabular}

Meal protein conditioned on three yield related traits (Table 5) illustrated that QTLs on LG7, 8, 10 and $13 \mathrm{kept}$ all similar additive effects but one on LG10 under MP|PH, and all other three loci failed to present significant effects except one on LG16 under MP|PH. Five additional QTLs presented on new genomic regions under MP|SW and MP|PH respectively. The genetic influence for meal protein caused by SW, NS and PH could be accounted for about 75, 30 and $60 \%$ of total additive effects.

Under conditional mapping for seed protein given three yield related traits, most of the epistatic pairs of loci lost significant effects, while a number of conditional ones with new combinations between loci did appear (Table 6). The epistatic effects for meal protein ( Table 7 ) showed less influence by yield related traits. Of six pairs of unconditional loci, three retained 
similar effects, the one on LG2/LG10 disappeared for PM|NS. Another three pairs were not detected and several new pairs occurred.

Table 6. Epistatic effects ( $a a)$ of QTLs for seed protein content (\%) and conditioned on three yield related traits

\begin{tabular}{|c|c|c|c|c|c|c|c|}
\hline LG & $\begin{array}{l}\text { Nearest } \\
\text { marker }\end{array}$ & LG & $\begin{array}{l}\text { Nearest } \\
\text { marker }\end{array}$ & $\mathrm{SP}^{\dagger}$ & $\mathrm{SP} \mid \mathrm{SW}^{\dagger}$ & $\mathrm{SP} \mid \mathrm{NS}$ & $\mathrm{SP} \mid \mathrm{PH}$ \\
\hline 1 & HMR292 & $14-1$ & HMR416b & $0.164 * *$ & & $0.161 * *$ & \\
\hline 1 & HMR338 & 17 & HMR332 & & & & $-0.169 * *$ \\
\hline 1 & HMR338 & 12 & HMR353b & & $-0.215^{* *}$ & $-0.137 * *$ & $-0.246^{* *}$ \\
\hline 1 & HMR327c & 3 & HMR085 & & $0.263^{* *}$ & $0.153^{* *}$ & \\
\hline 2 & HMR299b & 9 & HMR $311 b$ & & & & $0.247 * *$ \\
\hline 2 & HMR299d & 10 & HMR643b & $0.204 *$ & & & \\
\hline 2 & HMR299b & 15 & HMR354 & & & $-0.208 * *$ & \\
\hline 3 & MR132 & 7 & MD20 & & & $-0.151 * *$ & \\
\hline 3 & MR3 & 11 & HMR295b & & & & $0.141^{* *}$ \\
\hline 4 & MD2.2 & 12 & HMR353b & $0.160 *$ & $0.208 * *$ & & \\
\hline 5 & MR14 & 17 & MR127 & & & & \\
\hline 7 & MR133.2 & $14-2$ & HMR399a & $0.150 * *$ & & & \\
\hline 9 & HMR310 & $11-1$ & HMR314a & & & $0.186^{* *}$ & \\
\hline $11-1$ & HMR314a & 19 & HMR615a & & & $0.154 * *$ & \\
\hline 12 & HMR353b & 13 & MR61 & $-0.200^{* *}$ & $-0.129 * *$ & & \\
\hline 12 & HMR299c & 15 & MR97 & $-0.220 *$ & & & \\
\hline
\end{tabular}

$\dagger$ Abbreviations are the same as in table 4.

Table 7. Epistatic effects ( $a a)$ of QTLs for meal protein content (\%) and conditioned on three yield related traits

\begin{tabular}{|c|c|c|c|c|c|c|c|}
\hline LG & $\begin{array}{l}\text { Nearest } \\
\text { marker }\end{array}$ & LG & $\begin{array}{l}\text { Nearest } \\
\text { marker }\end{array}$ & $\mathrm{MP}^{\dagger}$ & $\mathrm{MP} \mid \mathrm{SW}^{\dagger}$ & $\mathrm{MP} \mid \mathrm{NS}$ & $\mathrm{MP} \mid \mathrm{PH}$ \\
\hline 1 & HMR344a & 3 & HMR440 & & $0.325^{* *}$ & $0.294^{* *}$ & \\
\hline 1 & HMR274b & 9 & HMR573 & $-0.271^{* *}$ & $-0.241^{* *}$ & $-0.228^{* *}$ & $-0.219^{* *}$ \\
\hline 1 & HMR292 & 17 & HMR332 & $-0.229 * *$ & & & \\
\hline 2 & HMR299d & 3 & MR123 & & & & $-0.280^{* *}$ \\
\hline 2 & HMR066 & 7 & MD20 & & & & $0.212^{* *}$ \\
\hline 2 & HMR066 & 10 & HMR643b & $0.210^{* *}$ & $0.280^{* *}$ & & $0.253^{* *}$ \\
\hline 3 & HMR085 & 7 & MR133.2 & & & $-0.239^{* *}$ & \\
\hline 3 & MR3 & 19 & HMR327b & $-0.243^{* *}$ & & & \\
\hline 4 & HMR637 & 7 & HMR133.2 & & $-0.235^{* *}$ & $-0.229 * *$ & \\
\hline 9 & HMR363b & $11-2$ & HMR295b & & & & $0.204 *$ \\
\hline 9 & MR230.1 & 13 & MR197.2 & $0.277 * *$ & & & \\
\hline $11-1$ & MR228 & 17 & HMR344b & & & $-0.266^{* *}$ & $-0.174 *$ \\
\hline $11-1$ & MR228 & 19 & HMR615a & $0.212^{* *}$ & $0.240 * *$ & $0.232 * *$ & $0.293 * *$ \\
\hline 12 & HMR353b & 13 & HMR337 & & $-0.220 * *$ & & \\
\hline
\end{tabular}

$\dagger, \ddagger$ Abbreviations are the same as in table 5 . 


\subsubsection{Discussion}

The present study based on conditional mapping analysis between oil, protein and three yield related traits showed principally in agreement with correlation coefficients. The results provide genetic explanations based on QTLs. First, it was found that the genetic relationships between oil and three yield related traits is relatively consistent with that for seed protein content. This might be due to the larger genetic overlapping of oil and protein in seed (Thesis 3.2 ). Furthermore oil and seed protein were affected by seed number and plant height through both additive and epistatic loci, which was supported by the observations of larger changes of additive loci or magnitude of effects when these two traits were conditioned, respectively. Seven and eight of nine unconditional epistatic pairs of loci for oil and all the pairs for seed protein but one ( LG1/LG14-1 for SP|NS ) lost significant effects, while 5 of 7 and all the conditional pairs for oil, 6 of 7 and all for seed protein displayed with new allele combinations when NS and PH were conditioned, respectively. Second, the genetic relationships between oil, seed protein and thousand seed weight were small and mainly effected by epistatic loci ( 7 of 8 oil and 4 of 5 seed protein loci kept similar additive effects under oil|SW and SP|SW respectively, while 7 of 9 and 4 of 6 pairs of loci lost significant epistatic effects and only one and two conditional pairs presented with new allele combinations under oil|SW and SP|SW respectively). Third, for the meal protein, the genetic influence from three yield related traits was mainly on the loci with additive effects, epistatic loci may play minor function. Thousand seed weight presented closer relationship than seeds per silique and plant height ( three conditional loci occurred on new genomic regions with relative larger effects and three unconditional loci lost significant effects, these resulted in larger changes of genetic basis than that under MP|NS and MP|PH ). Relatively small changes of epistatic effects on meal protein when three yield related traits were conditioned, respectively, illustrated that genetic influence caused by loci with digenic interaction from these traits for meal protein was less important.

Our results revealed several types of QTLs for the relationships between oil, protein and three yield related traits. 1 ) QTLs with either pleitropic effect or gene cluster. For instance, QTLs on LG1 were detected for oil, seed protein ( Table 2 and 4) and all three yield related traits as well (Table 8 ). Conditional mapping results confirmed their influence one another (except oil with SW ), so selection based on flanking markers might improve oil content with increased seed number and plant hight. QTLs on LG7, 11-1, 14-1 and 19 showed also positive linkage for oil with seed number or with plant height. These might be one explanation for significant positive correlation between oil and plant height and between oil and seed number 
Table 8. QTL positions and additive main effects of three yield related traits

\begin{tabular}{clllll}
\hline LG & Marker interval & SW $(\mathrm{g})^{\dagger}$ & LG & Marker interval & PH $(\mathrm{cm})$ \\
\hline 1 & HMR292/HMR327c & $0.121^{* *}$ & 1 & HMR292/HMR327 & $3.16^{* *}$ \\
1 & HMR295c/HMR293 & $0.125^{* *}$ & 3 & HMR449a/MR12 & $3.28^{* *}$ \\
7 & MD20/MR166 & $0.152^{* *}$ & 5 & HMR327a/MD21 & $1.55^{* *}$ \\
9 & HMR612a/ HMR612b & $-0.182^{* *}$ & 7 & MD20/ HMR166 & $1.67^{* *}$ \\
& & & 9 & HMR612b/MR230.1 & $-3.73^{* *}$ \\
& & & $11-1$ & MR148/HMR407a & $-1.42^{*}$ \\
\hline LG & Marker interval & NS (n) & 13 & MR203.2/HMR321 & $1.68^{* *}$ \\
\hline 1 & HMR292/HMR327 & $0.808^{* *}$ & $14-1$ & HMR403b/MR229 & $2.84^{* *}$ \\
3 & HMR327d/HMR085 & $0.939^{* *}$ & 16 & HMR348/MR133 & $4.64^{* *}$ \\
7 & HMR300c/MR133.2 & $-0.754^{* *}$ & 16 & HMR563/HMR373 & $-2.07^{* *}$ \\
$11-1$ & MR148/HMR407a & $-0.513^{*}$ & 17 & HMR349/MR127 & $-2.02^{* *}$ \\
& & & 19 & HMR643a/ HMR615a & $4.43^{* *}$ \\
\hline$\dagger$ & & & & &
\end{tabular}

${ }^{\dagger}$ Abbreviations are same as in Table 1

which coincide with the early observation (Olsson 1960). 2 ) QTLs independent to all three yield related traits. Like QTLs on LG12 and LG18 for oil and seed protein or QTLs on LG8 and LG13 ( except seed protein with plant height ) for seed and meal protein. Selection using flanking markers for quality improvement probably without changes for yield related traits evaluated in this study. 3 ) Some QTLs showed genetic relationship with yield related traits, while no QTLs could be traced for specific traits like oil QTLs on LG9 ( showed relationship with seed number) and LG11-1 (with seed size). The genetic relationships and influence directions between two kinds of trait were not clear under such situation therefore careful should be taken for practical breeding purpose.

To sum up, the results from this study revealed the genetic mechanisms for the relationships between oil or seed protein and seed number or plant height, and also provided the explanation for larger genetic correlation between meal protein and seed size. Marker based selection for combined increase of oil content and seed number is possible. Four of the 8 QTLs for oil content were also QTLs for plant height. This could be caused by pleiotropy, genetic linkage or by environmental influence since the lines with higher plants have a competitive advantage for absorbing sunlight to produce more photosynthetic products. The genetic correlation between oil content and seed size was insignificant, which is supported by the conditional mapping results. However this conclusion is not in agreement with the early observations (Olsson 1960; Riemann 1964). In conclusion, present study demonstrated the possible joint genetic improvement for oil, protein and yield related traits on individual gene loci, which is of interest for practical rapeseed breeding. 


\subsubsection{Summary}

Simultaneous increase of seed oil and seed yield normally is difficult in practical breeding in Brassica napus. The genetic relationships between oil, protein content and yield related traits on individual gene loci remain poorly understood. Present mapping study combined the statistical procedures for analyzing conditional genetic effects and the QTL mapping method, using a linkage map of 125 SSR marker loci and the doubled haploid (DH) population of 282 lines from Sollux/Gaoyou ( European/Chinese) grown under 4 environments, 2 in Germany and 2 in China. Conditional mapping results revealed that oil and seed protein were influenced by seed number and plant height through both additive and epistatic effects of loci. The genetic relationships between oil, seed protein and seed size were small. Meal protein showed closer relationship with seed size than seed number or plant height and mainly influenced by the loci with additive effects. The results disclosed several types of QTLs for the relationships between oil, protein and three yield related traits. 1) QTLs with either pleitropic effect or gene cluster 2 ) QTLs independent to all three yield related traits and 3 ) QTLs showed genetic relationship with some yield related traits, while no QTLs could be traced for specific traits. The results of this study is practically interesting in rapeseed breeding.

Key words Brassica napus L. · Oil and protein content · Yield related traits · Conditional QTL mapping $\cdot$ Epistasis

\subsubsection{References}

Cheung WY, Landry BS (1998) Molecular mapping of seed quality traits in Brassica juncea L. Czern. and Coss. Proc. Int. Symp on Brassica. Acta Hort. 459: 139-147

Ecke W, Uzunova M, Weißleder K (1995) Mapping the genome of rapeseed (Brassica napus L.). II.Localization of genes controlling erucic acid systhesis and seed oil content. Theor. Appl. Genet. 91: 972-977

Gül MK (2002) QTL x Kartierung und Analyse von QTL x Stickstoff Interaktionen beim Winterraps (Brassica napus L.) Ph.D thesis, Fachbereich Agtarwissenschaften der Georg-August-Universität, Göttingen

Leon J and Becker HC ( 1995 ) Genetics of physiological potentials for yield components of annual oil and protein crops. Advances in Plant Breeding 17: 53-90

Mendham NJ, Shipway PA and Scott RK (1981a) The effects of delayed sowing and weather on growth, development and yield of winter oil-seed rape (Brassica napus). Journal of Agricultural Science, Cambridge 96, 389-416 
Mendham NJ, Shipway PA and Scott RK (1981b) The effects of seed size, autumn nitrogen and plant population density on the response to delayed sowing in winter oil-seed rape (Brassica napus). Journal of Agricultural Science, Cambridge 96: 417-428

Mendham NJ and Salisbury PA (1995) Crop development, Growth and Yield. In Kimber D and McGregor DI (eds) Brassica Oilseeds: Production and Utilization. printed and bound in the UK at the University Press, Cambridge, pp: 11-64

Olsson G (1960) Some relationships between number of seeds per pod, seed size and oil content and the effects of selection for these characters in Brassica and Sinapis. Hereditas 46: 29-70

Reinhardt TC (1992) Entwicklung und Anwendung von Nah-In-frarot-spektroskopischen Methoden für die Bestimmung von Öl-Protein-, Glucosinolate-, Feuchte- und Fettsäure-Gehalten in intaker Rapssaat. Dissertation, Universität Göttingen, Cuvillier Verlag Göttingen

Riemann KH (1964) Untersuchungen zur Variabilität verschiedener Merkmale beim Raps und ihre Auswirkungen auf züchterische Maßnahmen. II. Mitteilung. Erkenntnisse zur Variabilität und korrelativen Bindung von Ertragsfaktoren und ihre Bedeutung für die Rapszüchtung. Züchter 34: 156-167

Sharma Ramavtar, Mohapatra T, Mukherjee AK, Krishanpal, Sharma RP (1999) Molecular markers for seed oil content in Indian mustard. Journal of plant biochemistry and biotechnology 8: 99-102

Tayo TO and Morgan DG (1975) Quantitative analysis of the growth, development and distribution of flowers and pods in oil-seed rape (Brassica napus L). Journal of Agricultural Science, Cambridge 85, 103-110

Thesis 3.1 Construction of a linkage map and identification of QTLs for oil content (manuscript 1 )

Thesis 3.2 QTLs for protein content and their relationships with oil content (manuscript 2 )

Thesis 3.3 Relationships between oil and protein content with developmental stages (manuscript 3 )

Thurling N and Vijendra Das LD (1977) Variation in the pre-anthesis development of spring rape (Brassica napus L.). Australian Journal of Agricultural Research 28: 597-607

Wang DL, Zhu J, Li ZK, Paterson AH (1999) Mapping of QTL with epistatic effects and QTL X environment interactions by mixed model approaches. Theor. Appl. Genet. 99: 1255-1264

Zhu J (1992) Mixed model approaches for estimating genetic variances and covariance. J. Biomath 7: 1-11

Zhu J (1995) Analysis of conditional genetic effects and variance components in developmental genetics.

Genetics 141: 1633-1639 


\subsection{QTLs for yield components and their relationships with developmental stages}

\subsubsection{Introduction}

The yield of rapeseed is the result of a number of complex growth and developmental processes. Seed yield per unit area can be subdivided into four major components, plant population density, the number of siliques per plant, the number of seeds per silique and individual seed weight ( Diepenbrock and Grosse 1995 ). Optimum plant densities much depend on environments and a large range of plant densities can result in a plateau of nearly equal seed yields (Mendham et al. 1981a; Scarisbrick et al. 1982; Ogilvy 1984). The number of siliques per plant is under environmental influence and largely varied with plant densities and fertility levels, the heritability is, therefore, low and selection for high number of siliques per plant did not show any selection response ( Olsson 1960; Leon and Becker 1995 ). Number of seeds per silique and seed weight are much less influenced by environment than the number of siliques per plant ( Olsson 1960; Diepenbrock and Grosse 1995 ). The observed high values of $\sigma^{2}$ gca $/ \sigma^{2}$ sca ratios indicated a predominance of additive genetic effects for these two traits ( Lefort and Dattee 1985a; 1985b). Silique length was found to show a strong positive correlation with seeds per silique (Rives 1957), and was therefore suggested for indirect selection for seeds per silique, while Riemann (1964) did not observe such significant relationship. The sequence of formation of the yield components and their timing in relation to environment (mainly temperature, radiation and water supply), which cause the variation of plant developmental stages, are the keys to understand how crop yields vary.

Recent advances in molecular-marker technologies have led to map QTLs for yield and yield components in many crops as rice ( Li et al. 1997; Xiao et al. 1996; Xing 2002 ); tomato (Eshed and Zamir 1995); maize (Veldboom and Lee 1996); soybean (Mansur et al. 1996 ) and barley ( Bezant et al. 1997). However, mapping studies for seed yield and yield components in Brassica species are limited. Butruille et al. (1999) detected two QTLs for seed yield and several QTLs for thousand seed weight using different populations in Brassica napus but no genetic linked QTL was found between two traits. Upadhyay et al.(1996) mapped QTL for seeds per silique by RFLP markers in Brassica juncea. However, we do not have sufficient knowledge for QTLs responsible for seed size, seeds per silique and silique length and their 
genetic relationships with developmental stages. The goal of this study was to identify the QTLs controlling thousand seed weight, seeds per silique and silique length by microsatellite markers using lager number of $\mathrm{DH}$ population derived from $\mathrm{F}_{1}$ of European and Chinese materials; to analyze the genetic respondence to developmental stages of thousand seed weight and seeds per silique. The results might be interest for yield improvement in B. napus.

\subsubsection{Material and Methods}

\section{Population and SSR map}

A doubled haploid (DH) population consisting of 282 lines was established by microspore culture from a cross between 'Sollux' and 'Gaoyou' (Thesis 3.1). 'Sollux' is an old variety from Germany and Gaoyou is an old landrace from China. Parental lines largely differed in many morphological traits like flowering time, plant type and yield components. Based on the DH population, a linkage map comprising 125 Microsatellite markers (SSRs) and covering a total length of $1196 \mathrm{cM}$ was used for mapping ( Thesis 3.1).

\section{Data collection}

As described previously ( Thesis 3.1), four experiments were conducted with two locations in China: Xian and Hangzhou, and two locations in Göttingen of Germany: Reinshof and Weende in $2000 / 2001$. The field experiments were in a randomized complete block design with two replications. The seeds were sown in two rows for each plot, $2.5 \mathrm{~m}$ in length with $0.33 \mathrm{~m}$ between rows and $0.12 \mathrm{~m}$ between plants within rows in Göttingen, and $2.5 \mathrm{~m}, 0.33 \mathrm{~m}$ and 0.15 $m$ respectively in China.

At the maturity stage, five representative plants from the middle of each plot were sampled for evaluating thousand seed weight (SW), number of seeds per silique (NS) and silique length (SL). The latter two traits were measured based on 10 siliques, 2 from each plant, taken from the low part of main inflorescence. Thousand seed weight was weighed using bulk harvested seeds from terminal raceme and the two uppermost primary branches. Developmental stages were observed, including beginning of flowering (50\% plants showed first flowers), end of flowering (50\% plants had no flowers and rest one flower left in maximum) and maturity (siliques changed to be yellow ). The traits analyzed were days from sowing to beginning of flower (DTF), days from sowing to maturity (DTM), Flowering duration ( days from flowering to the end of flowering, DFE), grain filling period (days from end of flowering to maturity, DEM) and days from flowering to maturity (DFM) were then calculated. 


\section{Data analysis}

QTLs with additive and additive $\mathrm{x}$ additive epistatic effects as well as their environmental interaction effects for three evaluated traits were mapped by QTLMapper version 1.0 (Wang et al. 1999). The conditional phenotypic value $\left(y_{h k(T \mid T 2)}\right)$ was obtained by the mixed model approaches for the conditional analysis of quantitative traits (Zhu 1995), where T1|T2 denotes trait 1 conditioned on trait $2(\mathrm{SW} \mid \mathrm{DTF}=$ thousand seed weight conditioned on days to flowering, $\mathrm{NS} \mid \mathrm{DTF}=$ seeds per silique conditioned on days to flowering, and so on ). Conditional QTL mapping used same program QTLMapper version 1.0 ( Wang et al. 1999 ). Results of conditional mapping present the effects of QTLs for trait 1 under the condition of no variation for trait 2. Comparison between unconditional ( mapping for trait 1 ) and conditional ( mapping for trair 1 conditioned on trait 2 ) mapping results, it is possible to find the genetic relationship between two traits on individual gene loci.

The models, explanations of all the conditional and unconditional parameters and detailed mapping procedure were described previously (Wang et al. 1999; Thesis 3.1 and 3.2). The likelihood -ratio threshold was chosen at $\alpha=0.005$ for claiming putative QTL and genetic effects.

\subsubsection{Results}

\section{Phenotypic variation}

Phenotypic distributions of thousand seed weight, seeds per silique and silique length, and their relationships in between at separate environment showed on Fig1. The relationships among pairs of these traits were significant in low correlation coefficients or insignificantly correlated. Genetic correlations further confirmed their small genetic relationships one another $\left(\mathrm{r}_{\mathrm{NS} / \mathrm{SW}}=\right.$ $\left.0.369^{* *}, \mathrm{r}_{\mathrm{NS} / \mathrm{SL}}=0.292^{* *}, \mathrm{r}_{\mathrm{SW} / \mathrm{SL}}=0.343^{* *}, \quad \alpha=0.01\right)$. Sollux showed larger seed size and longer silique length than Gaoyou in locations of Germany, but similar at test site in China; seeds per silique between parents showed no big difference in German experiments but Gaoyou was more seeds per silique than Sollux in locations of China. Large variation and transgressive segregation were observed for all three traits in each environment.

\section{QTLs and epistasis for thousand seed weight, seeds per silique and silique length}

In total, 7 QTLs with additive main effects $(a)$ and/or additive by environment interaction effects ( $a$ ) were detected for thousand seed weight ( Table1 ). Of these, 2 QTLs showed only $a$ effects, 3 showed only significant $a e$ effects and 2 exhibited both $a$ and ae effects. Results 


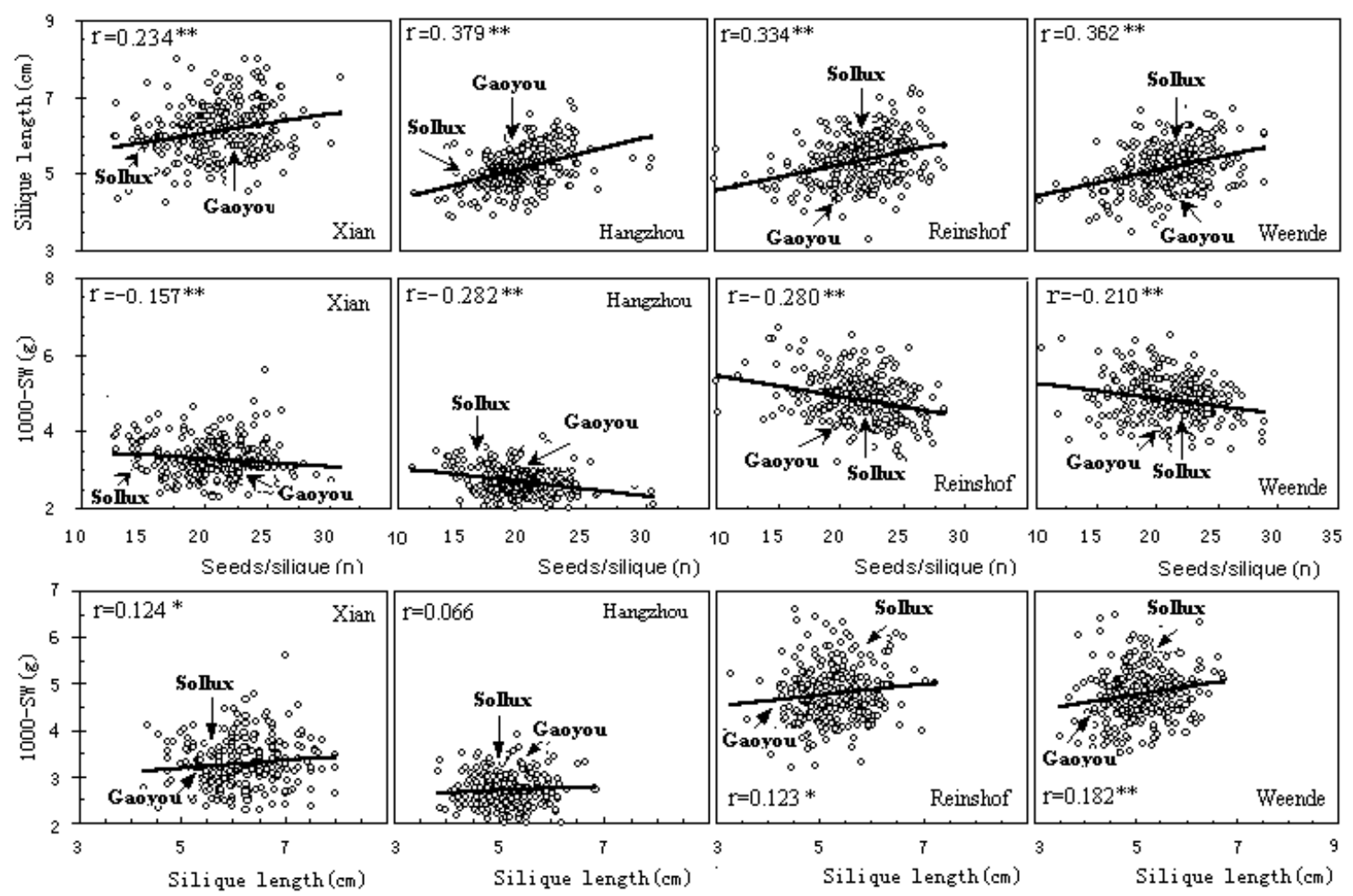

Fig 1.Distributions in the DH population for 1000 -seed weight, seeds per silique and silique length in four environments and their correlation in between. *** Significant at the 0.05 and 0.01 probability levels, respectively. Mean values of two parents are indicated by arrows.

Table 1. Estimated additive $(a)$ and additive $\mathrm{x}$ environment interaction ( $a$ e) effects of QTLs for 1000-seed weight $(\mathrm{g})$

\begin{tabular}{lllllllc}
\hline LG & Marker interval & $\begin{array}{l}\text { Position } \\
(\mathrm{cM})\end{array}$ & $a^{\dagger}$ & $\begin{array}{l}a e \text { in } \\
\text { Xian }\end{array}$ & $\begin{array}{l}a e \text { in } \\
\text { Hangzhou }\end{array}$ & $\begin{array}{l}a e \text { in } \\
\text { Reinshof }\end{array}$ & $\begin{array}{c}a e \text { in } \\
\text { Weende }\end{array}$ \\
\hline 1 & HMR292/HMR327c & 2.0 & $0.121^{* *}$ & $-0.087^{* *}$ & $-0.157^{* *}$ & $0.142^{* *}$ & $0.117^{* *}$ \\
1 & HMR295c & 0.0 & $0.125^{* *}$ & & & & \\
3 & MR123 & 0.0 & & $-0.058^{*}$ & & $0.076^{* *}$ & \\
7 & MD20/MR166 & 2.0 & $0.152^{* *}$ & $-0.073^{* *}$ & $-0.071^{* *}$ & & $0.100^{* *}$ \\
8 & HMR388 & 0.0 & & $-0.071^{* *}$ & $-0.068^{* *}$ & & $0.109^{* *}$ \\
9 & HMR612a/HMR612b & 6.0 & $-0.182^{* *}$ & & & & \\
12 & GMR132/HMR399b & 6.0 & & $-0.096^{* *}$ & $-0.091^{* *}$ & & $0.103^{* *}$ \\
\hline
\end{tabular}

$*, * *$ indicate the significance level at 0.005 and 0.001 respectively to declare the putative QTL positions and genetic effects. ${ }^{\top}$ Distance to the first marker of the indicated interval. ${ }^{*}$ The QTL effect, is the phenotypic effect due to substitution of an 'Gaoyou' allele by an allele of 'Sollux'.

Table 2. Estimated epistatic ( $a a)$ and epistasis X environment interaction ( $a a e$ ) effects of QTLs for 1000 -seed weight ( $\mathrm{g}$ )

\begin{tabular}{clllccccc}
\hline LG & Nearest marker & LG & Nearest marker & $a a^{\dagger}$ & $\begin{array}{c}\text { aae in } \\
\text { Xian }\end{array}$ & $\begin{array}{c}\text { aae in } \\
\text { Hangzhou }\end{array}$ & $\begin{array}{c}\text { aae in } \\
\text { Reinshof }\end{array}$ & $\begin{array}{c}\text { aae in } \\
\text { Weende }\end{array}$ \\
\hline 2 & HMR364a & 10 & HMR625 & & & & $0.169^{* *}$ & \\
2 & HMR364a & $11-2$ & HMR295b & $-0.078^{* *}$ & & & & \\
8 & HMR388 & 17 & HMR318 & $0.070^{*}$ & $-0.081^{* *}$ & $-0.095^{* *}$ & $0.192^{* *}$ & $0.062^{*}$ \\
9 & HMR363b & 19 & HMR615a & & & & & $0.126^{* *}$ \\
\hline
\end{tabular}

Sing of epistatic effect: negative indicates that recombinant alleles from two parents and positive means that parental digenic genotypes increase phenotypic values, respectively. 
indicted that of 4 QTLs with additive main effects, positive alleles were three from Sollux and one from Gaoyou. Together, they sum up to $1.16 \mathrm{~g}$ of 1000 -seed weight for homozygous genotypes and explained about $40 \%$ of the mean phenotypic variation observed in the DH population (difference between lines with highest and lowest mean values, data not shown). QTLs with ae interaction were detected in 5 genomic regions and all the Gaoyou and Sollux alleles showed positive effects for locations in China and Germany, respectively. Additive $\mathrm{x}$ additive epistatic QTLs accounted for small part of genetic basis for thousand seed weight, two pairs of loci with minor $a a$ or combined aae effects and additional two pairs of aae loci were detected.

Six QTLs with $a$ and/or $a e$ effects and seven pairs of digenic epistatic loci with $a a$ and/or aae affecting seeds per silique were identified ( Table3 and 4 ). Four additive main and six pairs of epistatic main QTLs sum up to increase 6 and 7 seeds per silique for homozygous genotypes. Of four additive main QTLs, the favorable alleles were two from Sollux and two from Gaoyou. Of six pairs of epistatic main loci, recombinant type of alleles (negative value of effects) on three pairs and parental digenic genotypes on another three pairs of loci ( positive value of effects) were resulted in increased seeds per silique. QTLs with ae effects for seeds per silique were clearly less important, while pairs of loci with aae effects were detected more than that for thousand seed weight. All the aae loci for seeds per silique displayed favorable combinations between alleles in opposite way at locations in China and Germany.

Table 3. Estimated additive ( $a$ ) and additive $\mathrm{X}$ environment interaction ( $a$ e) effects of QTLs for seeds per silique $(\mathrm{n})$

\begin{tabular}{llccccc}
\hline LG & Marker interval & $\begin{array}{c}\text { Position } \\
(\mathrm{cM})\end{array}$ & $a$ & $\begin{array}{c}a e \text { in } \\
\text { Xian }\end{array}$ & $\begin{array}{c}a e \text { in } \\
\text { Hangzhou }\end{array}$ & $\begin{array}{l}a e \text { in } \\
\text { Reinshof }\end{array}$ \\
\hline 1 & HMR292/HMR327 & 0.0 & $0.808^{* *}$ & & & \\
1 & HMR274b/HMR430 & 6.0 & & $0.545^{* *}$ & & \\
3 & HMR327d/HMR085 & 14.0 & $0.939^{* *}$ & & & \\
7 & HMR300c/MR133.2 & 4.0 & $-0.754^{* *}$ & $-0.566^{* *}$ & $0.582^{* *}$ & \\
$11-1$ & MR148/HMR407a & 12.0 & $-0.513^{* *}$ & & & \\
13 & HMR363c/MR140 & 0.0 & & & $-0.561^{* *}$ & $0.752^{* *}$ \\
\hline
\end{tabular}

Table 4. Estimated epistatic ( $a a)$ and epistasis $\mathbf{X}$ environment interaction ( aae ) effects of QTLs for seeds per silique $(\mathrm{n})$

\begin{tabular}{|c|c|c|c|c|c|c|c|c|}
\hline LG & Nearest marker & LG & Nearest marker & $a a$ & $\begin{array}{l}\text { aae in } \\
\text { Xian }\end{array}$ & $\begin{array}{l}\text { aae in } \\
\text { Hangzhou }\end{array}$ & $\begin{array}{l}\text { aae in } \\
\text { Reinshof }\end{array}$ & $\begin{array}{l}\text { aae in } \\
\text { Weende }\end{array}$ \\
\hline 3 & HMR440 & 15 & HMR354 & $0.670 * *$ & & & & \\
\hline 3 & MR123 & $11-2$ & HMR295b & $-0.630 * *$ & & & & \\
\hline 7 & MR133.2 & $11-1$ & HMR314a & $0.647 * *$ & & $-0.645^{* *}$ & $0.724 * *$ & $0.547 * *$ \\
\hline 9 & HMR311b & $11-2$ & HMR295a & $-0.478 * *$ & $-0.510 *$ & & & \\
\hline $11-1$ & HMR314a & 12 & MR132 & $0.645^{* *}$ & & $-0.667 * *$ & $0.823 * *$ & \\
\hline $11-1$ & HMR335b & 13 & MR61 & $-0.746^{* *}$ & & & & \\
\hline $14-1$ & MR155 & 17 & MR127 & & $-1.310^{* *}$ & $-1.235^{* *}$ & $0.475 * *$ & \\
\hline
\end{tabular}


Table 5. Estimated additive ( $a$ ) and epistatic ( $a a)$ main effects of QTLs for silique length $(\mathrm{cm})$

\begin{tabular}{llrllllc}
\hline LG & Marker interval & $a$ effect & LG & Marker interval & LG & Marker interval & $a a$ effect \\
\hline 1 & HMR407b/HMR292 & $0.108^{* *}$ & 1 & HMR274b/HMR430 & 8 & HMR613 & $0.074^{* *}$ \\
1 & HMR274b/HMR430 & $-0.079^{* *}$ & 1 & HMR274b/HMR430 & 13 & HMR321/HMR067 & $-0.063^{*}$ \\
2 & HMR066/HMR087 & $0.197^{* *}$ & 3 & MR12/MR3 & 19 & HMR327b & $0.057^{* *}$ \\
4 & HMR637/MD2.2 & $-0.069^{* *}$ & $11-1$ & MR228/HMR314a & 16 & HMR348/MR133 & $0.074^{* *}$ \\
7 & HMR300c/MR133.2 & $-0.127^{* *}$ & $11-1$ & MR228/HMR314a & 19 & HMR615a & $-0.067^{* *}$ \\
9 & HMR363b/ HMR612a & $-0.225^{* *}$ & $14-1$ & HMR403b/MR229 & 16 & HMR563/HMR373 & $-0.108^{* *}$ \\
$11-1$ & MR228/HMR314a & $0.169^{* *}$ & & & & & \\
12 & HMR353a/HMR353b & $0.115^{* *}$ & & & & & \\
17 & HMR438b/HMR344b & $-0.083^{* *}$ & & & & & \\
\hline
\end{tabular}

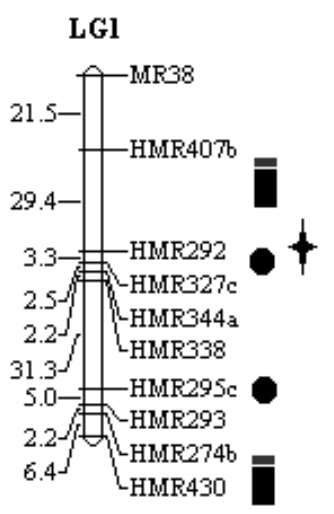

LG7

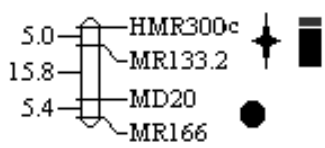

LG11-1

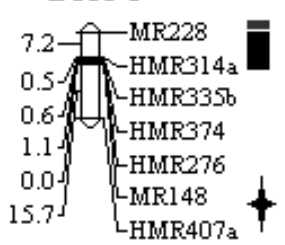

Main effect QTL affecting thousand seed weight

Main effect QTL affecting seeds per silique

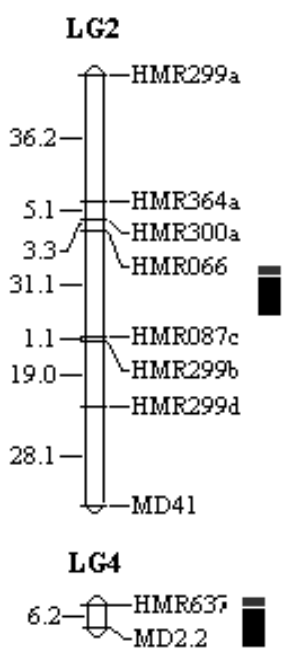

LG17

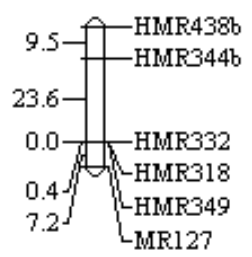

LG3

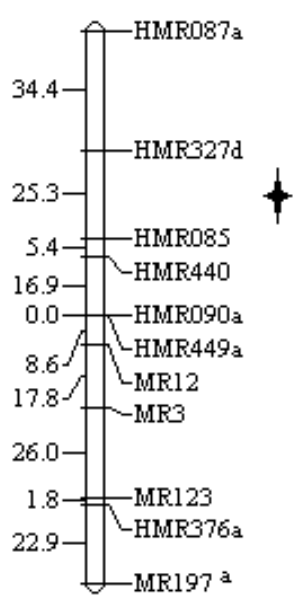

LG12

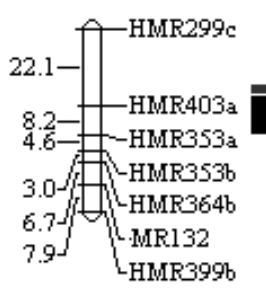

LG9

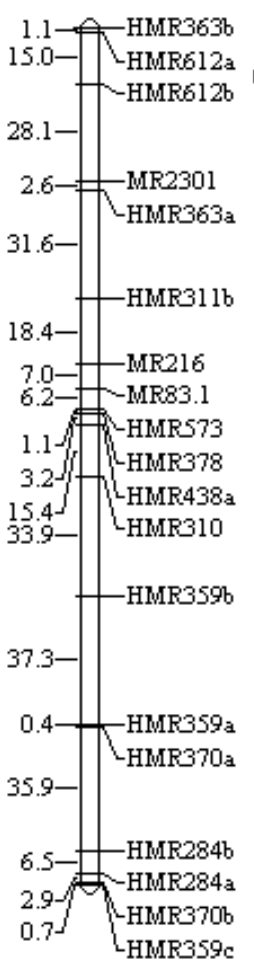

Main effect QTL affecting silique length

Fig 2. Genomic locations for QTLs with additive-main effects on thousand seed weight, seeds per silique and silique length.

Nine QTLs with main effects and six pairs of loci with epistatic effects were detected for silique length ( Table 5). These QTLs explained $70 \%$ and $25 \%$ of the mean phenotypic variation observed in the DH population ( difference between lines with highest and lowest of mean 
values, data not shown) respectively. $Q E$ interaction effects were minor both for additive and epistasis ( ae and aae, data not shown).

Genomic locations of QTLs with additive main effects affecting thousand seed weight, seeds per silique and silique length were presented on Fig 2. QTLs for three traits were found adjacent on linkage group (LG)1 and LG7. Thousand seed weight and silique length were detected on another two closely linked genomic regions, and seeds per silique was found to be linked with silique length on LG11-1. Four QTLs of silique length and one QTL for seeds per silique were separated on different groups.

\section{Genetic relationships between seed size, seed number and developmental stages}

Correlation analysis between three evaluated traits and individual developmental stage (Table 6) showed that seed weight had a weak negative correlation with flowering time, while strong positive correlation with grain filling period. Seeds per silique exhibited positive correlation with flowering time (DTF) and negative correlation with flowering duration (DFE) and grain filling period (DEM). Silique length showed similar magnitude and same directions as seeds per silique with developmental stages, showing consistent relationship with individual stages as seeds per silique.

\begin{tabular}{|c|c|c|c|c|c|c|c|}
\hline \multirow{4}{*}{\multicolumn{2}{|c|}{$\begin{array}{l}\text { Table } 6 \text {. Genetic (upper figure) and } \\
\text { phenotypic (low figure) correlation } \\
\text { between thousand seed weight, } \\
\text { seeds per silique, silique length } \\
\text { and developmental stages }\end{array}$}} & Traits & DTF $^{a}$ & DFE & DEM & DFM & DTM \\
\hline & & \multirow[t]{2}{*}{ 1000-SW } & $-0.282^{* *}$ & 0.074 & $0.875 * *$ & $0.404 * *$ & -0.136 \\
\hline & & & $-0.089-$ & -0.058 & $-0.098^{*}$ & 0.027 & -0.093 \\
\hline & & \multirow[t]{2}{*}{ Seeds/silique } & $0.254^{*}$ & $-0.580 * *$ & $-0.382 * *$ & $-0.585^{* *}$ & $=-0.026$ \\
\hline \multirow{3}{*}{\multicolumn{2}{|c|}{$\begin{array}{l}\text { *,** Significant at the } 0.05 \text {, and } 0.01 \\
\text { probability levels, respectively. } \\
\text { a DTF, DFE, DEM, DFM and DTM: } \\
\text { days to flowerirg, flowering duration, grain }\end{array}$}} & & $0.241 * *$ & $-0.229 * *$ & -0.052 & $-0.251 * *$ & -0.059 \\
\hline & & \multirow[t]{2}{*}{ Silique lengtl } & $0.217^{*}$ & $-0.356 *$ & $-0.421 * *$ & $-0.423 * *$ & 0.031 \\
\hline & & & $0.197^{* *}$ & $-0.264^{* *}$ & 0.004 & $-0.242 * *$ & 0.017 \\
\hline \multicolumn{8}{|c|}{ filling period, days from flowering to maturityand days from sowing to maturity, respectively } \\
\hline \multirow{6}{*}{$\begin{array}{l}\text { Table } 7 \text {. Genetic (above } \\
\text { diagonal) and phenotypic } \\
\text { (below diagonal) } \\
\text { correlations among } \\
\text { developmental stages }\end{array}$} & Traits & DTF $^{\mathrm{a}}$ & DFE & $\mathrm{DEM}$ & \multicolumn{2}{|c|}{ DFM } & DTM \\
\hline & DTF & 1 & $-0.994 * *$ & 0.001 & \multicolumn{2}{|c|}{$-0.762^{* *}$} & $0.910^{* *}$ \\
\hline & $\mathrm{DFE}$ & $-0.934^{* * *}$ & 1 & $0.844^{* * *}$ & \multicolumn{2}{|c|}{0.967 *** } & $-0.711^{\prime * * *}$ \\
\hline & DEM & $-0.189 *$ & $-0.451^{* * *}$ & 1 & \multicolumn{2}{|c|}{$0.582^{*}$} & $0.369^{*}$ \\
\hline & DFM & $-0.924^{* * *}$ & $0.965^{\text {*k }}$ & $0.932^{\text {*** }}$ & \multicolumn{2}{|c|}{1} & $-0.425^{*}$ \\
\hline & DTMI & $0.956^{\text {*k }}$ & $-0.195^{* * *}$ & $0.896^{* * *}$ & \multicolumn{2}{|c|}{$0.563^{*}$} & 1 \\
\hline
\end{tabular}

*,** sigrificant at 0.05 and 0.01 probability levels, respectively.

a Abbreviations for developmental traits are same as in table 6 . 
Genetic and phenotypic correlations among developmental stages ( Table 7 ) showed that flowering duration, period from flowering to maturity and maturity were all highly related with flowering time, and the strong positive correlation between DFE and DFM was observed. However, we found the genetic and phenotypic correlation coefficients on the pairs between flowering duration and grain filling period or both related to maturity showed large difference even in opposite directions, hinting that maturity could be much influenced by environmental factors, for example, temperature and disease resistance, therefore larger random error could happen and the phenotypic correlations might be overestimated.

For the purpose of dissecting the genetic relationships between seed size, seed number and different developmental stages on individual QTL, conditional mapping analysis were further conducted (Table 8 and 9 ). Results showed that both traits were influenced by all the

\begin{tabular}{|c|c|c|c|c|c|c|c|c|}
\hline \multirow{9}{*}{$\begin{array}{l}\text { Table } 8 \text {. Thousand seed } \\
\text { weight (SW) conditioned } \\
\text { on developmental stages } \\
\text { on additive main loci (g) }\end{array}$} & LG & Marker interval & SW & ${ }^{+} \mathrm{SW} \mid \mathrm{DTF}$ & $\mathrm{SW} \mid \mathrm{DFE}$ & SW |DEM & SW $\mid \mathrm{DFM}$ & I SW $\mid \mathrm{DTM}$ \\
\hline & 1 & HMR $292 / H M R 327 c$ & $0.121^{* * *}$ & & & & & \\
\hline & 1 & HMR29 s/ HMR293 & $0.125^{* * *}$ & & $0.112 *$ & & $0.113^{\text {*k }}$ & \\
\hline & 7 & $\mathrm{MD} 20 / \mathrm{MR} 166$ & $0.152^{* * *}$ & $0.127^{* * *}$ & $0.117^{* *}$ & $0.101^{\text {*** }}$ & $0.120^{\text {*k }}$ & $0.123^{* * *}$ \\
\hline & 9 & HMR612a' HMR61 2b & $-0.182^{* * *}$ & $*-0.155^{* * *}$ & $-0.152^{* * *}$ & $-0.161 * *$ & $-0.175^{\text {*k* }}$ & $-0.141 * *$ \\
\hline & 9 & HMR310/ HMR359a & & & & & $-0.052^{\text {*k }}$ & $-0.058^{* * *}$ \\
\hline & $11-2$ & HMR29 5b/ HMR274a & & $-0.097^{* * *}$ & $-0.115^{* * *}$ & & & \\
\hline & $14-1$ & HMR363c/GMR140 & & & & $-0.041^{* * *}$ & & \\
\hline & $14-2$ & HMR399a/MR155 & & & & $0.051^{* *}$ & & \\
\hline
\end{tabular}

\begin{tabular}{|c|c|c|c|c|c|c|c|}
\hline LG & Marker interval & NS & ${ }^{+} \mathrm{NS} \mid \mathrm{DTF}$ & NS IDFE & NS |DEM & NS |DFM & NS |DTM \\
\hline 1 & HMR 292/HMR 327c & $0.808^{* * *}$ & * $0.878^{* * *}$ & $0.701^{\text {**k }}$ & $0.794^{* * *}$ & $0.741^{* * *}$ & $0.837^{\text {*k }}$ \\
\hline 3 & HMR327d/HMR085 & $0.939^{\text {**t }}$ & $0.729^{* * *}$ & & $0.748^{* * *}$ & $0.720^{* * *}$ & $0.569^{* * *}$ \\
\hline 7 & HMR300c/MR133.2 & $-0.754^{\text {*k }}$ & & & & & \\
\hline $11-1$ & MR148/HMR 407a & $-0.513^{\text {*k* }}$ & & & & & \\
\hline 13 & HMR067/MR64 & & & & & & $0.313^{\text {** }}$ \\
\hline 19 & HMR281/HMR327b & & & & $-0.462 *$ & & \\
\hline
\end{tabular}

Table 9. Number of seeds per silique(NS) conditioned on developmental stages on additive main loci (n) ons 
by all developmental stages, while another two loci with Sollux alleles favourable to this trait showed no response to any of developmental stages but one of SN|DFE. Flowering duration and grain filling period expressed larger affection to seeds per silique than other stages, which 3 and 2 of 4 QTLs lost significant effects when these two stages was conditioned, respectively and one conditional QTL was detected under SN|DEM. These were also in general agreement well with the genetic correlations (Table 6).

\subsubsection{Discussion}

Seed yield and yield components of B. napus are complex quantitative traits and selection based on yield components to improve seed yield is difficult because these components are often negatively correlated ( Leon and Becker 1995). Recent QTL mapping studies provide the information of genetic basis for yield and its components in many crops ( Li et al. 1997; Xiao et al. 1996; Xing et al. 2002; Eshed and Zamir 1995; Veldboom and Lee 1996; Mansur et al. 1996 and Bezant et al. 1997 ), which are practical interesting for breeding purpose. Our results, using the DH population integrated European and Chinese rapeseed genetic background, revealed some genetic basis for three evaluated traits, analyzed the genetic relationships between thousand seed weight, seeds per silique and developmental stages on individual gene loci. Several important points were indicated from this study and merit further discussion.

First, QTLs affecting seed size, seed number and silique length often expressed in different patterns. This was supported by the observations that seed weight was controlled by QTLs mainly with additive effect and epistasis was minor, which in principle consistent with previous genetic analysis ( Lefort and Dattee 1985a and 1985b), the additive $\mathrm{X}$ environmental interactions were pronounced and positive alleles presented with same directions between parents and regions ( Europe or China ), which might be due to a ecological adaptation; seeds per silique was determined by QTLs with both additive and epistatic effects and $Q E$ interaction was medium, while for silique length, additive effect of QTLs was found to be more important than epistasis and $Q E$ interaction was very small.

Second, the genomic locations and genetic effects of QTLs for three evaluated traits partly disclosed the genetic relationships one another. It was proved that QTLs with additive main effects for thousand seed weight and seeds per silique occurred on two nearby genomic intervals, showing same and opposite effect directions for each pair, respectively. QTLs associating seeds per silique and silique length were located on the three adjacent genomic regions, two presented effects with same and one with opposite directions. The QTL distribution for thousand seed weight and silique length showed also two combinations of 
alleles on four genomic regions, either linkage of alleles from respective parent or parental genotype combinations on two regions for each, respectively. All the epistatic pairs of loci for three traits were completely different. These results might be explanation for small genetic correlation among three traits observed in this study.

Third, the linked QTLs among three traits provide some useful information for combined or indirect selection in breeding programs. For example, selection based on marker HMR292 of LG1, simultaneous increase of seed weight and seeds per silique is possible. Selection for silique length on marker intervals of HMR300c/MR133.2 on LG7 and HMR407b/HMR292 on LG1 might increase seeds per silique, showing the possible utilization of indirect selection for seeds per silique as suggested previously ( Leon and Becker 1995 ).

Fourth, conditional mapping analysis revealed, to some extent, the genetic response of thousand seed weight and seeds per silique to the variation of physiological developmental stages on individual gene loci. The fact that seed size was more related with days to flowering and grain filling period was in agreement with the genetic correlations (Table 6). The correlation between seed weight and period from flowering to maturity might be caused by significant correlation between DEM and DFM ( Table 7 ). The positive genetic relationship between thousand seed weight and grain filling period is consistent with previous observation ( Hocking and Mason 1993). Two QTLs for seed weight on LG1 linked QTL for days to flowering in opposite direction (Thesis 3.6 ), which may cause the weak negative correlation between these two traits. Both genetic correlation and conditional mapping analysis showed that seeds per silique was largely influenced by flowering period. This might be explained that most of seed abortion were happened in the first few days with continual reduction in a 2-3 week period after flowering ( Pechan and Morgan 1985; Schulz 1987 ) and longer period of flowering result in more energy consumption for developing flowers and subsequently with more aborted seeds in silique. Seeds per silique showed similar genetic correlation with the period from flowering to maturity (DFM) as observed with flowering duration and this might be due to the variation of DFM highly depends on flowering period ( Table 7). More growing days before flowering normally lead to vigorous plants with stronger photosynthesis, therefore increase of seeds per silique is possible. This could be one of explanations for positive genetic correlation between seeds per silique and days to flowering, which is also agreement with the previous observation that later sowing significantly decreased seeds per silique ( Mendham et al. 1981b) because of shorter growing days and small plant status before flowering. Two QTLs for 1000seeds weight on LG7 and LG9 and two QTLs for seeds per silique on LG1 and LG3 were independent of all development stages with one exception for SN|DFE, therefore using flanking 
markers for breeding purpose will not change physiological features. Marker based selection with HMR295c on LG1 for increasing seed size will result in about 2 days ( pleiotropy or close linkage a QTL for flowering time with $a=-1.22$, thesis 3.6 ) earlier flowering and with MR133.2 on LG7 for seeds per silique combine 1.5 days ( pleiotropy or close linkage a QTL for maturity with $a=0.85$, Thesis 3.6 ) earlier maturity than Sollux, respectively when homozygous genotype of loci, which might be also of interest for practical breeding.

\subsubsection{Summary}

Seed size and seed number are two important yield components, and silique length is normally highly correlate with seed number. In this study, we analyzed the genetic basis of these three traits by analysis of QTLs with additive and additive $\mathrm{x}$ additive epistasis as well as their interactions with environments using a population of 282 doubled haploid lines derived from a cross between European and Chinese rapeseed cultivars. When combining the statistical procedures for analyzing conditional genetic effects and the QTL mapping method, the genetic relationships between yield components and plant developmental stages were also analyzed on individual QTL. Measurements for the traits were obtained over 4 environments, 2 in Europe and 2 in China. A linkage map was constructed with 125 microsatellites marker loci.. Mapping results revealed in total, 7, 6 and 9 QTLs with additive main effects and/or additive by environment interaction effects for these three traits and collectively explained about 40, 35 and $70 \%$ of the mean phenotypic variation observed in the DH population by additive main loci, respectively. Digenic epistasis was small for seed size, negligible for silique length but significant for seed number. Significant $Q E$ interaction were detected for seed size, while minor for other two traits. The genomic locations and effects of QTLs for three traits partly disclosed the genetic relationships one another and consistent with the genetic correlations. Some QTLs provide valuable information for combined or indirect selection for yield components in breeding programs. Conditional mapping analysis revealed that QTLs for seed size were more related with flowering time and grain filling period, while QTLs for seed number were more influenced by flowering period.

Key words Brassica napus L. Y Yield components · QTL mapping · Conditional QTL mapping $\cdot$ Digenic interaction $\cdot$ QTL by environment interaction 


\subsubsection{References}

Bezant J, Laurie D, Pratchett N, Chojecki J, Kearsey M (1997) Mapping QTL controlling yield and yield components in a spring barley (Hordeum vulgare L.) cross using marker regression. Molecular Breeding 3: $29-38$

Butruille DV, Guries RP, Osborn TC (1999) Linkage Analysis of Molecular Markers and Quantitative Trait Loci in Populations of Inbred Backcross Lines of Brassica napus L. Genetics 153: 949-964

Diepenbrock W, Grosse F (1995) Rapeseed ( Brassica napus L.): Physiology of physiological potentials for yield components of annual oil and protein crops. Advances in Plant Breeding 17: 21-53

Eshed Y, Zamir D ( 1995 ) Introgression line population of Lycopersicon pennellii in the cultivated tomato enables the identification and fine mapping of yield-associated QTL. Genetics 141: 1147-1162

Hocking PJ, Stapper M (1993 ) Effects of sowing time and nitrogen fertilizer rate on the growth, yield and nitrogen accumulation of canola, mustard and wheat. In: Wratten, $\mathrm{N}$ and Mailer RJ ( ads ) Proceedings Ninth Australian Research Assembly an Brassica, Wagga Wagga, New South Wales, pp: 33-46

Lefort BM, Dattee Y ( 1985a ) Etude de I'heterosis chez le colza oleagineux d'hiver ( Brassica napus L. ). I. Comparaisons de deux populations, I'une homozygote et I'autre heterozygote. Agronomie 5: 101-109

Lefort BM, Dattee Y ( 1985b ) Etude de I'heterosis chez le colza oleagineux d'hiver ( Brassica napus L. ). II. Structure genetigue d'une population de lignees. Agronomie 5: 201-207

Leon J and Becker HC ( 1995 ) Genetics of physiological potentials for yield components of annual oil and protein crops. Advances in Plant Breeding 17: 53-90

Li ZK, Pinson SRM, Park WD, Paterson AH, Stansel JW (1997) Epistasis for three grain yield components in rice (Oryza sativa L.). Genetics 145: 453-465

Mansur LM, Orf JH, Chase K, Jarvik T, Cregan PB, Lark KG ( 1996 ) Genetic mapping of agronomic traits using recombinant inbred lines of soybean. Crop Science 36: 1327-1336

Mendham NJ, Shipway PA, Scott RK (1981a) The effects of delayed sowing and weather on growth, development and yield of winter oil-seed rape (Brassica napus). Journal of Agricultural Science, Cambridge 96: 389-416

Mendham NJ, Shipway PA, Scott RK (1981b) The effects of seed size, autumn nitrogen and plant population density on the response to delayed sowing in winter oil-seed rape (Brassica napus). Journal of Agricultural Science, Cambridge 96: 417-428

Ogilvy SE (1984 ) The influence of seed rate on population structure and yield of winter oilseed rape. Aspects of Applied Biology 6: 59-66

Olsson G (1960) Some relationships between number of seeds per pod, seed size and oil content and the effects of selection for these characters in Brassica and Sinapis. Hereditas 46: 29-70

Pechan PM, Morgan DG ( 1985 ) Defoliation and its effects on pod and seed development in oil seed rape (Brassica napus L ). J. Exp. Bot. 36: 458-468

Riemann KH (1964) Untersuchungen zur Variabilität verschiedener Merkmale beim Raps und ihre Auswirkungen auf züchterische Maßnahmen. II. Mitteilung. Erkenntnisse zur Variabilität und korrelativen Bindung von Ertragsfaktoren und ihre Bedeutung für die Rapszüchtung. Züchter 34: 156-167

Rives M (1957 ) Etude sur la selection du colza d'hiver. Ann. Amel. Plantes I, 61-107 
Scarisbrick DH, Daniels RW, Noor Rawi AB ( 1982 ) The effect of varying seed rate on the yield and yield components of oilseed rape (Brassica napus L.). J. Agric. Sci. ( Camb. ) 99: 561-568

Schulz S ( 1987 ) Eetragsphysiologische Untersuchungen zur Ontogenese der Rapsfrucht ( Brassica napus L. ). Doctoral Thesis, Kiel

Thesis 3.1 Linkage map by microsatellite markers and QTLs for oil content (manuscript 1)

Thesis 3.2 QTLs for protein content and their relationships with oil content (manuscript 2 )

Thesis 3.6 QTLs for plant height and branching number and for time of flowering and maturity ( Manuscript 6)

Upadhyay A, Mohapatra T, Pai RA, Sharma RP (1996) Molecular mapping and character tagging in mustard (Brassica juncea). II: Association of RFLP markers with seed coat colour and quantitative traits. Journal of Plant Biochemistry and Biotechnology 5: 17-22

Veldboom LR, Lee M ( 1996 ) Genetic mapping of quantitative trait loci in maize in stress and nonstress environments: I. Grain yield and yield components. Crop Science 36: 1310-1319

Wang DL, Zhu J, Li ZK, Paterson AH (1999) Mapping of QTL with epistatic effects and QTL x environment interactions by mixed model approaches. Theor. Appl. Genet. 99: 1255-1264

Xiao J, Li J, Yuan L, Tanksley SD (1996) Identification of QTLs affecting traits of agronomic importance in a recombinant inbred population derived from a subspecific rice cross. Theor. Appl. Genet. 92:230-244

Xing YZ, Tan YF, Hua JP, Sun XL, Xu CG, Zhang Q (2002) Characterization of the main effects, epistatic effects and their environmental interactions of QTLs on the genetic basis of yield traits in rice Theor. Appl. Genet. $105: 248-257$

Zhu J (1995) Analysis of conditional genetic effects and variance components in developmental genetics. Genetics 141:1633-1639 


\subsection{QTLs for plant height and branching number and for time of flowering and maturity}

\subsubsection{Introduction}

Plant height and the number of primary branches are two of the most important plant type traits related to yield potential in Brassica napus. Flowering time is a major determinant of the regional and seasonal adaptation of rape seed varieties and has a large influence on maturity ( Buzza 1995 ). Plant height may contribute to lodging resistance ( Becker et al. 1999 ), therefore breeders have attempted to select for shorter genotypes, however, commercial cultivars have shown little reduction in height ( Buzza 1995 ), indicating its genetic linkage with seed yield. Significant gca- and sca- variances were found for plant height (Grant and Beversorf 1985; Lefort et al.1986; 1987 ), demonstrating both additive and dominant gene effects. The number of primary branches is largely related with sowing date ( Diepenbrock and Grosse 1995 ) and influenced by plant density or fertility levels, therefore the heritability is low ( Leon and Becker 1995 ). Flowering time is controlled by a number of genes influenced by daylength and vernalization ( Thurling and Das 1977 ) and often used to select indirectly for maturity.

There have been many studies to analyze the genetics of flowering time using molecular markers in Brassica species. Three QTLs were detected by Ferreira et al. (1995) and Osborn et al. (1997) in B. napus (VFN1, VFN2 and VFN3) and two of them (VFN1 and VFN2) corresponded to two QTLs in B. rapa ( VFR1 and VFR2 ) ( Teutonico and Osborn 1995 ). The regions containing these two pairs of QTLs may correspond to two genes ( FLC and FRI) that regulate flowering time from Arabidopsis thaliana located at the top of chromosome 5 and chromosome 4 ( Koornneef et al. 1994; Lee et al. 1994; Osborn et al 1997; Kole et al. 2001 ). Butruille et al. (1999) identified seven QTLs for flowering time and two of them may correspond with VFN1 and VFN3 ( Ferreira et al. 1995; Osborn et al. 1997 ). Axelsson et al. ( 2001 ) reported that all the major flowering QTLs detected in the different species of Brassica could be the result of duplicated copies of the same ancestral gene. Camargo and Osborn (1996) mapped three QTLs for flowering time in B. oleracea and detected epistasis between two genomic regions, however the mapped QTLs were found not at similar genomic regions as observed in B. napus and B. rapa. Mapping results on plant height and number of primary branches are limited in oilseed rape. Butruille et al.( 1999 ) mapped four QTLs for plant height and showed pleiotropy with flowering time genes on two loci with large genetic effects. 
Present study analyzed genetic control system of four agronomic quantitative traits - plant height, the number of primary branches per plant, flowering time and maturity using a SSR linkage map and a large DH population derived from a cross between European and Chinese cultivars ( Thesis 3.1 ) by mapping QTLs with additive and epistatic effects and their interactions with environments. The objective of this study was to characterize the genetic basis of these four agronomic important traits and dissect the genetic relationships between pairs of traits. The mapping results may give suggestions for improvement of these traits to get higher seed yield both in China and Europe.

\subsubsection{Material and methods}

In total 282 doubled haploid lines ( DHLs ) were produced from the F1 between the old German cultivar Sollux and the Chinese landrace Gaoyou by microspore culture. A linkage map was constructed using 125 microsatellite markers. Details of developed DH population and SSR map were described previously ( Thesis 3.1). The DH lines, $\mathrm{F}_{1}$ generation and parents were grown in four environments in 2000/2001: two locations in Xian and Hangzhou, China, and two locations in Göttingen of Germany: Reinshof and Weende. Each plot consist of two rows with $0.33 \mathrm{~m}$ distance in between. Around 40-50 plants per plot and two replications were used in all locations. Four agronomic traits - plant height, the number of primary branches, flowering time and maturity were scored. Five representative plants of each plot were sampled for measuring plant height $(\mathrm{cm})$ and counting the number of primary branches before harvest. Flowering time and maturity were recorded as number of days from sowing until 50\% plants showed first flowers and from sowing until siliques changed to be yellow. Plant height was observed at all four locations, the other three traits were only investigated at three locations ( Weende was not included ).

QTLs with additive and additive $\mathrm{x}$ additive epistatic effects as well as their environmental interaction effects ( $Q E$ ) were mapped by QTLMapper version 1.0 ( Wang et al. 1999 ). The model, explanations of all parameters and detailed mapping procedure were described previously ( Wang et al. 1999; Thesis 3.1). The likelihood-ratio threshold was chosen at $\alpha=0.005$ for claiming putative QTL and genetic effects. 


\subsubsection{Results}

\section{Phenotypic variation}

The phenotypic frequency distributions of the 282 DHLs for four agronomic traits under three or four environments were continuous but different among traits and locations ( Fig 1). Both plant height and the number of primary branches behaved mostly between 120-160 cm height and 7-11 branches in Xian, while majority between 130-170 cm and 9-14 in Hangzhou and Reinshof ( Weende for plant height as well ). The distribution of flowering time and maturity were in general agreement. Lines in Hangzhou were much earlier in start of flower and maturity than that in Reinshof and these two traits in Xian were somewhat between Hangzhou and Reinshof. On average, Hangzhou showed highest plant height, earliest flowering time and maturity, Xian showed both lowest plant height and number of primary branches, while Reinshof had the longest vegetative and reproductive growing periods ( Table1). Standard deviation for each trait among locations were similar except flowering time, where less variation was observed in Xian than at other locations. Sollux was $40 \mathrm{~cm}$ taller in plant height than Gaoyou averaged over three locations except Hangzhou, where almost no difference between the two parents was observed. The number of primary branches between parents varied with environments. For flowering time, Sollux was 17 days later in Xian and 29 days
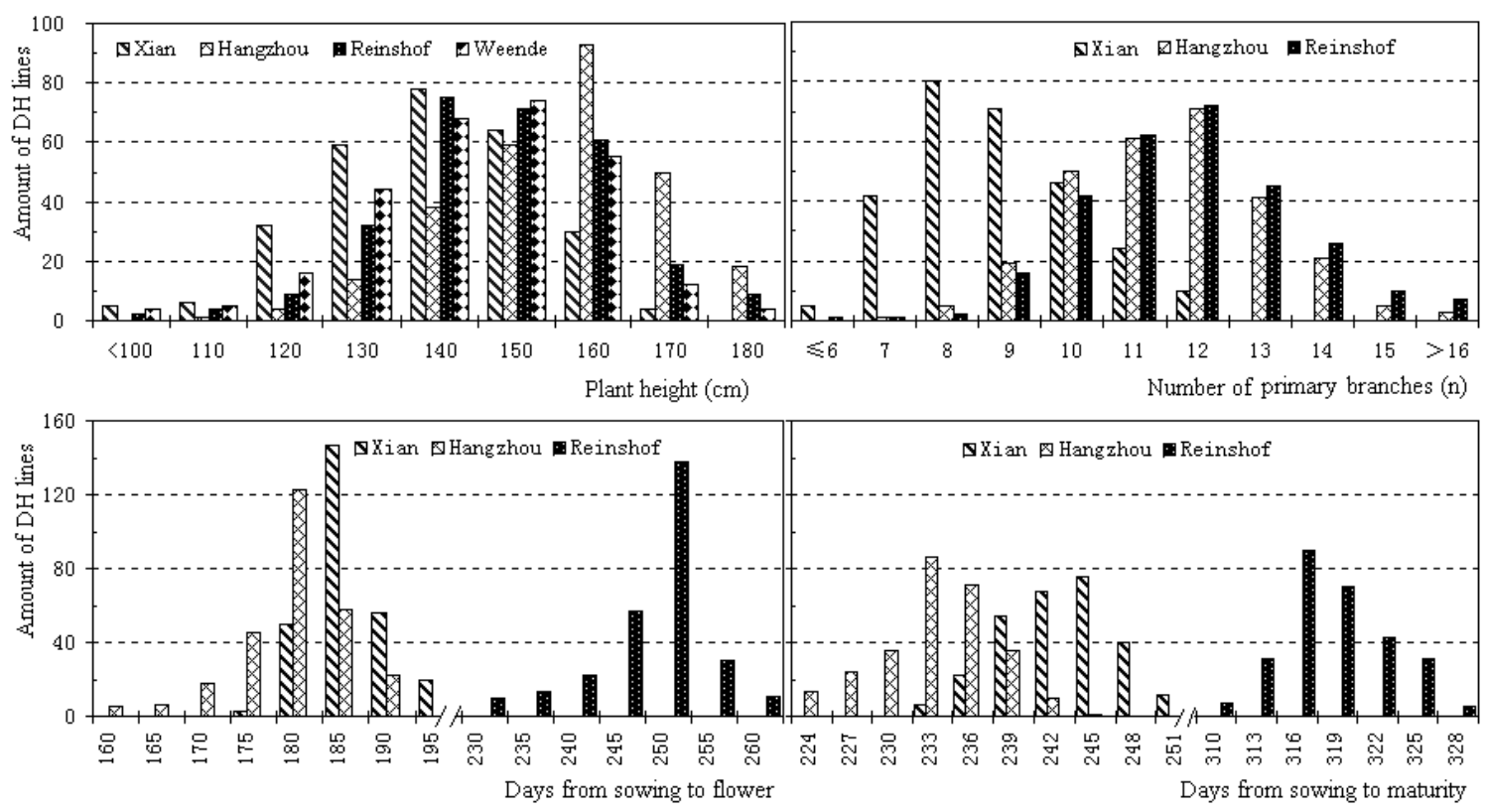

Fig1. Frequency distribution of four agronomic traits of the Sollux/Gaoyou derived DH lines 
later in Hangzhou and Reinshof than Gaoyou. The total growing period was about half month in difference between parents at all locations. Larger transgressive segregation were observed for plant height and the number of primary branches, and, to some extent, also for maturity but not for flowering time.

Table 1. Phenotypic variation of four agronomic traits

\begin{tabular}{|c|c|c|c|c|c|c|c|c|}
\hline \multirow{2}{*}{ Traits } & \multirow{2}{*}{ Locations } & \multicolumn{2}{|c|}{ Parents } & \multirow{2}{*}{$\mathrm{F} 1$} & \multicolumn{4}{|c|}{ DH population $(n=282)$} \\
\hline & & Sollux & Gaoyou & & Max & Min & Mean & SD \\
\hline \multirow{5}{*}{$\begin{array}{l}\text { Plant } \\
\text { height (cm ) }\end{array}$} & Xian & 156 & 100 & 153 & 166 & 78 & 135 & 14.0 \\
\hline & Hangzhou & 149 & 147 & 175 & 184 & 106 & 152 & 13.2 \\
\hline & Reinshof & 161 & 120 & 163 & 180 & 93 & 144 & 14.4 \\
\hline & Weende & 155 & 120 & 165 & 177 & 83 & 140 & 15.2 \\
\hline & Mean & 155 & 122 & 164 & 177 & 90 & 143 & 14.2 \\
\hline \multirow{4}{*}{$\begin{array}{l}\text { No. of primary } \\
\text { branches ( } n \text { ) }\end{array}$} & Xian & 7.8 & 8.0 & 8.0 & 12.0 & 5.0 & 7.8 & 1.10 \\
\hline & Hangzhou & 10.9 & 12.4 & 10.2 & 16.2 & 6.9 & 11.0 & 1.50 \\
\hline & Reinshof & 11.7 & 9.2 & 11.9 & 17.5 & 5.3 & 11.3 & 1.65 \\
\hline & Mean & 10.1 & 9.9 & 10.0 & 15.2 & 5.7 & 10.0 & 1.42 \\
\hline \multirow{4}{*}{$\begin{array}{l}\text { Days from } \\
\text { sowing to } \\
\text { flower (DTF) }\end{array}$} & Xian & 193 & 176 & 184 & 195 & 175 & 183 & 3.28 \\
\hline & Hangzhou & 189 & 160 & 179 & 190 & 159 & 177 & 6.60 \\
\hline & Reinshof & 251 & 222 & 245 & 257 & 226 & 245 & 6.05 \\
\hline & Mean & 211 & 186 & 203 & 214 & 187 & 202 & 5.31 \\
\hline \multirow{4}{*}{$\begin{array}{l}\text { Days from } \\
\text { sowing to } \\
\text { maturity (DTM) }\end{array}$} & Xian & 246 & 233 & 243 & 249 & 232 & 242 & 3.58 \\
\hline & Hangzhou & 239 & 224 & 236 & 243 & 220 & 232 & 4.00 \\
\hline & Reinshof & 324 & 309 & 317 & 326 & 305 & 316 & 3.86 \\
\hline & Mean & 270 & 255 & 265 & 273 & 252 & 263 & 3.81 \\
\hline
\end{tabular}

\section{QTLs for plant height}

The segregation of DHLs for plant height and the number of primary branches could be largely explained by several QTLs with additive or epistatic effects and their complex interactions with environment. In total, 17 QTLs with additive $(a)$ and /or additive $\mathrm{X}$ environment interaction effects (ae) located on 14 linkage groups and 7 pairs of loci with epistatic ( $a a)$ and/or epistatic $X$ environment interaction effects ( aae) were detected for plant height ( Table 2 ). Of these QTLs, 12 had significant $a$ effects and alleles from Sollux at 8 loci were in the direction of increasing plant height, while alleles from Gaoyou on the remaining 4 QTLs increased plant height. The change of plant height caused by individual a loci with homozygous genotype could range from about 3 to $9 \mathrm{~cm}$ in this population. All 12 QTLs collectively sum up to increase (or decrease) $65 \mathrm{~cm}$ in plant height with homozygous substitutions and explained $74 \%$ of the mean phenotypic variation observed in the DH population ( difference between lines with highest and lowest mean values, Table1). Ten QTLs had significant ae interaction effects, five 
combined with $a$ effect and the total effects of such QTLs were the sum of $a$ plus $a e$ (if any ) at a specific environment, another five QTLs only showed ae effects in two or three environments. More ae QTLs were found in locations of China than that in Germany, furthermore, 5 of 7 ae loci showed Gaoyou alleles in Hangzhou and all the ae loci but one had

Table 2. Additive ( $a$ ) and epistatic ( $a a$ ) effects of QTLs for plant height ( $\mathrm{cm}$ ) and with environmental interaction effects (ae, aae)

\begin{tabular}{|c|c|c|c|c|c|c|c|c|c|}
\hline LG & \multicolumn{3}{|l|}{$\begin{array}{l}\text { Marker } \\
\text { interval }\end{array}$} & $\begin{array}{l}\text { Position } \\
(\mathrm{cM})^{\mathrm{a}}\end{array}$ & ${ }^{\mathrm{b}} a$ & $\begin{array}{l}a e \text { in } \\
\text { Xian }\end{array}$ & $\begin{array}{l}a e \text { in } \\
\text { Hangzhou }\end{array}$ & $\begin{array}{l}a e \text { in } \\
\text { Reinshof }\end{array}$ & $\begin{array}{l}a e \text { in } \\
\text { Weende }\end{array}$ \\
\hline 1 & \multicolumn{3}{|c|}{ HMR292/ HMR327 } & 0.0 & $3.16^{* *}$ & & & & \\
\hline 2 & \multicolumn{3}{|c|}{ HMR364a/ HMR300a } & 6.0 & & & $-2.09 * *$ & $1.18^{* *}$ & $1.24 *$ \\
\hline 3 & \multicolumn{3}{|c|}{ HMR449a/MR12 } & 4.0 & $3.28 * *$ & & & & $2.53 * *$ \\
\hline 3 & \multicolumn{3}{|c|}{ HMR376a/MR197.1 } & 0.0 & & $-2.53 * *$ & $2.56^{* *}$ & & \\
\hline 4 & \multicolumn{3}{|c|}{ HMR637/MD2.2 } & 0.0 & & & $-1.92 * *$ & $1.07 *$ & $1.45^{* *}$ \\
\hline 5 & \multicolumn{3}{|c|}{ HMR327a/MD21 } & 0.0 & $1.55^{* *}$ & & & & \\
\hline 7 & \multicolumn{3}{|c|}{ MD20/ HMR166 } & 4.0 & $1.67 * *$ & & $1.70^{* *}$ & & \\
\hline 9 & \multicolumn{3}{|c|}{ HMR612b/MR230.1 } & 2.0 & $-3.73 * *$ & & & & \\
\hline 9 & \multicolumn{3}{|c|}{ HMR359a/HMR370a } & 0.0 & & $2.31 * *$ & & & $-1.73 * *$ \\
\hline $11-1$ & \multicolumn{3}{|c|}{ MR148/HMR407a } & 14.0 & $-1.42 *$ & & & & \\
\hline 12 & \multicolumn{3}{|c|}{ HMR353b/HMR364b } & 2.0 & & $2.46^{* *}$ & $-2.59 * *$ & & \\
\hline 13 & \multicolumn{3}{|c|}{ MR203.2/HMR321 } & 4.0 & $1.68 * *$ & & & & \\
\hline $14-1$ & \multicolumn{3}{|c|}{ HMR403b/MR229 } & 4.0 & $2.84 * *$ & $-2.32 * *$ & & $2.07 * *$ & \\
\hline 16 & \multicolumn{3}{|c|}{ HMR348/MR133 } & 0.0 & $4.64 * *$ & & $-1.59 * *$ & & \\
\hline 16 & \multicolumn{3}{|c|}{ HMR563/ HMR373 } & 4.0 & $-2.07 * *$ & & & & \\
\hline 17 & \multicolumn{3}{|c|}{ HMR349/MR127 } & 6.0 & $-2.02 * *$ & & & & \\
\hline 19 & \multicolumn{3}{|c|}{ HMR643a/HMR615a } & 4.0 & $4.32 * *$ & $3.11 * *$ & $-1.44 *$ & & \\
\hline \multicolumn{10}{|c|}{ Epistatic effects } \\
\hline LG & $\begin{array}{l}\text { Marker } \\
\text { interval }\end{array}$ & LG & & $\begin{array}{l}\text { arker } \\
\text { erval }\end{array}$ & $a a^{\mathrm{c}}$ & $\begin{array}{l}\text { aae in } \\
\text { Xian }\end{array}$ & $\begin{array}{l}\text { aae in } \\
\text { Hangzhou }\end{array}$ & $\begin{array}{l}\text { aae in } \\
\text { Reinshof }\end{array}$ & $\begin{array}{l}\text { aae in } \\
\text { Weende }\end{array}$ \\
\hline 1 & HMR292 & $14-1$ & & 229 & $-1.64 * *$ & & & & \\
\hline 2 & HMR300a & 12 & & KR399b & $-1.77 * *$ & & & & \\
\hline 3 & MR12 & 5 & $\mathrm{Ml}$ & 214 & $2.49 * *$ & $-1.49 * *$ & & & $1.25^{*}$ \\
\hline 3 & MR123 & 9 & & IR359a & $-1.56^{* *}$ & & & & $1.48 * *$ \\
\hline 7 & MR133.2 & 13 & $\mathrm{Ml}$ & 264 & $-1.33^{*}$ & & & & \\
\hline 9 & HMR311b & $11-1$ & & UR314a & & & $2.78 * *$ & $-1.98^{*}$ & \\
\hline 12 & HMR353b & 15 & $\mathrm{Ml}$ & 297 & $2.31 * *$ & & & & \\
\hline
\end{tabular}

*,** indicate the significance level at 0.005 and 0.001 respectively to declare the putative QTL positions and genetic effects. ${ }^{\mathrm{a}}$ Distance to the first marker of the indicated interval. ${ }^{\mathrm{b}}$ The QTL effect, is the phenotypic effect due to substitution of an 'Gaoyou' allele by an allele of 'Sollux'. 'Sing of epistatic effect: negative indicates that recombinant alleles from two parents and positive means that parental digenic genotypes increase phenotypic value respectively.

Sollux alleles in two locations of Germany increased plant height respectively, while in Xian, three alleles from Sollux and two alleles from Gaoyou displayed positive effects for plant height. Of seven pairs of epistatic loci for plant height, one showed only aae effect and the remaining six exhibited either $a a$ or $a a$ combined aae effects. Of these six pairs with main effects, two 
combined additive and three shared ae effects simultaneously. The sum of epistatic effects caused by six pairs of loci accounted for one third of total additive main effects.

\section{QTLs for number of primary branches}

For the number of primary branches, much less QTLs with additive main effects were identified compared to plant height ( Table 3 ). Four QTLs with favorable alleles of three from Sollux and one from Gaoyou located on four different linkage groups were detected, which jointly explained $22 \%$ of the total mean phenotypic variation with homozygous genotypes in this $\mathrm{DH}$ population ( difference between lines with highest and lowest mean values, Table1 ). Additive $\mathbf{x}$ environment interaction were substantial for three to six QTLs in different environments, showing dispersed alleles of parents. Also four digenic pairs of loci with epistatic main effects and more significant aae loci were detected. Together four pairs of main epistatic loci explained $17 \%$ of mean phenotypic variation for the number of primary branches among $\mathrm{DH}$

\begin{tabular}{|c|c|c|c|c|c|c|c|c|}
\hline \multirow{27}{*}{$\begin{array}{l}\text { Table 3. Additive ( } a \text { ) and } \\
\text { epistatic ( } a a \text { ) effects of QTLs } \\
\text { for the number of primary } \\
\text { branches and with } \\
\text { environmental interaction } \\
\text { effects ( } a \text {, aae) }\end{array}$} & & \multirow{2}{*}{\multicolumn{2}{|c|}{$\begin{array}{l}\text { Marker } \\
\text { interval }\end{array}$}} & & & & & \\
\hline & LG & & & $\begin{array}{l}\text { Position } \\
\text { (cM) }\end{array}$ & $a$ & $\begin{array}{l}\text { aein } \\
\mathrm{X} \text { ian }\end{array}$ & $\begin{array}{l}\text { aein } \\
\mathrm{H} \text { angzhou }\end{array}$ & $\begin{array}{l}\text { aein } \\
\text { Reinshof }\end{array}$ \\
\hline & 1 & \multicolumn{2}{|c|}{ HMR 40 Tb/ HMR292 } & 1.0 & & $-0.200 * *$ & $0.200 *$ & \\
\hline & 2 & \multicolumn{2}{|c|}{ HMR364a/HMR300a } & 0.0 & & $-0.202^{* * *}$ & & $0.380^{* * *}$ \\
\hline & 4 & \multicolumn{2}{|c|}{$\mathrm{HMR} 637 \mathrm{MD} 2.2$} & 0.0 & $0.356^{* * *}$ & & & \\
\hline & 7 & \multicolumn{2}{|c|}{$\mathrm{MD20/MR166}$} & 4.0 & & $0.204^{* * *}$ & & $-0.246^{* * k}$ \\
\hline & 9 & \multicolumn{2}{|c|}{ HMR612a/HMR612b } & 14.0 & & $0.143^{* * *}$ & $-0.141^{\text {*k* }}$ & \\
\hline & 9 & \multicolumn{2}{|c|}{ HMR $363 a / H M R 311 b$} & 28.0 & $0.357^{\text {*** }}$ & & & \\
\hline & $11-2$ & \multicolumn{2}{|c|}{ HMR295a/HMR295b } & 16.0 & $0.171^{\text {*** }}$ & & & \\
\hline & 12 & \multicolumn{2}{|c|}{ HMR299c/HMR 403a } & 4.0 & & & $-0.244^{* * *}$ & $0.301 * *$ \\
\hline & 16 & \multicolumn{2}{|c|}{ HMR348 } & 0.0 & & $0.345^{\text {*** }}$ & $-0.261^{* * *}$ & \\
\hline & 18 & \multicolumn{2}{|c|}{ MR335a/HMR588 } & 2.0 & $-0.145^{* * *}$ & & & \\
\hline & 19 & \multicolumn{2}{|c|}{ HMR643a/HMR615a } & 2.0 & & $0.166^{* * *}$ & & \\
\hline & \multicolumn{8}{|c|}{ Epistatic effects $(n)$} \\
\hline & LG & $\begin{array}{l}\text { Nearest } \\
\text { interval }\end{array}$ & LG & $\begin{array}{l}\text { Nearest } \\
\text { interval }\end{array}$ & $a a$ & $\begin{array}{l}\text { aae in } \\
\text { Xian }\end{array}$ & $\begin{array}{l}\text { ace in } \\
\mathrm{H} \text { angzhou }\end{array}$ & $\begin{array}{l}\text { aae in } \\
\text { Reinshof }\end{array}$ \\
\hline & 1 & HMR292 & 9 & HMR284b & $-0.230 * *$ & & & \\
\hline & 1 & $\mathrm{HMR} 407 \mathrm{~b}$ & 13 & MR64 & & & $0.268^{* *}$ & $-0.273^{* * *}$ \\
\hline & 1 & HMR344a & 19 & HMR61 5a & & $-0.181^{* * *}$ & & $0.172 *$ \\
\hline & 2 & HMR364a & 12 & $\mathrm{HMR} 353 \mathrm{~b}$ & $-0.215^{* * *}$ & & & \\
\hline & 2 & $\mathrm{HMR} 08 \mathrm{lc}$ & 13 & MR203.2 & $0.143^{* * *}$ & & & \\
\hline & 3 & HMR085 & 8 & HMR388 & & $0.170 *$ & $-0.240^{* * *}$ & \\
\hline & 3 & HMR085 & 12 & HMR $353 b$ & & & $0.239 * *$ & $-0.249^{* * *}$ \\
\hline & 5 & MR119 & 12 & GMR132 & & & $-0.238^{* * *}$ & $0.223^{* * *}$ \\
\hline & 9 & HMR 438a & $11-2$ & HMR295b & & $0.174 * *$ & $-0.248^{* *}$ & \\
\hline & 9 & HMR284a & 13 & HMR321 & $0.220^{* * *}$ & $-0.143^{*}$ & & \\
\hline & 12 & HMR $353 b$ & 13 & HMR321 & & & $-0.296^{* *}$ & $0.226^{* * *}$ \\
\hline & $14-2$ & MR155 & 18 & HMR $335 \mathrm{a}$ & & $-0.152^{* *}$ & $0.184^{*}$ & \\
\hline
\end{tabular}

lines, while effects caused by aae loci collectively accounted for 23,37 and 19\% of phenotypic variation observed in DH population respectively in Xian, Hangzhou and Reinshof. 
It should be noted that all the QTLs with $a$ and with $a e$ effects were located on different linkage groups, and all the pairs of loci with $a a$ and with aae effects but one presented with different combinations of gene loci.

\section{QTLs for flowering time and maturity}

Since the parents largely differed in flowering time, a strong segregation for this trait was observed in the DH population at all locations ( Fig1). Mapping analysis discovered ten QTLs with $a$ and/or $a e$ interaction effects for flowering time ( Table 4 ). Of these QTLs, two showed only ae effects and eight QTLs displayed $a$ or combined ae effects, and for seven of them, the Sollux alleles were delaying days to flower. The additive effects of eight main QTLs sum up to 19 days for flowering time when all loci were homozygous genotypes and explained about 70\% of the mean variation in DH population (difference between lines with highest and lowest mean values, Table1 ). Additive $\mathrm{x}$ environment interaction effects were identified at six genomic regions and four of them combined with additive main effects. One QTL on LG12 combining $a$ and ae effects causing small effects in locations in China, but resulted in 5 days earlier start of flowering than Sollux when homozygous at Reinshof. Alleles of ae loci were dispersed between parents, showing $Q E$ interaction in different way at individual ae loci.

Table 4. Additive $(a)$ and additive $\mathrm{x}$ environment interaction ( $a$ e ) effects of QTLs for flowering time (DTF) and maturity (DTM)

\begin{tabular}{|c|c|c|c|c|c|c|c|c|c|c|}
\hline \multirow[t]{2}{*}{ LG } & \multirow{2}{*}{$\begin{array}{l}\text { Marker } \\
\text { interval }\end{array}$} & \multirow{2}{*}{$\begin{array}{l}\text { Position } \\
(\mathrm{cM})\end{array}$} & \multicolumn{4}{|l|}{ DTF } & \multicolumn{4}{|l|}{ DTM } \\
\hline & & & $a$ & $a e_{1}$ & $a e_{2}$ & $a e_{3}$ & $a$ & $a e_{1}$ & $a e_{2}$ & $a e_{3}$ \\
\hline 1 & HMR295c/HMR293 & 2.0 & $-1.22 * *$ & & & & $-0.57 *$ & & $\cdot 1.05^{* *}$ & $1.16^{* *}$ \\
\hline 2 & HMR066/HMR087c & 26.0 & $1.54 *$ & & $1.68 * *$ & $-1.17 * *$ & & & & \\
\hline 3 & HMR376a/MR197.1 & 0.0 & & & $-0.79 * *$ & $0.85^{* *}$ & $0.77 * *$ & & $0.58 * *$ & $-0.89 * *$ \\
\hline 3 & MR12/MR3 & 16.0 & & & & & $0.74 *$ & $0.69 * *$ & & $0.52 *$ \\
\hline 7 & MR133.2/MD20 & 8.0 & & & & & $0.85^{* *}$ & $0.56 * *$ & $1.19 * *$ & $-1.96^{* *}$ \\
\hline $11-2$ & HMR295a/HMR295b & 8.0 & $1.15^{* *}$ & & & & & & & \\
\hline 12 & HMR299c/HMR403a & 0.0 & $1.13^{* *}$ & & & $1.21 * *$ & $1.54 * *$ & & & \\
\hline 12 & HMR353b/HMR364b & 2.0 & $1.32 * *$ & $-1.12^{* *}$ & $-0.79 * *$ & $1.41 * *$ & $1.10^{* *}$ & & & \\
\hline $14-1$ & HMR403b/MR229 & 4.0 & $0.71 * *$ & & & & & & & \\
\hline 15 & MR97/MR54 & 0.0 & & & & & $-0.56^{* *}$ & $0.55 * *$ & $\cdot 1.63^{* *}$ & $2.18^{* *}$ \\
\hline 16 & HMR348/MR133 & 0.0 & $1.18^{* *}$ & & & & $0.70 * *$ & & $0.97 * *$ & \\
\hline 18 & HMR335a/HMR588 & 2.0 & & & $-0.57 * *$ & $0.68 * *$ & & & & \\
\hline 19 & HMR643a/HMR615a & 4.0 & $1.07 *$ & $0.87 * *$ & & $-0.75 * *$ & & & & \\
\hline 19 & HMR281/HMR327b & 24.0 & & & & & $-0.67 * *$ & $0.93 * *$ & $\cdot 1.11^{* *}$ & \\
\hline
\end{tabular}

${ }^{\dagger} a e_{1}, a e_{2}$ and $a e_{3}$ represent the additive by environmental interaction in Xian, Hangzhou and Reinshof, respectively

Nine QTLs for plant maturity were resolved, two showing only additive main effect and the remaining seven joined $a$ with ae effects. Nine main effects of QTLs sum up to 15 days change 
of maturity with all homozygous genotypes, collectively accounted for about $70 \%$ of total variation observed in DH population over three environments. Sollux alleles delayed maturity on six gene loci, but caused early maturity on another three loci, furthermore, evenly alleles dispersion of ae loci between parents were observed at all three locations. These might be the reasons for transgrassive segregation of this trait observed in DH population. Four of eight main QTLs for flowering time were also QTLs for maturity with same effect direction. Significant ae interaction with relative larger effects for maturity on several gene loci were identified.

Epistasis of $a a$ effects clearly accounted for small portion of genetic basis for flowering time as well as for plant maturity ( Table 5 ). Three digenic pairs of main loci were detected both for flowering time and maturity, respectively. The significant level and magnitude of effects were relatively low, the aae effects were detected on five and two pairs for flowering time and maturity, respectively. Four of five pairs of loci with aae for flowering time were different as aa loci. Larger aae effects were identified at one pair on LG3/LG14-2 for flowering time, causing 10 and 4-5 days earlier flowering when two alleles from different

Table 5. Epistatic $(a a)$ and epistasis $\mathbf{x}$ environment interaction (aae) effects of QTLs for flowering time ( DTF ) and maturity ( DTM )

\begin{tabular}{|c|c|c|c|c|c|c|c|c|}
\hline Trait & LG & Marker interval & LG & Marker interval & $a a$ & ${ }^{\dagger} a a e_{1}$ & $\mathrm{aae}_{2}$ & $\mathrm{aae}_{3}$ \\
\hline \multirow[t]{7}{*}{ DTF } & 1 & HMR274b/HMR430 & 12 & HMR364b/GMR132 & & & $0.73 * *$ & $-1.19^{* *}$ \\
\hline & 1 & HMR407b/HMR292 & 13 & MR64/HMR376b & $-0.93 * *$ & & $-0.63 * *$ & \\
\hline & 3 & HMR376/MR197.1 & $14-2$ & HMR399a/MR155 & & $-2.59 * *$ & $-2.16^{* *}$ & $5.07 * *$ \\
\hline & 4 & HMR637/MD2.2 & 12 & HMR353b/HMR364b & $-0.84^{*}$ & & & \\
\hline & 8 & HMR577/ HMR613 & 9 & HMR612b/MR230.1 & & $0.54 * *$ & & $-0.55^{*}$ \\
\hline & 9 & HMR612b/MR230.1 & 12 & HMR353b/HMR364b & $-0.54^{*}$ & & & \\
\hline & $14-1$ & HMR403b/MR229 & 17 & HMR318/ HMR349 & & $0.49 * *$ & & $-0.71 * *$ \\
\hline \multirow[t]{4}{*}{ DTM } & 1 & HMR292/HMR327c & 1 & HMR293/HMR274b & & $1.22 * *$ & $1.47 * *$ & $-2.77 * *$ \\
\hline & 7 & HMR300c/MR133.2 & 13 & HMR067/MR64 & $-0.30^{*}$ & & & \\
\hline & 7 & MD20/MR166 & 13 & HMR337/MR61 & $0.40^{*}$ & $-1.02 * *$ & $-0.41^{*}$ & $0.92 * *$ \\
\hline & $11-1$ & HMR335b/HMR374 & 12 & HMR299c/HMR403a & $-0.46^{*}$ & & & \\
\hline
\end{tabular}

${ }^{\dagger} a a e_{1}, a a e_{2}$ and $a a e_{3}$ represent the epistasis by environmental interaction in Xian, Hangzhou and Reinshof, respectively

parents were homozygously recombined in Reinshof and when two alleles from the same parent were homozygously recombined in locations of China, respectively. Another aae pair of loci on LG1/LG1 for maturity, might lead to 5 and 2-3 days earlier maturity in German and 
Chinese locations, respectively, when the parental alleles were combined in the opposite way as described for flowering time on LG3/LG14-2. No identical $a a$ and aae pairs of loci were detected between flowering time and maturity.

\section{Relationships among QTLs for different traits}

Genetic and phenotypic correlations among four agronomic traits ( Table 6 ) showed two types of correlation in agreement well. Plant height showed significant correlation with flowering time and maturity, and flowering time also highly correlated with maturity and with the number of primary branches in medium coefficient, while there was no significant correlation observed between plant height and the number of primary branches. Inspection of the map locations and effects of the QTLs for these four traits disclosed that three genomic regions on LG14-1, 16 and 19 for plant height were also detected for flowering time and the additive effects of these QTLs were relatively larger (Table 2 and 4 ); three common or adjacent genomic regions with additive and one pair of common loci with epistatic effects were found both for plant height and total growth period as can be seen from Table 2, 4 and 5; larger significant correlation between flowering time and maturity might be due to the gene overlapping at four additive main loci on LG1, 12 and 16, collectively accounted for around 50\% of total additive effects for

\begin{tabular}{|c|c|c|c|c|c|}
\hline \multirow{5}{*}{$\begin{array}{l}\text { Table 6. Genetic (above } \\
\text { diagonal) and phenotypic } \\
\text { (below diagonal) } \\
\text { corr elations am ong four } \\
\text { agronomic traits }\end{array}$} & \multirow{2}{*}{ Traits } & $\mathrm{PH}^{+}$ & $\mathrm{NB}$ & DTF & \multirow{2}{*}{$\frac{\text { DTM }}{0.457^{* *}}$} \\
\hline & & 1 & 0.007 & $0.577^{* *}$ & \\
\hline & $\mathrm{NB}$ & $0.155^{*}$ & 1 & $0.385^{* *}$ & $0.154^{*}$ \\
\hline & DTF & $0.554 * *$ & $0.302 * *$ & 1 & $0.910^{* *}$ \\
\hline & DTM & $0.423^{* *}$ & 0.096 & $0.956^{* *}$ & 1 \\
\hline
\end{tabular}

flowering time and maturity, respectively; however only one identical genomic region was observed for flowering time and the number of primary branches. For all the alleles occurring on common regions for pairs of traits, the additive effects had the same direction. These results provide the genetic evidence for relationships among four traits estimated by conventional genetic analysis. 


\subsubsection{Discussion}

We used a mixed model based QTL mapping approach to detect QTLs with additive and epistatic effects, as well as their $Q E$ interaction effects for four agronomic important quantitative traits. This new method, compared with frequently being used ones as interval mapping or composite interval mapping, might provide more genetic information and be of interest for plant breeding. The results demonstrated that each trait was controlled by several additive main QTLs plus a number of QTLs with epistatic and $Q E$ interaction effects. Plant height was controlled by many QTLs and additive effects were predominant form, which are in agreement with previous researches ( Lefort et al.1986, 1987; Grant and Beversorf 1985 ). The variation of plant height caused by one main QTL in this DH population could be up to $9-10$ $\mathrm{cm}$ in maximum with homozygous genotypes, this is generally consistent with previous mapping results ( Butruille et al. 1999 ). The detected digenic epistasis loci and their complex combination with $a$ or $a e$ effects are not reported before in oilseed rape to our knowledge. Most of QTLs showed Sollux alleles increase of plant height, while there were also four loci with Gaoyou alleles increased plant height. The dispersion of allele phases between parents explained the large transgressive segregation observed in the DH population. QTLs with ae interaction effects were significant from three to seven at individual environment. It should be noted that most of ae QTLs in Hangzhou and all but one in two locations in Göttingen showed Gaoyou and Soullx alleles in the direction of increasing plant height, respectively as observed for oil content ( Thesis 3.1 ), indicating genes for plant height are, to some extent, under regulation of ecological environments. Allele distribution in experiment of Xian behaved dispersion of alleles with three by two, this might be explained that the environmental conditions in Xian, mainly temperature, are somewhat between Hangzhou and Göttingen ( Thesis 3.3 ).

Few QTLs with additive and epistatic main effects were identified for the number of primary branches, which jointly explained only around 22 and $17 \%$ of mean phenotypic variation observed in the DH population, respectively, while both ae and aae effects were quite substantial with dispersed alleles of parents. Furthermore, all the QTLs with $a$ and $a e$ or pairs of QTLs with $a a$ and aae presented on the different genomic regions or with different combination of loci. All these features might explain that the number of primary branches are highly influenced by environmental factors and led to less QTLs with additive or epistatic main effects. This is in agreement with low heritability reported earlier (Leon and Becker 1995 ). No common or adjacent QTLs were shared for plant height and the number of primary branches, 
explaining the insignificant genetic correlation between two traits (Table 6 ).

Seven of eight main QTLs showed early flowering alleles from Gaoyou and no clear transgressive segregation was observed. Gaoyou behaved more like a spring type cultivar under Europe growing conditions and the mapping results are similar as previously reported for populations from annual x biennial rapeseed ( Ferreira et al. 1995; Osborn et al. 1997 and Butruille et al. 1999 ). Since different marker system used as reported before, our results can not be directly compared with previously mapped QTLs, however, the total number of main QTLs and the magnitude of effects were similar as observed by Butruille et al. ( 1999 ). Each of two homozygous loci on LG12 could be 4-5 days early for flowering than Sollux at environment of Reinshof, which may be interesting for practical breeding. Another important point is that three QTLs with larger additive effects for plant height on LG14-1, 16 and 19 might be pleiotropy for flowering time as suggested by Butruille et al. ( 1999 ) and also provide the genetic basis for significant genetic correlation between two traits. However, QTLs on LG14-1 and 19 also positive linked QTL for oil content ( Thesis 3.4 ). Selection for reduced plant height and early flowering time might reduce oil content.

Plant maturity is largely determined by flowering time. The results from this study revealed four of nine QTLs for maturity overlapping with flowering time and the genetic effects in these loci are relatively larger, which is in agreement with highly significant correlation between two traits ( Table 6 ). The unshared QTLs might be related with flowering duration or grain filling period. There were three loci where Gaoyou alleles delayed the maturity, which provided the genetic explanation for transgressive segregation of maturity observed in the DH population. Unlike the situation for plant height and the number of primary branches, most of $a$ and $a e$ loci both for flowering time and maturity were detected in the same genomic regions, while the alleles of parents were dispersed in all environments, which results in similar total genetic effects for two traits, respectively, in each environment. This might be the explanation for highly positive correlations observed among three diverse environments both for flowering time and maturity ( Table 7 ).

Table 7. Correlation of flowering time (above diagonal) and maturity (below diagonal) among three locations ( $\mathrm{P}<0.01$ )

\begin{tabular}{llll}
\hline Locations & Xian & Hangzhou & Reinshof \\
\hline Xian & 1 & 0.776 & 0.693 \\
Hangzhou & 0.685 & 1 & 0.807 \\
Reinshof & 0.668 & 0.687 & 1 \\
\hline
\end{tabular}


Digenic epistatic QTLs both for flowering time and maturity were detected but much less than QTLs with additive effects. This observation is genera $x$ environmental interactions. These information are important in practical breeding programs. The pleiotropy or close linkage of QTLs among traits provide the possibilities for joint selection of traits based on marker assistant according to breeding purposes and specific environments.

\subsubsection{Summary}

Plant height and number of primary branches are two most important plant type traits related to yield potential in Brassica napus. Flowering time is a major determinant of the regional and seasonal adaptation of rapeseed varieties and has a large influence on maturity. Using a doubled haploid population of 282 lines from the cross of European with Chinese cultivars, agronomic phenotypic data sets from four environments, two in Germany and two in China, and a 125 SSR-marker linkage map, we performed QTL analyses using mixed model approach to detect QTLs with additive, epistasis as well as their interactions with environments $(Q E)$. The results demonstrated that each trait was controlled by several QTL with additive plus a number of QTLs with epistatic and $Q E$ interaction effects. Plant height was controlled by many QTLs ( 12 loci with $a$ or combined ae, 5 loci with $a e$ ). Additive effects were predominant and often combined with digenic epistasis effects. Most of QTLs with additive $\mathrm{x}$ environment effects showed ecologically favourable alleles in diverse regions. For the number of primary branches, few QTLs with additive and epistatic main effects were identified, while $Q E$ interaction effects were quite substantial. No common or adjacent QTLs were found for plant height and the number of primary branches.

Seven of eight main QTLs showed early flowering alleles from Gaoyou. Each of two homozygous loci on LG12 could be 4-5 days early flowering than Sollux at environment of Reinshof, which may be interesting for practical breeding purpose. Another point is that three QTLs with larger additive effects for plant height on LG14-1, 16 and 19 were pleiotropy for flowering time. The results confirmed that flowering time largely influence maturity. Digenic epistatic QTLs both for flowering time and maturity were detected but much less than QTLs with additive effects.

Key words: Brassica napus L. · Plant height · Number of primary branches · Flowering · Maturity · QTL mapping · Digenic interaction · QTL by environment interaction 


\subsubsection{References}

Axelsson T, Shavorskaya O, Lagercrantz U ( 2001 ) Multiple flowering time QTLs within several Brassica species could be the result of duplicated copies of one ancestral gene. Genome 44: 856-864

Becker HC, Löptien H and Röbblen G (1999) Breeding of Brassica: An overview. In Gomez-Campo C (eds) Biology of Brassica coenospecies. Elsevier, Science BV, Amsterdam, pp: 413-460

Butruille DV, Guries RP and Osborn TC (1999) Linkage Analysis of Molecular Markers and Quantitative Trait Loci in Populations of Inbred Backcross Lines of Brassica napus L. Genetics 153: 949-964

Buzza GC (1995) Plant Breeding. In Kimber D and McGregor DI (eds) Brassica Oilseeds: Production and Utilization, University Press, Cambridge, pp: 153-175

Camargo LEA, Osborn TC (1996) Mapping loci controlling flowering time in Brassica oleracea. Theor. Appl. Genet. 92: 610-616

Diepenbrock W and Grosse F (1995) Rapeseed ( Brassica napus L.): Physiology of physiological potentials for yield components of annual oil and protein crops. Advances in Plant Breeding 17: 21-53

Ferreira ME, Satagopan J, Yandell BS, Williams PH, Osborn TC (1995 ) Mapping loci controlling vernalization requirement and flowering time in Brassica napus. Theor. Appl. Genet. 90: 727-732

Grant I, Beversorf WD (1985 ) Agronomic performance of triazine-resistant single-cross hybrid oilseed rape (Brassica napus L.) . Can. J. Plant Sci. 65: 889-892

Koornneef M, Hanhart CJ, Van der Veen JH (1994) A genetic and physiological analysis of late-flowering mutants in Arabidopsis. Mol. Gen. Genet 229: 57-66

Kole C, Quijada P, Michaels SD, Amasino RM, Osborn TC ( 2001) Evidence for homology of flowering-time genes VFR2 from Brassica rapa and FLC from Arabidopsis thaliana. Theor. Appl. Genet. 102: 425-430

Lee I, Michaels SD, Masshardt AS, Amasino RM (1994) The late flowering phenotype of FRIGIDA and mutations in LUMINIDEPENDENS is suppressed in the Landsberg erecta strain of Arabidopsis. Plant J. 6: 903-909

Lefort BM, Guillot LB, Dattee Y (1986) Heterosis and genetic distance in rapeseed (Brassica napus L.). Use of different indicators of genetic divergence in a $7 \times 7$ diallel. Agronomie 6: 839-844

Lefort BM, Guillot LB, Dattee Y (1987) Heterosis and genetic distance in rapeseed (Brassica napus L.): crosses between European and Asiatic selfed lines. Genome 29: 413-418

Leon J and Becker HC ( 1995 ) Genetics of physiological potentials for yield components of annual oil and protein crops. Advances in Plant Breeding 17: 53-90

Osborn TC, Kole C, Parkin IAP, Sharpe AG, Kuiper M, Lydiate DJ, Trick M (1997) Comparison of flowering time genes in Brassica rapa, B. napus and Arabidopsis thaliana. Genetics 146:1123-1129

Teutonico RA, Osborn TC (1995) Mapping loci controlling vernalization requirement in Brassica rapa. Theor. Appl. Genet. 91: 1279-1283

Thurling N, Das LDV (1977) Variation in pre-anthesis development of spring rape (Brassica napus L.). Australian Journal of Agricultural Research 28: 597-607

Thesis 3.1 Construction of a linkage map and identification of QTLs for oil content (manuscript 1)

Thesis 3.3 Relationships between oil and protein content with developmental stages (manuscript 3 ) 
Thesis 3.4 Relationships between oil and protein content with plant height and yield components (manuscript 4 )

Wang DL, Zhu J, Li ZK, Paterson AH (1999) Mapping of QTL with epistatic effects and QTL X environment interactions by mixed model approaches. Theor. Appl. Genet. 99: 1255-1264 


\section{Summary}

\section{QTLs for oil content and their relationships to other agronomic traits in an European $x$ Chinese oilseed rape population}

Rapeseed oil is one of the most important vegetable oils for edible consumption both in China and Europe, while the meal, after extraction of the oil, has a high protein content with well balanced amino acid composition and is a valuable protein supplement in animal feed mixtures today. Therefore a better understanding of the genetic basis for oil and protein content by mapping QTLs ( Quantitative trait loci ) with molecular markers is important for rapeseed breeding. Analyzing the genetic relationships of these two traits with developmental stages, and with yield related traits on QTL level is of interest. A total of 282 doubled haploid ( DH ) population, which derived from the F1 between the old German cultivar Sollux and the Chinese landrace Gaoyou of Brassica napus by microspore culture, was developed and a linkage map including 125 SSR marker loci was constructed. The DH lines were grown in 4 environments, two in Germany ( Reinshof and Weende ) and two in China ( Hangzhou and Xian ). A new mapping program QTLMapper version 1.0 was used for mapping unconditional and conditional QTLs with additive $(a)$ and additive $\mathrm{x}$ additive epistatic ( $a a)$ effects, as well as their interaction effects with environments ( $Q E$, including ae and aae).

Both parents showed high oil content. Although the maximum difference between parents either for oil or for protein content were around $3 \%$ in all locations, large transgressive segregation for both traits within the $\mathrm{DH}$ lines was observed in each environment with extreme differences up to 17 and 10 percentages for oil and protein content in Germany, and 10 and $7 \%$, respectively, in China. Mapping results revealed 8, 5 and 7 QTLs with additive main effects, and 9, 6 and 6 pairs of digenic loci with epistatic main effects for oil, seed and meal protein content, respectively. The additive effects of these QTLs explained about 40, 30 and $40 \%$, and the epistatic effects of theses pairs accounted for about 40, 25 and $30 \%$ of the phenotypic variation observed for oil, seed and meal protein, respectively. For oil content, two important alleles were identified in the Chinese parent and two alleles in the European parent. These QTLs were confirmed by the comparison of the 20 highest and 20 lowest DH lines. A large number of QTLs with ae interaction effects demonstrated the complex inheritance for oil and protein content and suggest a joint utilization for QTLs with additive, epistatic and $Q E$ interaction effects by marker assisted selection in breeding programs. 
By combining the statistical procedures for analyzing conditional genetic effects and the QTL mapping program, conditional mapping analysis between oil and seed protein were performed. Results of conditional mapping present the effects of QTLs for oil content under the condition of no variation for seed protein content, and vice versa. Comparison between unconditional ( conventional QTL mapping) and conditional (oil conditioned on seed protein: oil|seed protein, or vice versa ) mapping results make it possible to distinguish between pleiotropic effect and gene linkage in the same genomic regions. The results can be summarized as follows: 1) Two QTLs might be responsible for pleiotropic effects because under conditional mapping for oil|seed protein and seed protein|oil, the QTLs did no longer show significant effects for both traits, and one QTL more likely shows gene linkage, since reduced genetic effects were detected for both traits under conditional mapping. 2) Two QTLs for oil and seed protein content respectively were independent while three oil QTLs were significantly influenced by seed protein content. 3 ) Large changes of QTLs with epistatic effects under conditional mapping analysis reflected the close genetic relationship between these two traits also through digenic epistatic loci. Oil and protein content in the seed share large part of their genetic basis. However, it is possible to combine high content of seed oil with high meal protein content. Four of seven additive QTL and two of six pairs of epistatic loci for meal protein were not affected by oil content and thus seed oil and meal protein show much less genetic overlapping than seed oil and seed protein.

The genetic influence on QTLs for oil and protein content due to the variation of developmental stages were analyzed by conditional mapping. Flowering time had more contribution to oil content, while flowering period and grain filling period were more related to seed and meal protein. The two oil QTLs having largest effects were identified independently of all developmental stages. The favorable alleles come from the Chinese parent. Most oil QTLs with favorable alleles from the European parent were closely linked with flowering time, but there was one QTL not related to any developmental stages and one linked with early flowering QTL.

Conditional mapping for oil and protein content when seed weight, seed number and plant height were conditioned, revealed that oil and seed protein were influenced by seed number and plant height both in additive and epistatic loci. The genetic relationship between oil, seed protein and seed weight was small.

Seed size and seed number are important yield components, and silique length is normally correlated with seed number. In total, 7, 6 and 9 QTLs respectively, were identified for these traits which explained about 40,35 and $70 \%$ of the mean phenotypic variation, respectively. 
Digenic epistasis was small for seed size, negligible for silique length but significant for seed number. QTLs for seed size were more related with flowering time and grain filling period, while QTLs for seed number were more influenced by flowering period.

In the last part of this thesis, the QTLs for two plant type traits and two important developmental traits were mapped. The results demonstrated that each trait was controlled by several additive main QTLs plus a number of QTLs with epistatic and $Q E$ interaction effects. Plant height was controlled by many QTLs ( 12 loci with $a$ or combined ae, 5 loci only with ae). Seven of eight main QTLs showed early flowering alleles from Gaoyou and no clear transgressive segregation was observed among DH lines.

It is possible to create new breeding materials or cultivars with increased oil content in seed and protein content in meal by marker assistant integration of favorable genes identified in this study. The genetic relationships between QTLs for oil ( or protein ) content and developmental stages ( or yield related traits ) further provide useful information for the utilization of these QTLs both in China and in Europe. 


\section{Zusammenfassung}

\section{QTL für Ölgehalt und deren Beziehung zu anderen agronomischen Eigenschaften in einer Europäisch $x$ Chinesischen Winterraps- Population}

Rapsöl dient sowohl in China als auch in Europa als eins der wichtigsten pflanzlichen Öle der menschlichen Ernährung. Das Rapsschrot hat einen hohen Proteingehalt und eine ausgewogenen Aminosäure-Zusammensetzung und wird als wertvolle Eiweißquelle im Mischfutter eingesetzt. Für die Rapszüchtung ist es daher wichtig, die genetische Grundlage von Öl- und Proteingehalt besser zu verstehen. Dafür ist die Identifizierung einzelner Gene (QTL = „Quantitative Trait Locus“ ) mit Hilfe molekularer Marker sehr hilfreich. Ebenfalls von großer Bedeutung ist es, den Zusammenhang zwischen QTL für Öl- und Proteingehalt und Entwicklungsstadien sowie Ertragskomponenten zu untersuchen. Aus einer Kreuzung zwischen der alten deutschen Sorte ,Sollux' und der chinesischen Landsorte ,Gaoyou' wurden über Microsporenkultur 282 verdoppelte haploide (DH) Linien entwickelt. Für diese Population wurde eine Kopplungskarte mit 125 SSR Markern erstellt. Die DH-Linien wurden an zwei Orten in Deutschland (Reinshof und Weende, beide in der Nähe von Göttingen) und an zwei Orten in China (Hangzou und Xian) angebaut. Es wurde eine neue Software (QTLMapper 1.0) verwendet, um für die QTL die additiven (a) und die additiv x additiv epistatischen (aa) Geneffekte sowie deren Interaktionen mit den Umwelten zu bestimmen.

Beide Elternlinien zeigten eine hohen Ölgehalt. Obwohl der Unterschied zwischen den Eltern für Öl- und Proteingehalt an allen Orten maximal $3 \%$ betrug, wurde bei den DH-Linien eine sehr große Variation beobachtet, die in Deutschland für den Öl- und Proteingehalt 17\% bzw. 10\% betrug und in China 10\% bzw. 7\%. Für die Merkmale Ölgehalt, Proteingehalt im Samen und Proteingehalt im Schrot konnten 8, 5, bzw. 7 OTL mit additiv-genetischen Effekten und 9, 6, bzw. 6 Genkombinationen mit epistatischen Effekten identifiziert werden. Die Additiveffekte erklärten für die einzelnen Merkmale zwischen 30 und $40 \%$ der phänotypischen Varianz, und die epistatischen Effekte erklärten zwischen 25 und $40 \%$ der phänotypischen Varianz. Für die wichtigsten vier Gene stammten je zwei der positiven Allele für den Ölgehalt von dem europäischen bzw. dem chinesischen Elter. Dieses Ergebnis wurde bestätigt durch die molekulare Charakterisierung der jeweils 20 DH-Linien mit dem höchsten bzw. niedrigsten 
Ölgehalt. Viele QTL zeigten außerdem Wechselwirkungen mit der Umwelt und bestätigten damit die sehr komplexe genetische Bestimmung von Öl- und Proteingehalt bei Raps.

Der Zusammenhang zwischen Öl- und Proteingehalt wurden näher analysiert durch ein „conditional mapping“, bei dem die Variation eines Merkmals (z.B. Ölgehalt) untersucht wird unter der Annahme, dass sich ein zweites Merkmal (z.B. Proteingehalt) nicht gleichzeitig auch ändert. Die Ergebnisse dieses „,conditional mapping“ zeigen, dass (i) es möglich ist, Pleiotropie und genetische Kopplung voneinander zu unterscheiden, (ii) die QTL für Öl- bzw. Proteingehalt teilweise voneinander unabhängig sind, teilweise aber auch QTL für eines der Merkmale direkt das andere Merkmal beeinflussen, und dass (iii) besonders für epistatische Wechselwirkungen zwischen Genen das „conditional mapping“ zu stark veränderten Ergebnissen führt. Öl- und Proteingehalt des Samens hängen genetisch eng miteinander zusammen. Daher ist es einfacher, einen hohen Ölgehalt im Samen mit einem hohen Proteingehalt im Rapsschrot zu kombinieren. Die meisten QTL für Proteingehalt im Schrot zeigten keinen Zusammenhang mit den QTL für Ölgehalt in den Samen.

Der Einfluss der Entwicklungsphasen auf den Öl- und Proteingehalt wurde ebenfalls mit dem „conditional mapping“ untersucht. Der Blühzeitpunkt wirkte sich vor allem auf den Ölgehalt aus, während die Kornfüllungsphase enger mit dem Proteingehalt zusammenhing. Die beiden wichtigsten QTL für dem Ölgehalt wurden in allen Entwicklungsphasen nachgewiesen, und die jeweils günstigen Allele stammten von dem chinesischen Elter. Drei QTL mit günstigen Allelen von den europäischen Eltern waren dagegen mit einem frühen Blühtermin assoziiert.

Ein „conditional mapping“ von Öl- und Proteingehalt unter Berücksichtigung von Samengewicht, Samen je Schote und Wuchshöhe zeigte sowohl additive als auch epistatische Genwirkungen. Die Merkmale Ölgehalt, Proteingehalt und Samengewicht hingen kaum miteinander zusammen.

Das Einzelsamengewicht und die Anzahl Samen je Schote sind wichtige Ertragskomponenten, und die Schotenlänge ist normalerweise hoch korreliert mit der Anzahl Samen je Schote. Für diese drei Merkmale wurden 7, 6, bzw. 9 QTL identifiziert, die 40, 35, bzw. $70 \%$ der phänotypischen Variation erklären. Für die Schotenlänge wurden keine und für das Samengewicht nur sehr geringe epistatische Effekte nachgewiesen, während diese Effekte für die Anzahl Samen je Schote signifikant waren. QTL für Samengewicht sind vor allem assoziiert mit Blühzeitpunkt und Kornfüllungsphase, während QTL für Anzahl je Schote eher mit der Blühdauer zusammenhängen.

Der letzte Teil der Arbeit beschäftigt sich mit der Kartierung von zwei Eigenschaften, die den Wuchstyp betreffen (Wuchshöhe und Anzahl Verzweigungen), sowie zwei phänologische 
Eigenschaften, Blüh- und Reifzeitpunkt. Für die Wuchshöhe wurden sehr viele QTL identifiziert. Beim Blühzeitpunkt fiel auf, dass bei sieben der acht identifizierten QTL das Allel für frühe Blüte aus dem chinesischen Elter stammt.

Zusammenfassend kann gesagt werden, dass eine markergestützte Erhöhung von Öl- und Proteingehalt erfolgversprechend ist. Dabei wird es wichtig sein, das komplexe Netzwerk aus Sameninhaltsstoffen und Umweltfaktoren sorgfältig zu analysieren und besser zu verstehen. 
5. Appendix

Appendix 1. Raw data of seed oil, seed protein ( SP ) content ( \% ) and days from sowing to beginning of flower ( DTF ) used for mapping analysis ( based on $9 \%$ moisture )

\begin{tabular}{|c|c|c|c|c|c|c|c|c|c|c|c|}
\hline \multirow[t]{2}{*}{ DHLs } & \multicolumn{3}{|l|}{ Xian } & \multicolumn{3}{|c|}{ Hangzhou } & \multicolumn{3}{|c|}{ Reinshof } & \multicolumn{2}{|c|}{ Weende } \\
\hline & oil & SP & DTF & oil & $\mathrm{SP}$ & DTF & oil & $\mathrm{SP}$ & DTF & oil & SP \\
\hline 1 & 44.44 & 21.64 & 184 & 40.72 & 22.74 & 180 & 54.03 & 15.33 & 248 & 52.02 & 16.62 \\
\hline 2 & 45.00 & 21.88 & 181 & 46.52 & 20.16 & 177 & 51.11 & 17. 29 & 249 & 49.55 & 19. 12 \\
\hline 3 & 45.51 & 21.45 & 176 & 44.45 & 21.40 & 169 & 48. 44 & 19. 38 & 237 & 48.51 & 19.98 \\
\hline 4 & 45.94 & 20.94 & 184 & 46. 30 & 20.07 & 178 & 53.96 & 15.09 & 248 & 53.20 & 15.86 \\
\hline 5 & 47.14 & 21.86 & 179 & 46.45 & 21.42 & 170 & 52.14 & 18.07 & 231 & 52.09 & 17.73 \\
\hline 6 & 42.72 & 22.60 & 184 & 40.60 & 23.74 & 176 & 50.46 & 16.92 & 247 & 50.61 & 18. 05 \\
\hline 7 & 48.07 & 20.98 & 184 & 44.94 & 21.82 & 181 & 55.82 & 14.92 & 249 & 52.59 & 17. 41 \\
\hline 8 & 44.34 & 22.10 & 179 & 41.29 & 23.04 & 170 & 50.20 & 17.85 & 247 & 51.41 & 17. 18 \\
\hline 9 & 46.95 & 20.07 & 178 & 46. 13 & 20.08 & 174 & 52.28 & 16.72 & 247 & 53.24 & 15.78 \\
\hline 10 & 46. 07 & 22.52 & 183 & 44.82 & 22.75 & 181 & 53.77 & 15.83 & 247 & 50.54 & 18.80 \\
\hline 11 & 44.50 & 24.10 & 186 & 44.04 & 22.73 & 178 & 49.57 & 19.25 & 247 & 49.42 & 19.41 \\
\hline 12 & 46.38 & 22.05 & 177 & 44.94 & 22.35 & 166 & 50.69 & 19. 36 & 237 & 49.73 & 20.02 \\
\hline 13 & 45.16 & 22.65 & 183 & 43. 35 & 21.49 & 172 & 51.52 & 17. 38 & 246 & 50.52 & 18. 29 \\
\hline 14 & 47.06 & 20.61 & 186 & 47.87 & 20.04 & 179 & 56.94 & 14.40 & 250 & 56.05 & 14.89 \\
\hline 15 & 46.94 & 20.93 & 185 & 49. 48 & 18.55 & 181 & 55.36 & 15.46 & 249 & 54.35 & 16.56 \\
\hline 16 & 45.42 & 21.31 & 175 & 42.42 & 22.40 & 158 & 46.30 & 22.12 & 222 & 46.99 & 19. 57 \\
\hline 17 & 46.33 & 21.56 & 185 & 45.83 & 21.44 & 178 & 54.09 & 16.07 & 248 & 54.35 & 15.93 \\
\hline 18 & 46.47 & 21.43 & 184 & 46. 14 & 20.52 & 175 & 52.85 & 16.50 & 230 & 52.35 & 17. 14 \\
\hline 19 & 45.26 & 23.75 & 186 & 45.45 & 22.68 & 176 & 53.36 & 17.51 & 250 & 50.90 & 19. 31 \\
\hline 20 & 46.62 & 22.26 & 177 & 44.84 & 22.21 & 169 & 53. 18 & 17.01 & 239 & 52.70 & 17.58 \\
\hline 21 & 45.57 & 22.25 & 184 & 44.97 & 21.38 & 177 & 54.91 & 14.87 & 242 & 51.73 & 17.15 \\
\hline 22 & 43.28 & 23.50 & 181 & 39. 17 & 26.17 & 172 & 48.53 & 20.58 & 244 & 48.28 & 20.94 \\
\hline 23 & 44. 03 & 21.48 & 180 & 42.59 & 22.28 & 173 & 49.53 & 17.76 & 238 & 48.52 & 19. 16 \\
\hline 24 & 43.38 & 22.79 & 187 & 43.62 & 23.80 & 184 & 50.01 & 18. 10 & 249 & 49.46 & 19.91 \\
\hline 25 & 44.59 & 22.18 & 187 & 47.59 & 19. 62 & 176 & 53.68 & 15. 20 & 248 & 53.31 & 15. 58 \\
\hline 26 & 47.03 & 21.32 & 179 & 45.11 & 22.41 & 171 & 52.66 & 17.24 & 236 & 51.38 & 17.98 \\
\hline 27 & 44. 38 & 23.13 & 184 & 43. 02 & 23. 19 & 177 & 50.61 & 18. 34 & 247 & 52.68 & 16. 38 \\
\hline 28 & 44. 86 & 22.03 & 183 & 46.11 & 20.77 & 176 & 50.75 & 18.03 & 248 & 49. 38 & 19. 39 \\
\hline 29 & 45.05 & 21.95 & 177 & 42.53 & 22.36 & 167 & 47.88 & 19.47 & 232 & 50.20 & 17.62 \\
\hline 30 & 45.61 & 21.70 & 176 & 45.79 & 20.55 & 163 & 49. 79 & 18. 32 & 231 & 49. 57 & 19.25 \\
\hline 31 & 46. 26 & 20.86 & 178 & 43.22 & 22.04 & 163 & 49. 78 & 18.68 & 225 & 49. 26 & 18. 08 \\
\hline 32 & 43.95 & 23.00 & 178 & 43.92 & 22.51 & 175 & 52.83 & 17.75 & 247 & 51.33 & 18.48 \\
\hline 33 & 45.96 & 21.35 & 185 & 44. 27 & 21.58 & 173 & 51.67 & 17.22 & 238 & 53.24 & 16. 62 \\
\hline 34 & 43. 16 & 21.94 & 177 & 41.61 & 22.06 & 158 & 51.04 & 17.79 & 222 & 52.98 & 16. 39 \\
\hline 35 & 44. 10 & 22.50 & 176 & 44.55 & 22.29 & 164 & 47.75 & 19.80 & 229 & 50.50 & 18. 40 \\
\hline 36 & 45.70 & 20.97 & 178 & 44.91 & 21.02 & 176 & 50.35 & 17.57 & 245 & 47.86 & 18. 20 \\
\hline 37 & 45.55 & 22.96 & 185 & 43.75 & 22.66 & 184 & 56.27 & 14. 64 & 248 & 52.87 & 17. 48 \\
\hline 38 & 43. 33 & 23.51 & 185 & 44.52 & 21.89 & 185 & 53.29 & 15.82 & 251 & 51.78 & 17.90 \\
\hline 39 & 41.66 & 23.04 & 179 & 41.21 & 23. 21 & 177 & 50.95 & 15.82 & 246 & 51.51 & 17.15 \\
\hline 40 & 41.20 & 21.15 & 179 & 45.32 & 19.59 & 174 & 48.72 & 18.34 & 246 & 48. 35 & 18.75 \\
\hline 41 & 41.46 & 22.41 & 178 & 42.70 & 21.89 & 180 & 48.03 & 17.70 & 248 & 49.56 & 18.11 \\
\hline 42 & 42.07 & 22.18 & 187 & 45.20 & 20.32 & 177 & 49. 61 & 17.13 & 248 & 50.06 & 17.29 \\
\hline 43 & 45.60 & 22.39 & 189 & 43.77 & 23. 39 & 189 & 54.02 & 17.23 & 250 & 52.13 & 18.74 \\
\hline 44 & 42.41 & 22.60 & 182 & 40.73 & 23.46 & 179 & 49. 88 & 17.38 & 249 & 49. 90 & 17.28 \\
\hline
\end{tabular}




\begin{tabular}{|c|c|c|c|c|c|c|c|c|c|c|c|}
\hline \multirow[b]{2}{*}{45} & \multirow[b]{2}{*}{44.95} & \multirow[b]{2}{*}{21.94} & \multirow[b]{2}{*}{188} & \multirow[b]{2}{*}{44.23} & \multirow[b]{2}{*}{21.48} & \multirow[b]{2}{*}{181} & \multirow[b]{2}{*}{53.29} & \multirow[b]{2}{*}{15.39} & \multirow[b]{2}{*}{249} & \multicolumn{2}{|c|}{ Continued } \\
\hline & & & & & & & & & & 51.25 & 17.51 \\
\hline 46 & 42.92 & 22.17 & 184 & 42.52 & 22.50 & 177 & 52.76 & 15. 94 & 244 & 51.00 & 17.25 \\
\hline 47 & 46.42 & 20.86 & 184 & 44.73 & 21.89 & 178 & 52.92 & 16. 42 & 246 & 53.79 & 15.64 \\
\hline 48 & 44. 14 & 23.00 & 184 & 44. 22 & 22.70 & 182 & 50.10 & 17.92 & 248 & 51.01 & 18. 12 \\
\hline 49 & 46.56 & 21.69 & 184 & 46. 04 & 21.39 & 180 & 53.29 & 16.59 & 249 & 51.11 & 18. 53 \\
\hline 50 & 44.61 & 22.22 & 186 & 46. 17 & 20.77 & 180 & 52.88 & 15.42 & 249 & 53.49 & 15.85 \\
\hline 51 & 42.59 & 22.22 & 188 & 42.82 & 22.45 & 186 & 49.75 & 17.82 & 250 & 47.71 & 19.65 \\
\hline 52 & 43.99 & 21.36 & 184 & 41.61 & 21.45 & 180 & 53.54 & 15.50 & 247 & 51.97 & 16. 06 \\
\hline 53 & 43. 47 & 23.92 & 183 & 43.95 & 23. 19 & 178 & 52.35 & 17.06 & 248 & 51.36 & 18. 15 \\
\hline 54 & 42.77 & 22.48 & 180 & 43.74 & 21.55 & 176 & 51.82 & 17. 13 & 247 & 51.81 & 16.90 \\
\hline 55 & 43. 66 & 21.79 & 186 & 41.82 & 23.10 & 185 & 51.93 & 17.08 & 251 & 50.94 & 18. 10 \\
\hline 56 & 42.90 & 21.86 & 188 & 43.74 & 22.89 & 187 & 51.53 & 17.80 & 252 & 50.10 & 19.91 \\
\hline 57 & 47.18 & 21.60 & 181 & 46. 18 & 21.42 & 179 & 52.97 & 16.34 & 248 & 53.40 & 16.14 \\
\hline 58 & 44.79 & 22.12 & 183 & 45.76 & 21.61 & 179 & 53.66 & 16.33 & 246 & 51.52 & 17.77 \\
\hline 59 & 45.66 & 21.19 & 185 & 41.45 & 23.63 & 181 & 52.76 & 16.35 & 249 & 49.46 & 19.09 \\
\hline 60 & 45. 39 & 21.82 & 186 & 42. 10 & 22.83 & 182 & 53.37 & 15.55 & 248 & 51.33 & 17.60 \\
\hline 61 & 42.64 & 23.40 & 185 & 43.46 & 23.86 & 181 & 53.89 & 17.15 & 249 & 52.58 & 18. 18 \\
\hline 62 & 45. 11 & 21.79 & 183 & 46.77 & 20.05 & 172 & 51.95 & 17.08 & 235 & 52.23 & 16. 97 \\
\hline 63 & 45.22 & 21.56 & 181 & 44.44 & 21.88 & 173 & 51.87 & 16.13 & 245 & 50.15 & 17.39 \\
\hline 64 & 43.23 & 23. 51 & 189 & 42.97 & 22.99 & 189 & 50.27 & 19. 18 & 251 & 51.66 & 18. 29 \\
\hline 65 & 44. 07 & 23.20 & 189 & 43. 55 & 23. 52 & 180 & 51.37 & 17.98 & 249 & 49. 63 & 19. 99 \\
\hline 66 & 46.78 & 20.26 & 182 & 47.76 & 20.47 & 176 & 55.16 & 15. 18 & 248 & 55.09 & 14.81 \\
\hline 67 & 43.87 & 22.01 & 185 & 45.37 & 21.63 & 178 & 52.81 & 16.63 & 249 & 52.41 & 17.14 \\
\hline 68 & 49. 18 & 20.37 & 177 & 46.35 & 22.08 & 173 & 52.94 & 17.14 & 241 & 51.92 & 17.80 \\
\hline 69 & 44.36 & 22.50 & 184 & 44.03 & 22.72 & 177 & 52.30 & 16.57 & 246 & 49.90 & 18. 36 \\
\hline 70 & 45.90 & 22.27 & 190 & 45.33 & 21.97 & 182 & 55.54 & 14.71 & 249 & 53.93 & 15.82 \\
\hline 71 & 44. 29 & 22. 32 & 185 & 46. 18 & 21.29 & 184 & 53. 31 & 16.15 & 250 & 52.00 & 17.53 \\
\hline 72 & 46.09 & 21.60 & 186 & 43.75 & 23.17 & 183 & 52.75 & 16.99 & 248 & 51.16 & 18.15 \\
\hline 73 & 44.77 & 22.19 & 183 & 44.58 & 22.33 & 183 & 52.86 & 16.79 & 249 & 51.99 & 17.41 \\
\hline 74 & 44.68 & 21.69 & 181 & 43. 37 & 20.54 & 178 & 51.11 & 15.88 & 248 & 52.43 & 15.72 \\
\hline 75 & 47. 36 & 21.27 & 179 & 45.32 & 21.13 & 176 & 53.89 & 16. 19 & 244 & 52.89 & 16.84 \\
\hline 76 & 45.81 & 22.15 & 178 & 44.75 & 21.99 & 176 & 54.77 & 15.59 & 244 & 53.79 & 16. 20 \\
\hline 77 & 43. 15 & 23. 80 & 184 & 44.23 & 22.78 & 178 & 47.84 & 19.70 & 249 & 48. 98 & 19. 46 \\
\hline 78 & 43. 09 & 23.23 & 177 & 38.69 & 24.92 & 174 & 50.10 & 17.53 & 242 & 47.55 & 19.14 \\
\hline 79 & 41.17 & 25.01 & 189 & 38.27 & 25.17 & 190 & 48. 96 & 17. 37 & 253 & 47. 17 & 19. 51 \\
\hline 80 & 44.13 & 22.02 & 185 & 44.94 & 22.17 & 178 & 52.31 & 16.63 & 248 & 50.81 & 18. 40 \\
\hline 81 & 43.90 & 21.13 & 187 & 45.62 & 21.56 & 177 & 52.47 & 16.52 & 247 & 49.72 & 18.95 \\
\hline 82 & 46. 66 & 21.28 & 179 & 44.23 & 22.16 & 168 & 49. 51 & 18. 81 & 234 & 50.73 & 18. 64 \\
\hline 83 & 41.82 & 22.83 & 184 & 42.75 & 22.48 & 180 & 51.07 & 16.91 & 248 & 49. 01 & 19. 26 \\
\hline 84 & 44.54 & 23.34 & 186 & 43.06 & 24.02 & 189 & 53.00 & 16.95 & 250 & 50.01 & 19.56 \\
\hline 85 & 45.50 & 21.61 & 186 & 41.10 & 23.97 & 186 & 52.33 & 17.29 & 250 & 52.12 & 17.37 \\
\hline 86 & 44.71 & 22.08 & 185 & 44.21 & 22.53 & 177 & 53.59 & 16.68 & 245 & 53. 33 & 16.53 \\
\hline 87 & 45.53 & 21.66 & 185 & 44.43 & 22.02 & 176 & 51.72 & 17.61 & 247 & 51.43 & 17.54 \\
\hline 88 & 42.84 & 23. 14 & 177 & 42.57 & 23.25 & 173 & 51.59 & 17.75 & 235 & 51.42 & 18. 26 \\
\hline 89 & 43. 12 & 22.22 & 180 & 46.32 & 19.79 & 179 & 53.78 & 15.58 & 248 & 54.31 & 15.24 \\
\hline 90 & 43.15 & 24.60 & 182 & 40.50 & 25.63 & 175 & 48.91 & 19.94 & 243 & 48. 71 & 20.72 \\
\hline 91 & 46. 14 & 20.20 & 185 & 43.41 & 22.41 & 178 & 52.03 & 16.88 & 246 & 52.92 & 16.06 \\
\hline
\end{tabular}




\begin{tabular}{|c|c|c|c|c|c|c|c|c|c|c|c|}
\hline & & & & & & & & & & \multicolumn{2}{|c|}{ Continued } \\
\hline 92 & 45.15 & 22.12 & 183 & 45.32 & 22.53 & 178 & 52.92 & 17.02 & 248 & 51.66 & 18.13 \\
\hline 93 & 44.60 & 22.28 & 185 & 43.54 & 22.13 & 181 & 54.64 & 15.52 & 248 & 51.00 & 18. 11 \\
\hline 94 & 44.21 & 21.53 & 176 & 46.40 & 20.49 & 158 & 47.75 & 20.09 & 223 & 50.36 & 18.63 \\
\hline 95 & 46.85 & 21.39 & 183 & 46.07 & 21.55 & 174 & 53.28 & 16.79 & 238 & 53.66 & 16.66 \\
\hline 96 & 43.33 & 22.88 & 183 & 45.47 & 21.14 & 179 & 51.86 & 17.34 & 247 & 47.53 & 19.76 \\
\hline 97 & 44.75 & 22.43 & 181 & 43.75 & 22.08 & 181 & 51.11 & 17.48 & 247 & 50.11 & 18.26 \\
\hline 98 & 42.87 & 22.56 & 183 & 43.84 & 21.99 & 179 & 51.92 & 16.91 & 247 & 51.79 & 17.56 \\
\hline 99 & 44.34 & 21.98 & 183 & 45. 09 & 21.42 & 179 & 50.99 & 17.21 & 247 & 50.91 & 17.95 \\
\hline 100 & 44.92 & 21.79 & 189 & 43.58 & 22.89 & 185 & 51.72 & 17. 19 & 251 & 49.73 & 18.53 \\
\hline 101 & 46.31 & 21.78 & 182 & 45.45 & 20.90 & 172 & 51.71 & 17.50 & 245 & 49. 84 & 18. 57 \\
\hline 102 & 44.58 & 21.44 & 178 & 46. 09 & 21.08 & 171 & 50.35 & 18.26 & 244 & 49.78 & 18.50 \\
\hline 103 & 45.45 & 22.56 & 184 & 45.78 & 22.18 & 181 & 54.90 & 15.41 & 249 & 51.77 & 17.90 \\
\hline 104 & 43.83 & 22.08 & 184 & 43. 48 & 22.79 & 179 & 51.72 & 16.52 & 246 & 51.39 & 16.91 \\
\hline 105 & 44. 99 & 22.21 & 178 & 45. 11 & 21.15 & 170 & 52.69 & 16.22 & 236 & 50.99 & 17.42 \\
\hline 106 & 46.36 & 21.03 & 182 & 45.02 & 21.74 & 179 & 55.33 & 14.55 & 250 & 53. 36 & 16.12 \\
\hline 107 & . & . & . & . & . & . & 52.45 & 17.46 & 252 & 49. 26 & 19. 97 \\
\hline 108 & 44.83 & 21.73 & 182 & 44. 31 & 22.27 & 175 & 52.00 & 16. 81 & 247 & 51.69 & 17. 47 \\
\hline 109 & 45.72 & 22.23 & 184 & 43. 06 & 22.95 & 181 & 53. 58 & 16. 34 & 250 & 51.38 & 18. 43 \\
\hline 110 & 42.13 & 24.17 & 184 & 42.96 & 23.78 & 183 & 50.88 & 19.62 & 251 & 50.18 & 18. 86 \\
\hline 111 & 42.28 & 23.66 & 188 & 42.12 & 24.07 & 182 & 51.84 & 17.84 & 250 & 50.74 & 18.95 \\
\hline 112 & 42.46 & 23.70 & 187 & 44.95 & 21.55 & 178 & 50.91 & 17.60 & 249 & 47.64 & 20.16 \\
\hline 113 & 42. 15 & 22.63 & 185 & 45.84 & 20.76 & 177 & 49.27 & 18. 92 & 248 & 48.65 & 19. 64 \\
\hline 114 & 42.52 & 22.97 & 184 & 45.31 & 21.08 & 178 & 49. 03 & 18.55 & 247 & 48. 92 & 19. 10 \\
\hline 115 & 43. 87 & 22.12 & 184 & 46.44 & 20.62 & 177 & 48. 04 & 19.45 & 247 & 47.05 & 20.05 \\
\hline 116 & 44.25 & 22.66 & 179 & 46.60 & 20.55 & 170 & 48.48 & 19.51 & 221 & 49. 39 & 18. 44 \\
\hline 117 & 44. 21 & 22.44 & 187 & 44. 14 & 21.99 & 185 & 54.10 & 16.23 & 248 & 50.58 & 19.01 \\
\hline 118 & 43.66 & 21.77 & 180 & 44.95 & 21.30 & 170 & 50.08 & 18.16 & 238 & 50.16 & 18.09 \\
\hline 119 & 44.51 & 22.02 & 185 & 44. 62 & 21.51 & 180 & 53.48 & 15.43 & 247 & 51.94 & 16.53 \\
\hline 120 & 40.46 & 23.58 & 180 & 44. 24 & 20.57 & 159 & 41.78 & 24.24 & 232 & 42.26 & 23.53 \\
\hline 121 & 46. 30 & 22.11 & 184 & 45.33 & 21.61 & 178 & 52.73 & 16.80 & 247 & 51.96 & 17.47 \\
\hline 122 & 43. 51 & 21.28 & 184 & 44. 11 & 20.96 & 176 & 52.10 & 16.45 & 247 & 52.57 & 16. 05 \\
\hline 123 & 44. 97 & 22.84 & 186 & 43. 62 & 21.80 & 176 & 52.43 & 16.81 & 246 & 50.71 & 18.75 \\
\hline 124 & 44.68 & 21.90 & 185 & 44.86 & 20.99 & 178 & 51.63 & 17.29 & 248 & 49.41 & 18.84 \\
\hline 125 & 46.54 & 21.29 & 187 & 46.62 & 20.65 & 183 & 54.96 & 15.27 & 249 & 52.91 & 16. 10 \\
\hline 126 & 45.96 & 21.69 & 185 & 44.81 & 22.75 & 184 & 54.32 & 16.42 & 250 & 53.06 & 16.47 \\
\hline 127 & 42.80 & 21.43 & 186 & 44. 39 & 22.24 & 183 & 50.18 & 17.54 & 250 & 50.91 & 17.72 \\
\hline 128 & 46.32 & 21.56 & 182 & 47.41 & 20.70 & 176 & 51.68 & 17.73 & 239 & 51.21 & 17.98 \\
\hline 129 & 47.64 & 20.40 & 183 & 47.33 & 21.41 & 176 & 53.99 & 16.35 & 242 & 52.18 & 17.41 \\
\hline 130 & 46.61 & 21.62 & 182 & 44. 88 & 21.46 & 176 & 51.71 & 17.20 & 246 & 52.00 & 17. 13 \\
\hline 131 & 47.82 & 20.15 & 182 & 45.83 & 21.45 & 175 & 52.20 & 17.14 & 244 & 51.31 & 17.24 \\
\hline 132 & 45. 13 & 21.14 & 184 & 45.68 & 21.18 & 178 & 54.13 & 16.55 & 248 & 52.64 & 17.93 \\
\hline 133 & 46. 77 & 21.23 & 182 & 42.81 & 22.20 & 172 & 53.61 & 16.03 & 239 & 51.76 & 17. 14 \\
\hline 134 & 45. 66 & 21.93 & 184 & 45.47 & 21.08 & 173 & 53.12 & 16. 97 & 240 & 51.98 & 17.71 \\
\hline 135 & 44. 24 & 22.26 & 185 & 41.51 & 24.06 & 177 & 52.89 & 16.35 & 247 & 49.57 & 18. 46 \\
\hline 136 & 46.88 & 21.56 & 185 & 44. 10 & 22.82 & 180 & 54.61 & 17.21 & 250 & 52.86 & 17. 67 \\
\hline 137 & 43.33 & 22.66 & 189 & 42.82 & 22.70 & 189 & 51.20 & 18. 11 & 251 & 48. 67 & 19. 94 \\
\hline 138 & 44.54 & 22.09 & 187 & 43. 33 & 22.22 & 178 & 52.45 & 16. 12 & 247 & 51.09 & 17. 29 \\
\hline
\end{tabular}




\begin{tabular}{|c|c|c|c|c|c|c|c|c|c|c|c|}
\hline & & & & & & & & & & \multicolumn{2}{|c|}{ Continued } \\
\hline 139 & 46.40 & 22.21 & 181 & 43.75 & 22.39 & 170 & 54.09 & 16.27 & 244 & 53.31 & 16.99 \\
\hline 140 & 43.72 & 22.19 & 184 & 42.00 & 24. 12 & 176 & 50.36 & 18.25 & 244 & 49. 99 & 18. 92 \\
\hline 141 & 44.46 & 22.91 & 185 & 45.33 & 22.78 & 172 & 52.09 & 16.83 & 246 & 51.97 & 17.33 \\
\hline 142 & 44.60 & 22.32 & 186 & 45.18 & 21.12 & 178 & 53.64 & 15.72 & 246 & 52.07 & 17.61 \\
\hline 143 & 45.07 & 22.69 & 184 & 44.89 & 22.30 & 183 & 51.92 & 17. 17 & 248 & 51.28 & 17.84 \\
\hline 144 & 45.16 & 23.03 & 183 & 44.97 & 22.80 & 178 & 49. 74 & 18. 80 & 248 & 50.91 & 18.27 \\
\hline 145 & 43.07 & 23.37 & 185 & 41.61 & 23.96 & 182 & 52.18 & 16.48 & 250 & 52.07 & 17.04 \\
\hline 146 & 43. 21 & 23.37 & 188 & 42.54 & 23. 22 & 183 & 52.75 & 16.22 & 251 & 50.03 & 18.80 \\
\hline 147 & 43.65 & 22.75 & 194 & 41.91 & 23.48 & 189 & 50.40 & 17.03 & 250 & 50.93 & 17.09 \\
\hline 148 & 47.90 & 21.12 & 183 & 49. 11 & 19. 31 & 174 & 53.51 & 16. 08 & 247 & 54.20 & 15.77 \\
\hline 149 & 43.57 & 22.53 & 180 & 46.34 & 20.16 & 174 & 52.30 & 16.61 & 245 & 52.18 & 16.52 \\
\hline 150 & 42.85 & 23.70 & 187 & 44. 13 & 22.34 & 186 & 53.20 & 16.62 & 251 & 52.36 & 16.95 \\
\hline 151 & 42.72 & 22.78 & 184 & 44.07 & 23.17 & 182 & 51.64 & 18. 20 & 249 & 49.90 & 19. 80 \\
\hline 152 & 46.66 & 21.59 & 184 & 47.36 & 20.27 & 182 & 53.51 & 17.32 & 250 & 52.53 & 17.76 \\
\hline 153 & 42.84 & 23. 02 & 178 & 40.32 & 24. 92 & 173 & 47.54 & 20. 32 & 236 & 47.77 & 18. 93 \\
\hline 154 & 44.68 & 22.19 & 184 & 42.34 & 22.16 & 176 & 53.27 & 17.15 & 238 & 53. 17 & 16.67 \\
\hline 155 & 44. 03 & 23.46 & 185 & 42.22 & 23.93 & 180 & 48.74 & 18.82 & 248 & 48. 32 & 19.82 \\
\hline 156 & 45.80 & 21.14 & 185 & 45.74 & 21.40 & 182 & 54.35 & 16.13 & 249 & 53.11 & 17.34 \\
\hline 157 & 44. 46 & 23.07 & 185 & 44. 76 & 21.88 & 173 & 51.28 & 17.65 & 242 & 51.14 & 18. 03 \\
\hline 158 & 46. 06 & 21.80 & 176 & 45.09 & 20.23 & 170 & 50.47 & 17.64 & 236 & 50.26 & 17.95 \\
\hline 159 & 43.35 & 20.41 & 184 & 44. 76 & 19. 55 & 178 & 51.43 & 16. 04 & 249 & 52.52 & 15.35 \\
\hline 160 & 42.01 & 23.28 & 185 & 41.99 & 22.44 & 174 & 52.01 & 16.44 & 248 & 48. 48 & 18. 91 \\
\hline 161 & 42.84 & 23.07 & 181 & 42.11 & 22.58 & 167 & 52.41 & 17.09 & 244 & 49. 08 & 19.32 \\
\hline 162 & 46.73 & 20.94 & 183 & 45.04 & 21.54 & 175 & 54.25 & 16.43 & 246 & 53.37 & 17.33 \\
\hline 163 & 47.31 & 21.69 & 184 & 46. 36 & 21.13 & 176 & 53.35 & 17.71 & 247 & 51.78 & 18. 66 \\
\hline 164 & 46.40 & 20.60 & 184 & 43.55 & 20.79 & 177 & 54.54 & 14.69 & 248 & 51.92 & 16.80 \\
\hline 165 & 40.70 & 24.85 & 184 & 42.69 & 24.13 & 178 & 50.00 & 19. 13 & 248 & 50.55 & 19.90 \\
\hline 166 & 42.13 & 21.60 & 187 & 44. 36 & 21.76 & 184 & 51.88 & 17. 12 & 250 & 52.32 & 17. 34 \\
\hline 167 & 47.31 & 21.55 & 184 & 43. 02 & 24.66 & 188 & 51.37 & 17.59 & 251 & 50.23 & 18. 38 \\
\hline 168 & 43.89 & 21.56 & 183 & 42.73 & 22.48 & 176 & 51.58 & 16.26 & 248 & 53.52 & 15.42 \\
\hline 169 & 44.17 & 22.65 & 184 & 44.25 & 22.24 & 177 & 52.02 & 17.42 & 242 & 53.16 & 16.27 \\
\hline 170 & 44. 77 & 21.53 & 183 & 44. 05 & 21.77 & 181 & 54.44 & 14. 67 & 248 & 53. 38 & 15.71 \\
\hline 171 & 46.55 & 21.12 & 184 & 46. 20 & 20.68 & 184 & 52.94 & 16.22 & 249 & 51.86 & 17.24 \\
\hline 172 & 42.64 & 23.06 & 187 & 42.57 & 22.80 & 178 & 51.80 & 16.06 & 249 & 51.72 & 16.56 \\
\hline 174 & 47. 10 & 21.93 & 184 & 46. 27 & 21.59 & 180 & 50.90 & 18.79 & 250 & 50.87 & 18. 69 \\
\hline 175 & 42.00 & 23.41 & 184 & 45.79 & 21.14 & 182 & 49. 74 & 19. 26 & 249 & 49. 85 & 19.11 \\
\hline 176 & 45.75 & 21.48 & 185 & 45.00 & 21.53 & 178 & 54.99 & 15.97 & 248 & 53. 30 & 17.24 \\
\hline 177 & 45.49 & 22.85 & 184 & 43.50 & 23.63 & 181 & 54.13 & 16.02 & 247 & 51.59 & 17.93 \\
\hline 178 & 43.59 & 21.28 & 184 & 45.09 & 19.71 & 180 & 37.79 & 24.08 & 252 & 40.73 & 21.92 \\
\hline 179 & 44.84 & 21.03 & 188 & 41.48 & 23. 27 & 180 & 53.97 & 14.99 & 250 & 51.09 & 17.57 \\
\hline 180 & 43. 22 & 21.64 & 182 & 46. 12 & 20.60 & 178 & 53.53 & 16.09 & 247 & 52.33 & 17.28 \\
\hline 181 & 46. 11 & 20.68 & 184 & 45.44 & 20.70 & 183 & 53.98 & 14.21 & 249 & 52.83 & 15.52 \\
\hline 182 & 40.39 & 21.16 & 180 & 43. 35 & 20.17 & 169 & 45.25 & 18.73 & 246 & 41.97 & 22.05 \\
\hline 183 & 45.68 & 21.49 & 185 & 44.89 & 21.01 & 186 & 52.50 & 16.23 & 251 & 52.16 & 16.25 \\
\hline 184 & 44. 21 & 22.52 & 188 & 44. 34 & 23.72 & 179 & 52.40 & 17.56 & 250 & 50.81 & 19. 16 \\
\hline 185 & 42.98 & 22.05 & 185 & 42. 39 & 22.86 & 181 & 51.84 & 16.13 & 247 & 51.56 & 16. 53 \\
\hline 186 & 43.02 & 24.47 & 188 & 41.41 & 24.37 & 186 & 54.48 & 16.45 & 250 & 51.84 & 18. 04 \\
\hline 187 & 42.26 & 21.59 & 188 & 42.24 & 22.73 & 179 & 49.49 & 17.13 & 247 & 50.23 & 17. 67 \\
\hline 188 & 45.74 & 22.35 & 184 & 44. 06 & 23.31 & 176 & 52.85 & 17. 03 & 246 & 50.91 & 18. 36 \\
\hline
\end{tabular}




\begin{tabular}{|c|c|c|c|c|c|c|c|c|c|c|c|}
\hline & & & & & & & & & & \multicolumn{2}{|c|}{ Continued } \\
\hline 189 & 44.97 & 21.76 & 187 & 44.53 & 21.59 & 185 & 54.02 & 15.53 & 249 & 52.12 & 16.47 \\
\hline 190 & 43. 23 & 22.56 & 188 & 44. 65 & 22.05 & 182 & 53. 22 & 16. 32 & 250 & 50.58 & 18.32 \\
\hline 191 & 46.56 & 22.44 & 183 & 46.87 & 20.57 & 176 & 50.28 & 17.54 & 248 & 50.38 & 18. 47 \\
\hline 192 & 45.15 & 21.91 & 187 & 44. 40 & 22.90 & 184 & 51.01 & 18. 26 & 250 & 49. 28 & 19. 44 \\
\hline 193 & 45.54 & 22.09 & 184 & 42.40 & 21.87 & 170 & 53.01 & 16.96 & 235 & 52.01 & 17.70 \\
\hline 194 & 46.81 & 21.79 & 178 & 45.96 & 20.58 & 167 & 48. 33 & 19.58 & 231 & 50.48 & 18.53 \\
\hline 195 & 43.49 & 22. 12 & 184 & 43.59 & 21.99 & 183 & 54.07 & 14.62 & 249 & 53.63 & 15.00 \\
\hline 196 & 43.94 & 21.17 & 184 & 44. 86 & 21.77 & 178 & 52.50 & 16. 61 & 247 & 51.44 & 16.73 \\
\hline 197 & 43.69 & 23. 21 & 188 & 42.68 & 23.47 & 188 & 55.71 & 14. 72 & 250 & 53.72 & 17.08 \\
\hline 198 & 48.50 & 20.60 & 181 & 47.77 & 21.12 & 180 & 57.04 & 14.07 & 247 & 54.90 & 16. 02 \\
\hline 199 & 43.95 & 22.20 & 183 & 44. 86 & 21.50 & 176 & 52.64 & 15. 79 & 246 & 50.95 & 17.59 \\
\hline 200 & 44.54 & 21.10 & 187 & 42. 39 & 21.89 & 184 & 54.00 & 15.06 & 251 & 51.31 & 17. 29 \\
\hline 201 & 46. 40 & 21.83 & 181 & 45.71 & 22.04 & 178 & 55.03 & 16.07 & 239 & 53. 31 & 17. 45 \\
\hline 202 & 44. 74 & 21.43 & 185 & 46.07 & 20.84 & 182 & 51.78 & 16.90 & 251 & 51.07 & 17.95 \\
\hline 203 & 46. 61 & 21.84 & 187 & 45. 17 & 22.44 & 183 & 55.75 & 15. 46 & 249 & 53.34 & 17. 49 \\
\hline 204 & 43.53 & 21.79 & 186 & 43.75 & 22.18 & 182 & 53.52 & 16. 61 & 249 & 51.21 & 18. 37 \\
\hline 205 & 46.62 & 20.19 & 184 & 47. 45 & 20.08 & 174 & 52.27 & 17.91 & 248 & 51.37 & 17.92 \\
\hline 206 & 44.04 & 21.55 & 187 & 45. 18 & 21. 09 & 184 & 53.86 & 15.06 & 250 & 52.00 & 16.60 \\
\hline 207 & 47.48 & 20.79 & 185 & 49. 07 & 19. 66 & 179 & 55.26 & 14.75 & 245 & 53.86 & 15.74 \\
\hline 208 & 45.96 & 22.17 & 180 & 43. 12 & 22. 82 & 174 & 51.96 & 17.74 & 241 & 49.81 & 19. 18 \\
\hline 209 & 43.83 & 22.23 & 183 & 43. 62 & 21.89 & 177 & 51.26 & 16. 45 & 248 & 51.82 & 16. 03 \\
\hline 210 & 44. 69 & 21.40 & 185 & 43. 19 & 21.18 & 180 & 54.72 & 14.57 & 249 & 53. 38 & 15.95 \\
\hline 211 & 43.73 & 24.14 & 184 & 42.48 & 24. 12 & 178 & 52.60 & 17. 18 & 248 & 50.24 & 18.74 \\
\hline 212 & 44. 59 & 22.83 & 183 & 43.22 & 23. 36 & 181 & 51. 18 & 18.58 & 248 & 50.78 & 19. 81 \\
\hline 213 & 42.61 & 23. 16 & 188 & 42.34 & 24.20 & 186 & 52.46 & 16.80 & 252 & 50.32 & 18.56 \\
\hline 214 & 46.64 & 21.27 & 185 & 44. 43 & 21.84 & 185 & 56.46 & 14. 40 & 251 & 54. 18 & 15.82 \\
\hline 215 & 45.01 & 22.03 & 188 & 42.84 & 23. 68 & 188 & 52.28 & 16.59 & 250 & 51.75 & 17. 21 \\
\hline 216 & 45. 08 & 22.48 & 184 & 43. 31 & 22.81 & 181 & 53. 37 & 17. 02 & 248 & 51.30 & 18.24 \\
\hline 217 & . & . & . & . & . & . & 53. 29 & 16. 21 & 249 & 52.12 & 17. 13 \\
\hline 218 & 47.47 & 19.86 & 184 & 46.60 & 19. 80 & 174 & 55.73 & 15.54 & 242 & 54.70 & 16.49 \\
\hline 219 & 45. 40 & 22.47 & 178 & 45. 09 & 22.20 & 171 & 52.18 & 17.56 & 231 & 51.01 & 18.78 \\
\hline 220 & 45.40 & 21.60 & 185 & 44. 38 & 22. 19 & 186 & 52.52 & 16. 34 & 249 & 50.74 & 18. 12 \\
\hline 221 & 44. 87 & 21.21 & 182 & 44.60 & 21. 09 & 176 & 49.94 & 17.10 & 242 & 51.32 & 16.33 \\
\hline 222 & 44. 34 & 22.20 & 179 & 43. 82 & 23. 02 & 175 & 52.11 & 17.47 & 237 & 52. 36 & 17. 41 \\
\hline 223 & 44. 43 & 23.27 & 188 & 44.28 & 23.14 & 189 & 53. 32 & 16.67 & 240 & 52.31 & 18. 28 \\
\hline 224 & 45.54 & 22.00 & 185 & 43. 10 & 23. 79 & 178 & 51.06 & 18. 25 & 248 & 51.06 & 18. 26 \\
\hline 225 & 45.28 & 23.48 & 178 & 43. 18 & 24. 20 & 166 & 49. 05 & 20.24 & 231 & 48. 96 & 19.85 \\
\hline 226 & 44. 45 & 22.28 & 182 & 44.07 & 21.94 & 178 & 50.81 & 17.35 & 247 & 49. 66 & 18. 24 \\
\hline 227 & 44. 92 & 22.28 & 183 & 45.53 & 21. 28 & 178 & 52.66 & 17.00 & 247 & 51. 66 & 17.44 \\
\hline 228 & 43.44 & 23.27 & 182 & 43.32 & 23. 31 & 178 & 49.96 & 18. 14 & 238 & 49. 32 & 19. 31 \\
\hline 229 & 44. 44 & 21.94 & 184 & 41.81 & 24. 09 & 179 & 52. 18 & 17. 29 & 241 & 50.36 & 18. 09 \\
\hline 230 & 43.94 & 21.73 & 185 & 43.99 & 22.13 & 183 & 52.57 & 15.93 & 246 & 51.08 & 17.34 \\
\hline 231 & 42.95 & 22.09 & 183 & 42.51 & 23. 22 & 179 & 50.52 & 16.83 & 240 & 51.63 & 16.33 \\
\hline 232 & 44.90 & 22.37 & 184 & 43. 36 & 23.64 & 182 & 51.92 & 17.61 & 249 & 49. 49 & 19. 52 \\
\hline 233 & 44. 28 & 22. 28 & 183 & 46.73 & 20.78 & 169 & 51.17 & 17.36 & 236 & 50.59 & 18. 24 \\
\hline 235 & 47.44 & 20.79 & 187 & 45. 36 & 22.24 & 177 & 51.87 & 17.37 & 249 & 52.29 & 16.87 \\
\hline 236 & 44. 33 & 23. 62 & 185 & 42.95 & 23.71 & 179 & 52.34 & 17.49 & 247 & 52.92 & 17.07 \\
\hline 237 & 45.35 & 22.80 & 184 & 45.43 & 21.89 & 186 & 53. 22 & 16. 57 & 251 & 51.78 & 18. 01 \\
\hline 238 & 44. 54 & 22.97 & 187 & 45.96 & 21.54 & 188 & 51.49 & 17.41 & 251 & 50.95 & 18.59 \\
\hline
\end{tabular}




\begin{tabular}{|c|c|c|c|c|c|c|c|c|c|c|c|}
\hline & & & & & & & & & & \multicolumn{2}{|c|}{ Continued } \\
\hline 239 & 43.33 & 23.64 & 182 & 42.39 & 24.66 & 175 & 53.39 & 15.90 & 248 & 50.91 & 18.46 \\
\hline 240 & 45.22 & 21.62 & 185 & 44. 18 & 22.28 & 178 & 50.69 & 17.84 & 250 & 50.42 & 18. 16 \\
\hline 241 & 44. 12 & 22.32 & 188 & 44. 70 & 22.36 & 180 & 53.65 & 15.56 & 249 & 52.99 & 16.38 \\
\hline 242 & 44.86 & 20.78 & 186 & 44. 74 & 20.68 & 179 & 53.05 & 14.94 & 244 & 50.87 & 16.93 \\
\hline 243 & 45.64 & 22.11 & 184 & 45.50 & 23.31 & 179 & 52.43 & 16.98 & 248 & 49. 39 & 19.37 \\
\hline 244 & 43.02 & 22.78 & 187 & 41.71 & 24.37 & 178 & 50.30 & 18.88 & 248 & 49.93 & 19.32 \\
\hline 245 & 43.36 & 22.58 & 184 & 44.95 & 19. 19 & 177 & 52.14 & 17.03 & 248 & 50.70 & 18.33 \\
\hline 246 & 44.68 & 21.93 & 177 & 42.89 & 22.38 & 161 & 42.73 & 23. 03 & 221 & 47.31 & 20.34 \\
\hline 247 & 45.63 & 22.60 & 187 & 43.85 & 21.28 & 177 & 52.42 & 17.74 & 242 & 52.30 & 17. 48 \\
\hline 248 & 41.96 & 22.69 & 189 & 43.93 & 22.17 & 184 & 53.87 & 16. 38 & 250 & 49.82 & 18.77 \\
\hline 249 & 44.34 & 22.94 & 187 & 47. 26 & 20.60 & 178 & 51.23 & 18. 17 & 247 & 48.59 & 20.04 \\
\hline 250 & 42.22 & 22.36 & 186 & 40. 19 & 23.84 & 178 & 49.59 & 18.45 & 249 & 49. 70 & 17.73 \\
\hline 251 & 43.54 & 22.00 & 183 & 43.50 & 22.47 & 175 & 51.33 & 17.09 & 244 & 50.30 & 17.87 \\
\hline 252 & 44.81 & 21.59 & 180 & 42.94 & 22.50 & 173 & 47.67 & 19. 26 & 246 & 47.91 & 19. 38 \\
\hline 253 & 46.24 & 20.71 & 173 & 44. 26 & 21.14 & 159 & 45.53 & 22. 17 & 221 & 49. 09 & 18.06 \\
\hline 254 & 47.96 & 20.09 & 181 & 46. 01 & 21.18 & 177 & 53.35 & 16. 81 & 234 & 52.61 & 17.14 \\
\hline 255 & 46.38 & 21.41 & 179 & 47. 07 & 20.66 & 175 & 53.49 & 15.73 & 244 & 53.72 & 15.61 \\
\hline 256 & 44.69 & 22.30 & 184 & 46.09 & 20.52 & 174 & 50.82 & 17. 38 & 246 & 50.36 & 18.18 \\
\hline 257 & . & . & . & . & . & . & 50.54 & 17.08 & 250 & 51.71 & 17.03 \\
\hline 258 & . & . & . & . & . & . & 51.58 & 17.64 & 247 & 48. 67 & 19. 86 \\
\hline 259 & 46.50 & 22.69 & 187 & 45.72 & 22.21 & 182 & 51.35 & 17.90 & 248 & 52.63 & 17.58 \\
\hline 260 & 45.91 & 23.68 & 188 & 41.85 & 23.66 & 189 & 53.04 & 17.89 & 250 & 50.28 & 19. 49 \\
\hline 261 & 40.56 & 23. 20 & 175 & 41.70 & 21.99 & 165 & 42.91 & 22.62 & 226 & 47.07 & 18.86 \\
\hline 262 & 46.78 & 21.88 & 187 & 44.00 & 22.49 & 186 & 53.48 & 15.73 & 250 & 52.59 & 16.89 \\
\hline 263 & 41.59 & 22.14 & 183 & 40.57 & 23.08 & 176 & 50.56 & 16. 80 & 245 & 47.72 & 19. 49 \\
\hline 264 & 45.25 & 21.85 & 184 & 45.74 & 21.10 & 179 & 52.81 & 16.63 & 248 & 52.26 & 17.13 \\
\hline 265 & 45.45 & 20.27 & 180 & 41. 17 & 23. 12 & 177 & 53.81 & 15.07 & 245 & 51.54 & 16.98 \\
\hline 266 & 46.29 & 20.43 & 184 & 45.51 & 20.92 & 173 & 52.74 & 15.92 & 230 & 52.85 & 16.37 \\
\hline 267 & 45.99 & 23.05 & 179 & 46. 24 & 22.26 & 176 & 54.99 & 15.22 & 243 & 54.49 & 15.99 \\
\hline 268 & 46.22 & 20.75 & 186 & 43.76 & 22.28 & 181 & 51.62 & 17.09 & 248 & 51.92 & 17.32 \\
\hline 269 & . & . & . & . & . & . & 50.65 & 18.70 & 250 & 47.85 & 20.77 \\
\hline 270 & 44. 67 & 20.86 & 181 & 40.70 & 22.83 & 178 & 51.07 & 17.43 & 247 & 49. 39 & 17.28 \\
\hline 271 & 44.50 & 22.31 & 180 & 45.76 & 20.98 & 175 & 50.76 & 18. 22 & 241 & 52.45 & 17.14 \\
\hline 272 & 46. 08 & 21.08 & 187 & 45.69 & 20.57 & 181 & 51.27 & 16. 79 & 251 & 47.93 & 20.84 \\
\hline 273 & 44. 21 & 23.01 & 183 & 43. 33 & 21.79 & 178 & 50.80 & 17.80 & 248 & 50.23 & 18.25 \\
\hline 274 & 43.62 & 21.66 & 184 & 46. 14 & 20.96 & 176 & 52.58 & 16.73 & 247 & 51.78 & 17. 44 \\
\hline 275 & 43.97 & 21.48 & 184 & 44. 31 & 21.80 & 178 & 52.89 & 16.67 & 248 & 52.02 & 17.58 \\
\hline 276 & 43.97 & 22.56 & 186 & 43. 36 & 23.75 & 179 & 52.82 & 15.71 & 248 & 50.54 & 18.52 \\
\hline 277 & 43.49 & 21.44 & 183 & 41.37 & 22.40 & 171 & 49. 61 & 17.34 & 244 & 48. 58 & 18.82 \\
\hline 278 & 44.22 & 22.20 & 186 & 44. 05 & 22.09 & 176 & 51.95 & 17.06 & 249 & 49. 65 & 19. 21 \\
\hline 279 & 47.29 & 21.26 & 184 & 43.98 & 22.90 & 175 & 54.40 & 15.64 & 239 & 52.73 & 16.70 \\
\hline 280 & 45. 26 & 21.72 & 181 & 43.93 & 23.09 & 178 & 51.58 & 17.52 & 246 & 49. 56 & 19. 18 \\
\hline 281 & 46.81 & 20.70 & 177 & 47.27 & 20.04 & 164 & 53.03 & 16. 26 & 234 & 52.59 & 16.45 \\
\hline 282 & 43.61 & 22.90 & 178 & 42.59 & 23.30 & 171 & 49.88 & 17.80 & 245 & 48.70 & 18.18 \\
\hline 283 & 44.50 & 22.85 & 178 & 42.99 & 23.08 & 171 & 48. 16 & 18. 29 & 243 & 48.48 & 18.64 \\
\hline 284 & 44. 52 & 23. 32 & 184 & 43.09 & 22.45 & 177 & 52.93 & 16.38 & 247 & 52. 17 & 17.90 \\
\hline
\end{tabular}


Appendix 2.1 General information on the development of DH populations

\begin{tabular}{|c|c|c|c|}
\hline \multirow[b]{2}{*}{ Items } & \multicolumn{3}{|c|}{ Genotypes ( F1 ) } \\
\hline & SolluxX Gaoyou & Gaoyou X Zhenyou & Shenyou X Jan 45 \\
\hline No of donor plants & 4 & 6 & 5 \\
\hline Experiments (n) & 28 & 36 & 18 \\
\hline $\begin{array}{l}\text { Transferred embryos } \\
\text { to S-Medium(n) }\end{array}$ & 3200 & 1200 & 1000 \\
\hline $\begin{array}{l}\text { No of embryos } \\
\text { treated with col- } \\
\text { chicine }(0.01 \% / 24 \mathrm{~h})\end{array}$ & 2300 & 230 & 600 \\
\hline $\begin{array}{l}\text { No of plantlets } \\
\text { transferred to peat } \\
\text { soil }\end{array}$ & 672 & 383 & 405 \\
\hline $\begin{array}{l}\text { No of plantlets } \\
\text { measured by flow } \\
\text { cytometry(n) }\end{array}$ & 629 & 273 & 313 \\
\hline $\begin{array}{l}\text { No of plantlets } \\
\text { treated with col- } \\
\text { chicine }(0.05 \% / 16 \mathrm{~h})\end{array}$ & 300 & 205 & 180 \\
\hline $\begin{array}{l}\text { No. of plants } \\
\text { transferred to pots } \\
(11 \times 11 \mathrm{~cm})\end{array}$ & 645 & 312 & 336 \\
\hline $\begin{array}{l}\text { No of DH plants } \\
\text { (with seeds) }\end{array}$ & 380 & 230 & 300 \\
\hline $\begin{array}{l}\text { DH plants } \\
\text { /plants(pots) (\%) }\end{array}$ & 59 & 74 & 89 \\
\hline
\end{tabular}


Appendix 2.2 Ploidy levels of plantlets and their fertility of plants with and without colchicine treatment during plantlet stage

\begin{tabular}{|c|c|c|c|c|c|c|c|c|c|c|c|c|}
\hline \multirow{4}{*}{$\begin{array}{l}\text { Donor } \\
\text { Ploidy } \\
\text { levels } \\
\text { (by Flow } \\
\text { Cytometry) }\end{array}$} & \multicolumn{12}{|c|}{ Sollux x Gaoyou (F1) } \\
\hline & \multicolumn{6}{|c|}{ Colchicine treatment ( plantlets $0.05 \% / 16 \mathrm{~h}$ ) } & \multicolumn{6}{|c|}{ Without treatment } \\
\hline & \multicolumn{3}{|c|}{ Diploid (D) } & \multicolumn{3}{|c|}{ Diploid/haploid (D/H) } & \multicolumn{2}{|c|}{ Diploid(D) } & \multicolumn{4}{|c|}{ Diploid/haploid(D/H) } \\
\hline & $\begin{array}{l}\text { Total } \\
\text { (D) }\end{array}$ & $\begin{array}{l}\text { No of } \\
\text { silique } \\
\text { /plant }\end{array}$ & $\begin{array}{l}\text { Length } \\
\text { of } \\
\text { Sili. }(\mathrm{cm})\end{array}$ & $\begin{array}{l}\text { Total } \\
(\mathrm{D} / \mathrm{H})\end{array}$ & $\begin{array}{l}\text { No of } \\
\text { silique } \\
\text { /plant }\end{array}$ & $\begin{array}{l}\text { Length } \\
\text { of } \\
\text { Sili. }(\mathrm{cm})\end{array}$ & $\begin{array}{l}\text { Total } \\
\text { (D) }\end{array}$ & $\begin{array}{l}\text { No of } \\
\text { silique } \\
\text { /plant }\end{array}$ & $\begin{array}{l}\text { Length } \\
\text { of } \\
\text { Sili.(cm) }\end{array}$ & $\begin{array}{l}\text { Total } \\
\text { (D/H) }\end{array}$ & $\begin{array}{l}\text { No of } \\
\text { silique } \\
\text { /plant }\end{array}$ & $\begin{array}{l}\text { Length } \\
\text { of } \\
\text { Sili.(cm) }\end{array}$ \\
\hline $\mathrm{D}(\mathrm{T}), \mathrm{T}(\mathrm{D})$ & -- & -- & -- & -- & -- & -- & $105(80)$ & 43.4 & 4.9 & $105(16)$ & 25.0 & 4.1 \\
\hline $\mathrm{D}(\mathrm{H}, \mathrm{T})$ & $27(3)$ & 45,3 & 4.5 & $27(14)$ & 14.6 & 3.3 & $59(6)$ & 45.8 & 4.8 & $59(9)$ & 14.0 & 2.3 \\
\hline$D(H), D$ & $72(5)$ & 35,4 & 4.4 & $72(56)$ & 15.8 & 4.4 & $51(5)$ & 40.2 & 4.5 & $51(4)$ & 25.5 & 3.4 \\
\hline$H(D)$ & $127(6)$ & 31,2 & 4.0 & $127(87)$ & 14.7 & 4.3 & -- & -- & -- & -- & -- & -- \\
\hline Total plants & \multicolumn{3}{|l|}{$226(14)$} & 226(157) & & & \multicolumn{3}{|l|}{ 215(91) } & \multicolumn{3}{|l|}{$215(29)$} \\
\hline Donor & \multicolumn{12}{|c|}{ Gaoyou x Zhenyou ( F1) } \\
\hline $\begin{array}{l}\text { Ploidy } \\
\text { levels }\end{array}$ & \multicolumn{6}{|c|}{ Colchicine treatment (plantlets $0.05 \% / 16 \mathrm{~h}$ ) } & \multicolumn{6}{|c|}{ Without treatment } \\
\hline (by Flow & \multicolumn{3}{|c|}{ Diploid(D) } & \multicolumn{3}{|c|}{ Dioloid/haploid(D/H) } & \multicolumn{2}{|c|}{ Diploid(D) } & & \multicolumn{3}{|c|}{ Dioloid/haploid(D/H) } \\
\hline & $\begin{array}{c}\text { Total } \\
\text { (D) }\end{array}$ & $\begin{array}{l}\text { No of } \\
\text { silique } \\
\text { /plant }\end{array}$ & $\begin{array}{l}\text { Length } \\
\text { of } \\
\text { Sili. }(\mathrm{cm})\end{array}$ & $\begin{array}{l}\text { Total } \\
(\mathrm{D} / \mathrm{H})\end{array}$ & $\begin{array}{l}\text { No of } \\
\text { silique } \\
\text { /plant }\end{array}$ & $\begin{array}{l}\text { Length } \\
\text { of } \\
\text { Sili. }(\mathrm{cm})\end{array}$ & $\begin{array}{c}\text { Total } \\
\text { (D) }\end{array}$ & $\begin{array}{l}\text { No of } \\
\text { silique } \\
\text { /plant }\end{array}$ & $\begin{array}{l}\text { Length } \\
\text { of } \\
\text { Sili. }(\mathrm{cm})\end{array}$ & $\begin{array}{l}\text { Total } \\
\text { (D/H) }\end{array}$ & $\begin{array}{l}\text { No of } \\
\text { silique } \\
\text { /plant }\end{array}$ & $\begin{array}{l}\text { Length } \\
\text { of } \\
\text { Sili. }(\mathrm{cm})\end{array}$ \\
\hline$D(T), T(D)$ & -- & -- & -- & -- & -- & -- & $54(32)$ & 33.1 & 6.5 & $54(14)$ & 13.0 & 4.3 \\
\hline $\mathrm{D}(\mathrm{H}, \mathrm{T})$ & $21(0)$ & -- & -- & $21(19)$ & 13.1 & 6.1 & $39(0)$ & -- & -- & $39(19)$ & 7.3 & 3.9 \\
\hline$D(H), D$ & $35(3)$ & 27.0 & 5.0 & $35(29)$ & 10.7 & 4.9 & 21(2) & 40.0 & 3.2 & $21(10)$ & 6.6 & 4.0 \\
\hline$H(D)$ & $78(0)$ & -- & -- & $78(53)$ & 10.0 & 6.2 & -- & -- & -- & -- & -- & -- \\
\hline Total plants & $134(3)$ & & & 134(101) & & & $114(34)$ & & & 114(43) & & \\
\hline \multirow{4}{*}{$\begin{array}{l}\text { Donor } \\
\text { Ploidy } \\
\text { levels } \\
\text { (by Flow } \\
\text { Cytometry) }\end{array}$} & \multicolumn{12}{|c|}{ Shenyou xJan45 ( F1 ) } \\
\hline & \multicolumn{6}{|c|}{ Colchicine treatment (plantlets $0.05 \% / 16 \mathrm{~h}$ ) } & \multicolumn{6}{|c|}{ Without treatment } \\
\hline & \multicolumn{3}{|c|}{ Diploid(D) } & \multicolumn{3}{|c|}{ Dioloid/haploid(D/H) } & \multicolumn{2}{|c|}{ Diploid(D) } & & \multicolumn{3}{|c|}{ Dioloid/haploid(D/H) } \\
\hline & $\begin{array}{l}\text { Total } \\
\text { (D) }\end{array}$ & $\begin{array}{l}\text { No of } \\
\text { silique } \\
\text { /plant }\end{array}$ & $\begin{array}{l}\text { Length } \\
\text { of } \\
\text { Sili. }(\mathrm{cm})\end{array}$ & $\begin{array}{l}\text { Total } \\
(\mathrm{D} / \mathrm{H})\end{array}$ & $\begin{array}{l}\text { No of } \\
\text { silique } \\
\text { /plant }\end{array}$ & $\begin{array}{l}\text { Length } \\
\text { of } \\
\text { Sili. }(\mathrm{cm})\end{array}$ & $\begin{array}{c}\text { Total } \\
\text { (D) }\end{array}$ & $\begin{array}{l}\text { No of } \\
\text { silique } \\
\text { /plant }\end{array}$ & $\begin{array}{l}\text { Length } \\
\text { of } \\
\text { Sili. }(\mathrm{cm})\end{array}$ & $\begin{array}{l}\text { Total } \\
\text { (D/H) }\end{array}$ & $\begin{array}{l}\text { No of } \\
\text { silique } \\
\text { /plant }\end{array}$ & $\begin{array}{l}\text { Length } \\
\text { of } \\
\text { Sili. }(\mathrm{cm})\end{array}$ \\
\hline $\mathrm{D}(\mathrm{T}), \mathrm{T}(\mathrm{D})$ & -- & -- & -- & -- & -- & -- & $75(44)$ & 32.2 & 4.3 & $75(20)$ & 15.1 & 2.8 \\
\hline $\mathrm{D}(\mathrm{H}, \mathrm{T})$ & $25(7)$ & 35.1 & 4.4 & $25(18)$ & 17.2 & 3.4 & $52(7)$ & 36.0 & 3.8 & $52(28)$ & 12.6 & 2.4 \\
\hline$D(H), D$ & $67(19)$ & 33.4 & 4.0 & $67(46)$ & 17.8 & 3.5 & $17(0)$ & -- & -- & $17(11)$ & 9.3 & 1.8 \\
\hline$H(D)$ & $37(5)$ & 27.2 & 3.5 & $37(30)$ & 15.4 & 3.6 & -- & -- & -- & -- & -- & -- \\
\hline Total plants & $129(31)$ & & & 129(94) & & & $144(51)$ & & & $144(59)$ & & \\
\hline
\end{tabular}


Appendix 3. Some examples of marker segregation within DHLs by SSR primer pairs, separated on $4 \%$ MethaPhor agarose gels. The first three slots are always P1 (Sollux), F1 and P2 (Gaoyou ) over all primers
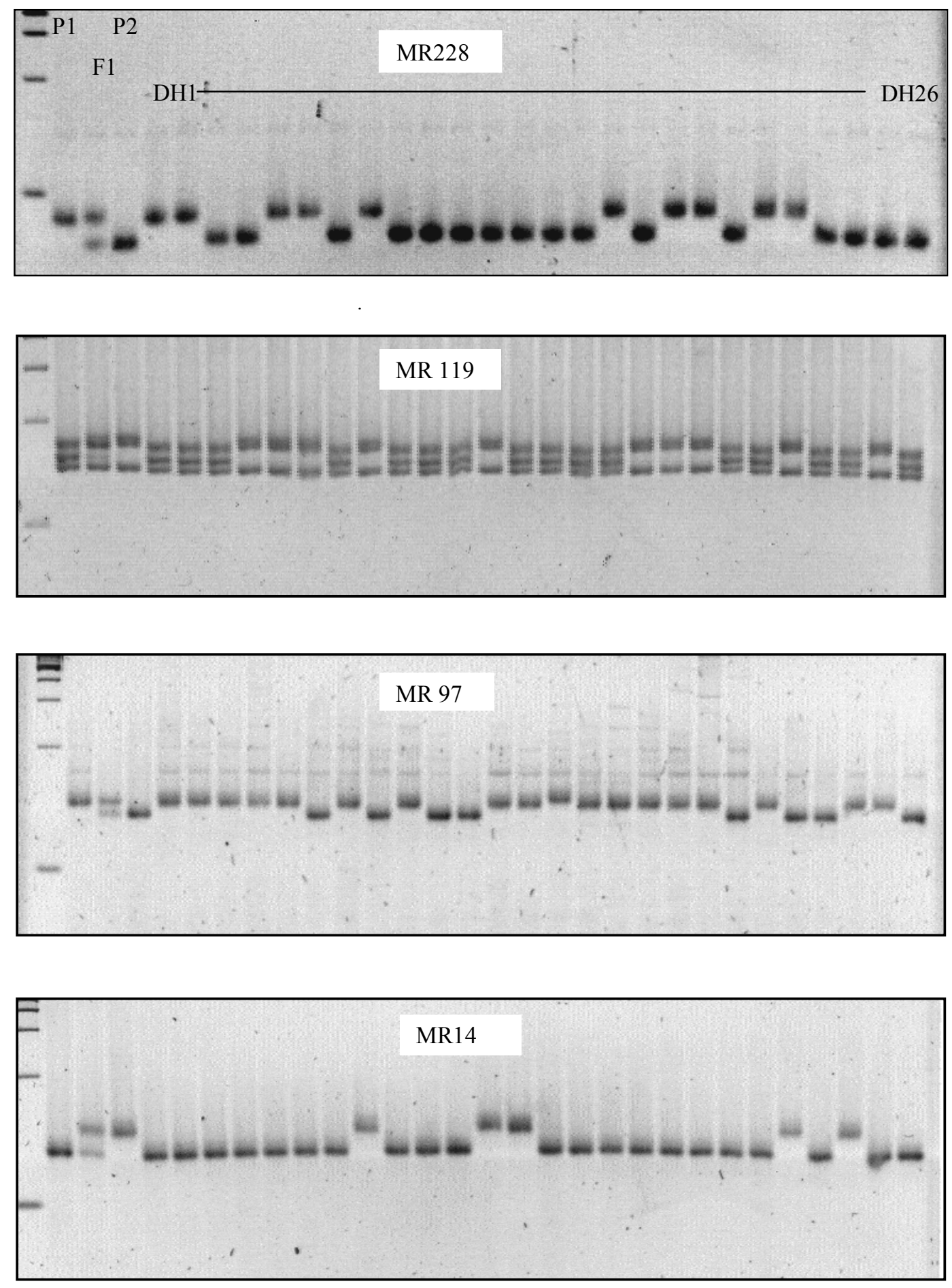
Continued
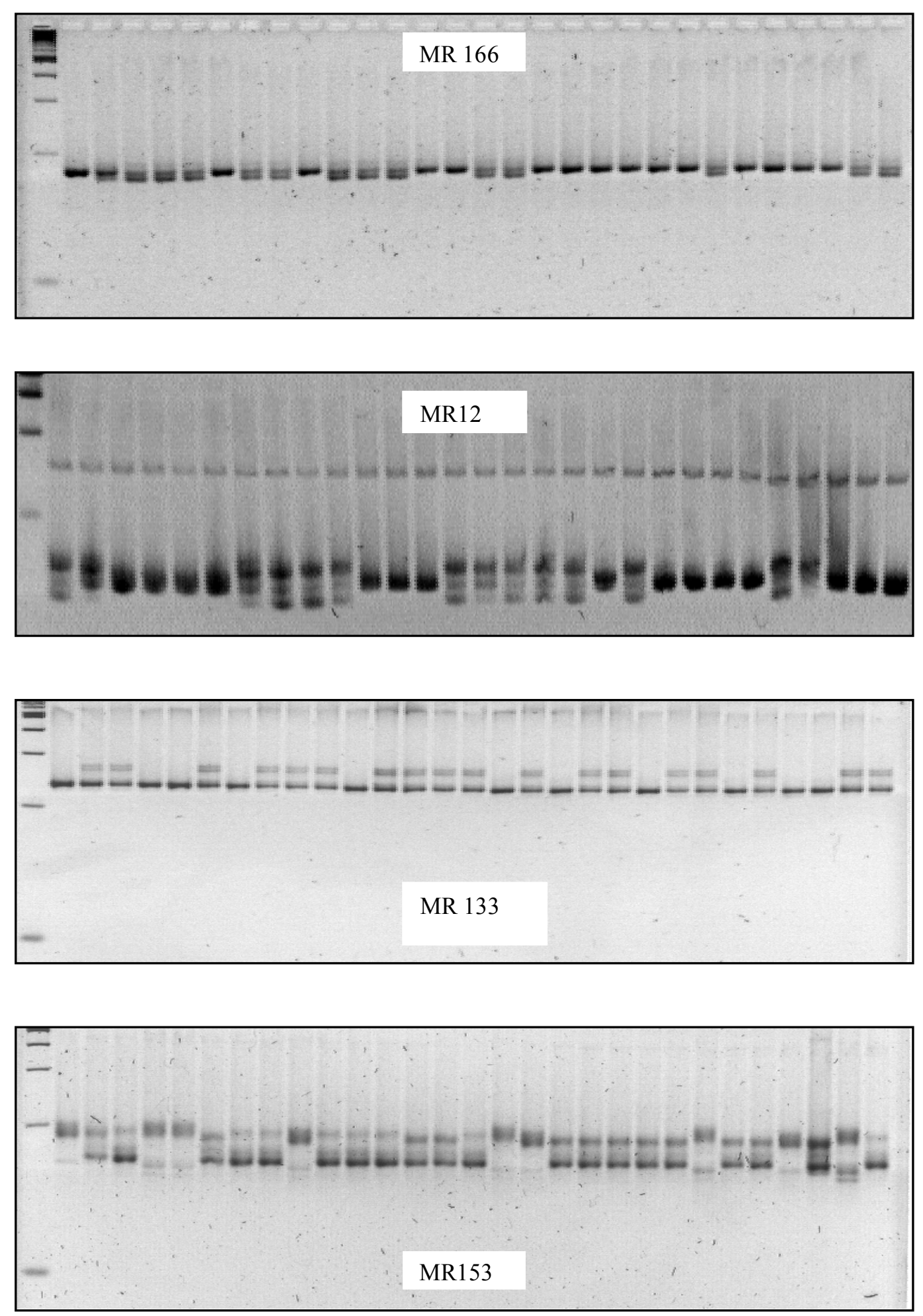


\section{Acknowledgments}

I am very much grateful for the help and support I received during my $\mathrm{Ph} . \mathrm{D}$ work at Institute of Agronomy and Plant Breeding, University of Georg August, Göttingen and Zhejiang Academy of Agricultural Sciences (ZAAS), Hangzhou. This work has been supported by the EU cooperative project IC18-CT 97-0172.

My deepest thanks, at first, to Prof. Dr. Heiko C. Becker, although, actually, no words can really express my appreciation of what he did for me in the nearly last ten years. I especially thank him for his excellent supervision, valuable suggestions, estimable critiques, corrections and numberless discussions in the whole doctoral period and all the manuscripts of my thesis. I appreciate his kindness, patience and encouragement during my stay in Göttingen. I am also thankful to Prof. Dr. Elke Pawelzik for kindly being my co-examiner. Thanks for Prof. Dr. R. Rauber, who accept to be my third examiner.

I would like to express my gratitude to Privatdozent Dr. Wolfgang Ecke for his support of my work in molecular genetic Lab., helpful comments and how he has shown me to construct linkage maps, more precise.

Thanks also to Dr. Christian Möllers for his great support and guidance of microspore culture technology, for reading and correcting several manuscripts and for his kindness.

Thanks also go to Dr. Sabine von Witzke for her perfect assistance of the general management in this EU project and her friendship.

A special acknowledgment to Prof. Dr. Jun Zhu for his valuable suggestion and discussion to QTL mapping analysis and the provision of working place, facilities and software during my data analysis in Hangzhou, China, for his reading and correcting some of manuscripts, especially for the part of statistical methods.

I particularly want to thank Frau Friederike Buggert for her great consolation and helps during my hardest time in Göttingen. Thanks also for her so many nice invitations at her house. I will never forget her friendship.

I also would like to thank Frau Bettina Fisher for kindly showing me the techniques of microspore culture, as well as for our good cooperation in marker analysis. Thanks also to Dr. Barbara Rudolph for explaining, showing and providing the procedure and protocols of SSR analysis. To Bettina Onken for her technique assistance.

Joerg Schondelmaier in Saaten-Union Resistenzlabor GmbH, Hovedissen, Germany, I would like to thank especially for his big contribution of marker analysis in this project.

I am grateful to all my colleagues both at the Institute of Agronomy and Plant Breeding, Göttingen and Crop research Institute, ZAAS in my home country for their various help and support. In particular, I must thank to John Nyikako for helping the observation of flowering time in field during my workshop in China and being a nice colleague and neighbor, to Dr. 
Andreas Girke for his arrangement of the harvest in the field and quality analysis by NIR and many other helps, to Dr. Memen Surahman for providing me the program of Mapmaker/EXP and showing me how to start for map construction, to Rubens Marschalek and Mahmoud Zeid for the nice discussion and cooperation in the Lab., to Dr. Lixi Jiang for his kind help in transplanting seedlings and helping while harvesting in greenhouse and to Tesfay Baye and Adefris Teklewold for the valuable discussion and friendship.

To all greenhouse and field staff, especially to Andreas Henn, Nicole Ritgen and Sonja.

My warmest thanks to my colleagues in Hangzhou, especially to Dongqing Zhang, Xhougfeng Zhang and Huidong Ding for their perfect cooperation and big responsibility for the part of project work in China, to Lihong Hu for designing the program of drawing the maps.

I also would like to thank Dr. Xiangyang Lou, Dr. Zihong Ye and Dr. Yan Lu for their kind help and discussion during my data analysis at Institute of Biomathematics, Huajiachi Campus of Zhejiang University.

Finally to my family, my beloved mother who always encourage me to do what I want, my husband, Qinming, for his tolerance and understanding. Particularly, I would like to express my great thanks to my dearest daughter, Mengyuan. I thank for her understanding and love and also for her big help to my work in greenhouse, field and in Lab. during her stay in Göttingen, which unfortunately made her hate my job and swear that she will never do a Ph.D when she grow up. Anyway, I thank her very much!

My thanks also to those who contributed in any way but are not mentioned here. 


\section{CURRICULUM VITAE}

\section{Personal data}

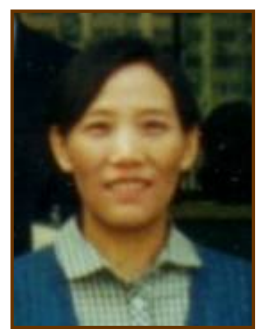

Jianyi Zhao / yzhao3@yahoo.com

Born in Shaoxing, Zhejiang, China, 05.03.58

Married since Aug. 1986 and has one daughter

\section{Education}

1965 - 1971 Primary school ( Shaoxing )

1971 - 1977 High secondary school ( Shaoxing )

1979 - 1982 Department of Agronomy, Zhejiang Agricultural University, ( Hangzhou ). Bachelor degree

1985 - 1987 Department of Agronomy and plant breeding, Huazhong Agricultural University, ( Wuhan ). Master degree

1998 - 2002 Georg-August University Göttingen, for Ph.D in Agronomy and Plant Breeding

\section{Professional Career}

1982 - 1985 Plant breeding and experimental station in Shaoxing, as an agronomist

1987 - 1998 Rapeseed breeder, Crop Institute of Zhejiang Academy of Agricultural Sciences, Hangzhou

1993 - 1994 Guest researcher, Institute of plant breeding, Swedish Universith of Agricultural Sciences, Svalöf, Sweden. 